\title{
Transient Inverse Calibration of Site- Wide Groundwater Model to Hanford Operational Impacts from 1943 to 1996-Alternative Conceptual Model Considering Interaction with Uppermost Basalt Confined Aquifer
}

\author{
V. R. Vermeul \\ C. R. Cole \\ M. P. Bergeron \\ P. D. Thorne \\ S. K. Wurstner
}

August 2001

Prepared for the U.S. Department of Energy

Under Contract DE-AC06-76RL01830 


\title{
DISCLAIMER
}

This report was prepared as an account of work sponsored by an agency of the United States Government. Neither the United States Government nor any agency thereof, nor Battelle Memorial Institute, nor any of their employees, makes any warranty, express or implied, or assumes any legal liability or responsibility for the accuracy, completeness, or usefulness of any information, apparatus, product, or process disclosed, or represents that its use would not infringe privately owned rights. Reference herein to any specific commercial product, process, or service by trade name, trademark, manufacturer, or otherwise does not necessarily constitute or imply its endorsement, recommendation, or favoring by the United States Government or any agency thereof, or Battelle Memorial Institute. The views and opinions of authors expressed herein do not necessarily state or reflect those of the United States Government or any agency thereof.

\author{
PACIFIC NORTHWEST NATIONAL LABORATORY \\ operated by \\ BATTELLE \\ for the \\ UNITED STATES DEPARTMENT OF ENERGY \\ under Contract DE-ACO6-76RLO183O
}

Printed in the United States of America
Available to DOE and DOE contractors from the Office of Scientific and Technical Information,
P.O. Box 62, Oak Ridge, TN 37831-0062;
ph: (865) 576-8401
fax: (865) 576-5728
email: reports@adonis.osti.gov

\author{
Available to the public from the National Technical Information Service, \\ U.S. Department of Commerce, 5285 Port Royal Rd., Springfield, VA 22161 \\ ph: (800) 553-6847 \\ fax: (703) 605-6900 \\ email: orders@ntis.fedworld.gov \\ online ordering: http://www.ntis.gov/ordering.htm
}




\title{
Transient Inverse Calibration of Site-Wide Groundwater Model to Hanford Operational Impacts from 1943 to 1996-Alternative Conceptual Model Considering Interaction with Uppermost Basalt Confined Aquifer
}

\author{
V. R. Vermeul \\ C. R. Cole \\ M. P. Bergeron \\ P. D. Thorne \\ S. K. Wurstner
}

August 2001

Prepared for the U.S. Department of Energy

under Contract DE-AC06-76RL01830

Pacific Northwest National Laboratory

Richland, Washington 99352 


\section{Executive Summary}

The U. S. Department of Energy (DOE) and Pacific Northwest National Laboratory (PNNL) have embarked upon a new initiative to strengthen the technical defensibility of and develop a more robust capability to incorporate uncertainty into the groundwater flow and transport model at the Hanford Site in Southeast Washington State. One aspect of the initiative is developing and using a three-dimensional transient inverse model approach to estimate the hydraulic conductivities, specific yields, and other site-wide scale parameters, including their uncertainties, by using data on the transient behavior of the unconfined aquifer system resulting from Hanford Site waste management since 1943. Over the historical period of Hanford operations, the large volumes of wastewater discharged to a variety of waste facilities resulted in large water table changes over most of the Hanford Site and created significant groundwater mounds (in excess of $20 \mathrm{~m}$ ) under waste management facilities in the central part of the site. Since 1988, the mission of the Hanford Site has changed from producing weapons to restoring the environment, and wastewater discharges have declined significantly, which has caused significant water table declines.

The three-dimensional transient inverse calibration, which an external peer review panel recommended to DOE, is being performed using UCODE, a universal inverse modeling code developed jointly by the U.S. Geological Survey and the International Groundwater Modeling Center of the Colorado School of Mines. The work uses the existing consolidated site-wide groundwater model (SGM) implemented with the Coupled Fluid Energy and Solute Transport (CFEST) code, which is the forward model whose parameters are estimated by UCODE. The transient inverse calibration uses over 76,000 water level measurements taken in about 1200 wells at the Hanford Site since the mid 1940s. The initial baseline transient inverse calibration effort (Cole et al. 2001a) significantly improved the capability of the baseline model over the prior model to simulate historical trends in water-table changes over the entire site for the entire 1943-1996 period of calibration, most notably the historical trends of water table changes and mound building observed near major discharge facilities in the 200 West Area. While all statistical measures (e.g., mean residual, range of residuals, and sum of squared residuals) were improved, some model parameters took on unrealistic values indicating that conceptual model improvements are needed. The primary objective of the inverse modeling effort described in this report was to investigate the effects of communication between the Hanford Site unconfined aquifer and the underlying upper basalt confined aquifer and to determine whether the inclusion of basalt leakage could improve parameter estimation results and/or overall model fit.

Implementation of basalt leakage in the SGM was accomplished by adding the following intercommunication mechanisms to the baseline inverse model in steps to investigate each feature's sensitivity and relationship with other estimated parameters:

- Head dependent areally distributed leakage through the basalt confining layer

- Increased leakage at an erosional window near Gable Mountain/Gable Butte

- Increased leakage at a smaller erosional feature near B-Pond

- Increased leakage along two fault zones. 
The model that resulted from this stepwise development approach (i.e., the initial alternative conceptual model, or ACM-1) provides a reasonable representation of basalt leakage response at the erosional window near Gable Mountain/Gable Butte, based on the general shape of the leakage response curve and results from previous design analysis. However, unrealistic flux values from the Gable Mountain fault along two segments of the fault close to the Columbia River, one to the northeast of Gable Butte and the other to the southwest of Gable Mountain, were suspect and will require additional investigation during follow-on studies of alternative conceptual models. Preliminary investigations of these localized unrealistic fluxes indicate they may be related to the current implementation of basalt leakage that does not allow drawdown in the basalt to limit the intercommunication flux. Assuming, as the preliminary studies indicate, that the high fault fluxes are an anomaly of the implementation, the simulated distribution of basalt leakage over the model domain was generally consistent with the conceptual model of basalt intercommunication prepared by Phil Rogers (in Appendix B of Cole et al. $2001 \mathrm{~b}$ [in press]) with downward leakage occurring throughout the area affected by the groundwater mound resulting from 200 Area wastewater disposal activities and upward leakage occurring throughout the eastern portion of the site. Making the corrections for the anomalies in the Gable Mountain fault fluxes, areal leakage is the dominant intercommunication flux followed by the fault fluxes and the erosional windows flux, which is consistent with Phil Rogers' interpretation and also that of Shlomo P. Neuman (personal communication).

Graphical comparisons and summary statistics illustrate that, over the entire prediction period, a slight measurable improvement in overall model fit was realized for the ACM-1 over that observed for the baseline inverse model. Residual error statistics indicate that 66.9 percent of the simulated values were within $\pm 1 \mathrm{~m}$ of measured values, and 99 percent were within $\pm 5 \mathrm{~m}$, compared to 65.8 and 98.6 percent, respectively, for the baseline inverse model. The overall mean residual was $0.09 \mathrm{~m}(-0.90 \mathrm{~m}$ for negative residuals and $1.26 \mathrm{~m}$ for positive residuals), which is slightly better than the residual results for the baseline inverse model of $-0.13 \mathrm{~m}$ for the overall mean residual $(1.34 \mathrm{~m}$ for negative residuals, $0.87 \mathrm{~m}$ for positive residuals). The median and mean absolute error for the ACM- 1 was $-0.11 \mathrm{~m}$ and $1.07 \mathrm{~m}$, respectively, also slightly better than the comparable baseline model statistics, which were 0.12 and 1.09, respectively. The residuals for the ACM-1 ranged from $-11.9 \mathrm{~m}$ to $11.0 \mathrm{~m}$ compared with $-11.1 \mathrm{~m}$ to $11.8 \mathrm{~m}$ for the baseline inverse model. The sum of squared residuals for the basalt leakage inclusive model was $1.79 \times 10^{5}$ while the sum of squared residuals for the baseline inverse model was slightly worse at $2.00 \times 10^{5}$. However, the most noteworthy improvements in the ACM-1 transient inverse calibrated model is not associated with overall model fit, but with incorporation of the following:

- a more realistic conceptual model

- parameter estimates closer to the expected ranges based on previous analysis of available characterization data and our current conceptual understanding of the hydrogeologic system being simulated (e.g., only 2 percent increase in the Unit 1 hydraulic conductivity distribution multiplier and an 8 percent decrease in the Unit 5 hydraulic conductivity distribution multiplier)

- best-fit estimates for natural recharge in ACM-1 were only 10 percent larger than previous estimates of natural recharge, which is well within the range of natural recharge values considered reasonable. This was a significant improvement over the 71 percent increase for the baseline inverse model, which resulted in unreasonable recharge estimates over a portion 
of the site. As had been postulated, based on the baseline inverse modeling effort, consideration of the interaction with the uppermost basalt confined aquifer improved the estimates of natural recharge by supplying a portion of the areally distributed flux entering the model domain that was needed to meet the objective function.

- parameter estimation results for the hydraulic conductivity of Unit 7 (i.e., reduction to a value similar to that of the fine-grained materials of Unit 6 and Unit 8) led to a conceptual model change consistent with Lindsey (1995) that Units 6, 7, and 8 should be interpreted as a single mud unit with discontinuous coarse unit inclusions and not as in the prior and baseline model as a continuous mud layer (Unit 6) over a continuous conductive layer (Unit 7) underlain by another continuous mud (Unit 8).

Although parameter estimates were improved and the conceptual model is more realistic, some parameters continue to take on unrealistic values, indicating that additional conceptual model improvements are needed. The best-fit estimate for the specific yield of the Hanford formation (Unit 1) and the Ringold Formation (Unit 5) (0.06 and 0.2, respectively) and associated confidence limits developed by the inverse calibration were not found to be consistent with reasonable ranges summarized in previous analyses for the specific yield of these units as discussed in the following:

- Hanford formation (Unit 1) specific yield best-fit estimate of 0.0625 is not consistent with the open-work gravels description for some of the facies of this unit, reasonable ranges summarized in previous analyses ( 0.1 to 0.3 ), or the depositional process (i.e., cataclysmic floods that inundated the Pasco Basin).

- Ringold Formation (Unit 5) specific yield best-fit estimate of 0.196 is not consistent with the "clast to matrix supported pebble to cobble gravel with a fine to medium sand matrix with some lenticular sand and silt interbeds" facies description associated with this unit, the range of previous estimates ( 0.05 to 0.2 ), or wet sieve analyses of results for outcrop and intact core samples that indicate grain size distributions that are bimodal with $67 \%$ by weight pebbles and cobbles and the remainder consisting of medium- to fine-grained sand with mud content less than $5 \%$ by weight.

Inconsistencies between the calibrated values and the prior information for both the Hanford formation and the Ringold Formation suggest that processes other than those considered in the numerical implementation of the ACM-1 require evaluation. Other processes that may be evaluated in future inverse calibration efforts for their ability to provide more realistic specific yield estimates are the inclusion of facies-based zonation of hydraulic properties for the main transmissive model layers (i.e., Units 1 and 5) and uncertainty in the time required for wastewater discharges applied at ground surface to migrate through the vadose zone.

In summary, the baseline three-dimensional transient inverse model for the estimation of site-wide scale flow parameters, including their uncertainties, using data on the transient behavior of the unconfined aquifer system over the entire historical period of Hanford Site operations, has been modified to account for the effects of basalt intercommunication between the Hanford Site unconfined aquifer and the underlying upper basalt confined aquifer. Both the baseline and ACM-1 applications of this newly developed methodology considered only the groundwater flow component and corresponding 
observational data set used in the three-dimensional transient inverse calibration efforts. Subsequent efforts will examine both flow and transport. Comparisons of the goodness of fit measures and parameter estimation results for the ACM-1 transient inverse calibrated model with those from previous SGM modeling efforts illustrate that the new three-dimensional transient inverse model approach will strengthen the technical defensibility of the final calibrated model(s) and provide the ability to incorporate uncertainty in model predictions related to both conceptual model and parameter uncertainty. These results, however, indicate that additional improvements to the current conceptual model framework are required. An investigation was initiated at the end of this basalt inverse modeling effort to determine whether facies-based zonation of Unit 1 and Unit 5 would improve specific yield parameter estimation results (ACM-2). A description of the justification and methodology used to develop this zonation is discussed, although results were not obtained in time to be included in this report. Studies are under way to implement and test these and other improvements to the conceptual model. 


\section{Glossary}

CFEST

CFEST-INV

CHARIMA

DOE-RL

GIS

GEOFEST

HEIS

HGWP

IGWMC

MASS1

MRGT

MTT

ONWI

PNNL

PERL

PSPL

SGM

TRANSS

UCODE

USGS

VTT
Coupled Fluid, Energy, and Solute Transport

Coupled Fluid, Energy, and Solute Transport Inverse computer code

Charriages de Rivierres Mailles (a computer code for simulating transport of river sediments)

U.S. Department of Energy, Richland Operations Office

Geographic Information System

Geological Finite Element Synthesis Tool

Hanford Environmental Information System

Hanford Groundwater Project

International Groundwater Modeling Center

Modular Aquatic Simulation System 1D

Multiple Realization Generator Task

Multicomponent Mass Transport

Office of Nuclear Waste Isolation

Pacific Northwest National Laboratory

Practical Extraction and Report Language, a Freeware Language Designed For Text Manipulation

Puget Sound Power and Light

Site-Wide Groundwater Model

A Simplified Model for Radioactive Transport

Universal Inverse Modeling Code

U. S. Geological Survey

Variable Thickness Transient 



\section{Acknowledgments}

Many people contributed to the development of this report. The authors wish to thank Dr. Sumant Gupta (CFEST Co.) for his technical assistance and implementation of modifications to CFEST to simplify its use with UCODE with the calibration and evaluation of the current conceptual model. The authors also thank Doug Hildebrand (DOE-RL) for his ongoing encouragement and support for our efforts and the useful review comments and suggestions he provided on the draft of the report.

Thanks and appreciation also go to other PNNL staff who provided invaluable assistance in the important areas of data processing and model data input preparation and final report preparation. Will Nichols assisted in the development of historical artificial discharge database used in the calibration. Greg Guensch and Marshall Richmond generated the data used to approximate the historical river stages used to represent the Columbia River-boundary condition during the period of calibration. Mark

Williams provided technical support in translating historical river stage to model boundary input files. Tim Scheibe provided technical peer review and Sheila Bennett provided technical editing support. 



\section{Contents}

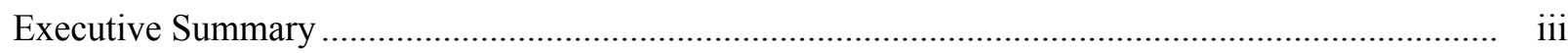

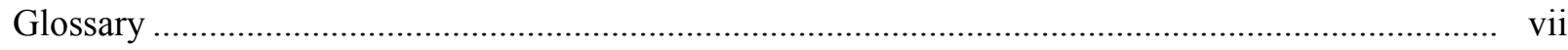

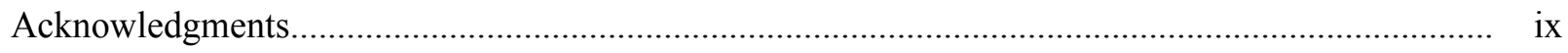

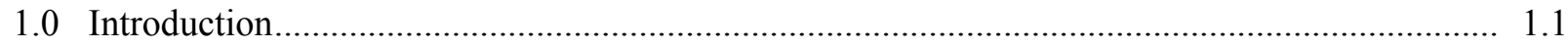

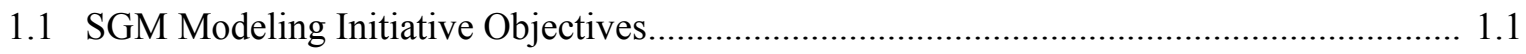

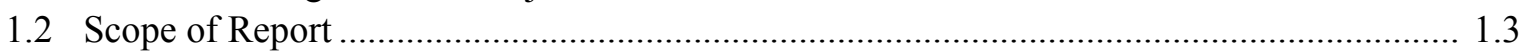

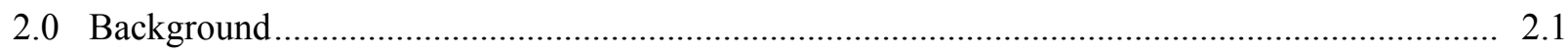

2.1 Groundwater Flow Model Selection and Chronology ................................................... 2.2

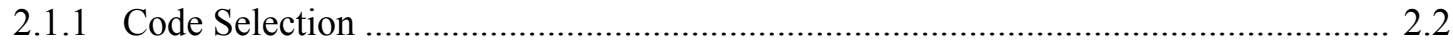

2.1.2 Chronology of Site-Wide Groundwater Model Development ................................ 2.2

3.0 Description of the Groundwater Flow Model ............................................................. 3.1

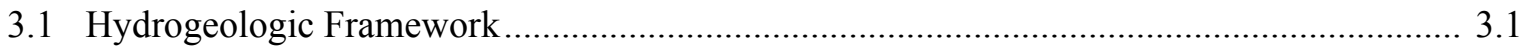

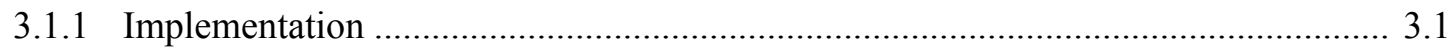

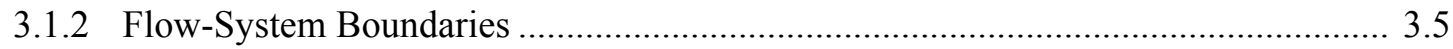

3.1.3 Natural and Artificial Recharge ..................................................................... 3.8

3.1.4 Hydraulic Properties................................................................................. 3.10

4.0 Modifications to Account for Basalt Intercommunication ................................................. 4.1

4.1 Potential Mechanisms for Aquifer Intercommunication ................................................ 4.1

4.2 Model Design Analysis for the Basalt Leakage Boundary ................................................... 4.6

4.2.1 Head-Dependent Areally Distributed Leakage .................................................... 4.6

4.2.2 Increased Leakage Through the Erosional Window ........................................... 4.10

4.2.3 Increased Leakage at Faults ...................................................................... 4.17

5.0 Inverse Methodology and Computation Codes................................................................ 5.1

6.0 Implementation of the Transient Inverse Approach ….................................................. 6.1

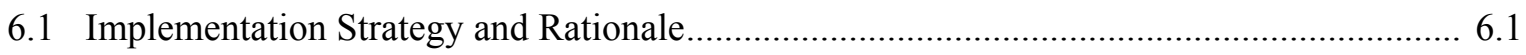

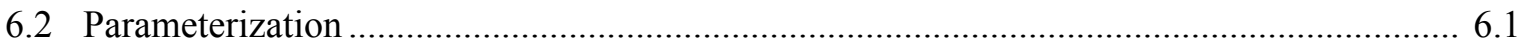

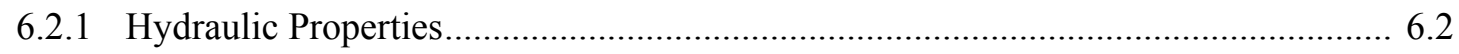



6.3 Well Observation Processing and Weighting for Use in Regression .................................. 6.3

6.4 Initial Evaluation of Parameter Sensitivities .................................................................. 6.4

7.0 Results and Evaluation of Baseline Transient Simulation .................................................... 7.1

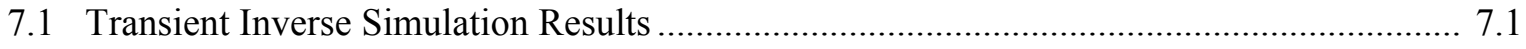

7.2 Evaluation of Transient Inverse Model ......................................................................... 7.5 
8.0 Stepwise Model Modification: Baseline to Full Implementation of Alternative

SGM Conceptual Model with Basalt Intercommunication (ACM-1) ...................................... 8.1

8.1 Head-Dependent Flux with Uniform Basalt Thickness and Permeability ........................... 8.1

8.2 Combining Units 6, 7, and 8 Into a Single Aquitard Unit ............................................. 8.2

8.3 Inclusion of Basalt Thickness and Erosional Window ...................................................... 8.4

8.4 Inclusion of Yakima Ridge and Gable Mountain/Gable Butte Thrust Faults...................... 8.5

8.5 Inclusion of Facies-Based Zonation of Unit 1 and Unit 5 ............................................ 8.7

9.0 Results and Evaluation of the ACM-1 Transient Inverse Simulation..................................... 9.1

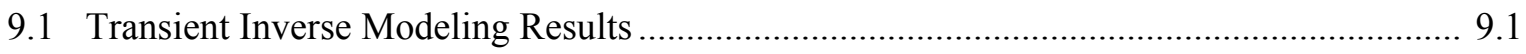

9.1.1 Spatial and Temporal Distributions of Residual Errors ........................................... 9.1

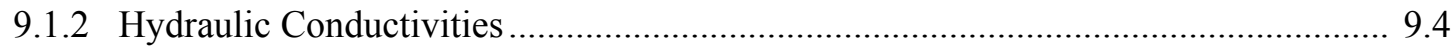

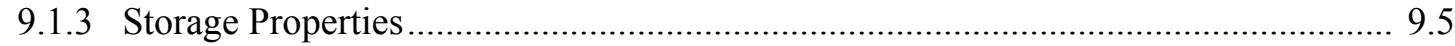

9.1.4 Boundary Flux Estimates................................................................................. 9.6

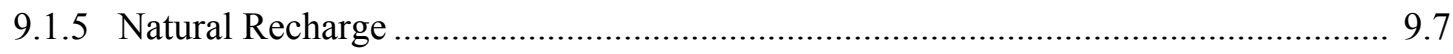

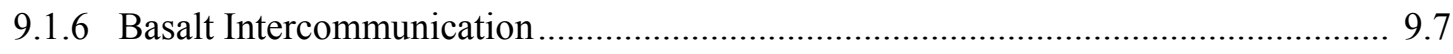

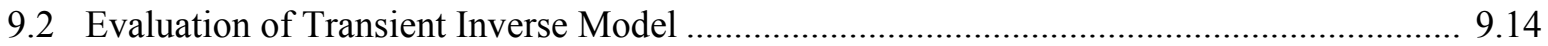



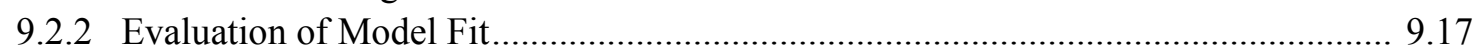

9.2.3 Evaluation of Optimized Parameter Values........................................................ 9.19

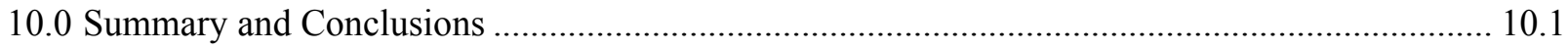

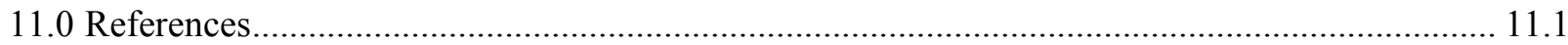

Appendix - Comparison of Selected Plots of Water Table Elevations and Head Residuals from Simulation of Hanford Wastewater Discharges (1943-1996) Using Baseline and Alternative Conceptual Models (ACM) 


\section{Figures}

1.1 Location of the Hanford Site

3.1 Regional Setting for the Hanford Site Unconfined Aquifer System (Part of the Saturated Suprabasalt Sediments) Located Within the Pasco Basin and Part of the Regional Columbia Plateau Aquifer System that Covers Most of Eastern Washington and Parts of Idaho and Oregon... 3.2

3.2 Structural Geologic Features of the Pasco Basin

3.3 (a) Pasco Basin Cross Section B-B' (Figure 3.1), (b) Hydrostratigraphic (Left) and Stratigraphic (Right) Columns Illustrating the Geohydrology of the Pasco Basin and the Nine Supra-Basalt Hydrostratigraphic Units of the SGM

3.4 Finite-Element Grid and Boundary Conditions Used in the Three-Dimensional Flow Model

3.5 SGM Model Domain Within the Pasco Basin Illustrating the Location of the Important Flow System Boundaries for the Hanford Site Groundwater Model ....................................... 3.7

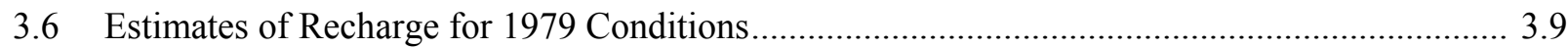

3.7 Artificial Discharges to the Unconfined Aquifer from 1943 to1998 …................................... 3.10

3.8 Transmissivity Distribution Developed from the Two-Dimensional Inverse Calibration ........... 3.11

3.9 Hydraulic Conductivity Distribution Used in the Prior Model .............................................. 3.12

3.10 (a) Cross Section A-A' Showing Distribution of Hydrogeologic Units.................................... 3.13

3.10 (b) Cross Section A-A' Showing Distribution of Hydraulic Conductivity in the Prior Model

3.11 (a) Cross Section B-B' Showing Distribution of Hydrogeologic Units .................................... 3.14

3.11 (b) Cross Section B-B' Showing Distribution of Hydraulic Conductivity in the Prior Model .... 3.14

4.1 Conceptual Model for Flow in the Basalt Aquifer System .

4.2 Isopach Map of the Elephant Mountain Basalt on the Hanford Site Showing the Portion of the Erosional Window Where the Unconfined and Upper Confined Aquifer Systems are in Direct Contact.

4.3 Isopach Map of the Elephant Mountain Basalt in the West Lake and B Pond Area Showing the Area Where the Basalt Is Absent Between Gable Mountain and Gable Butte and Two Other Localized "Pockets" to the Southeast

4.4 Isopach Map of the Rattlesnake Ridge Interbed in the Vicinity of B Pond and West Lake

4.5 Water-Level Data from Monitoring Wells Completed in the Unconfined Aquifer Within

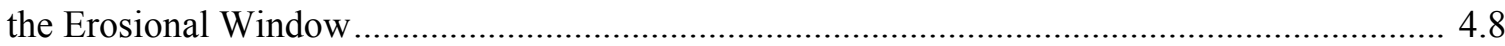

4.6 Potentiometric Surface Map of the Upper Basalt-Confined Aquifer in 1943 .......................... 4.9

4.7 Potentiometric Surface Map of the Upper Basalt-Confined Aquifer in 1965 .......................... 4.10

4.8 Potentiometric Surface Map of the Upper Basalt-Confined Aquifer in 1995 ............................ 4.11

4.9 Diagram Showing the Location of the Erosional Window and Nearby Monitoring Wells and Thickness Contours (m) for the Elephant Mountain Confining Layer....

4.10 Distance Versus Hydraulic Head Data from Rattlesnake Ridge Monitoring Wells Within the Radius of Influence of the Erosional Window Leakage Effect.

4.11 Simplified Conceptual Model of Leakage at the Erosional Window in a) Plan View and b) Cross Section 
4.12 Erosional Window Leakage Calculated Using Both the Head-Dependent Flux and Equilibrium Equation Approaches

4.13 Location of Thrust Faults and Normal Faults on the Hanford Site.

5.1 Flowchart for Estimating Parameters With UCODE ..................................................... 5.4

7.1 Measured Versus Predicted Heads (45-Degree Plot); All Observations for Best-Fit

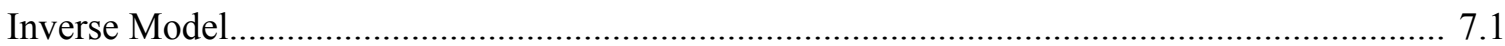

7.2 Histogram of Predicted Head Residuals; All Observations for Best-Fit Inverse Model............. 7.2

7.3 Hydraulic Conductivity Distribution from Best-Fit Inverse Model ............................................ 7.4

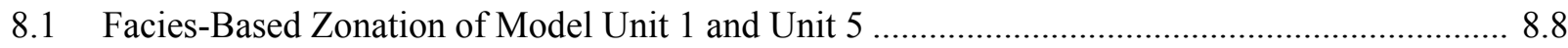

9.1 Measured Versus Predicted Heads (45-Degree Plot); All Observations for Best-Fit ACM-1d Inverse Model....................................................................................... 9.2

9.2 Histogram of Predicted Head Residuals; All Observations for Best-Fit

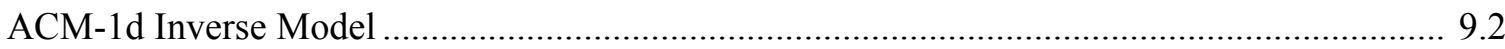

9.3 Hydraulic Conductivity Distribution for Best-Fit ACM-1d Inverse Model............................... 9.4

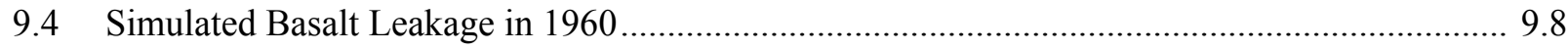

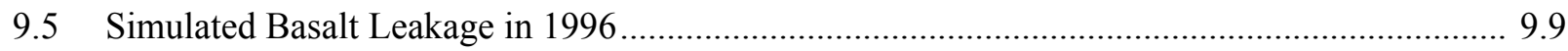

9.6 Estimated and Simulated Leakage from the Upper Basalt Confined Aquifer at the

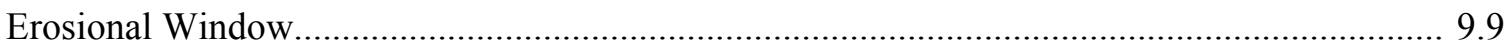

9.7 Areally Distributed Basalt Leakage Flux Over the Simulated Period....................................... 9.10

9.8 Relative Contribution of Each Basalt Leakage Feature to Net Leakage Flux............................ 9.11

9.9 Uncorrected Leakage Flux at the Gable Mountain Fault ..................................................... 9.11

9.10 Comparison of Histogram of Predicted Head Residuals........................................................ 9.12 


\section{Tables}

3.1 Major Hydrogeologic Units Used in the Site-Wide Three-Dimensional Model....................... 3.5

3.2 Summary of Calculated Fluxes in Four Regions ............................................................... 3.7

3.3 Range of Hydraulic Conductivities by Hydrogeologic Unit in the Prior Model........................ 3.14

5.1 Brief Description of the Various UCODE Phases and Their Functions ................................... 5.3

7.1 Summary of Residual Error Statistics of Best-Fit Inverse Model ........................................... 7.3

7.2 Statistical Information Provided by UCODE ............................................................... 7.6

7.3 Summary of Parameter Scaling Factors Derived for the Baseline Inverse Model ..................... 7.8

7.4 Parameter Cross-Correlation Matrix Plot (Baseline Inverse Model) ........................................ 7.9

7.5 Parameter Scaling Factor Estimates and Associated Confidence Intervals

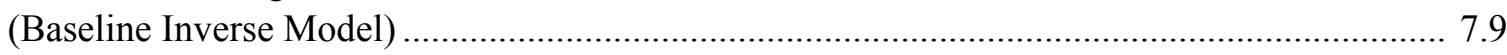

8.1 Summary of Starting Parameter Factors and Scaled-Parameter Estimation Results

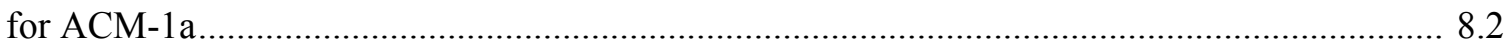

8.2 Summary of Starting Parameter Scaling Factors and Estimation Results for ACM-1b ............ 8.3

8.3 Summary of Starting Parameter Scaling Factors and Estimation Results for ACM-1d ............. 8.7

8.4 Statistics of the Hydraulic Conductivity Distribution of Elements Within

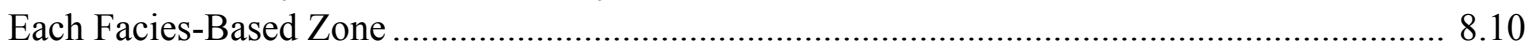

9.1 Summary of Residual Error Statistics of Best-Fit ACM-1d Inverse Model ............................ 9.3

9.2 Summary of Residual Error Statistics for ACM-1 …............................................................ 9.13

9.3 Parameter Scaling Factor Estimates and Regression Measures as a Function of Parameter Estimate Iteration (i) ........................................................................................................... 9.16

9.4 Summary of Parameter Scaling Factor Estimates Derived for the Basalt Leakage



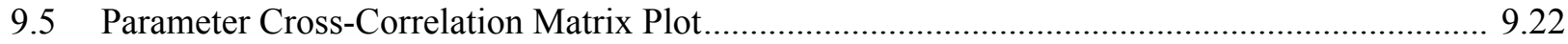

9.6 Parameter Scaling Factor Estimates and Associated Confidence Intervals ............................. 9.23 


\subsection{Introduction}

In 1996, the U.S. Department of Energy Richland Operations Office (DOE-RL) initiated a project to consolidate multiple groundwater models at the Hanford Site (Figure 1.1) into a single consolidated sitewide groundwater model (SGM). From that process, RL selected a three-dimensional groundwater flow and transport model developed by the Hanford Groundwater Project (DOE 2000) as the preferred alternative for the initial phase of the SGM consolidation process. The existing consolidated SGM was calibrated using 1979 data and a steady-state inverse approach along with trial-and-error transient model calibration runs using estimates of artificial discharges and a limited set of representative head observations from 1979 to 1996 . It will generally be referred to in this report as the prior model.

In the autumn of 1998, an external peer review panel was convened to conduct a technical review of the selected Hanford SGM, or prior model. A formal report transmitted to RL on January 14, 1999 documents the results of their review. ${ }^{\text {(a) }}$ The panel agreed with the concept of developing a broadly applicable SGM and made several general comments and related recommendations that centered on a broad theme of uncertainty.

\subsection{SGM Modeling Initiative Objectives}

During the first year of this initiative (FY 2000), efforts focused on 1) characterization of major uncertainties in the then current conceptual model (i.e., the prior model) that could affect model predictions and 2) development of a calibration approach and methodology that could be implemented to assist the testing and evaluation of plausible alternative conceptual models of the Hanford Site aquifer system. The model that resulted from this FY 2000 effort is referred to in this report as the baseline inverse model. The initial transient inverse calibration effort (Cole et al. 2001a), was undertaken as part of the effort to address the panel's specific recommendation that the concept of uncertainty be acknowledged and embraced from the outset and that a new modeling framework be established that is stochastic rather than purely deterministic, with both the expected values of heads and concentrations and range (distribution) of predictions being products of any modeling effort. A companion report (Uncertainty Analysis Framework-Hanford Site-Wide Groundwater Flow and Transport Model [Cole et al. 2001b]) discusses the uncertainty analysis framework developed for the Hanford Site SGM that will enable the key uncertainties in model predictions of groundwater flow and transport to be quantified.

The calibration process developed involves transient inverse calibration of plausible alternative models of the Hanford Site unconfined groundwater system to historical observations of hydraulic and water-quality impacts to the system from Hanford Site operations that began in the mid-1940s. From the beginning of operations in 1943, Hanford Site activities discharged large volumes of wastewater to a variety of waste facilities. These operational discharges raised the water table and created groundwater mounds. They were the source of contaminant plumes along the Columbia River and in the central part

(a) S Gorelick, C Andrews, and J Mercer. January 14, 1999. Report of the Peer Review Panel on the Proposed Hanford Site-Wide Groundwater Model. Letter report to U. S. Department of Energy, Richland Operations Office, Richland, Washington. 


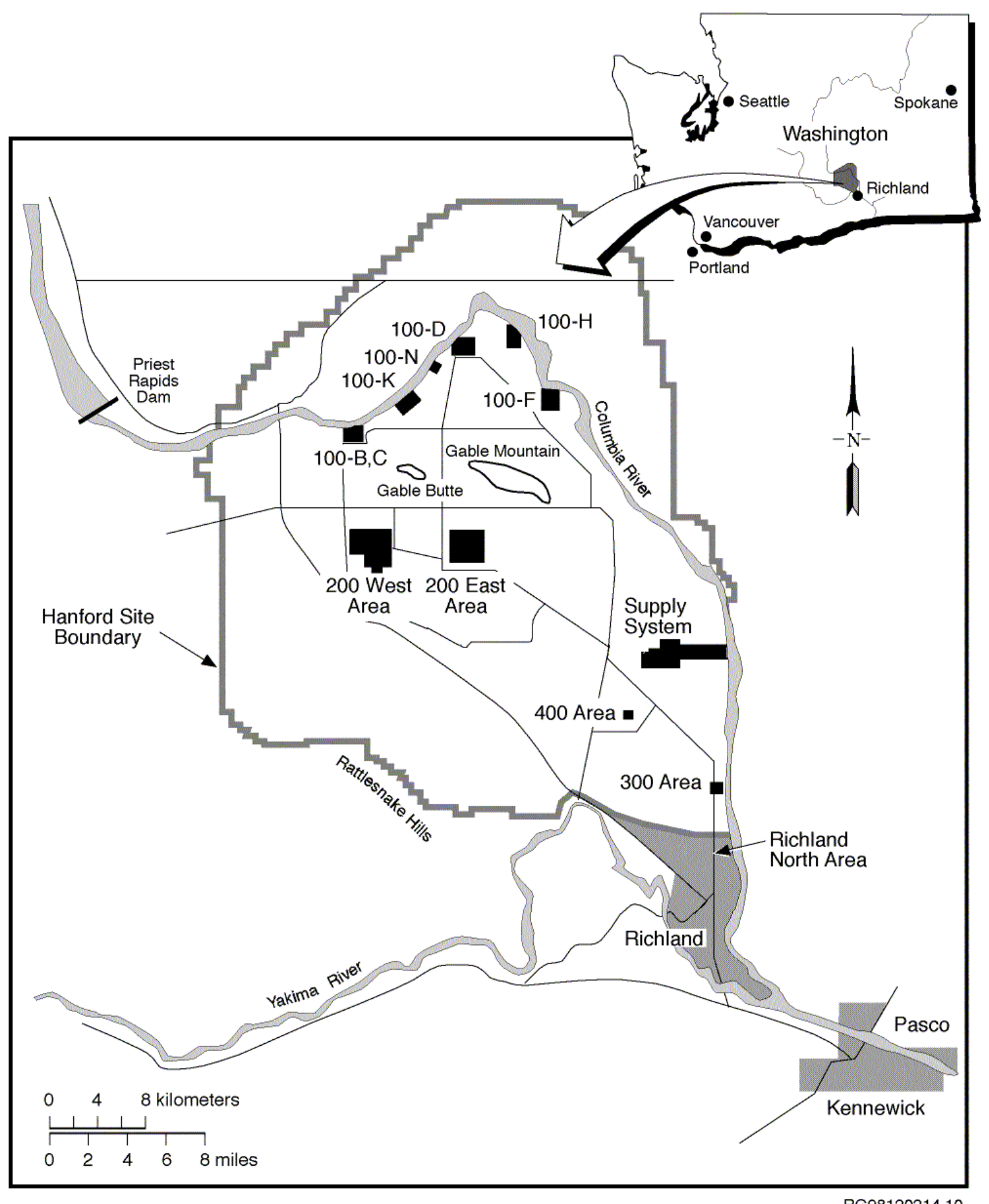

Figure 1.1. Location of the Hanford Site 
of the site. In 1988, Hanford's mission changed from weapons production to environmental restoration. The attendant reduction in wastewater discharges has resulted in significant declines in the water table over the past decade. Results from the baseline inverse modeling effort have identified weaknesses in the prior model that have aided in the development of plausible alternative conceptual models. The statistical information from the inverse modeling of alternative conceptual model interpretations allows this conceptual and parameter uncertainty to be factored into predictions of future groundwater flow and contaminant transport.

The focus of this effort in FY 2001, as documented in this report, has been to use the inverse calibration methodology to test an alternative conceptual model that no longer considers the underlying basalt bedrock system as the no-flow base of the unconfined aquifer system as it has been treated in the past. The alternative SGM model discussed in this report, which will generally be referred to as ACM-1 (i.e., an alternative conceptual model that represents the initial implementation of basalt leakage in the SGM), was used to examine and evaluate a variety of mechanisms that affect intercommunication between the Hanford Site unconfined aquifer system and the underlying upper basalt-confined aquifer system. The report also briefly discusses work initiated this year to examine and correct a second weakness of both the prior and baseline conceptual models related to the way the hydraulic conductivity zones were specified directly from early two-dimensional steady-state inverse modeling (Cole et al. 1997). In this effort (ACM-2), facies-based zonation of both the Hanford formation (Unit 1) and the middle Ringold Formation (Unit 5) were developed, and an inverse effort with these facies-based parameter zones is under way.

\subsection{Scope of Report}

The scope of this report is to 1) provide a brief description of the technical approach and methods used to perform a three-dimensional transient inverse calibration of the Hanford SGM alternative conceptual models, 2) describe the approach and methodology used to incorporate and evaluate various mechanisms that affect intercommunication between the Hanford Site unconfined aquifer system and the underlying upper basalt-confined aquifer system, 3) present the initial facies-based zonation of the primary conductive units in the SGM, and 4) summarize results from the basalt inverse modeling effort. Results from this basalt inverse modeling are compared with historical information over the period from 1943 to 1996 and with the results obtained from the initial baseline inverse model.

Section 2.0 of this report provides general background information on the prior model, including the chronology of its development and the selection of the computer code to implement it. Section 3.0 summarizes the current understanding of the Hanford Site aquifer system (i.e., the conceptual model) and its numerical implementation. Section 4.0 presents the technical approach and methods adapted or developed to incorporate various potential basalt leakage mechanisms into the baseline inverse model. Section 5.0 provides a brief description of the methodology and computational codes used to implement the inverse calibration approach. Section 6.0 provides a brief description of the implementation of the baseline inverse model. Section 7.0 briefly summarizes the results from the transient inverse simulation of the baseline inverse model for the 1943-1996 period from Cole et al. (2001a) that will be compared with the results from the basalt inverse model. Section 8.0 describes the stepwise conceptual model modifications that were performed to modify the baseline inverse model to account for the effects of basalt leakage from various potential basalt leakage mechanisms. This section also describes the 
approach used to develop the initial facies-based zonation of Units 1 and 5, which is currently being investigated with inverse methods. Section 9.0 discusses the results and evaluation of the basalt leakage inclusive transient inverse simulation for the 1943-1996 period. Section 10.0 summarizes the main conclusions resulting from this transient inverse calibration effort of the alternative conceptual model and compares results to those obtained from the baseline inverse. Section 11.0 provides the cited references. 


\subsection{Background}

The model developed in the initial calibration effort (i.e., the baseline inverse model) and modified in the current inverse calibration effort that accounts for basalt leakage was based on the existing threedimensional numerical model for groundwater flow of the Hanford Site unconfined aquifer that was developed and enhanced as part of the Hanford Groundwater Project (HGWP) (Thorne and Chamness 1992; Thorne et al. 1993; 1994; Wurstner et al. 1995; Cole et al. 1997). This three-dimensional model was developed to better understand future changes in water levels and to enhance predictions of contaminant plume movement that were being monitored by the HGWP (Cole et al. 1997). Applications and developments made to the HGWP's three-dimensional site-wide model of the Hanford Site unconfined aquifer system are routinely reported in the Hanford Site annual groundwater monitoring report (e.g., Hartman et al. 2001). This HGWP model, i.e., the prior model, was calibrated using 1979 data and a two-dimensional steady-state inverse approach (Wurstner and Devary 1993; Jacobson and Freshley 1990) in conjunction with additional trial-and-error three-dimensional transient model calibration runs using estimates of artificial discharges and a limited set of representative head observations between 1979 and 1996 (Cole et al. 1997). The following paragraphs outline the basic reports that discuss the historic development of the prior model but, more importantly, identify the basic reports that document the available data on the Hanford unconfined aquifer system and the existing interpretations of that data.

Hydraulic property data used in the development of the prior model were obtained from the results of hydraulic tests documented in Bierschenk (1959), Kipp and Mud (1973), Deju (1974), Lindberg and Bond (1979), Graham et al. (1981), DOE (1988), Liikala and Aaberg (1988), Thorne and Newcomer (1992), Peterson (1992), Connelly et al. (1992a, 1992b), Swanson (1992), Thorne et al. (1993), Connelly (1994), and Swanson (1994). Information was also obtained from new tests and tests that were previously undocumented. Information on the subsurface geologic framework came primarily from interpreting geologic descriptions of samples acquired during well drilling. These interpretations were based on work by Lindsey et al. (1991, 1992), Lindsey (1992), Lindsey and Jaeger (1993), Lindberg (1993a, 1993b), Hartman and Lindsey (1993), and Swanson (1992) in the 100, 200, and 300 Areas of the Hanford Site, which use the lithofacies units outlined in Lindsey (1991).

Many of the wells used to define the geologic framework of the prior model were drilled to basalt as part of a study for a proposed nuclear power plant (PSPL 1982). Other information used in defining the top of basalt came from wells drilled for the Basalt Waste Isolation Project (DOE 1988), which studied the basalts underlying the Hanford Site for disposal of high-level nuclear waste. Approximately 550 wells were used to define the three-dimensional hydrogeologic structure of the unconfined aquifer system. Many of these wells were used to determine the elevation of the top of basalt, and not all have been interpreted over their entire depth. Information on the southern part of the Hanford Site and the Richland area came from studies conducted by the U.S. Geological Survey (Ebbert et al. 1993), from Liikala (1994), and from private well logs filed with the State of Washington Department of Ecology (Ecology). Information on the construction of Hanford Site wells was obtained from Chamness and Merz (1993) and the Hanford Environmental Information System (HEIS) database. 


\subsection{Groundwater Flow Model Selection and Chronology}

The prior three-dimensional groundwater flow and transport model developed for the Hanford Groundwater Project, as well as the baseline model (Cole et al. 2001a) and the current inverse model that considers basalt interactions, are implemented numerically using the Coupled Fluid, Energy, and Solute Transport (CFEST) code (Gupta et al. 1987; Cole et al. 1988; Gupta 1997). The CFEST code was originally designed to support the radioactive waste repository investigations under DOE's Civilian Radioactive Waste Management Program (Gupta et al. 1987). The chemical waste-management community has also used it effectively for conducting exposure assessments, evaluating remediation alternatives, and designing extraction and control systems for aquifers.

\subsubsection{Code Selection}

Evans et al. (1988) and Wurstner et al. (1995) described the capabilities and approach used in the CFEST code and its selection for the Hanford Groundwater Project. The chronology in the continuing development of the Pacific Northwest National Laboratory (PNNL) site-wide model of the unconfined aquifer is outlined below. CFEST is an approved code for working on Hanford Federal Facility Agreement and Consent Order (Tri-Party Agreement) (Ecology 1989) milestones related to risk assessment (DOE 1991). The CFEST software library was tested extensively and brought under strict software quality assurance/quality control procedures by the Office of Nuclear Waste Isolation (ONWI) when it was developed for the Civilian Radioactive Waste Management Program. The supercomputer version (CFEST-SC), developed to run on all major UNIX workstations (Cole et al. 1988), was used for all flow and transport modeling before FY 1997. In FY 1997, the refinement of the site-wide threedimensional model continued with its application to contaminant transport of selected contaminant plumes (Cole et al. 1997). An updated version of the CFEST code called CFEST96 (Gupta 1997) was used in this effort. This version of the code runs in a PC or UNIX environment, the direct solver has been replaced with an iterative solver, and the disk storage requirements have been reduced from the previous version of CFEST.

Results from CFEST are graphically displayed using the ARC/INFO ${ }^{\circledR(a)}$ geographic information system (GIS) and Tecplot ${ }^{\circledR}{ }^{(b)}$ The ARC/INFO ${ }^{\circledR}$ GIS package is also used to store fundamental hydrogeologic data and information used to represent the three-dimensional conceptual model and to construct the three-dimensional numerical model. The three-dimensional visualization software package known as EarthVision ${ }^{\mathbb{B}(c)}$ is used to manipulate hydrogeologic data for the conceptual model.

\subsubsection{Chronology of Site-Wide Groundwater Model Development}

Summarizing from the chronology discussed in Wurstner et al. (1995) and Kincaid et al. (1998), a site-wide flow and transport model has been under continuous development by PNNL staff since the early 1960s as part of PNNL's continuing involvement in Hanford's groundwater monitoring efforts. The

(a) ARC/INFO is a registered trademark of Environmental Systems Research Institute, Inc., Redlands, California.

(b) Tecplot is a registered trademark of Amtec Engineering, Inc., Bellevue, Washington.

(c) EarthVision is a registered trademark of Dynamic Graphics, Inc., Alameda, California. 
capabilities of the site-wide flow and transport model are refined and updated as additional information is gathered and as conditions and application needs change at the Hanford Site. PNNL's Hanford Site unconfined aquifer model consists of a conceptual model and database that define current system understanding.

Early flow models were two-dimensional (e.g., the Variable Thickness Transient [VTT] code) (Kipp et al. 1972), and transport modeling, depending on application, was of the advective type (e.g., Hanford Pathline Calculation code) (Friedrichs et al. 1977), the quasi-three-dimensional particle tracking type (e.g., the Multicomponent Mass Transport [MMT] code) (Alhstrom et al. 1977), or the multiple streamtube type (e.g., the TRANSS code) (Simmons et al. 1986). Early flow models were calibrated with a streamtube approach that used available field measurements of transmissivity, river stage, disposal rates to ground, and head in an iterative approach to determine the Hanford unconfined aquifer transmissivity distribution (Transmissivity Iterative Calculation Routine) (Cearlock et al. 1975). Freshley and Graham (1988) describe applications of the VTT, MMT, and TRANSS codes at the Hanford Site.

In the mid 1980s, the CFEST code was selected for upgrading PNNL's two-dimensional modeling capability. CFEST has been used to model Hanford and a number of other sites in two and three dimensions (Dove et al. 1982; Cole et al. 1984; Gale et al. 1987; Foley et al. 1995). Evans et al. (1988), in a 1987 Hanford Site groundwater monitoring report, discuss selection of the CFEST code for modeling flow and transport in the Hanford Site's unconfined aquifer.

Initial flow modeling with the CFEST code was two-dimensional as it had been with the previous VTT code. New data were used to recalibrate the CFEST two-dimensional groundwater flow model of the Hanford Site unconfined aquifer. A steady-state finite-element inverse calibration method developed by Neuman and Yakowitz (1979) and modified by Jacobson (1985) was used in this effort. All available information on aquifer hydraulic properties (e.g., transmissivities), hydraulic heads, boundary conditions, and discharges to and withdrawals from the aquifer were included in this inverse calibration. Evans et al. (1988) described inverse calibration efforts, Jacobson and Freshley (1990) described final calibration results, and Wurstner and Devary (1993) described the calibrated two-dimensional model of the unconfined aquifer.

Two-dimensional flow models used extensively at the Hanford Site before disposal operations ceased were generally adequate for predicting aquifer head changes and directions of groundwater flow. This is because groundwater levels were somewhat stable through time across the Hanford Site. However, in the early 1990s, it was recognized that a three-dimensional model was needed to accurately calculate future aquifer head changes, directions of groundwater flow, mass transport, and predictions of contaminant concentrations. The three-dimensional model was needed because there is significant vertical heterogeneity in the unconfined aquifer, and the water table was dropping over most of the Hanford Site in response to cessation of large liquid disposals to the ground. Development of a three-dimensional model began in 1992 (Thorne and Chamness 1992) and was completed in 1995 (Wurstner et al. 1995). Thorne et al. (1994) interpreted the hydrogeology of the Hanford Site unconfined aquifer as an alternating series of transmissive units that are separated from each other in most places by less transmissive or mud units. Accounting for this vertical heterogeneity is particularly important for unconfined-aquifer predictions at the Hanford Site as future water table changes result in the dewatering of hydrogeologic layers. The water table is near the contact between the Hanford formation and the underlying, and much less permeable, Ringold Formation over a large part of the Hanford Site. Water level declines caused by 
decreased discharge at disposal facilities is causing, and will continue to cause, dewatering of the highly permeable Hanford formation sediments in some areas (Wurstner and Freshley 1994). This may result in aquifer transmissivity changes of an order of magnitude or more that would not be properly accounted for by two-dimensional flow and transport models that average vertical properties at each spatial location. As a result, a two-dimensional model cannot accurately simulate changes in groundwater levels, groundwater flow direction, and contaminant transport because it cannot properly account for the three-dimensional routing of groundwater flow and contaminant mass resulting from the vertical heterogeneity.

The initial three-dimensional model of the Hanford Site unconfined aquifer (Wurstner et al. 1995) was calibrated in a two-step process. In the first step, the two-dimensional model was recalibrated with a steady-state, statistical inverse method implemented with the CFEST-INV computer code (Devary 1987). The two-dimensional transmissivity distribution from this inverse modeling was preserved during the calibration of the three-dimensional model as is described in Wurstner et al. (1995).

The site-wide model was improved further during FY 1996 and FY 1997 as part of the HGWP. The purpose of this effort was to assist the HGWP in interpreting monitoring data, to investigate contaminant mass transport issues and evaluate the future movement of existing contaminant plumes, and to identify and quantify potential groundwater quality problems for onsite and offsite use. The report on this effort (Cole et al. 1997) describes the improvements to the three-dimensional model, the model recalibration, and the application of the model to predict the future transport of existing contaminant plumes in the unconfined aquifer. Cole et al. (1997) presents predicted changes in transient-flow conditions in the unconfined aquifer to the year 4000 .

In FY 2000, the initial transient inverse calibration effort (Cole et al. 2001a) was undertaken as part of the effort to address the external peer review panel's specific recommendation ${ }^{(a)}$ that the concept of uncertainty be acknowledged and embraced and that a new modeling framework be established that is stochastic rather than purely deterministic, with both the expected values of heads and concentrations and the range or a distribution of predictions being the products of any modeling effort. As discussed in Section 1.0, the focus during the first year was on characterization of major uncertainties that could affect model predictions in the then current conceptual or prior model documented in Cole et al. (2001b) and development of a calibration approach and methodology that could be implemented to assist testing and evaluation of plausible alternative conceptual models of the Hanford Site unconfined and underlying confined aquifer system, as necessary. This FY 2000 effort, documented in Cole et al. (2001a), resulted in the baseline inverse model that will be compared with the conceptual model that considers interactions with the underlying basalt aquifer system.

(a) S. Gorelick, C. Andrews, and J. Mercer. January 14, 1999. Report of the Peer Review Panel on the Proposed Hanford Site-Wide Groundwater Model. Letter report to U. S. Department of Energy, Richland Operations Office, Richland, Washington. 


\subsection{Description of the Groundwater Flow Model}

This section briefly describes the conceptual and numerical basis for the consolidated SGM of the Hanford Site unconfined aquifer system that was used in the baseline three-dimensional transient inverse calibration effort and was the starting point for this effort, which evaluated the potential basalt-unconfined interactions identified and reported in Cole et al. (2001b). Section 4.0 briefly describes the technical approach and methods adapted or developed to incorporate various potential basalt leakage mechanisms into the SGM baseline inverse model. The SGM conceptual model was developed from information on the hydrogeologic structure of the aquifer, spatial distributions of hydraulic and transport properties, aquifer boundary conditions, and distribution and movement of contaminants. Development of the basic aspects of this three-dimensional conceptual model of the Hanford Site unconfined aquifer system is documented in Thorne and Chamness (1992), Thorne et al. (1993, 1994), and Wurstner et al. (1995), and uncertainties associated with the SGM are fully discussed in Cole et al. (2001b).

\subsection{Hydrogeologic Framework}

The Hanford Site lies within the Pasco Basin, a structural depression that has accumulated a relatively thick sequence of fluvial, lacustrine, and glaciofluvial sediments (Figure 3.1). The geology and hydrology of the Hanford Site have been studied extensively for more than 50 years and are summarized in a number of documents (Wurstner et al. 1995 and references therein). The Pasco Basin and nearby anticlines and synclines initially developed in the underlying Columbia River Basalt Group, a sequence of continental flood basalts covering more than 160,000 $\mathrm{km}^{2}$ (Figures 3.1 and 3.2). Overlying the basalt within the Pasco Basin are fluvial and lacustrine sediments of the Ringold Formation and the glaciofluvial Hanford formation and pre-Missoula gravels. Together, these sedimentary deposits comprise the Hanford Site unconfined aquifer system, which in the prior and baseline SGM consists of nine hydrostratigraphic units. The saturated thickness of this unconfined aquifer system is greater than $61 \mathrm{~m}$ in some areas but pinches out along the flanks of the basalt ridges, as illustrated by the B-B' cross section of Figure 3.3 (b). The corresponding hydrostratigraphic (left) and stratigraphic (right) columns illustrating the geohydrology of the Pasco Basin along with the relationship to the nine supra-basalt hydrostratigraphic units of the SGM is shown in Figure 3.3 (a). Depth to the groundwater ranges from less than $0.3 \mathrm{~m}$ near the Columbia River to more than $100 \mathrm{~m}$ near the 200 Areas. Groundwater in this unconfined aquifer system generally flows from recharge areas in the west to the Columbia River in the east.

The Hanford and Ringold formations can be defined as several distinct hydrogeologic units. Data from wells on the site were used to define these hydrogeologic units based on textural composition. A brief summary of each of these units is provided in Table 3.1, based on descriptions in Wurstner et al. (1995).

\subsubsection{Implementation}

The lateral extent and relationships between the nine hydrogeologic units, including the subunits of the Ringold Formation, the Hanford Formation, and the pre-Missoula gravels, were defined by determining geologic contacts between these layers at as many wells as possible. These interpreted distributions and thicknesses were input to EarthVision ${ }^{\circledR}$, which was used to construct a database for formulating the three-dimensional Hanford Site conceptual model. The resulting numerical model contains nine hydrogeologic units above the top of the underlying basalt aquifer system. The Geological Finite Element Synthesis Tool (GEOFEST) described in Foley et al. (1995) was used to transfer the interpreted water 


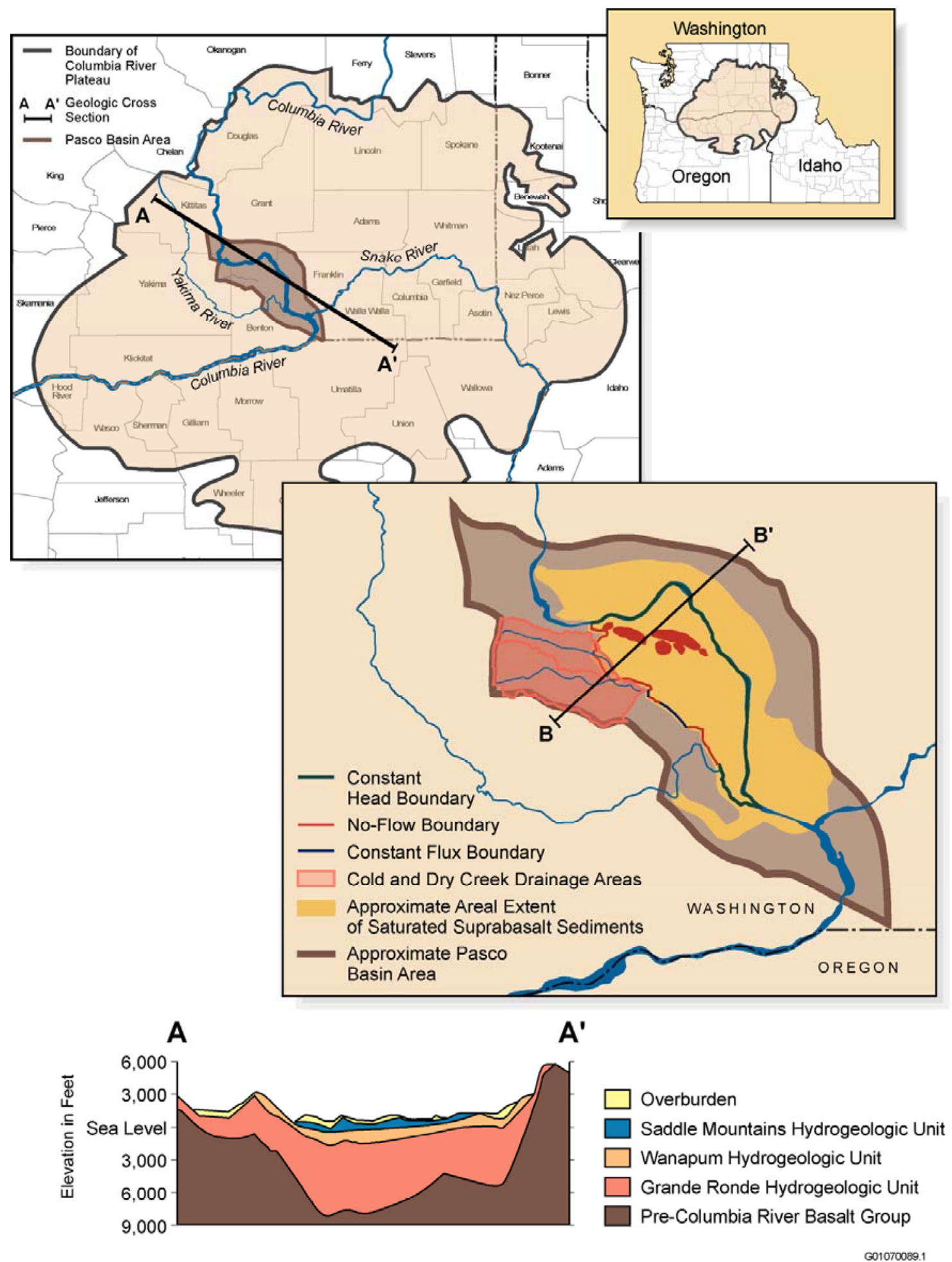

Figure 3.1. Regional Setting for the Hanford Site Unconfined Aquifer System (Part of the Saturated Supra-Basalt Sediments) Located Within the Pasco Basin and Part of the Regional Columbia Plateau Aquifer System that Covers Most of Eastern Washington and Parts of Idaho and Oregon 
Figure 3.2. Structural Geologic Features of the Pasco Basin 
a)

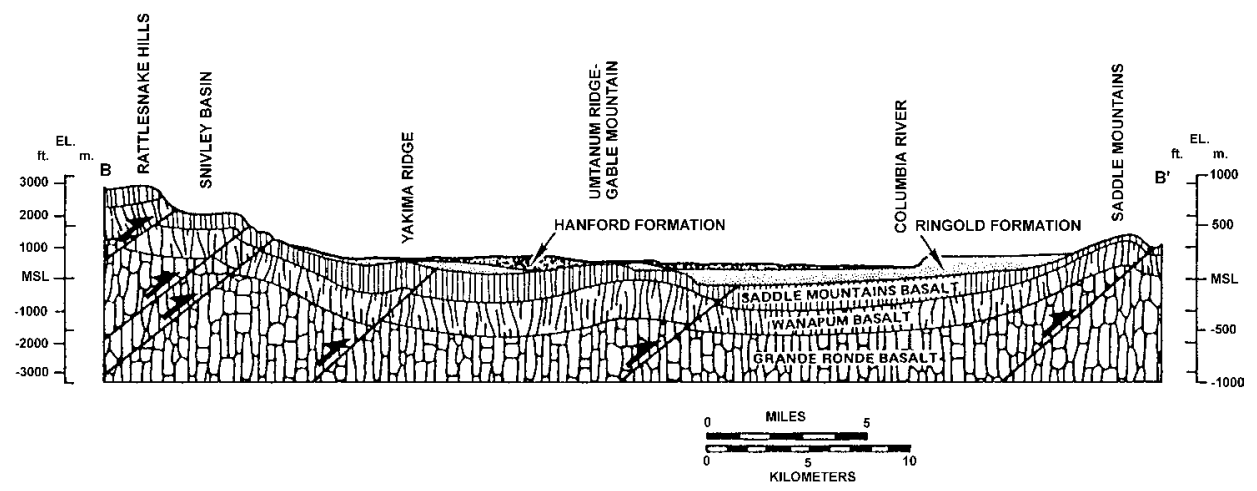

VERTICAL EXAGgeration 5.2X

b)

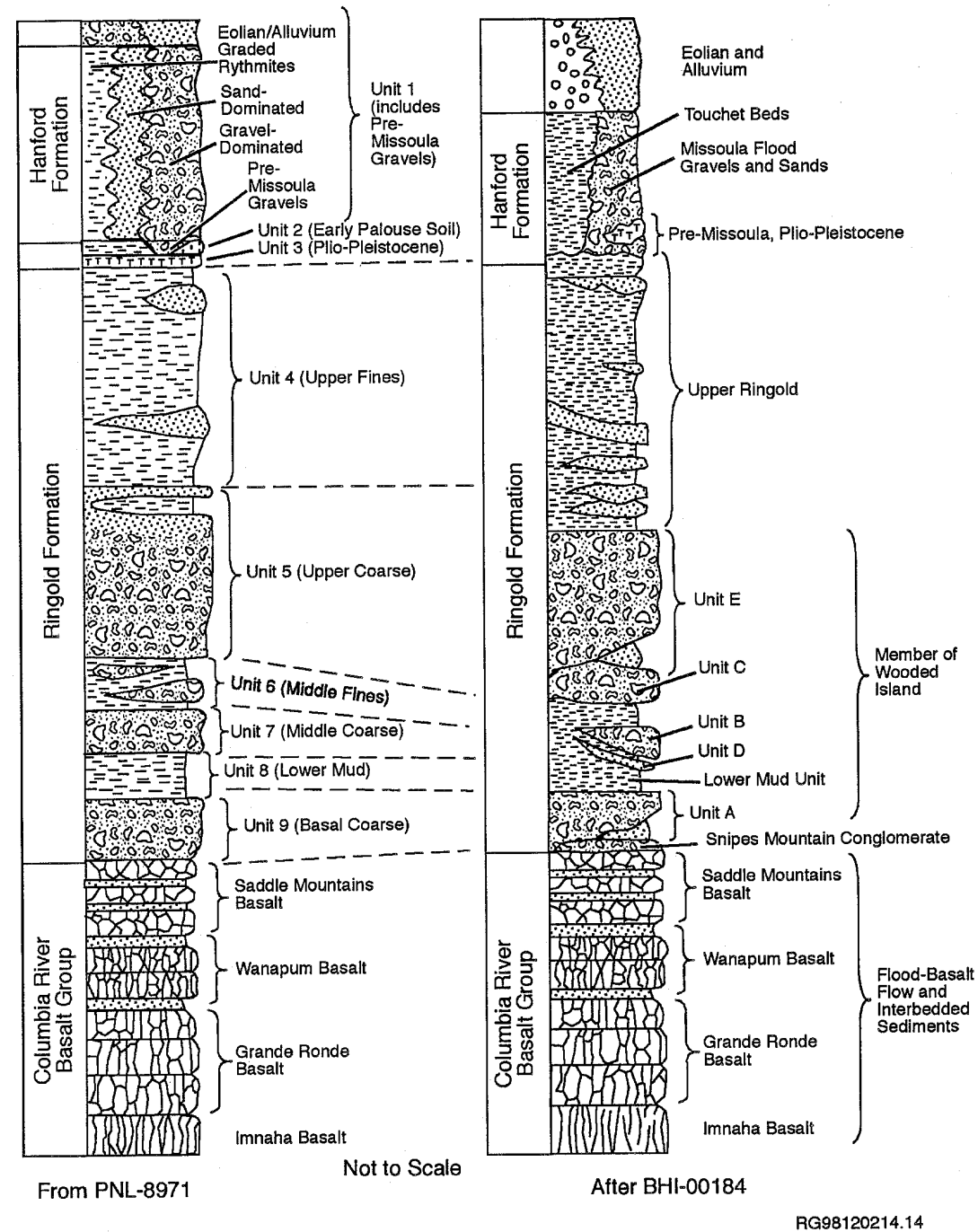

Figure 3.3. (a) Pasco Basin Cross Section B-B' (Figure 3.1), (b) Hydrostratigraphic (Left) and Stratigraphic (Right) Columns Illustrating the Geohydrology of the Pasco Basin and the Nine Supra-Basalt Hydrostratigraphic Units of the SGM 
Table 3.1. Major Hydrogeologic Units Used in the Site-Wide Three-Dimensional Model

\begin{tabular}{|c|l|l|}
\hline $\begin{array}{c}\text { Unit } \\
\text { Number }\end{array}$ & \multicolumn{1}{c|}{ Hydrogeologic Unit } & \multicolumn{1}{c|}{ Lithologic Description } \\
\hline 1 & $\begin{array}{l}\text { Hanford Formation and Pre- } \\
\text { Missoula Gravels }\end{array}$ & Fluvial gravels and coarse sands \\
\hline 2 & Palouse Soils & Fine-grained sediments and eolian silts \\
\hline 3 & Plio-Pleistocene Unit & $\begin{array}{l}\text { Buried soil horizon containing caliche and basaltic } \\
\text { gravels }\end{array}$ \\
\hline 4 & Upper Ringold Formation & Fine-grained fluvial/lacustrine sediments \\
\hline 5 & $\begin{array}{l}\text { Middle Ringold } \\
\text { (Unit E) }\end{array}$ & Semi-indurated coarse-grained fluvial sediments \\
\hline 6 & $\begin{array}{l}\text { Middle Ringold } \\
\text { (Unit C) }\end{array}$ & $\begin{array}{l}\text { Fine-grained sediments with some interbedded } \\
\text { coarse-grained sediments }\end{array}$ \\
\hline 7 & $\begin{array}{l}\text { Middle Ringold } \\
\text { (Unit B and D) }\end{array}$ & Coarse-grained sediments \\
\hline 8 & $\begin{array}{l}\text { Lower Mud Sequence } \\
\text { (Lower Ringold and part of } \\
\text { Basal Ringold) }\end{array}$ & Lower blue or green clay or mud sequence \\
\hline 9 & Basal Ringold (Unit A) & Fluvial sand and gravel \\
\hline 10 & Columbia River Basalt & Basalt \\
\hline
\end{tabular}

table and the extent and thickness of major hydrogeologic layers to the correct format for input to CFEST to develop the regional numerical model of the Hanford Site. Bottom elevations of layers, elevation of the water table, and grids representing hydraulic conductivity zones were input to GEOFEST.

A plan view of the finite-element grid and boundary conditions used in the three-dimensional flow model is illustrated in Figure 3.4. Most of the interior surface elements are regular elements that are $750 \mathrm{~m}$ on a side. The total number of surface elements in the three-dimensional model is 1606 , and the total number of nodes is 1784 . The three-dimensional model, based on this surface grid, comprises a total of 7200 elements and 8765 nodes.

\subsubsection{Elow System Boundaries}

The conceptual model for the baseline SGM contains several important flow-system boundaries illustrated in Figure 3.5. The unconfined aquifer system, which extends beyond the boundaries of the existing SGM, is recharged by groundwater from those portions of the unconfined aquifer that extend westward into the Cold Creek and Dry Creek Valleys (Figures 3.4 and 3.5). Additionally, the unconfined aquifer is recharged from springs and runoff that infiltrate the aquifer along the northern side of the Rattlesnake Hills and the western edge of the model (Figures 3.4 and 3.5). To approximate the groundwater flux entering the modeled area from these valleys and the Rattlesnake Hills, both prescribed head and prescribed flux boundary conditions were defined. For previous steady-state model calibration runs, a prescribed head-boundary condition was used to estimate boundary fluxes entering into the aquifer system from the Cold Creek and Dry Creek Valleys as well as along the Rattlesnake Hills. These calculated fluxes, summarized in Table 3.2, provided the initial estimates of boundary fluxes for the transient inverse calibration simulations. 


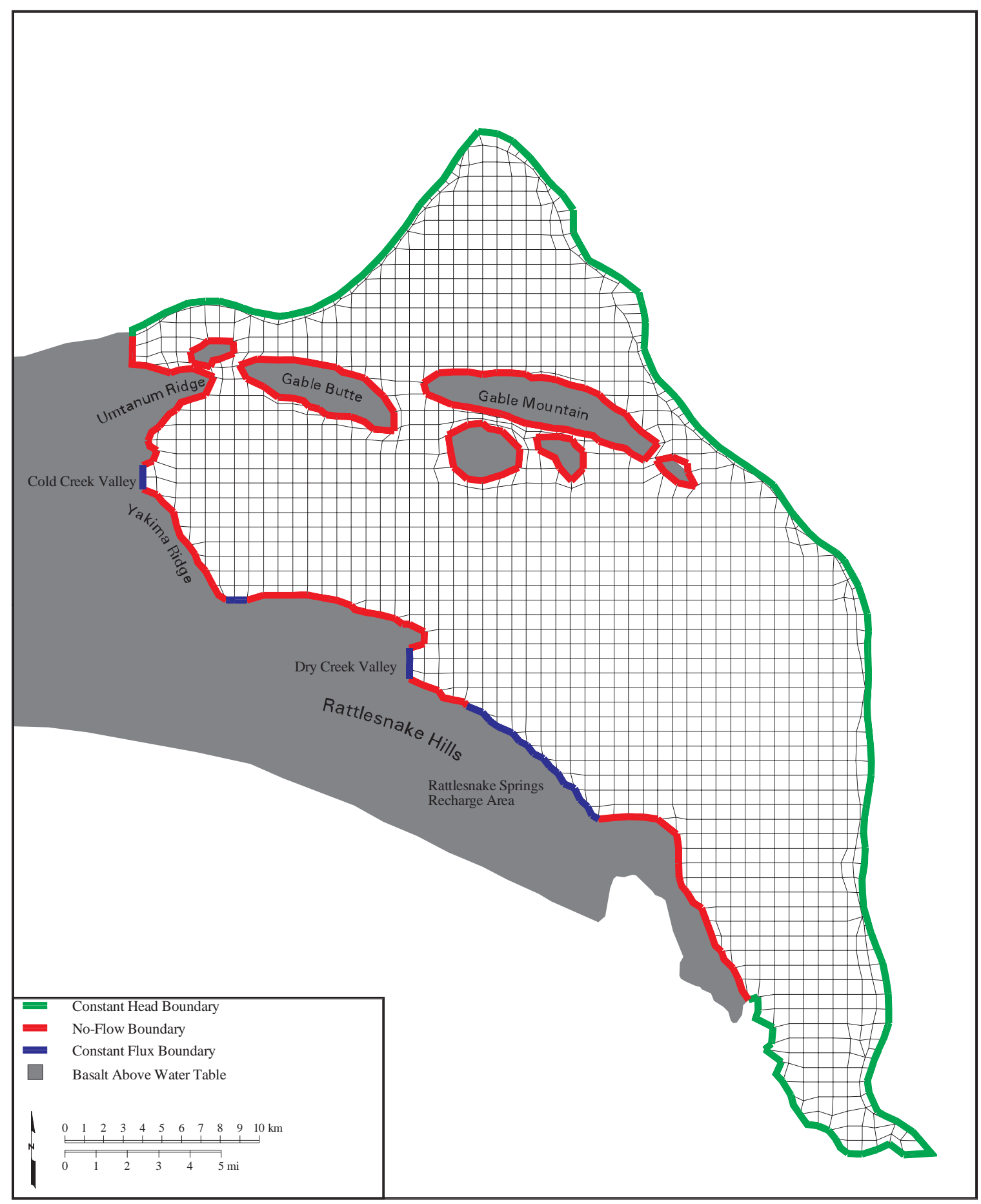

skw00078.eps December 10, 2000

Figure 3.4. Finite-Element Grid and Boundary Conditions Used in the Three-Dimensional Flow Model 


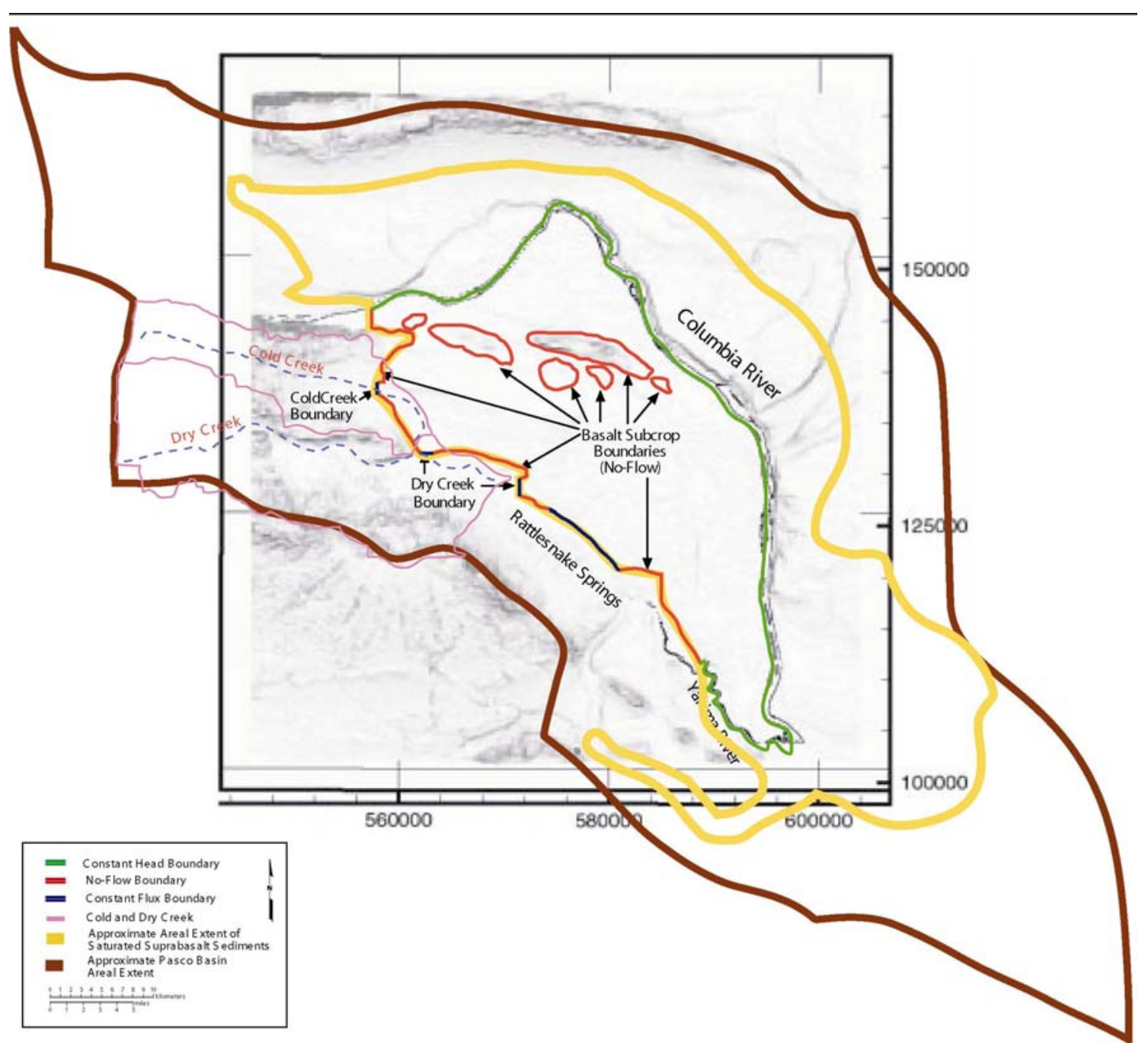

Figure 3.5. SGM Model Domain Within the Pasco Basin Illustrating the Location of the Important Flow System Boundaries for the Hanford Site Groundwater Model

The flow system is bounded by the Columbia River on the north and east and by the Yakima River and basalt ridges on the south and west, respectively. The Columbia River is assumed to represent a point of regional discharge for the unconfined aquifer system. The amount of groundwater discharging to the river is a function of the local hydraulic gradient between the groundwater elevation adjacent to the river and the river-stage elevation. This hydraulic gradient is highly variable because the river stage is affected by releases from upstream dams. To approximate the long-term effect of the Columbia River on the

Table 3.2. Summary of Calculated Fluxes in Four Regions

\begin{tabular}{|c|c|}
\hline Cold Creek Valley & $2881.3 \mathrm{~m}^{3} / \mathrm{yr}$ \\
\hline Dry Creek Valley & $1207.0 \mathrm{~m}^{3} / \mathrm{yr}$ \\
\hline Rattlesnake Hills & $3104.4 \mathrm{~m}^{3} / \mathrm{yr}$ \\
\hline Surface Natural Recharge & $8.47 \times 10^{6} \mathrm{~m}^{3} / \mathrm{yr}$ \\
\hline
\end{tabular}


unconfined aquifer system in the existing SGM (i.e., the prior model), the CHARIMA river-simulation model (Walters et al. 1994) was used to generate the long-term, average river-stage elevations for the Columbia River.

Because of the long-term nature of the calibration period, the previous design of the Columbia River boundary was modified during development of the baseline inverse model to approximate the major annual changes in river flow that have occurred since the early 1940s. Water-surface elevation boundary conditions for the Hanford Reach of the Columbia River were generated using the Modular Aquatic Simulation System 1D (MASS1) (Cole et al. 2001a). Results of the MASS1 modeling provided the historical Columbia River stages that were averaged into 6-month time steps to represent the gross annual and seasonal changes in river stage during the period. The effects of annual flow and stage fluctuations in the Yakima River during the calibration period were assumed to be less important than those of the Columbia River on the aquifer. Therefore, they were approximated using the annual average flow and stage used in previous modeling (e.g., Cole et al. 1997).

In the prior model and initial baseline inverse calibration effort, the uppermost units of basalt underlying the unconfined aquifer are assumed to represent the lower boundary for the Hanford Site unconfined aquifer system. The potential for interflow (recharge and discharge) between the basaltconfined aquifer system and the unconfined aquifer system was largely unquantified but was postulated to be very small relative to the other flow components estimated for the unconfined aquifer during the Hanford Site operational period. Therefore, the underlying basalt units were not included in these models, and the bottom of the unconfined aquifer was treated as a no-flow boundary. As discussed previously, one of the primary objectives of the inverse calibration effort documented in this report was to evaluate the interactions between the unconfined aquifer system and the uppermost confined aquifer of the Columbia River Basalt system and develop the technical approach and methods required to incorporate the effects of basalt leakage into the SGM. Work on this alternative conceptual model began in FY 2000 with a study that prepared a bibliography and assembled other preliminary information on the intercommunication between the unconfined aquifer and the uppermost confined aquifer at the Hanford Site, which can be found in Appendix B of Cole et al. (2001b) that discusses the uncertainty analysis framework being developed for the SGM.

\subsubsection{Natural and Artificial Recharge}

Natural recharge from precipitation falling on the Hanford Site is highly variable both spatially and temporally, ranging from near zero to more than $100 \mathrm{~mm} / \mathrm{yr}$ depending on climate, vegetation, and soil texture (Gee et al. 1992; Fayer and Walters 1995). Areas with shrubs and fine-textured soils like silt loams tend to have low recharge rates, while areas with little vegetation and coarse-textured soils, such as dune sands, tend to have high recharge rates. Recharge is also generally higher near the basalt ridges because of greater precipitation and runoff. Past estimates of recharge have been summarized in status reports (Thorne and Chamness 1992; Thorne et al. 1993). Fayer and Walters (1995) developed a natural recharge map (Figure 3.6) for 1979 conditions to support the three-dimensional model. The distributions of soil and vegetation types were mapped first. A recharge rate was then assigned to each combination on the basis of data from lysimeters, tracer studies, neutron probe measurements, and computer modeling. Estimated recharge rates for 1992 were found to range from 2.6 to $127 \mathrm{~mm} / \mathrm{yr}$, and the total volume of natural recharge from precipitation over the Hanford Site was estimated at $8.47 \times 10^{6} \mathrm{~m}^{3} / \mathrm{yr}$. This value is 

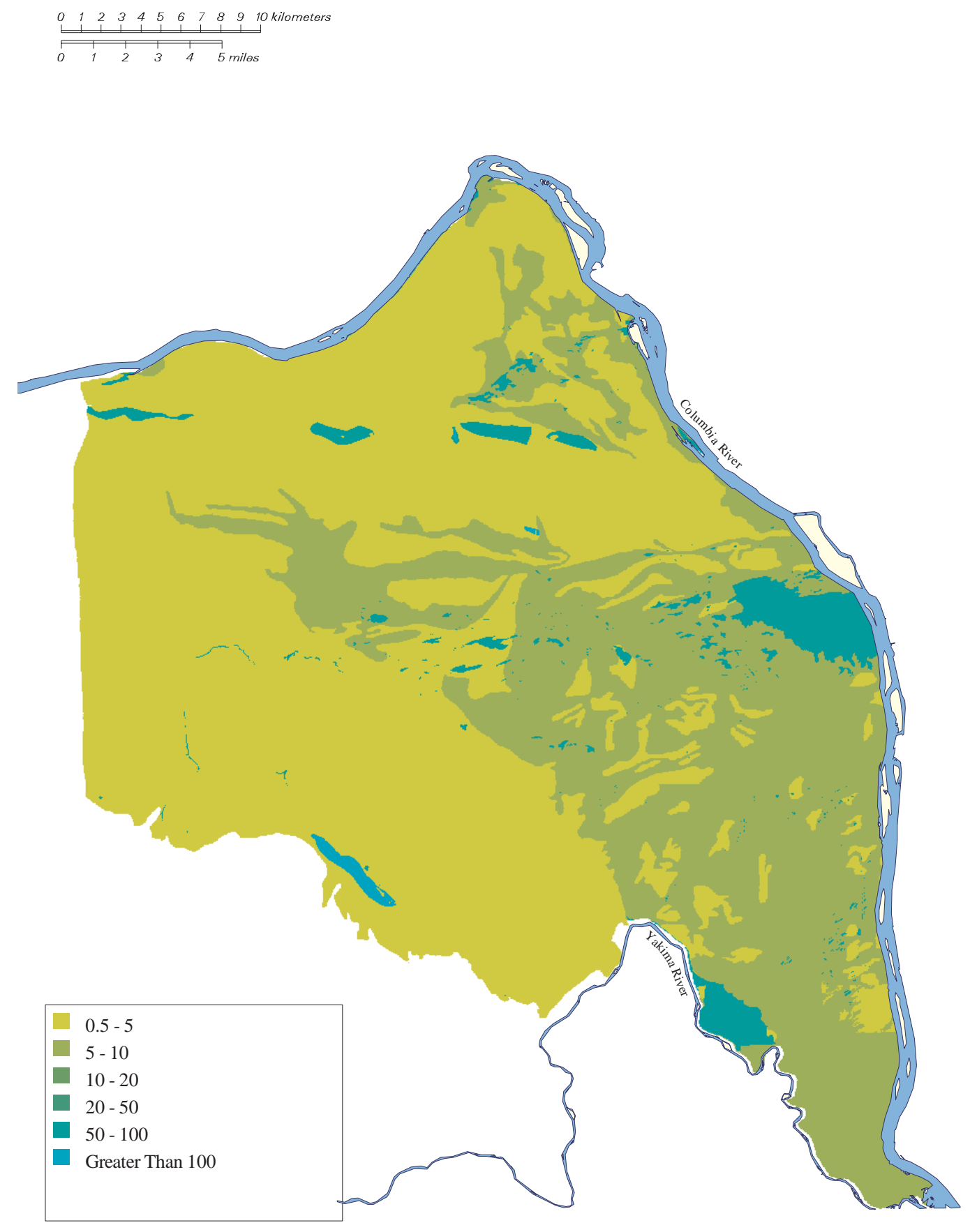

Figure 3.6. Estimates of Recharge for 1979 Conditions (Fayer and Walters 1995)

of the same order of magnitude as the artificial recharge to the 200-Area waste disposal facilities during 1992 and is about half the volume of discharge to these facilities during 1979 (Fayer and Walters 1995).

The other source of recharge to the unconfined aquifer is artificial recharge from wastewater disposal. Over the past 50 years, the large volume of wastewater discharged to disposal facilities at the Hanford 
Site has significantly affected groundwater flow and contaminant transport in the unconfined aquifer (Figure 3.7). The volume of artificial recharge has decreased significantly during the past 10 years and continues to decrease. Wurstner et al. (1995) summarized the major discharge facilities incorporated in the three-dimensional model. Cole et al. (1997) summarized the major wastewater discharges from both past and future sources. There are significant uncertainties associated with the artificial discharges related to the spatial location and timing of their arrival at the water table as well as the quantity that will be addressed in subsequent alternative conceptual model studies.

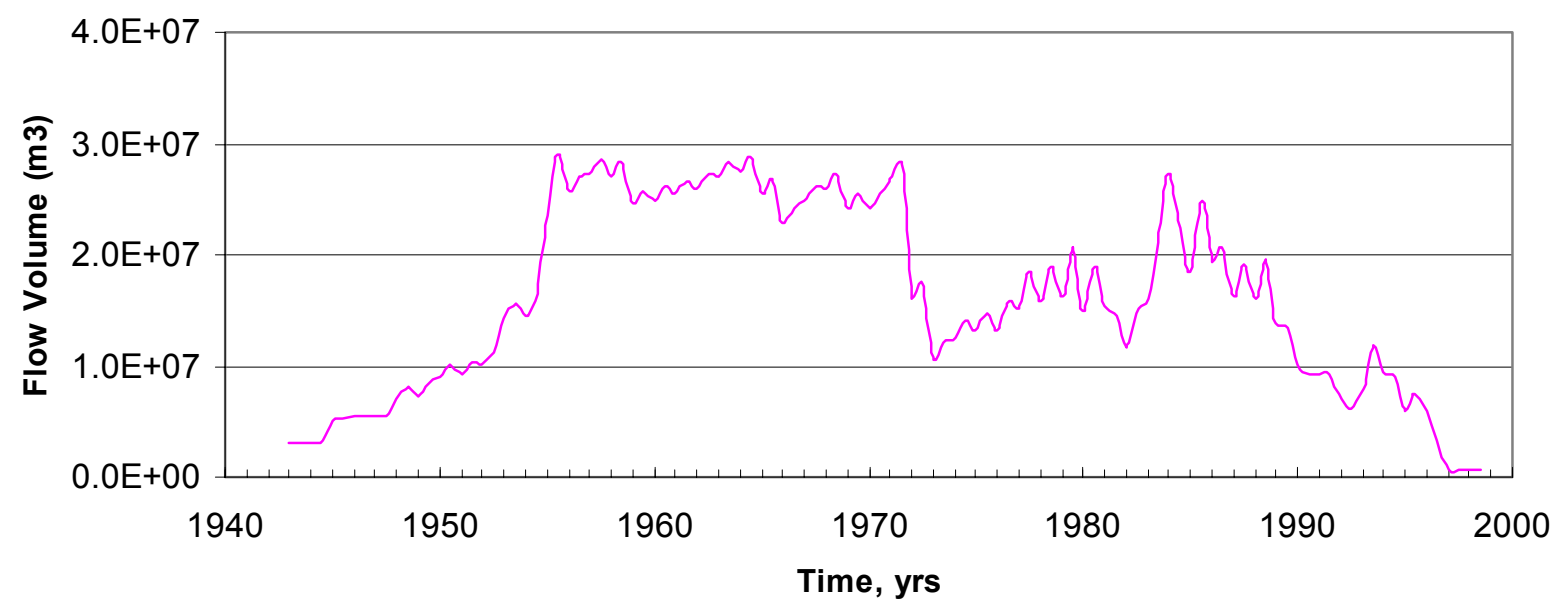

Figure 3.7. Artificial Discharges to the Unconfined Aquifer from 1943 to 1998

\subsubsection{Hydraulic Properties}

Hydraulic properties important to the conceptual model include both horizontal and vertical hydraulic conductivities, storativity, and specific yield. To apply a numerical model, the distribution of these parameters must be specified for each hydrogeologic unit. Hydraulic properties have been measured for the unconfined aquifer (considered as a simple hydrogeologic unit) mainly during aquifer pumping tests and from laboratory permeability tests. The results of these tests have been documented over the past 50 years and recently summarized (DOE 1988; Thorne and Newcomer 1992). As indicated in these documents, the quality of results from aquifer tests at the site varies widely and is affected by both aquifer conditions and analysis procedures. Thorne and Newcomer (1992) and Wurstner et al. (1995) reanalyzed the aquifer tests, many of which were single-well pumping tests, and Wurstner et al. (1995) selected the set of aquifer transmissivity calibration data (Figure 3.8) that was used in the two-dimensional inverse model calibration that gave rise to the transmissivity distribution illustrated in Figure 3.8. Figure 3.9 shows the hydraulic conductivity distribution for hydrogeologic units that outcrop at the water table and are defined in the prior three-dimensional model. Figures 3.10(a) and 3.11(a) show the vertical distributions of the major hydrogeologic units and their associated hydraulic conductivities along the A-A' and B-B' cross-section lines in Figure 3.9 that are defined in the prior three-dimensional model. Table 3.3 summarizes the range of hydraulic conductivities for each hydrogeologic unit. 


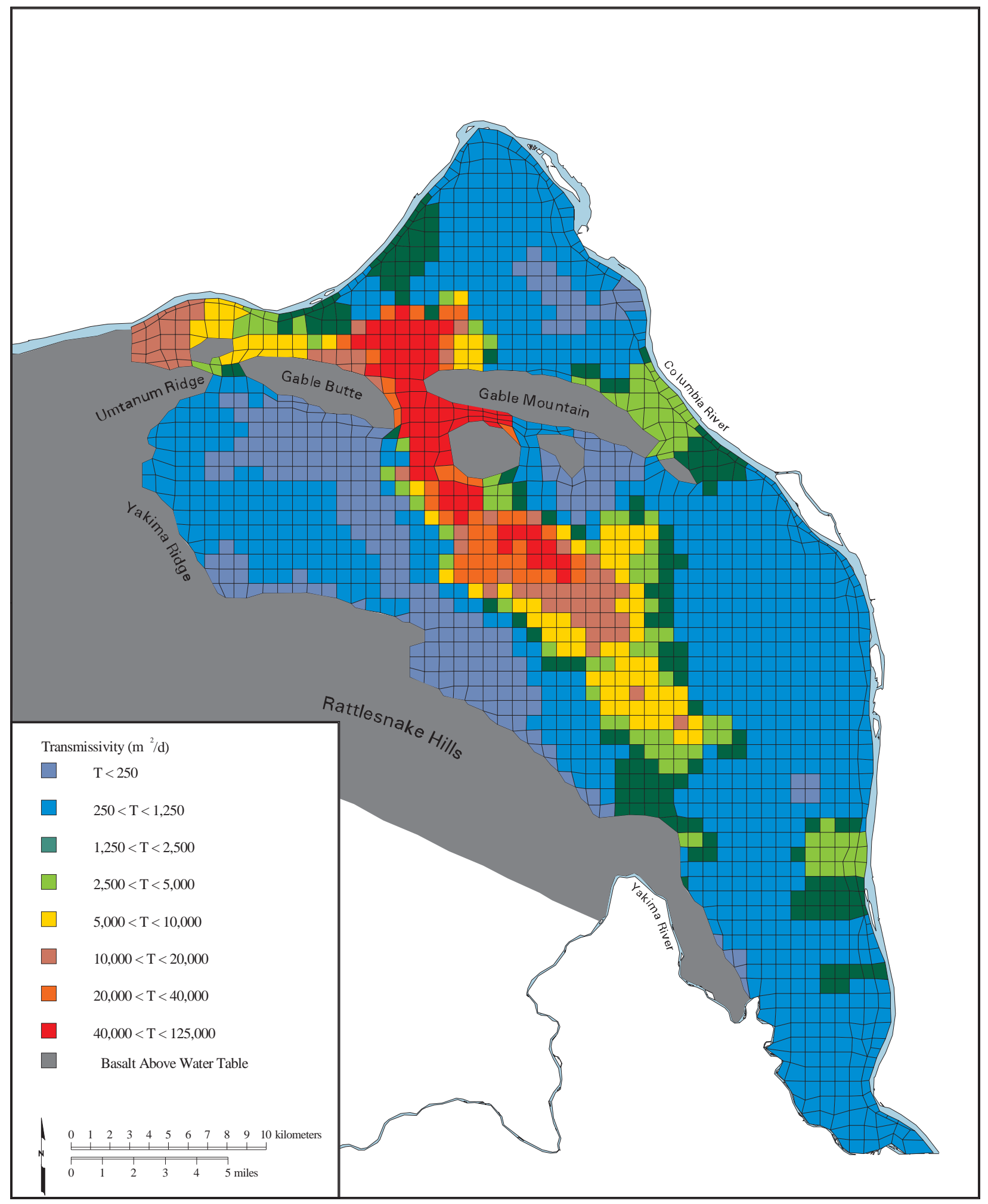

97skw019.eps December 02, 1997

Figure 3.8. Transmissivity Distribution Developed from the Two-Dimensional Inverse Calibration 


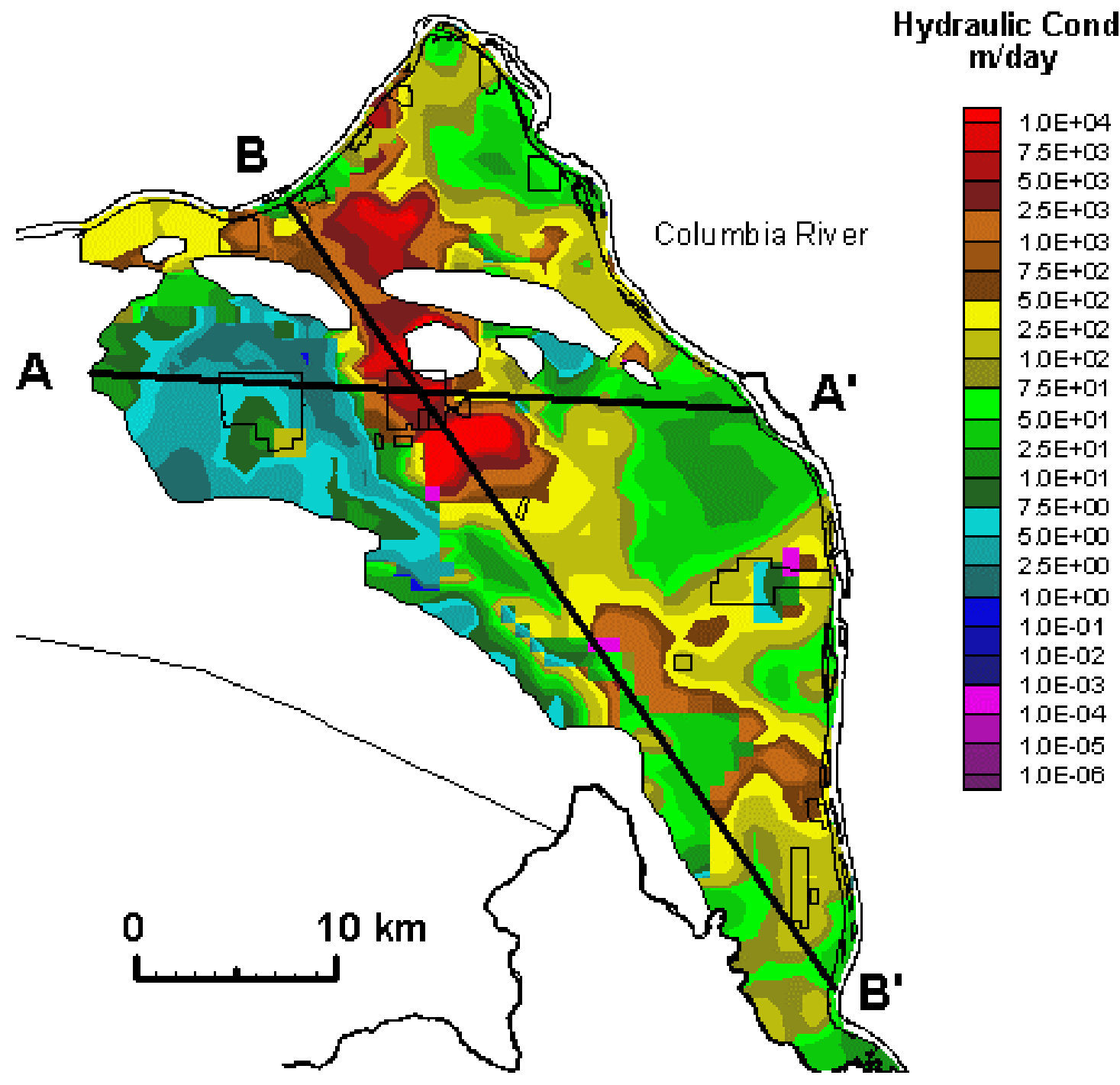

Figure 3.9. Hydraulic Conductivity Distribution Used in the Prior Model 


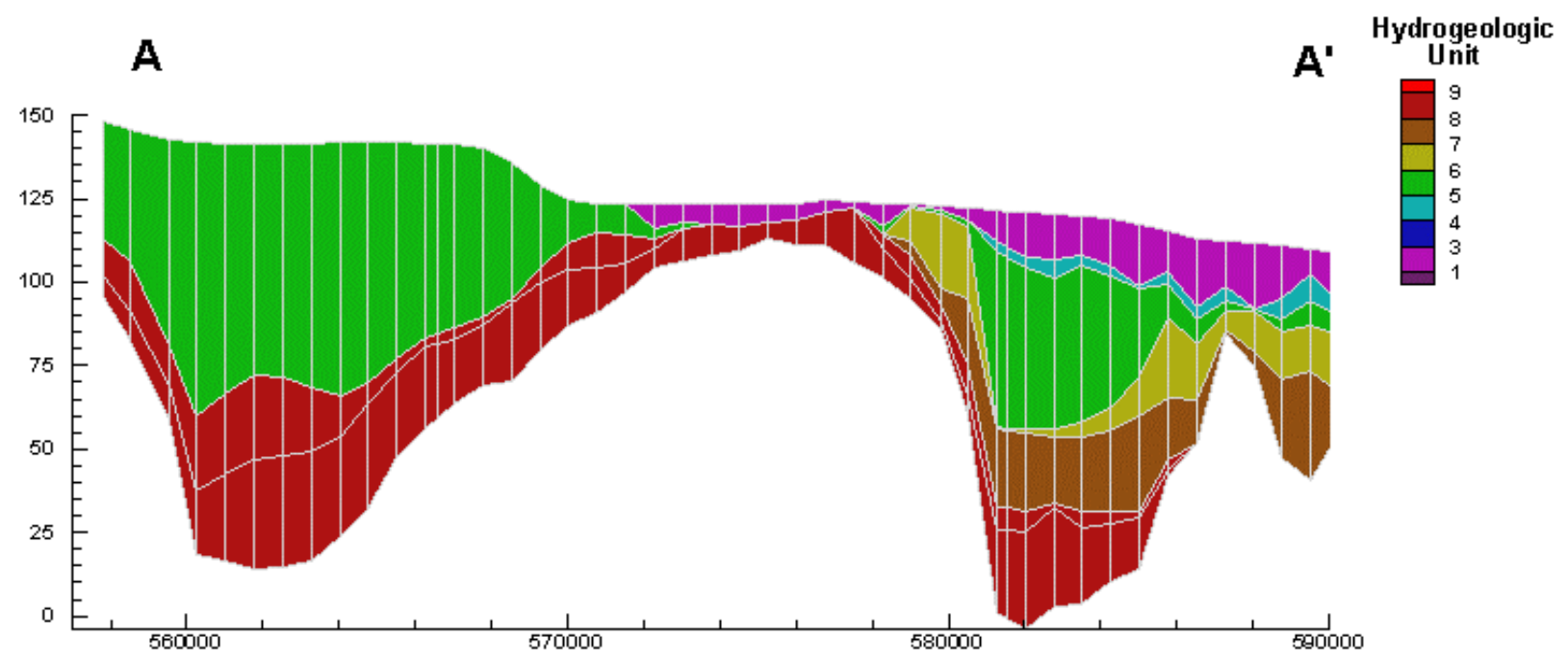

Figure 3.10 (a). Cross-Section A-A' Showing Distribution of Hydrogeologic Units

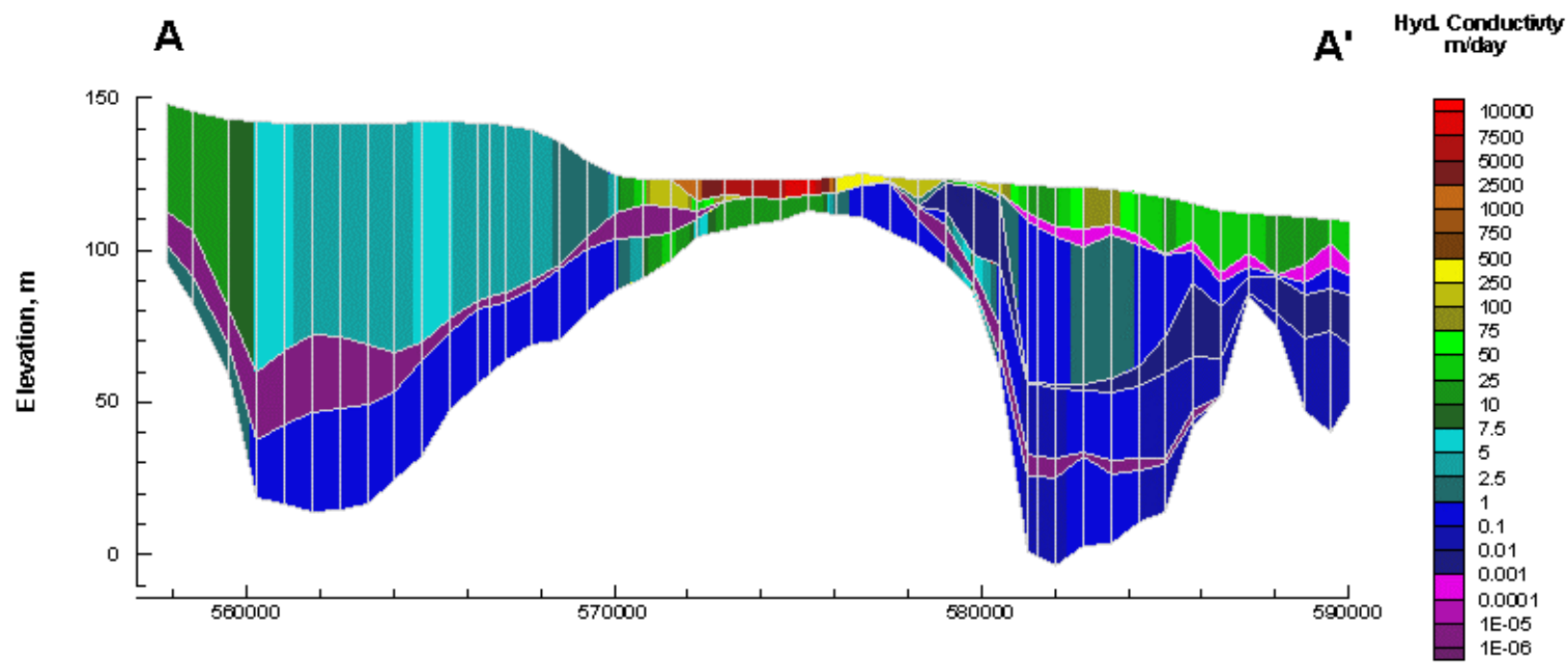

Figure 3.10 (b). Cross-Section A-A' Showing Distribution of Hydraulic Conductivity in the Prior Model 


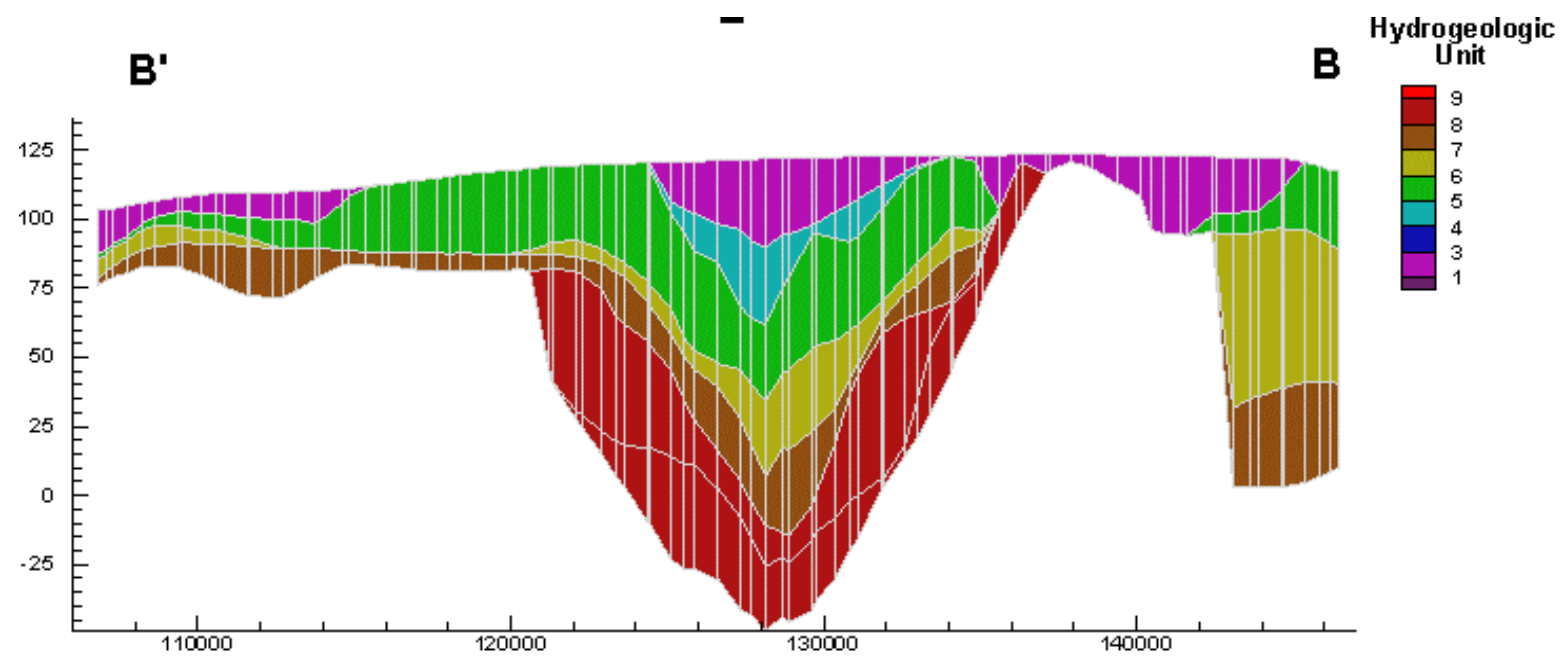

Figure 3.11(a). Cross-Section B-B' Showing Distribution of Hydrogeologic Units

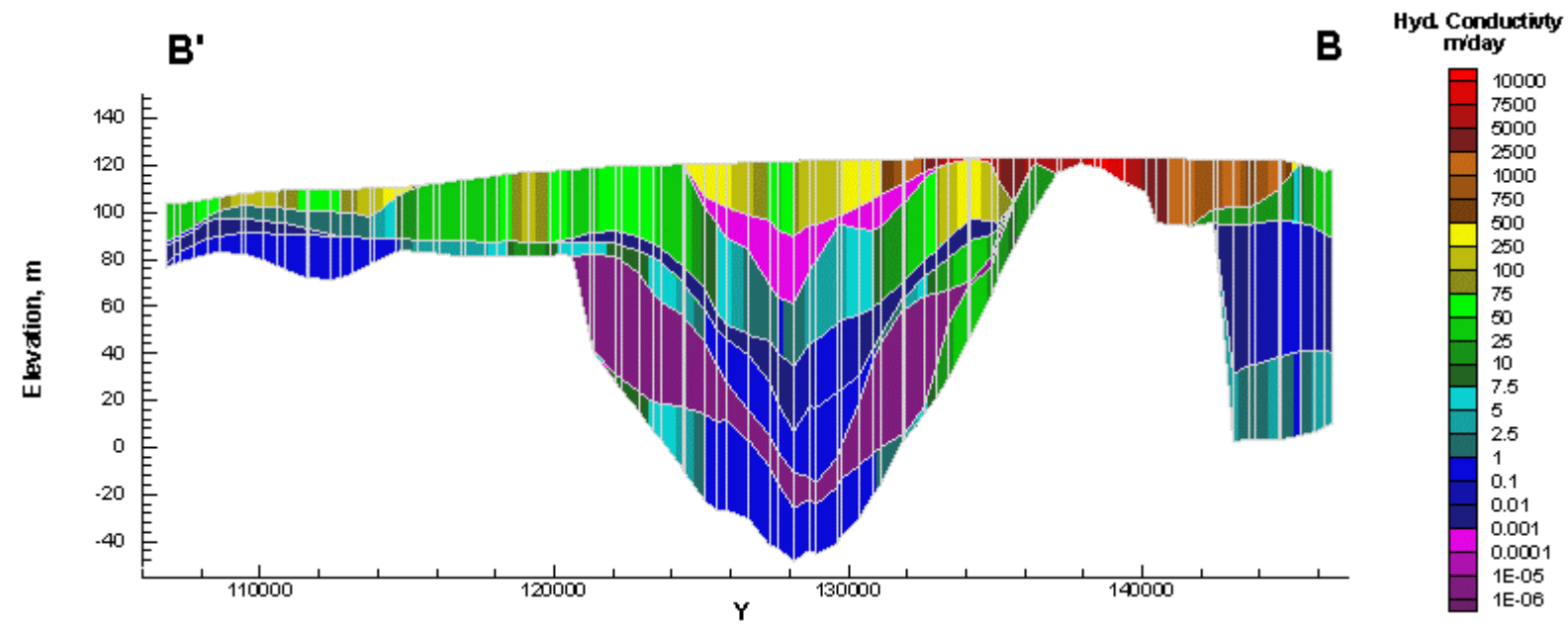

Figure 3.11(b). Cross-Section B-B' Showing Distribution of Hydraulic Conductivity in the Prior Model

Table 3.3. Range of Hydraulic Conductivities by Hydrogeologic Unit in the Prior Model

\begin{tabular}{|c|c|c|}
\hline & \multicolumn{2}{|c|}{$\begin{array}{c}\text { Range in Hydraulic } \\
\text { Conductivity (m/day) }\end{array}$} \\
\hline Hydrogeologic Unit & Minimum & Maximum \\
\hline 1 & 1.77 & 33122 \\
\hline 3 & 14.2 & 190.5 \\
\hline 4 & $5 \mathrm{E} 10-3$ & $5 \mathrm{E} 10-3$ \\
\hline 5 & 0.04 & 1696.5 \\
\hline 6 & 0.01 & 0.1 \\
\hline 7 & 0.008 & 85.7 \\
\hline 8 & $1 \mathrm{E} 10-5$ & $1 \mathrm{E} 10-5$ \\
\hline 9 & 0.008 & 210.8 \\
\hline
\end{tabular}




\subsection{Modifications to Account for Basalt Intercommunication}

The following sections discuss potential mechanisms for intercommunication between the Hanford Site unconfined aquifer and the underlying upper basalt confined aquifer and how these mechanisms have been implemented in the SGM. The underlying regional aquifer system that lies within the basalts was not considered in the baseline SGM domain. The base of the unconfined aquifer system in the prior and baseline SGM was initially assumed to be a no-flow boundary, and no interactions with the underlying basalt aquifer system were accounted for. However, it is known that some flow occurs between these aquifer systems, and this creates a potential error in the model implementation. Including the entire regional aquifer within the model domain is not considered a reasonable option because flow through the local unconfined aquifer system is small compared to flow in the regional confined system (Figure 3.1), and the uncertainties in regional recharge and discharge would be too large compared with the volume of interflow between these systems.

Several past investigations have provided important geologic, geophysical, hydrologic, and hydrochemical data relative to potential intercommunication between the unconfined aquifer and the uppermost confined aquifer. Contamination in the unconfined aquifer in the 200 areas was documented as early as 1950 (Brown and Rupert 1950), and in 1976 an investigation of contaminants in the Mabton interbed was published (Atlantic Richfield Hanford Company 1976) in which it was hypothesized that there may be an area of intercommunication in the vicinity of Gable Mountain Pond. The most focused and relevant information and data on potential intercommunication between the unconfined and uppermost confined aquifers are found in Graham et al. (1984), DOE (1988), and Jensen (1987). A summary of these efforts and various sources on basalt and intercommunication between the basalts was prepared by Phil Rogers and is published in Appendix B of Cole et al. (2001b).

\subsection{Potential Mechanisms for Aquifer Intercommunication}

Potential intercommunication between aquifer systems at the Hanford Site is between water-bearing units in the Saddle Mountain hydrostratigraphic unit and the overlying unconfined aquifer system (Figure 3.3). The main water-bearing zones in the Saddle Mountain basalt are the sedimentary interbeds and the interflow zones between basalt flows associated with the interconnecting vesicles and fractures of basalt flow tops (Figure 4.1). Collectively, these interbedded sediments and the Saddle Mountain basalt interflow zones form an extensive confined aquifer system, which in this report is referred to as the uppermost basalt-confined aquifer.

The bottom of the unconfined aquifer throughout most of the Hanford Site is the top of the Elephant Mountain basalt flow interior where it is present, and in some areas, the basal Ringold where it occurs as a low permeability silt and clay lying over the basalts. There are locations where the Elephant Mountain basalt has been fully eroded and is absent, specifically between Gable Mountain and Gable Butte in the vicinity of West Lake. Figure 4.2 is an isopach map of the Elephant Mountain basalt on the Hanford Site that shows the portion of the erosional feature where the unconfined and upper confined aquifer systems are in direct contact (referred to in this report as the erosional window). The Elephant Mountain thickness data presented in Figure 4.2 is modified from DOE (1988) based on more recent geologic characterization data. Figure 4.3 is an isopach map of the Elephant Mountain basalt in the West Lake and B Pond area 


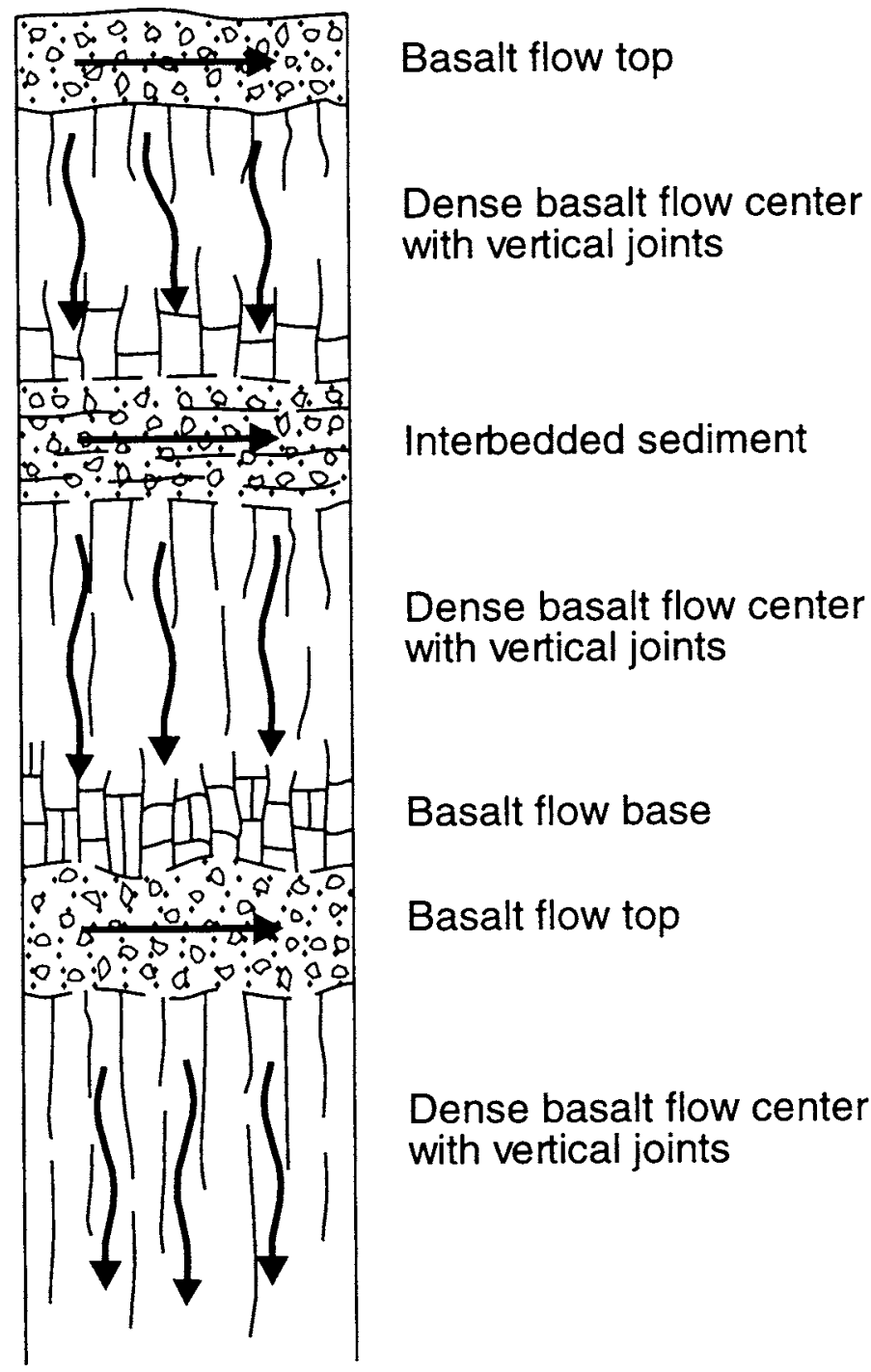

Figure 4.1. Conceptual Model for Flow in the Basalt Aquifer System (After Drost et al. 1997)

showing the area where the basalt is absent between Gable Mountain and Gable Butte and two other localized "pockets" to the southeast. The Rattlesnake Ridge interbed that lies directly beneath the Elephant Mountain basalt has also been removed by erosion in the gap area as illustrated in Figure 4.4, which is an isopach map of the Rattlesnake Ridge interbed in the vicinity of B Pond and West Lake.

Five principal intercommunication mechanisms were identified in a previous report documenting various sources of uncertainty in the Hanford Site groundwater model (Cole et al. 2001b). Potential leakage mechanisms include:

1. Leakage through erosional windows where the confining layer is absent

2. Flow along faults that connect the upper basalt-confined and unconfined aquifer systems 


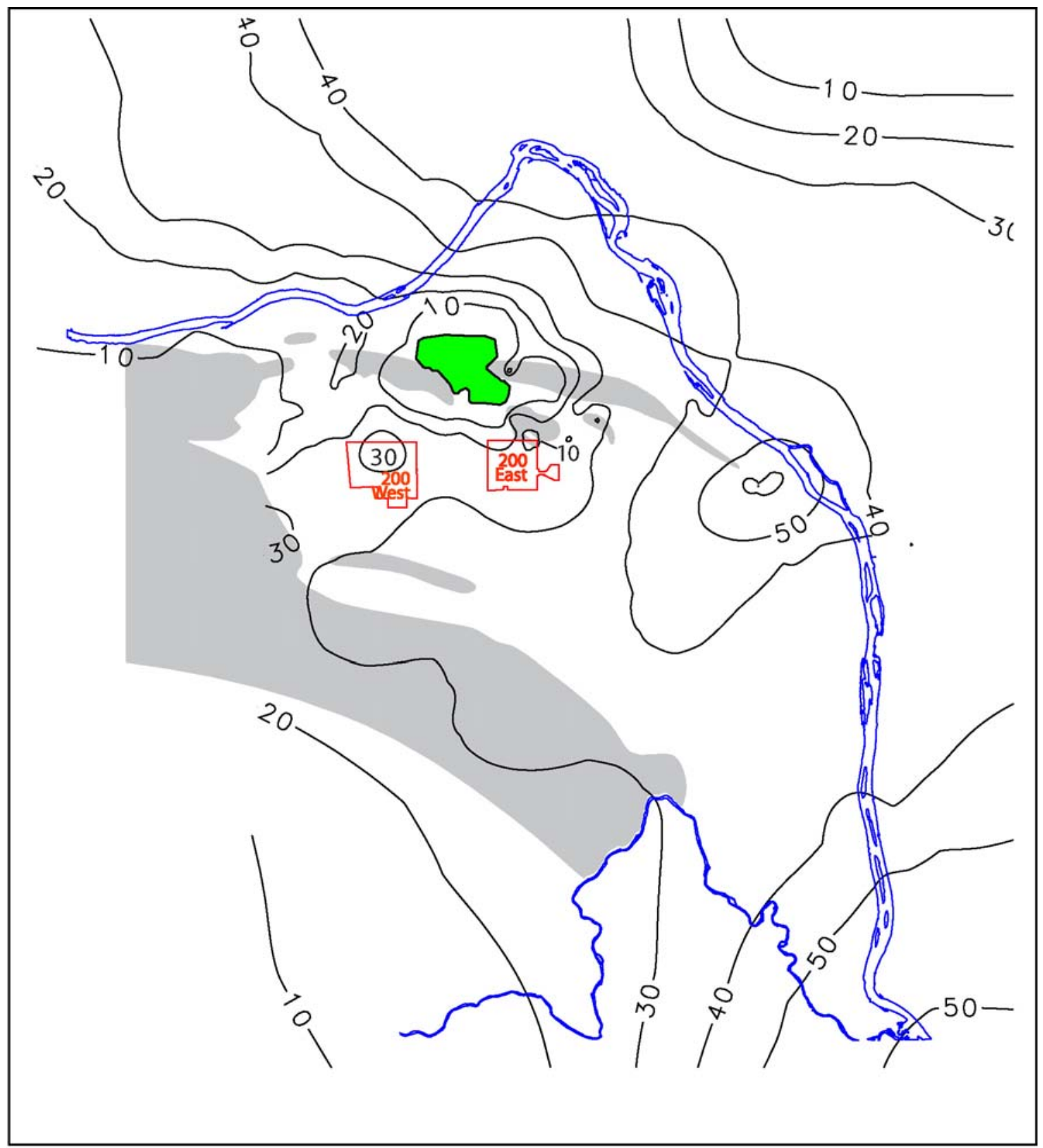

Basalt Above Unconfined Aquifer Water Table

Erosional Window in Contact with Unconfined Aquifer System

-10 Estimated Elephant Mountain Thickness (m)

Figure 4.2. Isopach Map of the Elephant Mountain Basalt on the Hanford Site Showing the Portion of the Erosional Window Where the Unconfined and Upper Confined Aquifer Systems Are in Direct Contact 


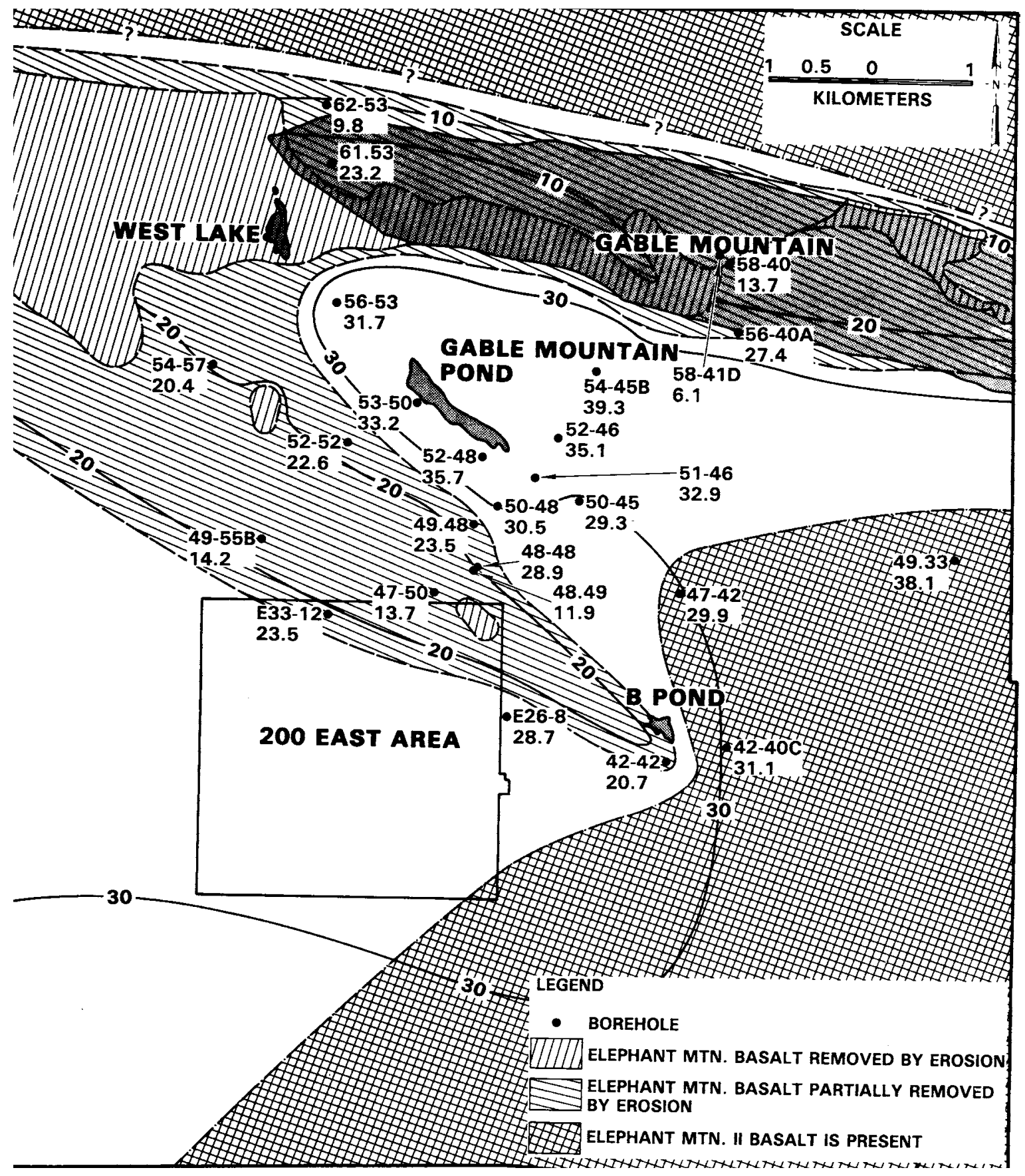

Figure 4.3. Isopach Map of the Elephant Mountain Basalt in the West Lake and B Pond Area Showing the Area Where the Basalt Is Absent Between Gable Mountain and Gable Butte and Two Other Localized "Pockets" to the Southeast (taken from Graham et al. 1984)

3. Leakage in structurally deformed areas, such as anticlines, where dense interiors may be highly fractured. Pervasive and relatively uniform leakage through the confining layer (basalt flow interior)

4. Human intrusion associated with improperly constructed wells and boreholes. 




Figure 4.4. Isopach Map of the Rattlesnake Ridge Interbed in the Vicinity of B Pond and West Lake (Contours are in Meters) (Taken From Graham et al. 1984)

Evidence that hydraulic intercommunication occurs in the Gable Mountain-Gable Butte Gap area, where erosional windows have been identified, includes:

- chemical composition of groundwater indicating mixing

- presence in the uppermost confined aquifer of chemical species (i.e., nitrate ion) and radioisotopes (e.g., tritium and I-129) that are associated with near-surface waste water disposal 
- similarity of hydraulic heads in the unconfined and uppermost confined aquifers in the vicinity of the Gable Mountain -Gable Butte Gap where the Elephant Mountain basalt is absent

- geologic information from borehole logs and geophysical information indicating an area where the Elephant Mountain basalt (confining layer) is absent, and within this area, locations where the underlying Rattlesnake Ridge interbed (water-bearing unit) and portions of the Pomona basalt (confining layer) are absent.

The area where the Elephant Mountain basalt is absent (Figure 4.3) represents an area where increased aquifer intercommunication occurs, unimpeded by a confining layer. Another area where increased leakage may occur is in the vicinity of fault zones. Springs are present in the Rattlesnake Hills along the western boundary of the SGM domain that bring groundwater from the basalt-confined aquifer system to the surface. These springs are found where major thrust faults intersect the ground surface (DOE 1988). This provides evidence that the major thrust faults provide conduits for flow between aquifer systems. Anticlines may also be areas of increased communication because of fracturing. However, there is no direct evidence of intercommunication associated with anticlines other than in the area where erosional windows are also present.

Elsewhere on the Hanford Site, the Elephant Mountain basalt provides a significant impediment to vertical intercommunication between the aquifers owing to its thickness (Figure 4.3) and low vertical hydraulic conductivity, which may range from $1 \mathrm{E}-8 \mathrm{~m} / \mathrm{d}(3.3 \mathrm{E}-8 \mathrm{ft} / \mathrm{d})(\mathrm{Graham}$ et al. 1984) to $2.6 \mathrm{E}-4 \mathrm{~m} / \mathrm{d}$ (8.5E-4 ft/d) (Nevulis et al. 1987). The effectiveness of the Elephant Mountain basalt as a confining layer and impediment to vertical communication between the unconfined and uppermost confined aquifers is evidenced by the hydraulic head difference between the two aquifers and difference in groundwater chemistry. However, the rate of pervasive flow through the confining unit may still be significant because it takes place over a large area.

\subsection{Model Design Analysis for the Basalt Leakage Boundary}

The design analysis presented in this section was performed to provide preliminary estimates of hydrologic parameters controlling intercommunication with the upper basalt confined aquifer. These estimates were used as initial conditions for the inverse simulations and as guidance to determine when the inverse parameter estimation scheme was driving the solution toward unreasonable parameter values. In cases where the inverse could not determine a given parameter, the parameter value was set to the design analysis estimates, which represents a best estimate based on available hydrogeologic information.

\subsubsection{Head-Dependent Areally Distributed Leakage}

As discussed previously, including the regional basalt-confined aquifer system within the model domain is not considered a reasonable option because flow through the local unconfined aquifer system is small compared with flow in the regional confined system, and the uncertainties in regional recharge and discharge would be large in comparison with the volume of interflow between these systems. To avoid including the local upper basalt-confined aquifer system within the SGM model domain but still accounting for intercommunication, an approach was adopted that calculates the head gradient between the unconfined aquifer (simulated in the SGM) and upper basalt-confined aquifer. Hydraulic heads for the upper basalt-confined system were based on potentiometric surfaces developed from spatially and 
temporally distributed water levels measured in monitoring wells completed within the upper basaltconfined system. This head gradient is used along with an estimate of the thickness and vertical hydraulic conductivity of the basalt-confining layer to calculate flux across the confining layer. Depending on the temporal and spatial location within the model domain, either leakage from the confined to unconfined system (i.e., the predominant case) or from the unconfined to confined systems (e.g., 200 Area plateau under wastewater mounding conditions) can occur.

The first step in developing the head-dependent areally distributed leakage from the basalt boundary condition for the SGM was to obtain spatially and temporally distributed hydraulic-head data for the upper basalt-confined aquifer system. Areal distributions were developed from available data approximately every 10 years starting in 1943 (i.e., interpretations for 1943, 1955, 1965, 1975, 1985, and 1995 were prepared). Additionally, an extrapolation for 2005 was prepared). Hydraulic head for other times was then interpolated from these prepared data sets. Spane and Raymond (1993) developed a head map for the upper basalt-confined system for March 1993. This was a time when a relatively large number of well measurements were available for the upper basalt-confined aquifer system. Therefore, the 1993 head distribution was used as a basis for creating head distributions at other points in time. Available historic water-level data from wells completed in the upper basalt-confined aquifer were compiled. Missing data were interpolated for some wells where earlier and later measurements were available. The head changes at each of these wells for the intervals 1943 to 1955,1955 to 1965,1965 to 1975,1975 to 1985,1985 to 1993, 1993 to 1995, and 1995 to 2005 were then calculated and used to develop regular grids (150m x $150 \mathrm{~m}$ ) of the head change during each of these time periods covering the entire model area. The grids were plotted as contour maps and adjusted to honor the well data and general knowledge of head changes across the site such as the location of discharge facilities. Hydraulic-head grids for each time plane were calculated by adding or subtracting the appropriate head-change grids to or from the 1993 hydraulic-head grid based on Spane and Raymond (1993). This process resulted in regular grids (150 m x $150 \mathrm{~m}$ ) of hydraulic head for the upper basalt-confined aquifer for each of the seven times (i.e., 1943, 1955, 1965, 1975, 1985, 1995, and 2005).

The potentiometric surface maps for the upper confined aquifer were then supplemented with head data from the unconfined aquifer over the area comprising the erosional window where the aquifers are in direct communication. This was done under the assumption that the highly conductive Hanford unconfined aquifer would act as a source or sink for the upper basalt-confined aquifer along both the northern and southern boundaries of the erosional window where the two aquifer systems interconnect, thereby causing the head in the confined system to track the head in the unconfined system along this interface. Flow direction across this interface would thus depend on the relative potentials in the two systems. Previously reported interpretations of head within the upper confined aquifer had failed to make this correction, which assumes that the head along this erosional interface is the same in both the confined and unconfined systems. This correction is required to appropriately represent heads at the boundary of the window and implement a scheme to estimate head-dependent leakage through the window (Section 4.2.2). Head data from monitoring wells completed in the unconfined aquifer within the erosional window, which was a subset of the data that defined the objective function in the inverse simulations, were plotted to show their spatial and temporal variability (Figure 4.5). The dataset fell into two distinct groupings, one representing the southern half and the other the northern half of the erosional window, indicating that heads along the northern and southern boundaries of the erosional window could be treated as a time-varying constant across the entire boundary. The head along the southern boundary was consistently higher than that along the northern boundary, confirming a generally northern flow direction through the gap between Gable Mountain and Gable Butte. 


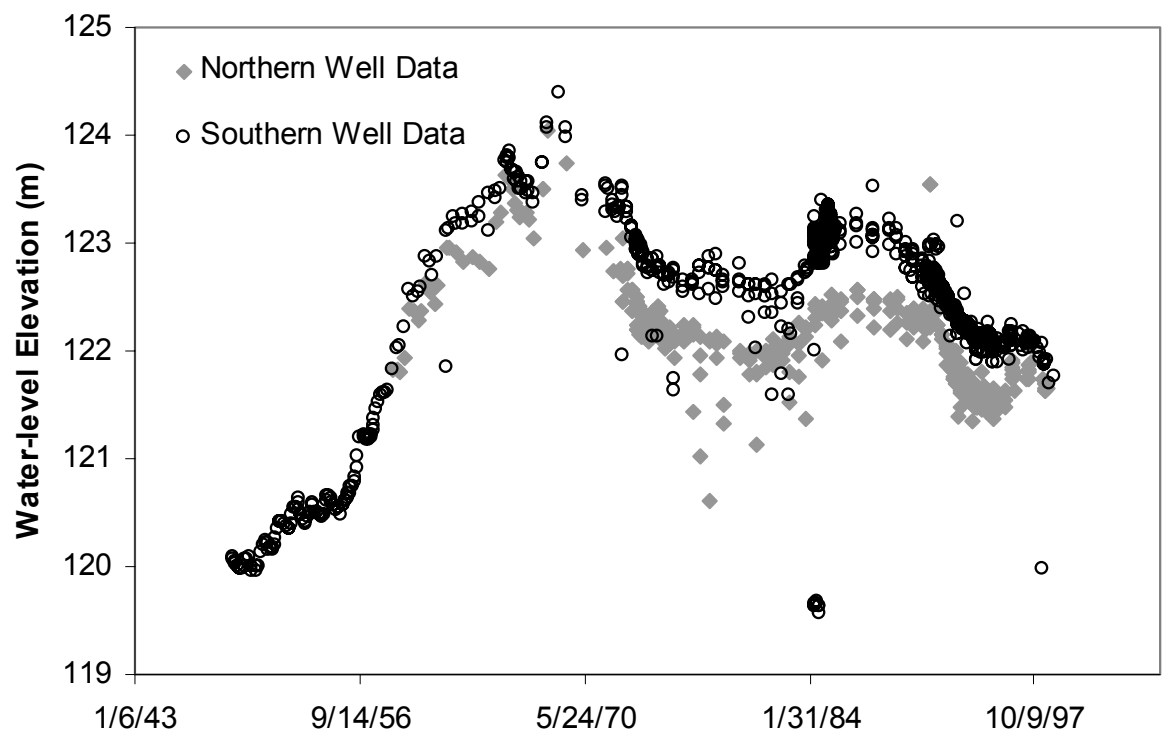

Figure 4.5. Water Level Data from Monitoring Wells Completed in the Unconfined Aquifer Within the Erosional Window

Based on these data, the average head level for both the northern and southern boundaries was calculated for each of the time planes where a potentiometric map of the upper confined aquifer was generated. The upper basalt confined aquifer potentiometric surfaces were corrected by applying the calculated head values to both the northern and southern boundaries of the erosional window and smoothing the data to approximate the expected head profile extending radially from the northern and southern erosional window boundaries to points within the upper confined aquifer where observed head data were available.

Figures 4.6, 4.7, and 4.8 are examples of the developed potentiometric surface maps of the upper confined aquifer for 1943, 1965, and 1995, respectively. The effect of the source/sink interconnection assumption and smoothing is most evident in the 1995 potentiometric surface shown in Figure 4.8, when the potentials in the unconfined system are lower than those in the upper basalt-confined aquifer (see the 122,123 , and 124 meter contours). Inspection of head contours in the vicinity of the erosional window indicates a positive gradient from the upper confined aquifer to the unconfined aquifer in 1945 (basalts recharging the unconfined aquifer), a flow reversal in 1965 (unconfined aquifer recharging basalts) resulting from increased heads in the unconfined aquifer associated with wastewater disposal in the 200 Areas, and another example of the predominant positive gradient in 1995. These generalized results are consistent with a more detailed analysis of leakage through the erosional window discussed in Section 4.2.2. Once potentiometric surface maps were developed at the specified time planes (1943, 1955, 1965, 1975, 1985, 1995, and 2005), GIS and Perl programming routines were developed to sample the head grids at each model node location and time plane and interpolate the information onto the SGM time steps. These data manipulation routines resulted in a file containing an estimate of hydraulic head in the upper confined aquifer for each SGM node at each of the 108 time steps between 1943 and 1996. 


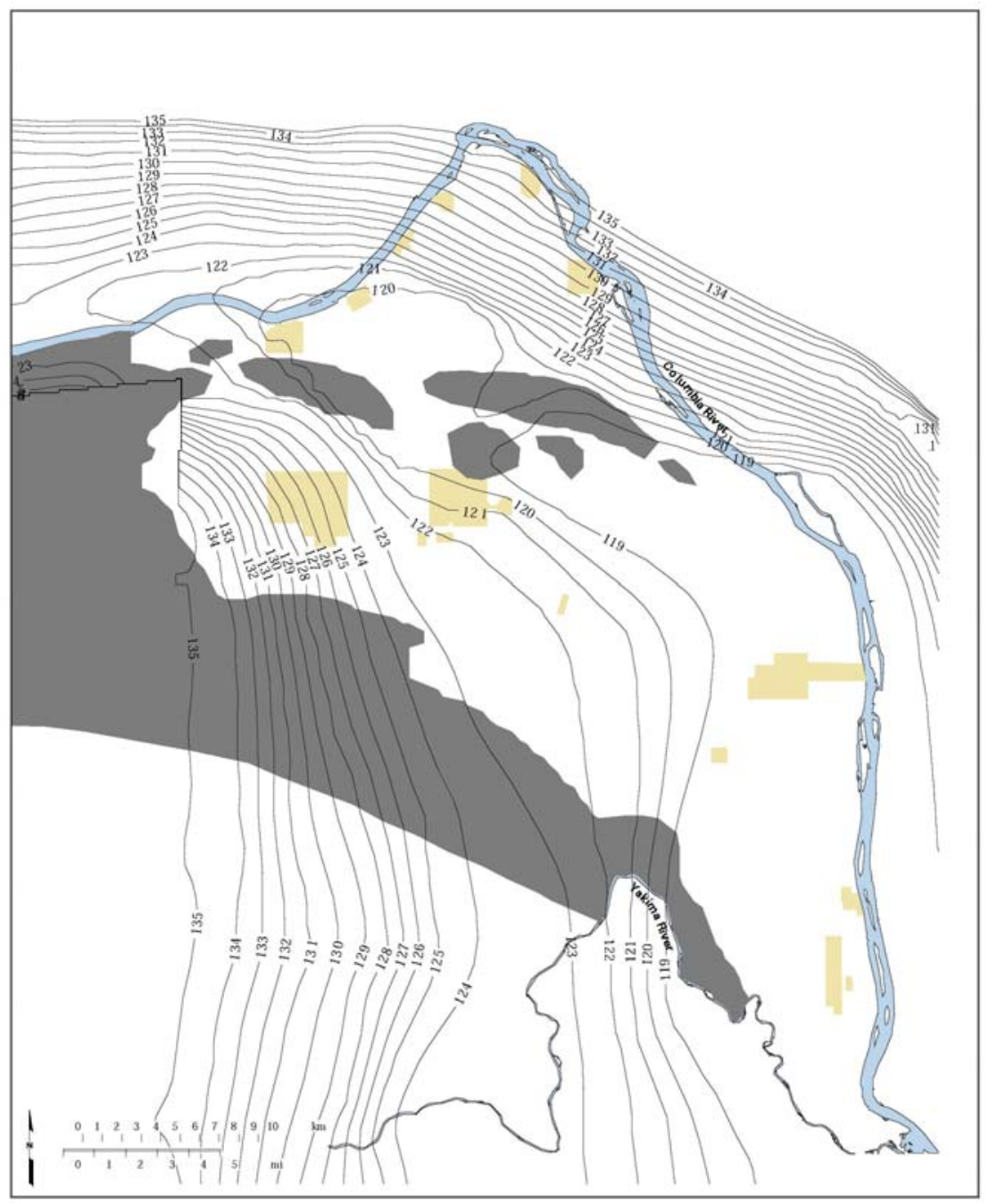

Figure 4.6. Potentiometric Surface Map of the Upper Basalt-Confined Aquifer in 1943

After spatially and temporally distributed hydraulic head estimates were generated for the upper confined aquifer, an analysis was conducted to provide an initial estimate of the vertical hydraulic conductivity of the Elephant Mountain flow interior (i.e., basalt aquifer-confining layer). Results from the baseline inverse simulation (Section 7.0) indicated that the infiltration of areal recharge from precipitation, which was the only other areally distributed flux considered in the baseline model, was a factor of 1.7 too low. Because the natural recharge estimates in the baseline model were based on detailed analysis that considered both the spatial and temporal variability in local climate, soil type, and vegetation (Fayer and Walters 1995), it was considered misguided to adjust this parameter without first determining whether areally distributed intercommunication with the upper basalt-confined aquifer could produce the additional flux required to better match the objective function. As an initial estimate of vertical hydraulic conductivity, the average hydraulic gradient across the confining layer (i.e., the arithmetic mean of the gradient at each model node location based on 1979 head data) and the vertical hydraulic conductivity (i.e., unknown parameter) were equated through Darcy's equation with the approximate spatially averaged flux associated with areal recharge from precipitation. 


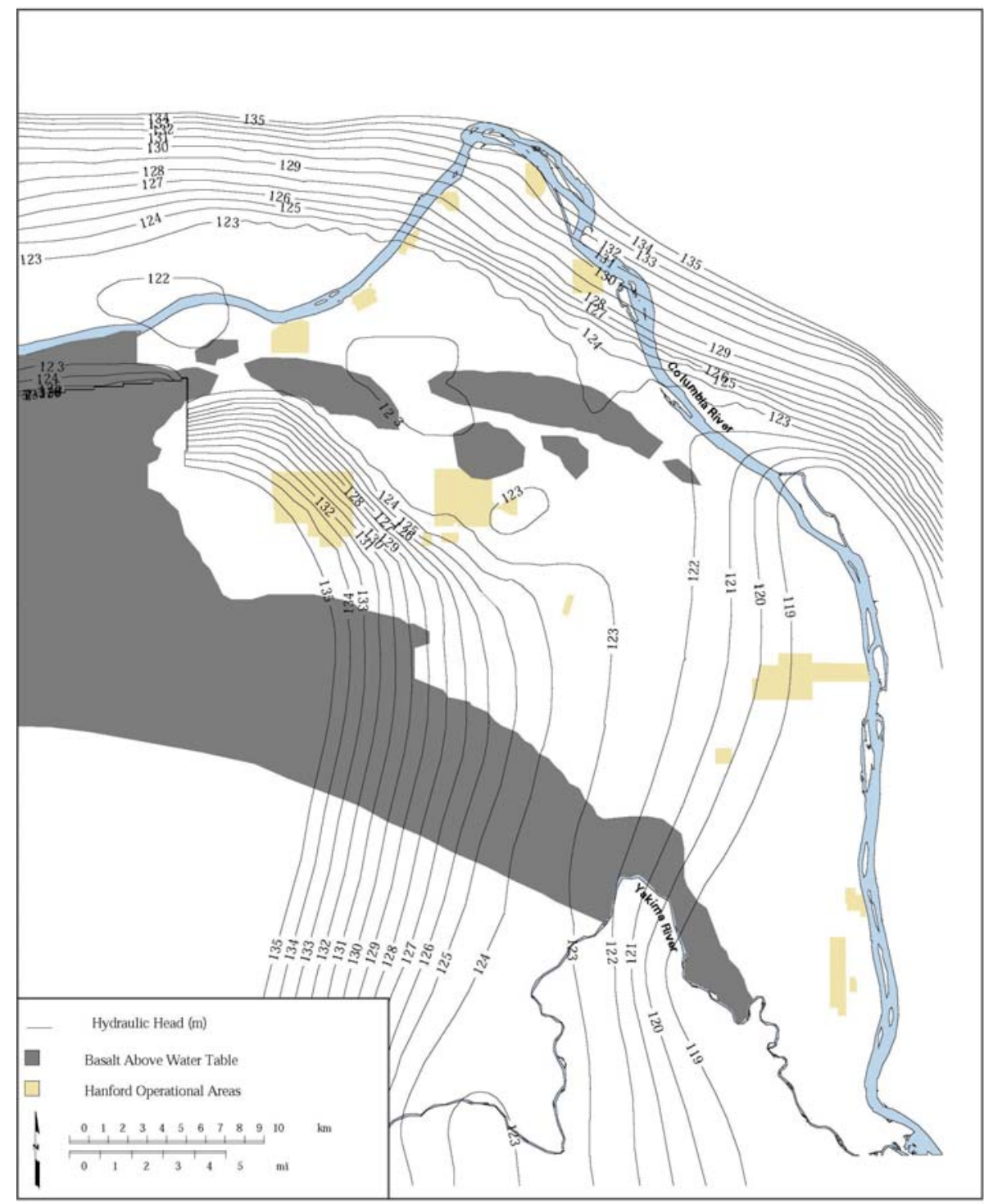

Figure 4.7. Potentiometric Surface Map of the Upper Basalt-Confined Aquifer in 1965

This calculation resulted in a preliminary estimate for vertical hydraulic conductivity of the Elephant Mountain unit of 4E- $6 \mathrm{~m} / \mathrm{d}$. This estimate falls at the approximate midpoint of the range cited in Section 4.1, providing corroborating evidence that it represents a good initial estimate for this parameter.

\subsubsection{Increased Ieakage Through the Frosional Window}

As discussed in Section 4.1, an isopach map of the Elephant Mountain unit, including an erosional window in the confining layer throughout the gap area between Gable Mountain and Gable Butte, was used to define the thickness of the confining layer between the unconfined and upper confined aquifer systems. To develop a preliminary estimate of leakage through the erosional window, water level data collected from wells within and at various radial distances from the erosional window (unconfined aquifer and Rattlesnake Ridge Interbed data, respectively) were analyzed over the period of simulation (1943 through 1996). Head values at the boundary of the erosional window were set based on the analysis 


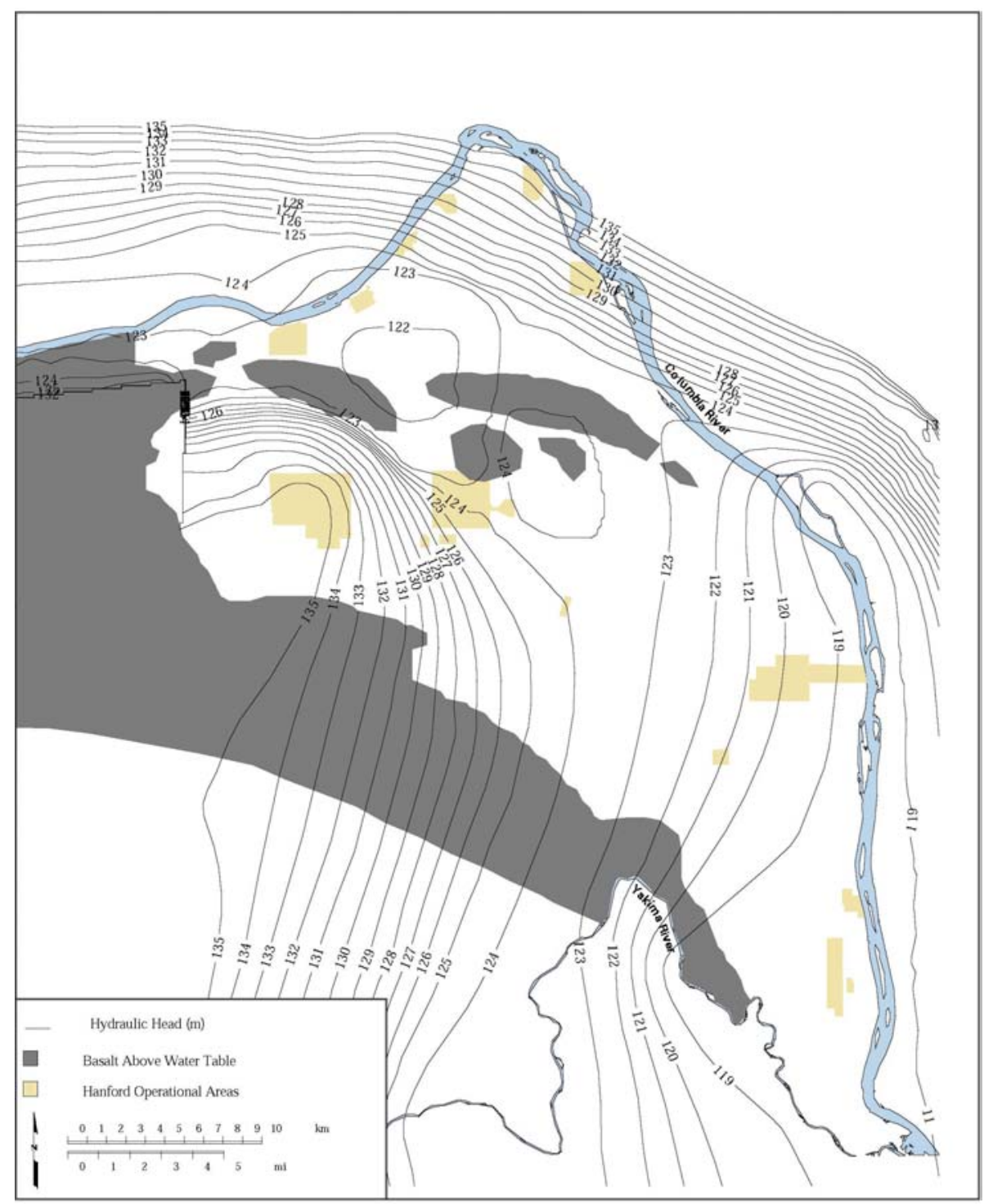

Figure 4.8. Potentiometric Surface Map of the Upper Basalt-Confined Aquifer in 1995

discussed in Section 4.2.1. Several wells were selected that monitored hydraulic head in the Rattlesnake Ridge interbed at various radial distances from the erosional window. Locations of the selected wells are shown in Figure 4.9 (wells 299-E16-1, 299-E33-12, 699-47-50, 699-49-55B, 699-54-57, and 699-56-53). Due to the lack of upper basalt monitoring wells in the vicinity of the northern boundary of the erosional window, the analysis was targeted at the southern boundary where adequate data were available.

Preliminary analysis of available water-level data indicated a discernable response in wells monitoring the Rattlesnake Ridge interbed to leakage effects associated with the erosional window. A plot of the distance versus hydraulic head response using 1995 water-level measurements is shown in Figure 4.10. The first data point, located at a radial distance of $2000 \mathrm{~m}$, represents the approximate radius of the erosional window (i.e., the boundary). The effective radius was calculated by measuring the actual area of the irregularly shaped erosional window and equating it to the area of a circle. The remaining data points represent hydraulic head data at various radial distances from the approximate center of the 


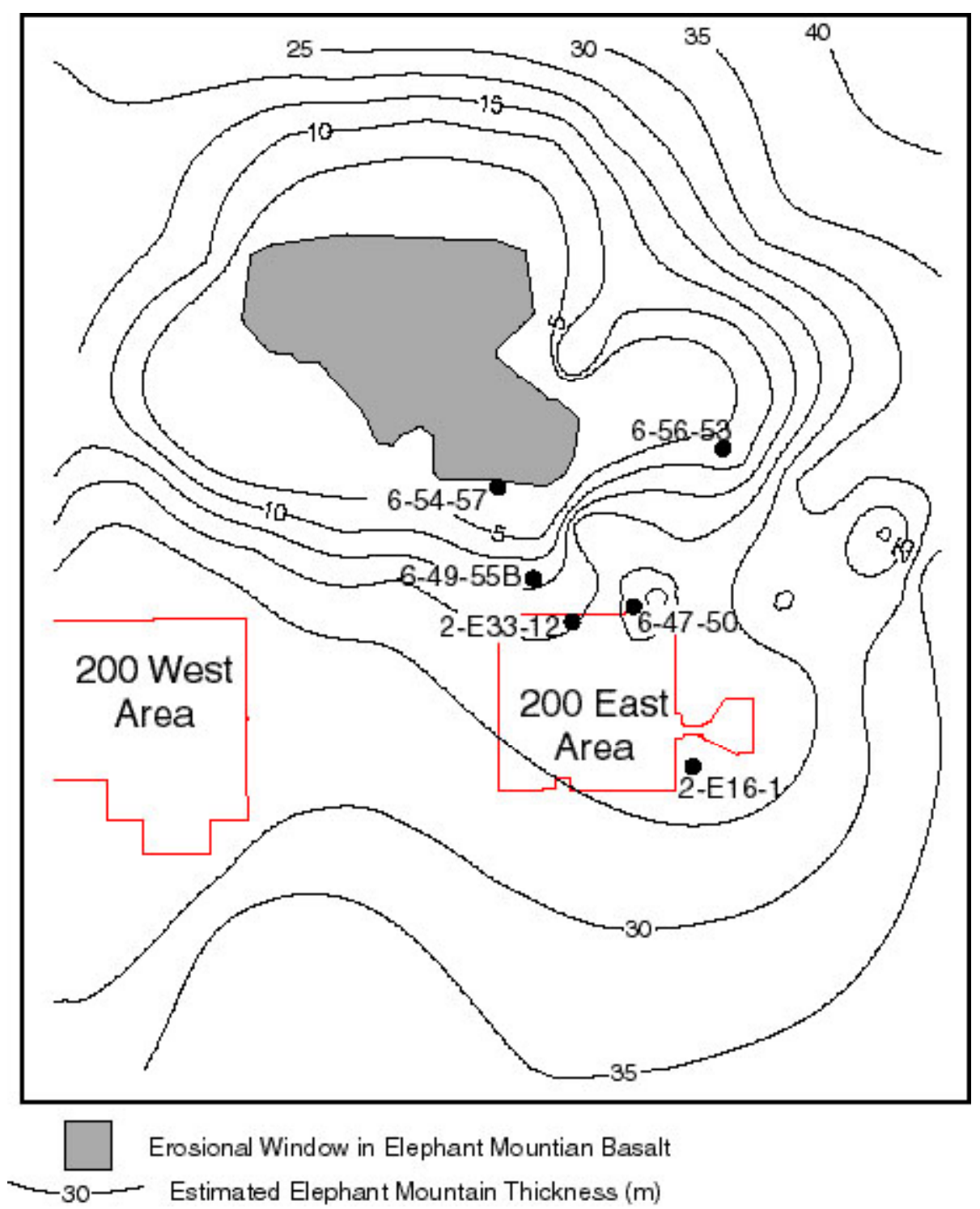

Figure 4.9. Diagram Showing the Location of the Erosional Window, Nearby Monitoring Wells (299-E16-1, 299-E33-12, 699-47-50, 699-49-55B, 699-54-57, 699-56-53), and Thickness Contours (m) for the Elephant Mountain Confining Layer

erosional window. These data show a response that is typical of a distance drawdown response resulting from a long-duration pumping test in a groundwater well. This same general distance drawdown response (Figure 4.10) was observed in all post-1975 data sets analyzed; an analyzable distance drawdown response was not observed in the hydraulic head data sets prior to 1975. Although the 1965 data set indicated the occurrence of a leakage reversal (i.e., higher pressures in the unconfined aquifer than the upper basalt-confined aquifer), no discernable distance versus pressure buildup response was observed in the wells used for this analysis. It should be noted that availability of hydraulic head data from the upper confined aquifer prior to 1985 was limited (see discussion in Section 4.2.1), and much of the data had to be estimated by equating temporal water-level changes in wells having no observations with changes in nearby wells where data were available. 


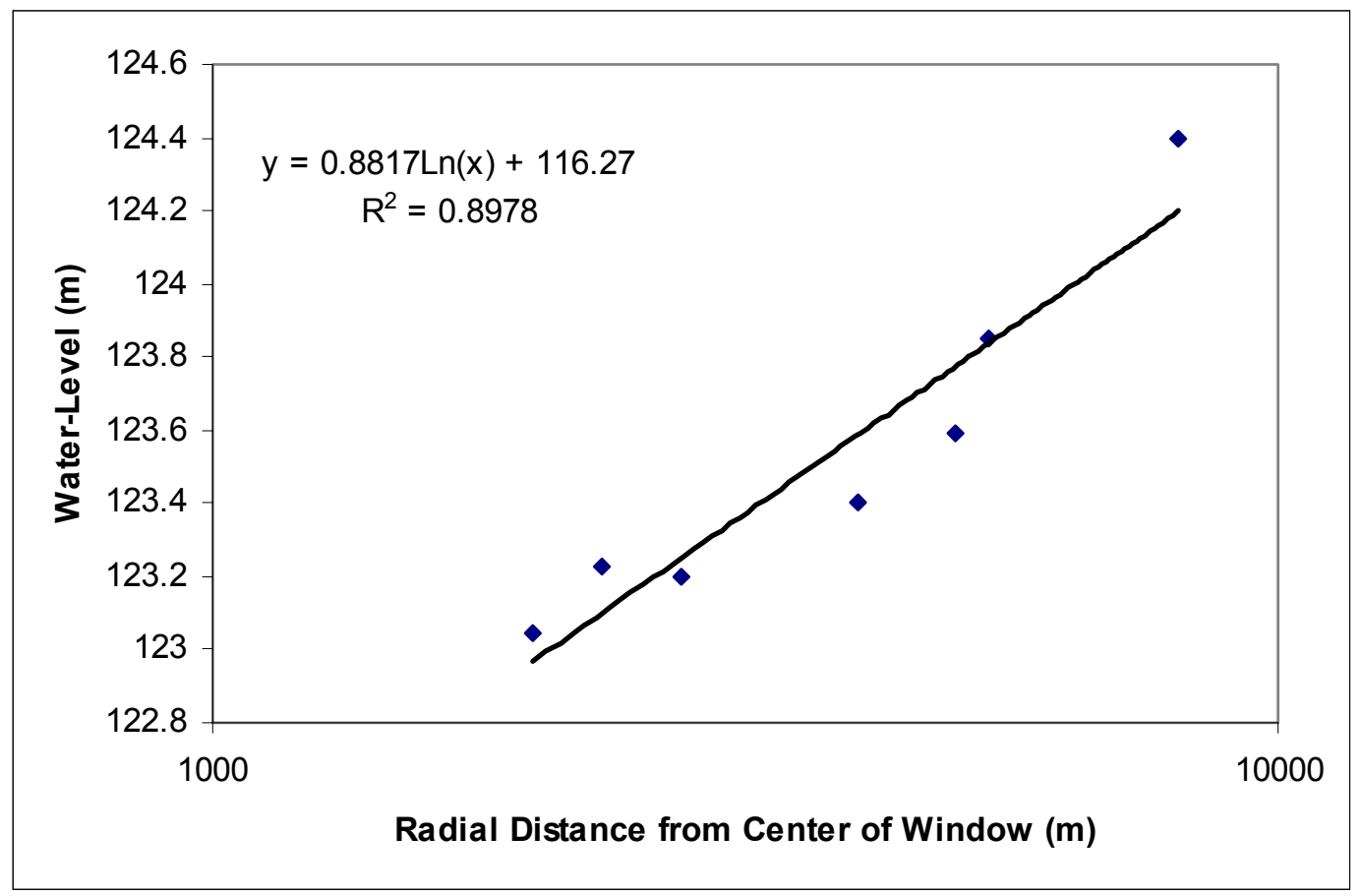

Figure 4.10. Distance Versus Hydraulic Head Data from Rattlesnake Ridge Monitoring Wells Within the Radius of Influence of the Erosional Window Leakage Effect (1995 Data)

To provide a preliminary estimate of the magnitude of leakage occurring through the erosional window, the distance drawdown responses discussed above were analyzed using the equilibrium equation (Thiem 1906). Use of the equilibrium equation is predicated on the assumption that flux through the erosional window is analogous to flow to a large diameter well during a long-duration pumping test in a groundwater well. Although not strictly correct (i.e., the solution assumes the system has reached equilibrium and that no external stresses or flow boundaries are affecting the response, which may not be the case for all of the data sets analyzed), the analysis method provides an appropriate method of obtaining an order of magnitude estimate of the total flux associated with leakage through the erosional window. Formulation of the equilibrium equation in a confined aquifer is as follows:

$$
\mathrm{Q}=\frac{2.73 \mathrm{~Kb}(\mathrm{H}-\mathrm{h}}{\log \mathrm{R} / \mathrm{r}}
$$

where $\mathrm{Q}=$ pumping rate (in this case leakage), $\mathrm{m}^{3} / \mathrm{d}$

$\mathrm{K}=$ hydraulic conductivity, $\mathrm{m} / \mathrm{d}$

$\mathrm{b}=$ aquifer thickness, $\mathrm{m}$

$\mathrm{H}=$ static head, $\mathrm{m}$

$\mathrm{h}=$ equilibrium head at center of cone of depression, $\mathrm{m}$

$\mathrm{R}=$ radius of influence, $\mathrm{m}$

$\mathrm{r}=$ radius of well (in this case erosional window), $\mathrm{m}$.

Hydrologic parameter values used in the calculation were based on analysis results of hydraulic tests conducted in the Rattlesnake Ridge interbed in the vicinity of the erosional window (Spane and Vermeul 1994). The average aquifer thickness and hydraulic conductivity for wells used in this analysis were 
approximately $12 \mathrm{~m}$ and $2 \mathrm{~m} / \mathrm{d}$, respectively. The radius of influence, which could not be determined explicitly from the available data, was assumed to be 8000 meters. However, a sensitivity analysis of this parameter indicated the solution was relatively insensitive to the radius of influence value used and thus did not have a significant effect on estimation results. Based on the equilibrium equation approach, for each of the specified time planes where an analyzable distance drawdown response was observed (1975, 1985, and 1995), the estimated total leakage flux rate through the erosional window was $150 \mathrm{~m}^{3} / \mathrm{d}$, $110 \mathrm{~m}^{3} / \mathrm{d}$, and $130 \mathrm{~m}^{3} / \mathrm{d}$, respectively.

The above method provided a good approach for obtaining an initial estimate of leakage through the erosional window. Although hydraulic head data for the upper confined aquifer prior to 1975 was generally not sufficient to provide even a qualitative estimate of flux, comparison of heads in the upper basalt confined and unconfined aquifers did provide a measure of whether the basalts were discharging to or being recharged by the unconfined aquifer. These limitations in the availability of hydraulic head data in the wells used in the analysis required that a more rigorous approach be developed. To eliminate reliance of the analysis on head values at the six wells used in the equilibrium equation analysis, a method was developed that used the regularly spaced grid of hydraulic head data for the upper confined aquifer (see Section 4.2.1) to compute the flux entering the erosional window boundary at each SGM node location and perform a summation of the individual fluxes to obtain an estimate of total leakage through the erosional window. This is the same approach used in the SGM to compute leakage at the erosional window during the transient inverse simulations.

Leakage at the erosional window was implemented in the SGM using the simplified conceptual model illustrated in Figure 4.11. Flux was calculated at the boundary of the erosional window using a head-dependent flux boundary condition based on Darcy's equation $\left(\mathrm{V}_{\mathrm{Df}}=\mathrm{K} \mathrm{dh} / \mathrm{dx}\right)$. The first step in developing this approach was to identify model nodes located along the boundary of the erosional window where the calculated flux would be applied. To determine which nodes would receive the flux, an arc coverage representing the boundary of the erosional window was laid over the finite element grid, and boundary surface nodes were identified. Next, model layering at each identified surface node was inspected to determine the lower most unconfined aquifer layer present. Flux was applied to this layer based on the hydraulic head gradient between the boundary node and a node located one grid space away $(750 \mathrm{~m})$ from the boundary. Other hydrologic parameters used in the SGM were identical to those used in the equilibrium equation analysis $(K=2 \mathrm{~m} / \mathrm{d}$ and $\mathrm{b}=12 \mathrm{~m})$. The area across which the Darcy flux velocity $\left(\mathrm{V}_{\mathrm{Df}}\right)$ was applied to calculate the flux at each node was equal to the aquifer thickness times the segment length associated with each node. Elements within the interior of the erosional window were specified as no-flow boundaries, which assumes that no leakage associated with the erosional window is occurring from the deeper basalts.

To test this approach for representing erosional window leakage based on head-dependent flux calculations at each boundary node, a Perl programming routine was developed that sampled the upper basalt confined potentiometric surfaces (Section 4.2.1), both at the erosional window boundary and one model node away, and calculated flux at each node using the same scheme as the SGM. Results of this test are shown in Figure 4.12 along with results from the equilibrium equation analysis. As indicated (and discussed in Section 4.2.1), hydraulic head data indicate that leakage at the erosional window is dominated by upward leakage from the upper basalt-confined aquifer into the unconfined aquifer. However, the 1965 data set indicates a reversal that likely results from increased heads in the unconfined aquifer associated with wastewater disposal in the 200 Areas. Figure 4.12 also shows relatively good agreement between this approach and the equilibrium equation results (where adequate data for the analysis were 




a)

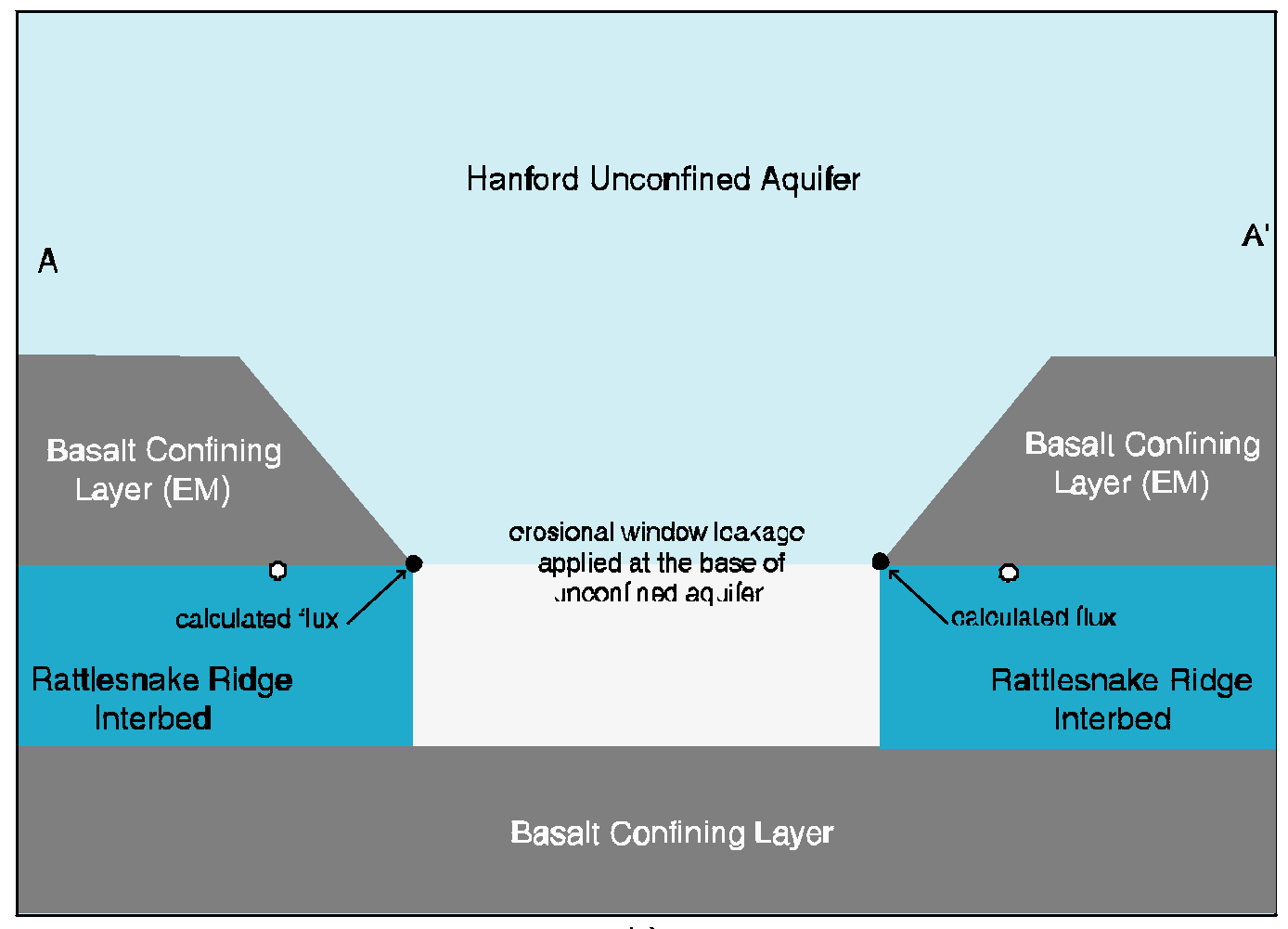

b)

Figure 4.11. Simplified Conceptual Model of Leakage at the Erosional Window in a) Plan View and b) Cross Section 


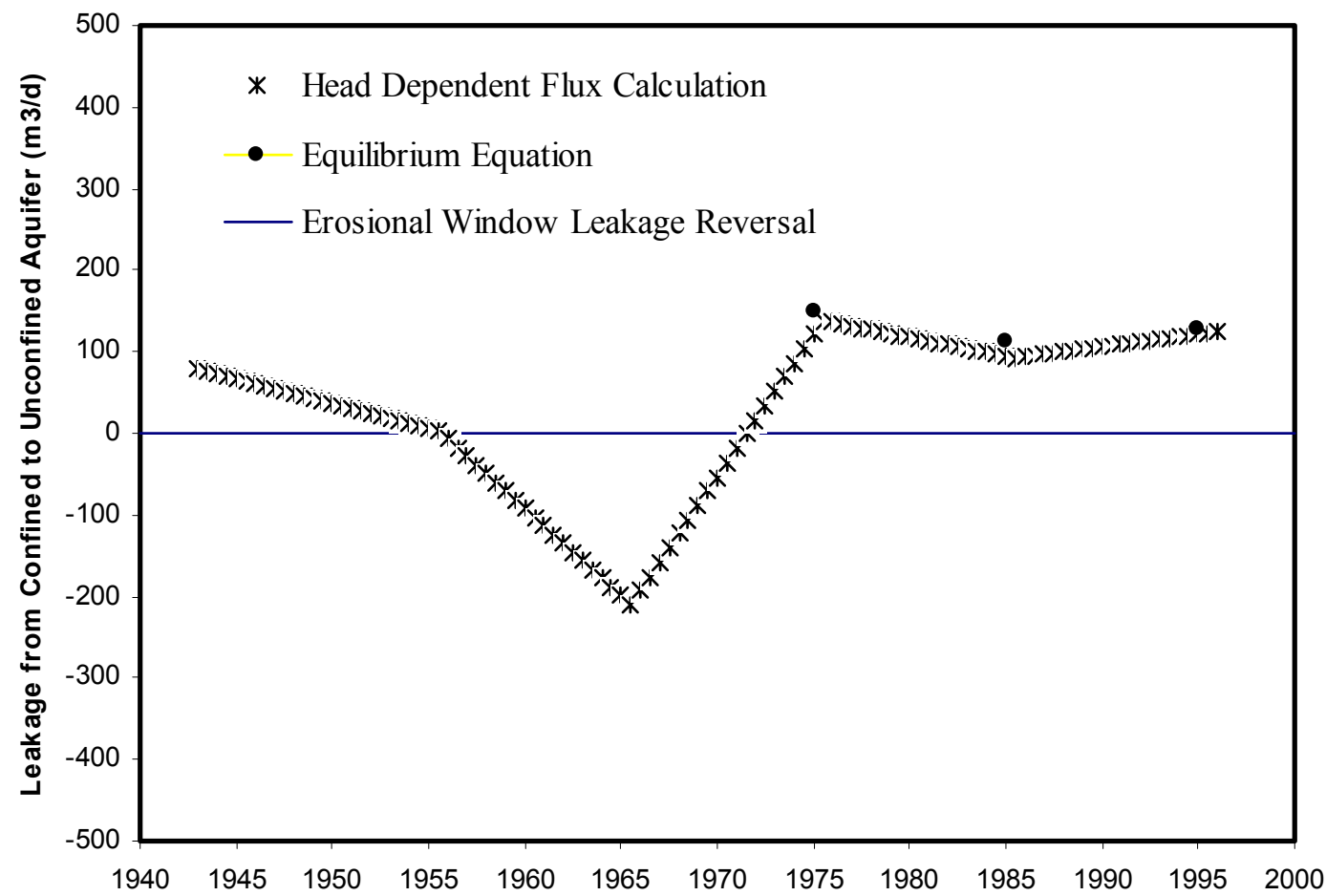

Figure 4.12. Erosional Window Leakage Calculated Using Both the Head-Dependent Flux and Equilibrium Equation Approaches

available). Agreement between these two independent analyses indicates that the developed upper basaltconfined aquifer hydraulic head data is representative of observed water-level conditions near the erosional window and that the head-dependent flux boundary condition approach utilized by the SGM provides a good representation of the leakage effect.

In addition to the large erosional window between Gable Mountain and Gable Butte, past investigations have speculated that several other relatively small, isolated erosional features may exist to the southeast of the erosional window. Because the size, location, and/or existence of these erosional features is not well understood and likely represents a much less significant pathway for intercommunication than the erosional window, these smaller features were not included in the conceptual model of basalt leakage. However, one area where the potentiometric surface within the upper basalt-confined aquifer indicated a potential region of increased leakage was near B-Pond (Figure 4.3). Inspection of limited pressure response data for a well near B-Pond that was completed in the Rattlesnake Ridge interbed showed a similar temporal response as nearby wells in the unconfined aquifer, providing corroborating evidence of intercommunication in this area. To provide a means to account for increased leakage in the vicinity of B-Pond, two SGM elements were identified that lie within the central portion of the pressure mound.

These two model elements were assigned an initial hydraulic conductivity value equivalent to the low end of the range of typical Rattlesnake Ridge interbed hydraulic conductivities $(0.02 \mathrm{~m} / \mathrm{d})$ to represent the increased hydraulic conductivity of the partially eroded Elephant Mountain confining layer in the area of B-Pond. The hydraulic conductivity in this partially eroded area was designated as a separate parameter in the inverse to determine the solution's sensitivity to leakage at B-Pond and whether the hydraulic conductivity of the partially eroded area was a determinable parameter. 


\subsubsection{Increased Ieakage at Faults}

As discussed in Section 4.1, another potential area for increased leakage between the upper basaltconfined and unconfined aquifers is along fault zones. Springs are present in the Rattlesnake Hills, along the western boundary of the SGM domain, that bring groundwater from the basalt-confined aquifer system to the surface. These springs are found where major thrust faults intersect the ground surface (DOE 1988). This provides evidence that the major thrust faults provide conduits for flow between aquifer systems. Major thrust faults within the SGM domain include a fault along Yakima Ridge and another along the Gable Mountain-Gable Butte outcrops (Figure 4.13).

Two normal faults have been identified by apparent offset of both the basalts and units within the sediments overlying basalt on the Hanford Site. These are called the May Junction fault and the Cold Creek fault (Figure 4.13). Because of the offset of units within the aquifer, these faults may affect flow through the supra-basalt aquifer system and could potentially conduct some water from the basalts into the unconfined aquifer above it. However, the May Junction and Cold Creek faults were not initially

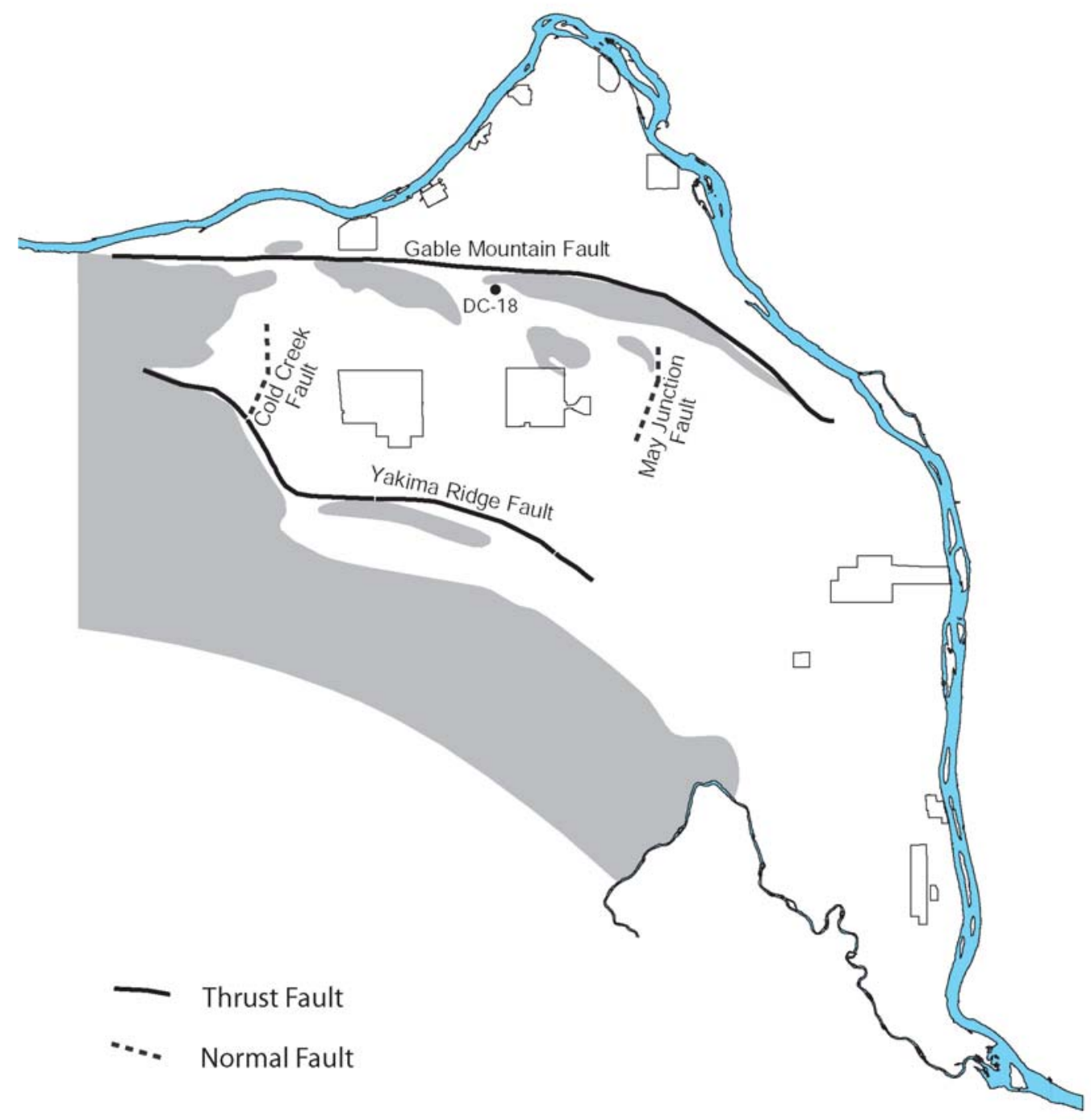

Figure 4.13. Location of Thrust Faults and Normal Faults on the Hanford Site 
included in the conceptual model as areas of potential increased leakage because they were not expected to be significant contributors to intercommunication relative to the thrust faults. This assumption is supported by hydrologic observations at the Cold Creek fault, which appears to act as a barrier to lateral flow within the basalt-confined aquifer because it coincides with a drastic west-to-east change in hydraulic gradient. The difference in head across the fault within the Wanapum Basalt Formation was more than $80 \mathrm{~m}$ (DOE 1988). It is thought that low-permeability fault gouge has created a barrier to lateral flow within the basalt-confined aquifers.

The first step in implementing increased leakage at the thrust faults was to identify model elements along the fault zones where the basalt permeability would be increased. To determine which elements would represent each fault, an arc showing the fault zones was laid over the finite element grid and model element numbers were identified and tabulated. Implementing the potential for increased leakage at thrust faults along with that at B-bond (discussed in the previous section), resulted in the segregation of the basalt-confining layer (Unit 10) into four separate zones whose parameters could be estimated independently. This zonation, which was handled directly by the inverse methodology, consisted of one zone for the thrust fault near Yakima Ridge, one for the thrust fault near the Gable Mountain-Gable Butte outcrops, one to represent leakage near B-Pond, and one for the remaining elements in the model domain.

A preliminary estimate of fracture zone hydraulic conductivity was based on previous investigations within the upper basalt-confined aquifer system. Detailed hydrologic tests (i.e., straddle packer tests) conducted by the Basalt Waste Isolation Project (BWIP) of interflow zones and flow interiors provide a range and average value for these basalt flow features. Results from these tests indicate that basalt interflow zones (i.e., for the Saddle Mountains and Wanapum Basalt Formations) range primarily between $1 \mathrm{E}-3$ to $1 \mathrm{E} 3 \mathrm{~m} / \mathrm{d}$, with a geometric mean of $\sim 1 \mathrm{~m} / \mathrm{d}$; while flow interiors (for the Wanapum and Grande Ronde Basalt Formations) primarily range between $1 \mathrm{E}-10$ and $1 \mathrm{E}-4 \mathrm{~m} / \mathrm{d}$, with a geometric mean of $\sim 5 \mathrm{E}-7 \mathrm{~m} / \mathrm{d}$ (DOE 1988).

Quantitative information pertaining to the enhanced vertical permeability induced by fracturing along these prominent structural features is limited. To obtain a preliminary estimate, an argument could be made that the permeability would be similar to that characterized for basalt interflow zones. Only two identified tectonic fracture zones were tested within BWIP boreholes on the Hanford Site. A recognized tectonic breccia within the Frenchman Springs (Wanapum Basalt) flow interior, which exhibited abundant alteration clay and secondary mineralization, provided a relatively low hydraulic conductivity, ranging between 1E-7 to $1 \mathrm{E}-6 \mathrm{~m} / \mathrm{d}$ (DOE 1988). The second feature tested was an open, productive tectonic fracture zone ( $\sim 1$ to $2 \mathrm{~m}$ thick) near the bottom of the Umtanum basalt flow (Grande Ronde Basalt) that provided a relatively high hydraulic conductivity value of $\sim 40 \mathrm{~m} / \mathrm{d}$ (Strait and Spane 1983).

The two tectonic features described above are small features of limited extent. Perhaps of more practical application for assessing larger-scale, enhanced fracture permeability within basalt structural areas is a hydrochemical/isotopic study of the downward movement of groundwater within the Gable MountainGable Butte structural area, as described in Early et al. (1988). As noted in Early et al. (1988) and listed in Crowley and Ledgerwood (1988), pervasive tectonic fracturing occurred within all basalt flows encountered at borehole DC-18. Based on the hydrochemical and isotopic profiles at this borehole, vertical flow velocities ranging from 8 to $34 \mathrm{~m} / \mathrm{yr}$ were inferred to occur within the Saddle Mountain Basalt through to the upper Wanapum Basalt (Rosalia flow top) in this structural region. If the downward migration of observed hydrochemical and isotopic constituents was induced by an increase of head within 
the unconfined aquifer of $\sim 3 \mathrm{~m}$ due to Hanford Site disposal activities at this borehole location (as indicated in Early et al. 1988), an approximate vertical head gradient of $0.015 \mathrm{~m} / \mathrm{m}$ would be imposed from the Saddle Mountain Basalt to the Rosalia flow top. Based on the inferred vertical flow velocities and vertical hydraulic gradient, a vertical hydraulic conductivity range of 1 to $10 \mathrm{~m} / \mathrm{d}$ can be estimated within this structural area. This inferred vertical hydraulic conductivity range is similar to the geometric mean of $\sim 1 \mathrm{~m} / \mathrm{d}$ previously cited for Saddle Mountain and Wanapum Basalt interflow zones.

Before these estimates of vertical hydraulic conductivity for the fault zones could be used in the model, they needed to be adjusted to account for the difference between the actual assumed width of the fracture zones and the width of the model elements that were being used to represent it $(750 \mathrm{~m})$. As an initial estimate, fracture width was assumed to be $5 \mathrm{~m}$, resulting in a reduction in the vertical hydraulic conductivity of fracture zones, as represented in the SGM, from the previously estimated $\sim 1 \mathrm{~m} / \mathrm{d}$ to $\sim 7 \mathrm{E}-3 \mathrm{~m} / \mathrm{d}$. 


\subsection{Inverse Methodology and Computation Codes}

This section discusses the basic concepts used in the universal inverse modeling code UCODE (Poeter and Hill 1998), selected for application to the Hanford Site SGM. More detailed information is presented in Cole et al. (2001a), including discussions of the objective function and the modified GaussNewton method used in UCODE to perform the nonlinear regression, operational aspects of UCODE, and recent enhancements to UCODE and CFEST to increase the efficiency of inverse parameter estimation. Hill (1998) provides a full discussion of all other aspects of UCODE and MODFLOW inverse model implementation. Much of the basic regression theory implemented is discussed in Cooley and Naff (1990). Other programs used by UCODE to test weighted residuals and calculate linear confidence and prediction intervals are discussed in Hill (1994).

UCODE (Poeter and Hill 1998) performs universal inverse modeling using an indirect approach in which the unknown parameters for the problem being solved are considered to be the dependent variables (Peck et al. 1988). In the indirect approach, normal model equations (referred to as the forward equations) are solved, and parameter estimates are sought that minimize a set of residuals (e.g., differences between observed and model predicted quantities). The UCODE concept of universal comes from the fact that UCODE solves the inverse problem through an indirect approach that is not directly linked or tied to any particular forward model and implementing computer code.

The inverse problem of groundwater flow consists of estimating the vector of flow parameters being determined based on a number of field observations of dependent variables (e.g., hydraulic head and flux to streams) and independent information about the parameters themselves (i.e., prior information). If concentration and travel time observations/estimates as well as information on prior estimates for additional transport parameters (e.g., dispersivity) are also available, they can be added as additional observations and prior information, and a coupled inverse problem involving both flow and transport can be posed.

An objective function is a measure of the fit between simulated values and the observations that are being matched by the regression. The purpose of the regression is to calculate values for the poorly known parameters that minimize the objective function. The resulting values are said to be "optimal," "optimized," or "estimated by regression." In UCODE, the objective function used in the nonlinear regression to determine the vector of unknown parameters being estimated is a weighted least squares function (e.g., the sum of the weighted square of differences between simulated and observed values). The regression consists of calculating the vector of the unknown parameter values that minimize the objective function.

In UCODE, an estimated parameter can be any quantity that appears in the input files of the application model(s) or that can be used in conjunction with user-defined functions to calculate a quantity that appears in the input files. Observations to be matched in the nonlinear regression performed by UCODE can be any quantity for which a simulated equivalent value can be produced. Simulated equivalent values are calculated using values that appear in the application model output files and a set of additive and multiplicative functions. Also in UCODE, prior or direct information on estimated parameters can be included in the regression. 
UCODE is designed to operate in phases; it is useful to begin with PHASE $=1$ and proceed to 2 or 22, and then 3. Runs with PHASE $=33,44$, and 45 generally are run only using a satisfactorily calibrated model. Phase 11 produces values that can be used to create a sum-of-squared, weighted residuals contour graph and may never be used in some circumstances. The function of each PHASE is described in Table 5.1 (from the UCODE manual).

UCODE allows for restarts and provides a variety of printed results (at each iteration if desired) and also results in the form of files to allow for graphical analysis and to allow the user to analyze the regression results. Parameter statistics reported allow the user to learn of the optimal parameter values and evaluate the quality of the calibration. Parameter statistics reported include scaled sensitivities, composite-scaled sensitivities, parameter covariance matrix, parameter values, standard deviations, coefficients of variation, 95\% linear individual confidence intervals, and correlation coefficients.

Regression performance measures reported include Marquardt parameter, the parameter that changed the most, and the amount of change. A fairly comprehensive set of statistical results is made available to check fit and residual statistics in the regression results. These include:

- table of observations, simulated values, residuals, and weighted residuals

- maximum, minimum, and average weighted residuals

- number of residuals $>=0$ and number of residuals $<0$

- number of sequences of residuals with the same sign (+ or -)

- least-squares objective function with and without the prior information

- weighted least-squares objective function value

- calculated error variance

- standard error of the regression

- square root of the calculated error variance

- correlation coefficients with prior information

- maximum likelihood objective function, and the AIC and BIC statistics ${ }^{(a)}$

- ordered weighted residuals

- correlation between ordered weighted residuals and normal order statistics.

A UCODE flowchart (Figure 5.1) from Poeter and Hill (1998) provides a graphical representation of the inverse parameter estimation approach. A more detailed discussion of UCODE and its implementation based on the CFEST code are available in Cole et al. (2001a).

(a) The use and derivation of these statistics and additional references are provided in Hill (1998). 
Table 5.1. Brief Description of the Various UCODE Phases and Their Functions (Poeter and Hill 1998)

\begin{tabular}{|c|c|}
\hline PHASE & Function \\
\hline 1 & $\begin{array}{l}\text { Parameter substitution and forward modeling using the starting parameter values specified in the } \\
\text { prepare file. }\end{array}$ \\
\hline 11 & $\begin{array}{l}\text { Substitutes parameters, performs a forward model run, and calculates the sum-of- squared, weighted } \\
\text { residuals objective function for many sets of parameter values. PHASE }=11 \text { produces data sets from } \\
\text { which objective-function contour graphs can be produced. Execution of PHASE }=11 \text { requires } \\
\text { modification of the search-string lines of the fn.pre file. }\end{array}$ \\
\hline 2 & Sensitivities at starting parameter values \\
\hline 22 & $\begin{array}{l}\text { Sensitivities and parameter variances, covariances and correlations at starting parameter values. } \\
\text { Execution time for } 22 \text { is about twice that of } 2 \text { because central differences, rather than forward } \\
\text { differences are calculated. }\end{array}$ \\
\hline 3 & Perform regression. \\
\hline \multicolumn{2}{|c|}{$\begin{array}{l}\text { PHASE }=33 \text { and } 44 \text { need to be preceded by executing UCODE with PHASE }=3 \text { and GRAPH }=1 \text { in the same } \\
\text { directory (GRAPH is a variable in fn.uni). }\end{array}$} \\
\hline 33 & $\begin{array}{l}\text { Calculate the modified Beale's measure of model linearity using methods discussed by Cooley and } \\
\text { Naff (1990) and Hill (1994). }\end{array}$ \\
\hline 44 & $\begin{array}{l}\text { Calculate predictions and their linear confidence and prediction intervals. Only PHASE is read from } \\
\text { the universal file. }\end{array}$ \\
\hline \multicolumn{2}{|c|}{ PHASE $=45$ needs to be preceded by executing UCODE with PHASE $=44$ in the same directory. } \\
\hline 45 & $\begin{array}{l}\text { Calculate differences and their linear confidence and prediction intervals. Only PHASE is read from } \\
\text { the universal file. }\end{array}$ \\
\hline
\end{tabular}

1. Calculated using a slightly modified version of the computer program YCINT (Hill, 1994). 




Figure 5.1. Flowchart for Estimating Parameters with UCODE. 


\subsection{Implementation of the Transient Inverse Approach}

This section summarizes the approach used to set up the transient inverse calibration of the SGM for the historical period of Hanford Operations (1943-1996). A detailed discussion of the numerical implementation and evaluation approach, which was based on the Guidelines for Effective Model Calibration (Hill 1998), is contained in Cole et al. (2001a).

\subsection{Implementation Strategy and Rationale}

The site-wide groundwater model (prior model) was selected for use in the initial inverse calibration effort instead of developing a new model because the selection allowed technical emphasis to be placed on developing and testing the inverse approach and not on model building. It also allowed activities such as gathering the information necessary to evaluate potentially key components missing from the prior conceptual model that were identified as part of the various reviews of the Hanford SGM (DOE 2000) to be developed and these alternative conceptual models and numerical implementations to proceed in parallel. These activities include development and evaluation of the effects of basalt leakage (as documented in this report), development of alternative interpretations for the areal extent and thickness clay units, and development of regional scale facies-based zonation of hydraulic conductivity and specific yield for the Hanford and middle Ringold formations (preliminary efforts discussed in this report). The transient inverse calibration of the prior conceptual model provided baseline model fit information for comparison with subsequent alternative models, and this transient inverse calibration also provided additional information about flaws and/or weaknesses in the prior conceptual model that had not yet been identified.

The rationale for the selected period of calibration (1943-1996), even though little observational data are available early in the time period, is that the groundwater system prior to this time period was not affected by artificial recharge associated with Hanford Site operations and thus was in a state of approximate equilibrium with natural recharge and mean river flow conditions. This means that when performing a forward model run for a new set of parameters as part of the transient inverse, initial conditions at the start of each new forward model run could be determined by calculating them from a steady-state model run that considered only natural recharge and mean annual river flow stage for river boundary conditions. Preparing for simulation of this extended calibration period required developing a complete set of head observations for the entire extended calibration period from 1943 to 1996, developing estimates of river stage variations for the entire extended period, and developing estimates of the artificial discharges resulting from Hanford Site operations prior to 1979 to supplement the existing 1979-1996 data set prepared as part of the earlier calibration efforts for the prior model (Cole et al. 1997). Existing recharge estimates were already a best long-term estimate based on conditions prior to Hanford Site operations.

\subsection{Parameterization}

In developing the parameterization, all model parameters, including 1) parameters that represent the hydraulic properties of all the hydrogeologic units, and 2) parameters that represent all the specified boundary conditions except for artificial discharges associated with Hanford Site operations and pumping 
well rates were considered for inclusion in keeping with Guideline 3 of Guidelines for Effective Model Calibration (Hill 1998). Artificial discharges and pumping were excluded because records are available that adequately quantify these model inputs relative to the uncertainty associated with other inputs. Uncertainty in these artificial discharge estimates is the subject of an ongoing effort that will be factored into subsequent inverse analyses. Hydraulic property parameters for the saturated fined grained mud and clay units (Units 4, 6, and 8 of Table 3.1) were not included in this inverse analysis. It was believed that this would be better addressed by the ongoing activity to develop alternative model structure interpretations by examining the interpretational uncertainty in the areal extent and thickness of the various fine-grained mud and clay units. Additional hydraulic properties not considered are the specific yields of those hydrologic units below the water table, which includes the specific yield of hydrologic Units 7 and 9. Of the various specified model boundaries, only those used to represent the Columbia and Yakima River stages were not specifically addressed in the baseline inverse calibration effort. This is because they are treated as constant-head boundary conditions that vary in time and space, and the estimates for these spatial and temporal variations are a function of historical river flows and channel configuration that are reasonably well documented. The intensive computational requirements of the inversing process provide additional motivation to limit the number of estimated parameters to only those not well quantified by available hydrogeologic or operational data.

Estimating hydraulic parameters in the baseline inverse was limited to the conductive units. The final list of model parameters that were initially evaluated in the inversing process by performing a UCODE phase 22 analysis to examine parameter correlations and sensitivity coefficients was limited to

- hydraulic conductivity of conductive units: Hanford formation (Unit 1), Ringold Formation (Unit 5), Ringold Formation (Unit 7), and Ringold Formation (Unit 9)

- $\quad$ specific yield of the units containing the water table: Hanford formation (Unit 1) and Ringold Formation (Unit 5)

- $\quad$ specific storage of all the conductive units: Hanford formation (Unit 1), Ringold Formation (Unit 5), Ringold Formation (Unit 7), and Ringold Formation (Unit 9)

- boundary Fluxes: Cold Creek Valley, Dry Creek Valley, Rattlesnake Hills, and Surface Natural Recharge

- $\quad$ single anisotropy ratio applied to all conductive hydrogeologic units.

Parameter sensitivity analysis results (UCODE phase 22) provide information to determine whether some parameters should be omitted from early phases of the regression to maintain a well-posed regression problem. Since parameter sensitivity coefficients change throughout the regression process as a result of nonlinearities, the sensitivities need to be reinvestigated as the regression proceeds and parameters move away from their starting values.

\subsubsection{Hydraulic Properties}

As outlined above, the hydraulic properties considered in the initial evaluation of the prior Hanford Site focused on the model characteristics of the major permeable hydrogeologic units identified in the model (model Units 1,5,7, and 9). The properties evaluated included the hydraulic conductivities and the 
anisotropy of all major permeable units, the specific yields of the units that are found at the water table, and the specific storage of the units found below the water table.

Parameters that could be used to represent the hydraulic conductivities of the major units were evaluated first. Hydraulic conductivities of the major hydrogeologic units that were developed from the prior model-calibration process are highly variable (see discussion in Section 3.1.4). Without some simplification of these spatial distributions into a distribution of hydraulic conductivity zones, the number of parameters to consider in the inversing process could potentially be as large as the number of elements in the model. Using the required large number of parameters to represent the aquifer system as currently represented in the inversing process would not be practical.

The specific yields of the uppermost hydrologic units were considered to be homogeneous in the prior model, and as a result, only one parameter value was needed to describe the specific yield for the Hanford formation (Unit 1) and one for the Ringold Formation (Unit 5), which are the dominant hydrogeologic units found at the water table. The initial specific yield was set at that of the prior model, or 0.25 for the Hanford formation and 0.1 for the Ringold Formation. The specific storage of all units found at or below the water table were considered to be homogeneous, and as a result, required only four additional parameters, one for the Hanford formation and one for each of the three permeable Ringold Formation units. The initial specific storage was assumed to be $1 \times 10^{-6}$ for all model units considered.

\subsubsection{Boundary Conditions}

Three parameters were used to perturb each of the major boundary flux distributions within the baseline inverse model because they are all spatially variable. This includes one parameter each for the prescribed upgradient spatially distributed fluxes at the Cold Creek Valley, Dry Creek Valley, and the Rattlesnake Hills Springs model boundaries, respectively. An additional parameter was used to perturb the spatial distribution of natural recharge fluxes infiltrating at the water table boundary of the model.

\subsection{Well Observation Processing and Weighting for Use in Regression}

As many different kinds of observational data as possible need to be included in the regression to provide the variety of constraints needed to break intrinsic correlations (e.g., recharge and hydraulic conductivity). Inclusion of flow observations (e.g., base stream flow contributed by the groundwater system) generally provides more information about the hydrologic system for groundwater flow model calibration. Although previous studies of groundwater-river interactions on the Hanford Site provide estimates of groundwater discharge to the Columbia River at discrete locations, the incremental river fluxes related to groundwater system contributions cannot be directly measured and are not well characterized over the entire model boundary. However, while there are no observational flux measurements available for wastewater disposal activities associated with Hanford Site operations, the quantities of water discharged is relatively well documented, although still uncertain. These specified artificial discharges, whose magnitude is estimated to be much greater than natural recharge, may play a similar role relative to breaking the typical correlation between hydraulic conductivity and recharge.

The only observations available for inclusion in the regression are measured hydraulic heads made in wells completed in the unconfined aquifer. For the period between 1943 and 1996, approximately 
76,000 individual measurements were used in the calculations, with the initial measurements becoming available in 1948. These 76,000 observations were used by UCODE during the parameter-estimation process to define the objective function for the period of model simulation.

For the inversing process, each measurement of head had the following quantities specified: measured head value, well location, the principal contributing model unit represented by the measurement, and a statistical measure that would be representative of the potential measurement error in the observation. In UCODE, the measurement error is specified as either using a specified standard deviation and calculating the variance or specifying the variance for use in the residual head analysis.

\subsection{Initial Evaluation of Parameter Sensitivities}

Parameter sensitivities need to be examined at the outset to start the regression with a well-posed problem, which means that only parameters whose composite scaled sensitivities are within a factor of 100 of the maximum can generally be determined. Fifteen parameters that could be determined by regression were identified by making a UCODE phase 22 analysis, which evaluates the 1 percent scaled sensitivity coefficients for all parameters being considered. The scaled sensitivity coefficient for each parameter is calculated by evaluating the change in the objective function (i.e., residual between simulated and observed heads) to a 1 percent change in each of the parameters evaluated. The results are summarized in a scaled composite sensitivity coefficient of each parameter that is formed by summing up the calculated residuals for all observations and dividing that quantity by the total number of observations.

Results of the calculated scaled composite-sensitivity coefficients for all parameters considered in the baseline calibration effort were used to identify the most sensitive and least sensitive parameters and provided the basis for selecting the parameters to move forward within the initial calibration runs. Based on the results of this analysis, the calibration effort primarily focused on estimating the following parameter values:

- Scaling factors on hydraulic conductivity distributions within

- Hanford formation (Unit 1)

- Ringold Formation (Unit 5)

- Ringold Formation (Unit 7)

- Ringold Formation (Unit 9)

- Scaling factors on the specific yield of the

- Hanford formation (Unit 1)

- Ringold Formation (Unit 5)

- Scaling factors for the

- Cold Creek Valley boundary fluxes

- Dry Creek Valley boundary fluxes

- Rattlesnake Hills boundary fluxes

- Surface recharge from natural sources 
The following list of parameters, because of their associated low-sensitivity coefficients (i.e., a factor of at least 100 smaller than the maximum sensitivity coefficient), were not given further consideration and were fixed during most subsequent activities associated of the baseline inverse calibration:

- Scaling factors on hydraulic conductivity distributions within Ringold Formation (Unit 7)

- Scaling factors on the specific storage values of the

- Hanford formation (Unit 1)

- Ringold Formation (Unit 5)

- Ringold Formation (Unit 7)

- Ringold Formation (Unit 9).

- Scaling factor for the anisotropy of all hydrogeologic units.

Some parameters (e.g., storage) were never revisited to see whether their sensitivities changed while others were occasionally revisited to see if they had become sensitive near the optimized values for the other parameters being regressed. Parameter correlation coefficients and their influence on how well posed the regression are discussed in Section 7.0. 


\subsection{Results and Evaluation of the Baseline Transient Inverse Simulation}

This section summarizes results from the baseline transient inverse calibration (Cole et al. 2001a), including the evaluation of model fit and optimized parameter values based on various regression and statistical performance measures. This summary provides for direct comparison with transient inverse results presented in Section 9.0 for the alternative conceptual model being presented in this report that considers interactions with the underlying basalt aquifer system. The summary provides sufficient detail and facilitates comparison by using the same format (i.e., tables and figures) used in Section 9.0. Detailed discussions of the baseline transient inverse calibration effort and results can be found in Cole et al. (2001a).

\subsection{Transient Inverse Simulation Results}

An overall comparison of simulated and measured water levels for the entire calibration period (1943 - 1996), with the first observations starting in 1948, is shown in Figure 7.1 as a scattergram plot of simulated head from the inversed model plotted versus the measured head. The scattergram also contrasts the scatter of residual error points with a 45-degree line that represents a perfect match between model and data, with the individual plotted points color-coded to indicate the magnitude of the residual error. Figure 7.2 shows a residual frequency histogram over this same calibration time period that plots the number of residuals in each residual category from $-12 \mathrm{~m}$ to $+12 \mathrm{~m}$ in 1-m increments. The associated statistics for these comparisons are found in Table 7.1.

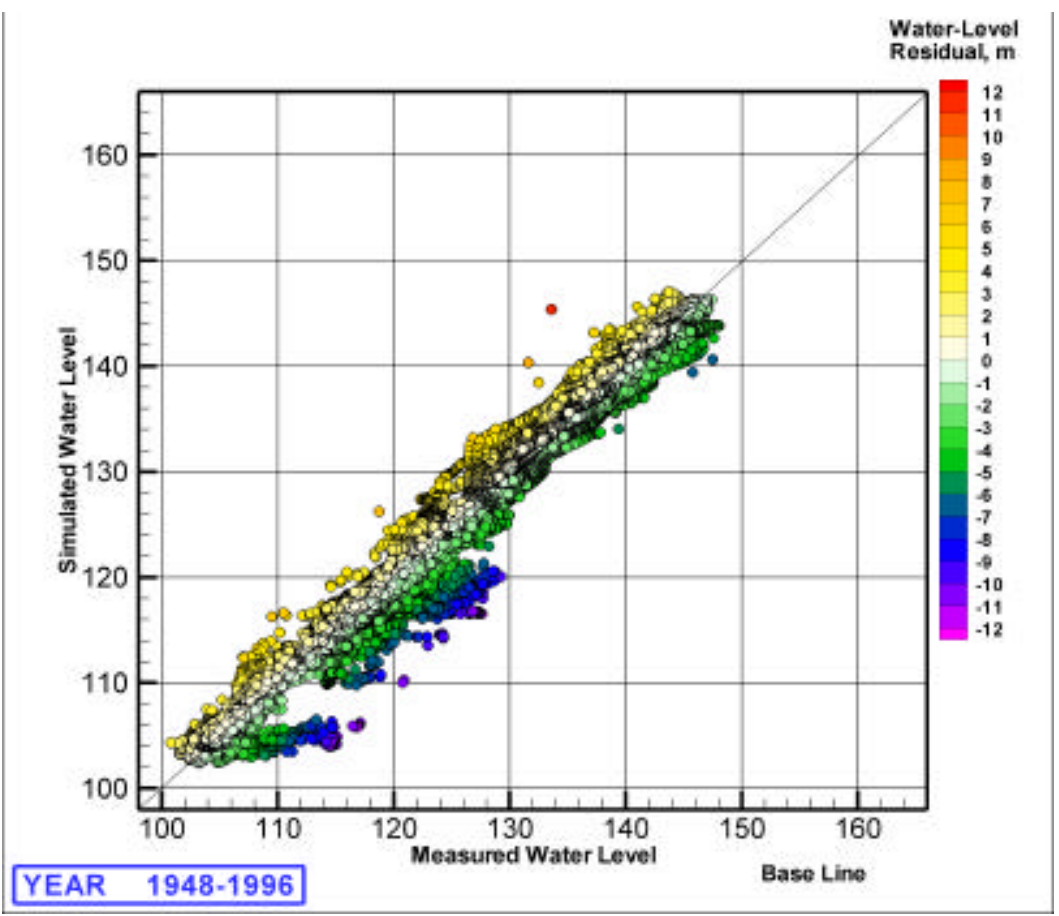

Figure 7.1. Measured Versus Predicted Heads (45-degree plot); All Observations for Best-Fit Inverse Model 


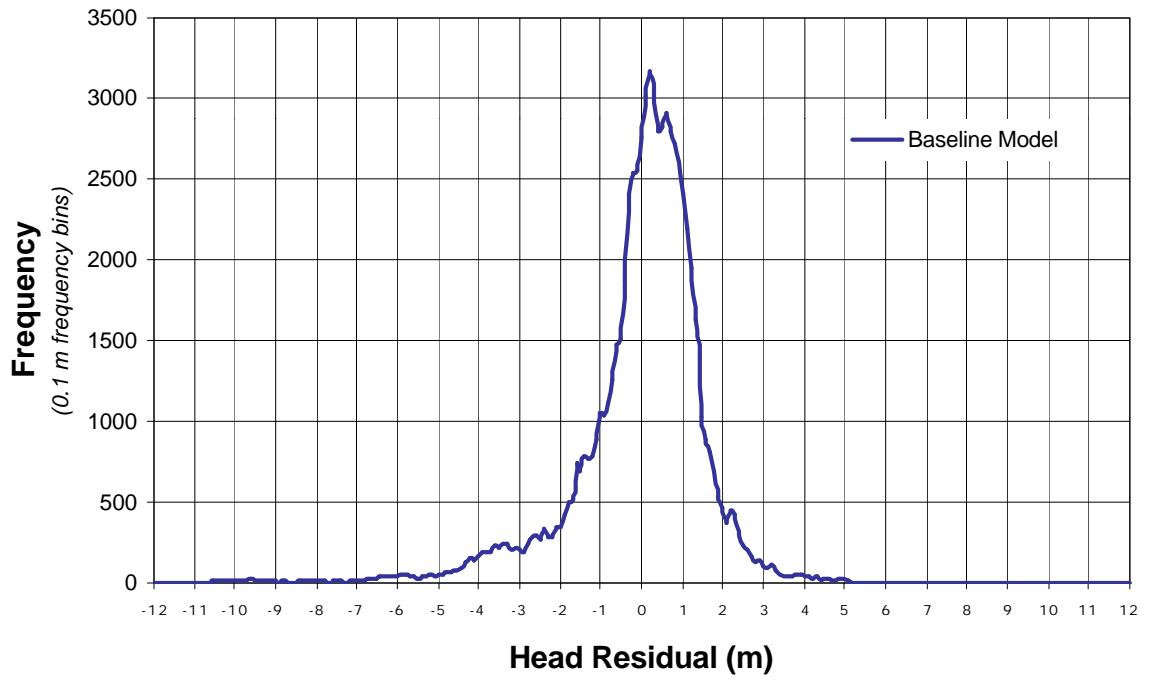

Figure 7.2. Histogram of Predicted Head Residuals; All Observations for Best-Fit Inverse Model

The graphical comparisons and summary statistics illustrate that, over the entire prediction period, 65.8 percent of the simulated values for the baseline inverse model were within $\pm 1 \mathrm{~m}$ of measured values and 98.6 percent were within $\pm 5 \mathrm{~m}$, compared to 53.6 and 81.7 percent, respectively, for the prior model. The mean residual for the baseline model was $-0.13 \mathrm{~m}$ ( $1.34 \mathrm{~m}$ for negative residuals and $0.87 \mathrm{~m}$ for positive residuals), which compares to $0.67 \mathrm{~m}$ ( $1.54 \mathrm{~m}$ for negative residuals and $3.10 \mathrm{~m}$ for positive residuals) for the prior model. The median and mean absolute error for the baseline model was $0.12 \mathrm{~m}$ and $1.09 \mathrm{~m}$, respectively, which compares to $-0.06 \mathrm{~m}$ and $2.28 \mathrm{~m}$ for the prior model. The residuals ranged from $-11.1 \mathrm{~m}$ to $11.8 \mathrm{~m}$ for the baseline model, which compares to $-11.6 \mathrm{~m}$ to $24.8 \mathrm{~m}$ for the prior model. The sum of squared residuals was calculated to be $2.00 \times 10^{5}$ while the sum of squared residuals for the prior model was 1.01E+06. The predicted change in water-table elevation contours is presented for 1943 and in 10-year increments between 1950 and 1996 in a series of plots found in the Appendix (Figures A.1a through A.1g). The Appendix also contains color-coded plots illustrating how the spatial distribution of measurements, their locations, and the associated head residuals vary for the same times for which water- table elevation contours are shown (Figures A.2a through A.2g). In addition, the Appendix shows scattergrams of simulated versus measured heads for the same times for which water table elevation contours and spatial distributions of residuals are shown (Figures A.3a through A.3g). The scattergrams contrast the scatter of residual error points with a 45-degree line that would represent a perfect match between model and data. The individual plotted points are also color-coded to indicate the magnitude of the residual error. All of the plots presented in the Appendix A also have equivalent plots for the alternative conceptual model that considers interactions with the underlying basalt aquifer system presented on the same page for comparison (see Section 9.0).

Revised distributions of the hydraulic conductivities similar to those presented in Section 3.1.4 for the prior model (see Figure 3.9) but representing results from the baseline inverse are presented in Figure 7.3 to illustrate the changes in properties of the Hanford and Ringold sediments that contain the water table resulting from this initial inverse calibration. The most notable changes are seen in the distribution of hydraulic conductivities of the Ringold Formation (Unit 5), which outcrops at the water table over much of the western and southwestern part of the Hanford Site. 
Table 7.1. Summary of Residual Error Statistics of Best-Fit Inverse Model

\begin{tabular}{|c|c|c|}
\hline Residual Statistic & Value & $\begin{array}{c}\text { Number of } \\
\text { Observations }\end{array}$ \\
\hline \multicolumn{3}{|l|}{ Positive Residuals } \\
\hline Mean (m) & 0.87 & 41719 \\
\hline Standard Deviation (m) & 0.74 & \\
\hline $\operatorname{Min}(\mathrm{m})$ & 0.00 & \\
\hline $\operatorname{Max}(\mathrm{m})$ & 11.76 & \\
\hline \multicolumn{3}{|l|}{ Negative Residuals } \\
\hline Mean (m) & -1.34 & 34316 \\
\hline Standard Deviation (m) & 1.55 & \\
\hline $\operatorname{Max}(\mathrm{m})$ & -11.07 & \\
\hline $\operatorname{Min}(\mathrm{m})$ & -0.00 & \\
\hline Overall Mean (m) & -0.13 & 76035 \\
\hline Standard Deviation $(\mathrm{m})$ & 1.62 & \\
\hline Median (m) & -0.06 & \\
\hline Mean Absolute Error (m) & 2.28 & \\
\hline $\begin{array}{l}\text { Sum of Squared Residuals } \\
\left(\mathrm{m}^{2}\right)\end{array}$ & $2.00 \mathrm{E}+05$ & \\
\hline Residual Range & Percent of Total & \\
\hline Between 1 and $-1 \mathrm{~m}$ & 65.8 & \\
\hline Between 2 and $-2 \mathrm{~m}$ & 87.1 & \\
\hline Between 3 and $-3 \mathrm{~m}$ & 93.6 & \\
\hline Between 4 and $-4 \mathrm{~m}$ & 97.1 & \\
\hline Between 5 and $-5 \mathrm{~m}$ & 98.6 & \\
\hline $\begin{array}{l}\text { Greater Than } 5 \text { or } \\
\text { Less Than }-5 \mathrm{~m}\end{array}$ & 1.4 & \\
\hline
\end{tabular}

Recalibrating the prior model using the transient inverse calibration procedures in UCODE significantly improved the capability of the model to simulate historical trends in water-table changes over the entire site, but the specific yield parameters for the Hanford (Unit 1) and Ringold (Unit 5) formations took on unrealistic values indicating that parameter zonation and/or conceptual model improvements are needed. The improved inversing methodology provided in UCODE and the additional information provided in the longer period of calibration (i.e., 1943-1996) were both contributing factors that improved the ability of the recalibrated prior model to simulate historical trends in water-table changes. All goodness of fit measures were significantly improved over measures of fit for the previously calibrated prior model for the same simulation period. The most noteworthy improvement by the baseline inverse discussed in Cole et al. (2001a) is its capability to fit historical trends of water-table changes 


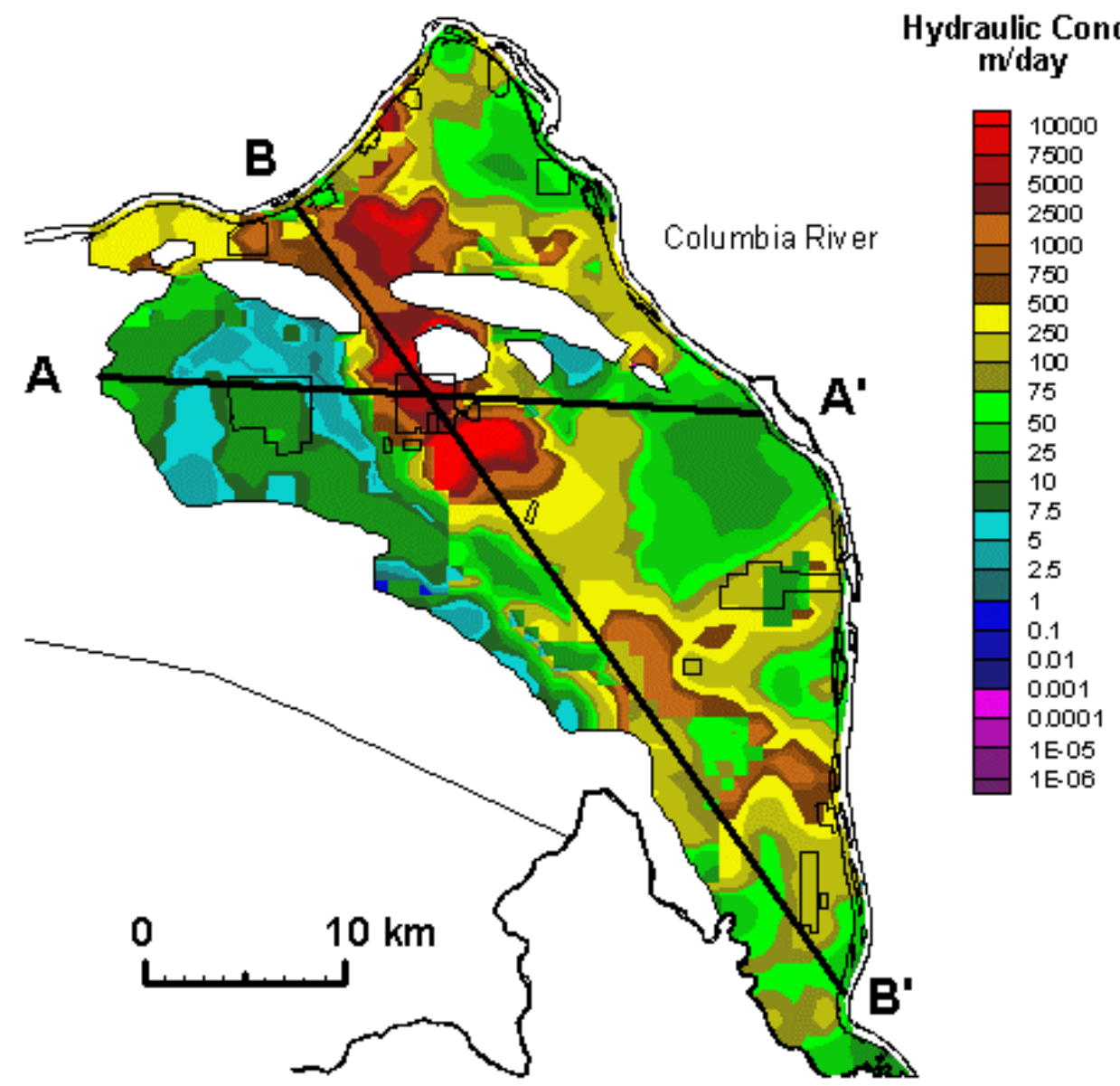

Figure 7.3. Hydraulic Conductivity Distribution from Best-Fit Inverse Model

and mound building observed near major discharge facilities in the 200 West Area. This improvement in the overall fit resulted in improved statistical performance in all categories (mean residual, range of residuals, and sum of squared residuals) for the 1943-1996 period of calibration.

The majority of changes in the parameter estimates derived from the transient inverse calibration of the prior conceptual model using the UCODE methodology produced new estimates and linear confidence intervals consistent with prior knowledge of these parameters. However, estimates for the specific yield of the Hanford formation (between 0.06 to 0.07 ) and the Ringold Formation (between 0.20 and 0.21 ) from the three-dimensional transient inverse calibration were not consistent with current understanding of the characteristics of these sediments. The unrealistic estimates for these two parameters combined with the increased estimates from the inversing for natural recharge as well as boundary fluxes for Cold Creek Valley and Rattlesnake Hills Springs indicated that the conceptual model being evaluated was incomplete and that other processes such as intercommunication with the underlying basalt-confined aquifer, exclusion of any facies-based zonation of hydraulic properties for the postRingold sediments (model layer 1), and/or changes in the timing and location of wastewater discharges (e.g., uncertainty in the travel time through the vadose zone) may be needed for the inverse calibration procedure to estimate these parameter values within their expected range. 


\subsection{Evaluation of Transient Inverse Model}

This section is comprised of a series of tables that contain the information required to evaluate the regression results, model fit, and optimized parameter values for the baseline inverse calibration. These tables are discussed in detail in Cole et al. (2001a). The tables, as discussed previously, are included because they facilitate direct model fit comparisons between the baseline and ACM 1 inverse calibrations. A shorthand is needed to describe table entries for the ten parameter scaling factors estimated for the baseline and inverse models presented in this section. The shorthand symbol for each of the ten parameter multipliers (i.e., parameter "scaling factors" discussed in Section 6.0) investigated are as follows:

- K-U1 Hanford (Unit 1) Hydraulic Conductivity Multiplier

- K-U5 Ringold (Unit 5) Hydraulic Conductivity Multiplier

- K-U7 Ringold (Unit 7) Hydraulic Conductivity Multiplier

- K-U9 Ringold (Unit 9) Hydraulic Conductivity Multiplier

- SY-U1 Hanford (Unit 1) Specific Yield Multiplier

- SY-U5 Ringold (Unit 5) Specific Yield Multiplier

- F-CC Cold Creek Valley Flux Multiplier

- F-DC Dry Creek Valley Flux Multiplier

- F-NR Natural Recharge Multiplier

- F-RH Rattlesnake Hills Flux Multiplier

Tables included in this section include:

- Table 7.2 contains the following statistical information provided by UCODE (Poeter and Hill 1998) with descriptions of their use and meaning summarized from Hill (1998):

- Least-Squares Objective Function (dependent variable only and with parameters). In UCODE, the objective function used in the nonlinear regression to determine the vector of NP unknown parameters, $\underline{b}$, being estimated is a weighted least squares function, $\mathrm{S}(\underline{b})$ (i.e., the sum of the weighted square of differences between simulated, $y_{i}$, and observed values, $y_{I}$ as well the sum of weighted differences of prior information on parameters). The regression consists of calculating the vector of parameter values, $\underline{b}$, that minimize the objective function, $\mathrm{S}(\underline{b})$. The weighted least-squares objective function, $\mathrm{S}(\underline{b})$, used in UCODE is

$$
\mathrm{s}(\underline{\mathrm{b}})=\Sigma^{\mathrm{ND}} \omega_{\mathrm{i}}\left[\left(\mathrm{y}_{\mathrm{i}}-\mathrm{y}_{\mathrm{i}}^{\prime}(\underline{\mathrm{b}})\right]^{2}+\Sigma^{\mathrm{NPR}} \omega_{\mathrm{p}}\left[\mathrm{P}_{\mathrm{p}}-\mathrm{P}_{\mathrm{p}}^{\prime}(\underline{\mathrm{b}})\right]^{2}(7.1)\right.
$$

where for the ND observations of $y, y_{i}{ }_{i}(\underline{b})$ is the value simulated with the forward model that corresponds to the $\mathrm{i}$-th observation $\mathrm{y}_{\mathrm{i}} ; \omega_{\mathrm{i}}$ is the weight for the $\mathrm{i}$-th observation; $\mathrm{P}_{\mathrm{p}}{ }_{\mathrm{p}}(\underline{\mathrm{b}})$ is the value simulated with the forward model that corresponds to the $\mathrm{p}$-th observation of parameter $\mathrm{P}_{\mathrm{p}}$ (i.e., prior information), $\omega_{\mathrm{p}}$ is the weight for the $\mathrm{p}$-th prior estimate, and NPR is the number of observations of prior information. Given randomly distributed residuals and the same observations and weight matrix, a lower value of the least-squares objective function indicates a closer model fit to the data. While the value of the weighted least-squares objective function is often used informally to indicate model fit. It is rarely used for more formal comparisons because its value nearly always decreases as more parameters are added, 
Table 7.2. Statistical Information Provided by UCODE

\begin{tabular}{|cc|}
\hline Least-Squares Objective Function & \\
(Dependent Variable Only) & $\mathbf{0 . 7 1 3 8 1 e + 0 8}$ \\
(W/Parameters) & $\mathbf{0 . 7 1 3 8 1 e + 0 8}$ \\
Calculated Error Variance & $\mathbf{9 3 8 . 8 8}$ \\
Standard Error Of The Regression & $\mathbf{3 0 . 6 4 1}$ \\
Correlation Coefficient & $\mathbf{0 . 9 9 9 9}$ \\
Correlation Coefficient (W/Parameters) & $\mathbf{0 . 9 9 9 9 0}$ \\
Maximum Likelihood Objective Function & $\mathbf{0 . 7 1 5 3 4 e + 0 8}$ \\
AIC Statistic & $\mathbf{0 . 7 1 5 3 4 e + 0 8}$ \\
BIC Statistic & $\mathbf{0 . 7 1 5 3 4 e + 0 8}$ \\
Hannan Statistic & $\mathbf{0 . 7 1 5 3 4 e + 0 8}$ \\
& \\
\hline
\end{tabular}

and the negative aspect of adding parameters is not reflected. The negative aspect of adding parameter values is that as the data available for the estimation get spread over more and more parameter values, the certainty with which the parameter values are estimated decreases. Other statistical measures presented in Table 7.2 and discussed below more effectively account for this circumstance.

- Calculated Error Variance and Standard Error of the Regression. The calculated error variance, $\mathrm{s}^{2}$, is a commonly used indicator of the overall magnitude of the weighted residuals is computed directly from the weighted least-squares objective function as follows:

$$
\mathrm{s}^{2}=\mathrm{s}(\underline{\mathrm{b}}) /(\mathrm{ND}+\mathrm{NPR}-\mathrm{NP})
$$

Given randomly distributed residuals, smaller values of the calculated error variance are desirable. Values less than 1.0 indicate that the model generally fits the data better than is consistent with the variances used to weight the observations and prior information; values greater than 1.0 indicate that the fit is worse. The square root of the calculated error variance, $\mathrm{s}$, is called the standard error of the regression and also is used to indicate model fit. Smaller values of both the calculated error variance and the standard error indicate a closer fit to the observations, and smaller values are preferred as long as the weighted residuals do not indicate model error.

- Correlation Coefficient and Correlation Coefficient with Prior Information. Ideally, the simulated values are close to observations so that weighted simulated values are close to weighted observations, and when weighted observations are plotted against weighted simulated values, the hope is that the points fall close to a line with slope equal to 1.0 and an intercept of zero, as was the case when measured versus predicted heads were plotted in Figure 7.1. A summary statistic that reflects how well this is accomplished is the correlation coefficient between the weighted observations and the weighted simulated values. This correlation coefficient, $\mathrm{R}$, is calculated as discussed in Cooley and Naff (1990, p. 166): 


$$
\mathrm{R}=\frac{\left(\underline{\omega}^{1 / 2} \underline{\mathrm{y}}-\underline{\mathrm{m}}_{\mathrm{y}}\right)^{\mathrm{T}}\left(\underline{\omega}^{1 / 2} \underline{\mathrm{y}}^{\prime}-\underline{\mathrm{m}}_{\mathrm{y}^{\prime}}\right)}{\left[\left(\underline{\omega}^{1 / 2} \underline{\mathrm{y}}-\underline{\mathrm{m}}_{\mathrm{y}}\right)^{\mathrm{T}}\left(\underline{\omega}^{1 / 2} \mathrm{y}-\underline{\mathrm{m}}_{\mathrm{y}}\right)\left(\underline{\omega}^{1 / 2} \mathrm{y}-\underline{\mathrm{m}}_{\mathrm{y}^{\prime}}\right)^{\mathrm{T}}\left(\underline{\omega}^{1 / 2} \mathrm{y}^{\prime}-\underline{\mathrm{m}}_{\mathrm{y}^{\prime}}\right)\right]^{1 / 2}}
$$

where $\underline{\omega}$ is the weight matrix, and $\underline{y}$, and $y^{\prime}$ are the vectors of observations and simulated values and include terms for both the observations and the prior information for the measure of Correlation Coefficient and Correlation Coefficient with Prior Information respectively. Also $\mathrm{m}_{\mathrm{y}}$ and $\mathrm{m}_{\mathrm{y}}{ }^{\prime}$ are vectors with all ND elements equal to:

$$
\begin{aligned}
\mathrm{m}_{\mathrm{y}_{\mathrm{i}}} & =\sum_{\mathrm{q}=1}^{\mathrm{ND}}\left(\underline{\omega}^{1 / 2} \underline{\mathrm{y}}\right)_{\mathrm{q}} / \mathrm{ND} \\
\mathrm{m}_{\mathrm{y}_{\mathrm{i}}^{\prime}} & =\sum_{\mathrm{q}=1}^{\mathrm{ND}}\left(\underline{\omega}^{1 / 2} \underline{\mathrm{y}}^{\prime}\right)_{\mathrm{q}} / \mathrm{ND}
\end{aligned}
$$

Thus, $m_{y_{i}}$ is simply a vector with each component equal to the average of the weighted dependent variable observations, and $m_{y_{i}^{\prime}}$ is an analogous vector using the weighted simulated values. Generally, R needs to be greater than 0.90 as correlation coefficient values below about 0.9 indicate poor model fit.

- Maximum Likelihood Objective Function, and the AIC, BIC, and Hannan Statistics. The maximum-likelihood objective function, equation 7.6, is calculated and printed by UCODE

$$
\mathrm{S}^{\prime}(\underline{\mathrm{b}})=(\mathrm{ND}+\mathrm{NPR}) \ln 2 \pi+\ln |\underline{\omega}|+\left(\underline{\mathrm{y}}-\underline{\mathrm{y}}^{\prime}\right)^{\mathrm{T}} \underline{\omega}\left(\underline{\mathrm{y}}-\underline{\mathrm{y}}^{\prime}\right)
$$

where $\ln |\omega|$ is the determinant of the weight matrix and it is assumed that the common error variance equals 1 at the optimal set of parameter values b' because it can be used as a measure of model fit (Carrera and Neuman 1986b.; Loaiciga and Marino 1986). The AIC (Akaike 1974), BIC (Akaike 1977), and Hannan statistics (Hannan 1980) were developed to address the criticism that the calculated error variance and standard error do not sufficiently represent the drawbacks associated with increasing the number of estimated parameters. As indicated in Equations 7.7, 7.8, and 7.9 for these statistics, they reflect the fact that adding too many parameters produces unreliable parameter estimates as each of these statistics involve the sum of the maximum-likelihood objective function evaluated at the optimal parameter values, $S^{\prime}$ (b'), and terms that become large as more parameters are added. Although these statistics were developed for time-series problems, Carrera and Neuman (1986b) successfully used them to discriminate between different parameterizations of a test case of groundwater flow. For these statistics, given randomly distributed residuals, smaller values indicate a more accurate model. However, if the statistics for a model with fewer parameters are only slightly larger than the statistics of another model, it may be better to select the model with fewer parameters unless the investigator has sufficient information to indicate the validity of the more complicated model. 


$$
\begin{gathered}
\operatorname{AIC}\left(b^{\prime}\right)=S^{\prime}\left(b^{\prime}\right)+2 \mathrm{NP} \\
\operatorname{BIC}\left(b^{\prime}\right)=S^{\prime}\left(b^{\prime}\right)+N P \ln (N P+N P R) \\
\text { HANNAN }\left(b^{\prime}\right)=S^{\prime}\left(b^{\prime}\right)+c N P \ln (\ln (N P+N P R))
\end{gathered}
$$

where $\mathrm{c}$ is an arbitrary constant.

- Table 7.3. This table contains a summary of the parameter scaling factors derived for the baseline inverse model (Note: As discussed in Section 6.0, a "scaling factor" approach was used so that the values in Table 7.3 are parameter multipliers to be applied to the actual model parameters specified in the original input file). For example, since the initial value for specific yield is 0.1 in the input file and the scaled parameter estimate is 2.12 , the specific yield of the Ringold Formation Unit 5 determined by the inverse approach is equal to the product (i.e., $2.12 \times 0.1$ ) or 0.212. In a similar manner, for example, the hydraulic conductivity distribution in the Hanford formation (Unit 1) is smaller than that used in the prior model by a factor of 0.901 .

Table 7.3. Summary of Parameter Scaling Factors Derived for the Baseline Inverse Model

\begin{tabular}{||c|c|}
\hline Scaling Factor Description & $\begin{array}{c}\text { Scaling Factor } \\
\text { Estimates }\end{array}$ \\
\hline Hydraulic conductivity distributions within & \\
\hline Hanford Formation (Unit 1) & 0.901 \\
\hline Ringold Formation (Unit 5) & 2.25 \\
\hline Ringold Formation (Unit 7) & Not Estimated \\
\hline Ringold Formation (Unit 9) & Not Estimated \\
\hline & \\
\hline Specific yield of the & \\
\hline Hanford Formation (Unit 1) & 0.278 \\
\hline Ringold Formation (Unit 5) & 2.12 \\
\hline & \\
\hline Specific storage values of the & Not Estimated \\
\hline Hanford Formation (Unit 1) & Not Estimated \\
\hline Ringold Formation (Unit 5) & Not Estimated \\
\hline Ringold Formation (Unit 7) & Not Estimated \\
\hline Ringold Formation (Unit 9) & \\
\hline \multicolumn{2}{|l}{} \\
\hline Boundary Fluxes & Not Estimated \\
\hline Cold Creek Valley & 2.09 \\
\hline Dry Creek Valley & Not Estimated \\
\hline Rattlesnake Hills & 4.37 \\
\hline Surface Natural Recharge & 1.71 \\
\hline & \\
\hline Anisotropy of All Hydrogeologic Units & \\
\hline \hline
\end{tabular}


- Table 7.4. This table is the symmetric parameter cross-correlation matrix or the Pearson correlation coefficient matrix as it is known in the statistical literature. This statistic is a measure of the linear relationship between two parameters. Each of the correlation coefficients in the matrix shown in the table is a unit-free normalized measure of this linear relationship between the parameters derived by normalizing the covariance matrix, which is a measure of the joint variation of the parameter pairs around their means. For any set of parameter values, absolute values larger than about 0.95 may indicate that two or more parameters cannot be uniquely estimated.

- Table 7.5. This table contains a summary of parameter scaling factor estimates and associated confidence intervals as determined from the inverse procedure. The confidence intervals on optimized parameter values indicate the precision with which the values are estimated. The linear confidence intervals reflect the uncertainty of the optimal parameter values. The confidence limits shown are the 95\% linear individual confidence intervals, and according to Hill (1998), they apply when the residuals are normally distributed, the optimized parameter values are reasonable, a satisfactory model fit is obtained, and the model is linear (e.g., as determined by a UCODE phase 33 run).

Table 7.4. Parameter Cross-Correlation Matrix Plot (Baseline Inverse Model)

\begin{tabular}{|c|r|r|r|r|r|r|r|}
\hline Parameter & \multicolumn{1}{|c|}{ K-U1 } & \multicolumn{1}{c|}{ K-U5 } & \multicolumn{1}{c|}{ SY-U1 } & \multicolumn{1}{c|}{ SY-U5 } & \multicolumn{1}{c|}{ F-CC } & \multicolumn{1}{c|}{ F-NR } & \multicolumn{1}{c|}{ F-RH } \\
\hline K-U1 & $\mathbf{1 . 0 0 0}$ & $\mathbf{0 . 3 0 9}$ & 0.074 & 0.172 & 0.148 & $\mathbf{0 . 6 2 3}$ & 0.072 \\
\hline K-U5 & $\mathbf{0 . 3 0 9}$ & $\mathbf{1 . 0 0 0}$ & $\mathbf{0 . 2 5 6}$ & -0.165 & $\mathbf{0 . 2 8 8}$ & $\mathbf{0 . 4 5 6}$ & 0.030 \\
\hline SY-U1 & 0.074 & $\mathbf{0 . 2 5 6}$ & $\mathbf{1 . 0 0 0}$ & -0.083 & -0.116 & $\mathbf{0 . 3 2 9}$ & 0.127 \\
\hline SY-U5 & 0.172 & -0.165 & -0.083 & $\mathbf{1 . 0 0 0}$ & $\mathbf{0 . 6 0 5}$ & $\mathbf{0 . 2 7 0}$ & -0.158 \\
\hline F-CC & 0.148 & $\mathbf{0 . 2 8 8}$ & -0.116 & $\mathbf{0 . 6 0 5}$ & $\mathbf{1 . 0 0 0}$ & -0.110 & $\mathbf{0 . 3 5 3}$ \\
\hline F-NR & $\mathbf{0 . 6 2 3}$ & $\mathbf{0 . 4 5 6}$ & $\mathbf{0 . 3 2 9}$ & $\mathbf{0 . 2 7 0}$ & -0.110 & $\mathbf{1 . 0 0 0}$ & $\mathbf{- 0 . 5 2 1}$ \\
\hline F-RH & 0.072 & 0.030 & 0.127 & -0.158 & $\mathbf{0 . 3 5 3}$ & $\mathbf{- 0 . 5 2 1}$ & $\mathbf{1 . 0 0 0}$ \\
\hline
\end{tabular}

Table 7.5. Parameter Scaling Factor Estimates and Associated Confidence Intervals (Baseline Inverse Model)

\begin{tabular}{|l|c|c|c||}
\hline $\begin{array}{c}\text { Scaling Factor } \\
\text { Description }\end{array}$ & $\begin{array}{c}\mathbf{9 5} \% \\
\text { Confidence Interval }\end{array}$ & $\begin{array}{c}\text { Best Fit } \\
\text { Estimate }\end{array}$ & $\begin{array}{c}\mathbf{9 5} \% \\
\text { Confidence Interval }\end{array}$ \\
\hline K-U1 & 0.91 & 0.90 & 0.89 \\
\hline K-U5 & 2.27 & 2.25 & 2.23 \\
\hline SY-U1 & 0.29 & 0.28 & 0.27 \\
\hline SY-U5 & 2.15 & 2.12 & 2.08 \\
\hline F-CC & 2.12 & 2.09 & 2.05 \\
\hline F-NR & 1.78 & 1.71 & 1.65 \\
\hline F-RH & 4.48 & 4.37 & 4.27 \\
\hline
\end{tabular}




\subsection{Stepwise Model Modification: Baseline to Full Implementation of Alternative SGM Conceptual Model with Basalt Intercommunication (ACM-1)}

This section describes the development approach and simulation runs that were conducted to investigate and develop an alternative SGM conceptual model that considers a variety of mechanisms to account for intercommunication between the Hanford Site unconfined aquifer system with the underlying upper basalt confined aquifer system. The development approach involved starting with the baseline conceptual model (i.e., basalt boundary represented by no-flow conditions) and adding potential basalt intercommunication features in a stepwise fashion to investigate each feature's sensitivity (i.e., determinability) within the context of the groundwater flow model based on available operational data over the simulated period (1943-1994).

\subsection{Head-Dependent Flux with Uniform Basalt Thickness and Permeability}

The initial basalt transient inverse calibration (ACM-1a) was designed to analyze the effects of areally distributed leakage through the basalt confining layer and to verify that the starting vertical hydraulic conductivity estimate for the Elephant Mountain unit (see parameter estimation discussion in Section 4.2.1) was of the correct order of magnitude. This unit thickness basalt confining layer model, although relatively crude, was easy to implement and provided preliminary information that helped guide development and implementation of more complex conceptual models of basalt leakage. Following are the specifications of ACM-1a and a brief discussion of inverse calibration results. Starting parameter multiplication factor values and corresponding results for each of the estimated parameters are contained in Table 8.1.

Conceptual model:

- uniform unit thickness defined for basalt confining layer

- erosional window not represented

- uniform hydraulic conductivity defined for the basalt confining layer

- a time varying constant head boundary condition was applied to the bottom of the confining layer estimated from observed heads in wells monitoring the Rattlesnake Ridge interbed

- estimated potentiometric surface of the Rattlesnake Ridge interbed was not corrected with head information from the unconfined aquifer within the erosional window, where the two aquifers are in direct communication

Parameter estimation results of interest:

- results for the hydraulic conductivity of Unit 7 indicated it should be reduced to a value similar to that of Units 6 and 8, creating a thicker aquitard unit comprising Units 6, 7, and 8, which is consistent with other interpretations of this sequence (Figure 3.3b). The key is whether Unit 7 is viewed as a sand unit with clay stringers or a clay unit with sand stringers. 
Table 8.1. Summary of Starting Parameter Scaling Factors and Estimation Results for ACM-1a

\begin{tabular}{|c|c|c|}
\hline Scaling Factor Description & $\begin{array}{l}\text { Scaling Factor } \\
\text { Starting Values }\end{array}$ & $\begin{array}{l}\text { Scaling Factor } \\
\text { Estimates }\end{array}$ \\
\hline \multicolumn{3}{|l|}{ Hydraulic Conductivity Distributions Within: } \\
\hline Hanford Formation (Unit 1) & 1.0 & 0.90 \\
\hline Ringold Formation (Unit 5) & 1.0 & 2.10 \\
\hline Ringold Formation (Unit 7) & 1.0 & $2.0 \mathrm{E}-3$ \\
\hline Ringold Formation (Unit 9) & 1.0 & 0.52 \\
\hline \multicolumn{3}{|l|}{ Specific Yield of the } \\
\hline Hanford Formation (Unit 1) & 1.0 & 0.25 \\
\hline Ringold Formation (Unit 5) & 1.0 & 2.06 \\
\hline \multicolumn{3}{|l|}{ Boundary Fluxes } \\
\hline Cold Creek Valley & 1.0 & 2.00 \\
\hline Dry Creek Valley & 1.0 & Not Determinable \\
\hline Rattlesnake Hills & 1.0 & 4.36 \\
\hline Surface Natural Recharge & 1.0 & 1.22 \\
\hline Areally Distributed Basalt Leakage & 1.0 & 2.17 \\
\hline Erosional Window Leakage (Basalt) & & Not Estimated \\
\hline B-Pond Leakage (Basalt) & & Not Estimated \\
\hline Fault Zone Leakage (Basalt) & & Not Estimated \\
\hline
\end{tabular}

- results for the vertical hydraulic conductivity of the basalt confining layer, which was based on the estimated value required to produce an areally distributed flux equal to that of natural recharge, indicated that the parameter was determinable and the inversed result did represent a similar magnitude of flux as natural recharge.

- consistent with the baseline inverse, specific yield parameter estimates for Unit 1 and Unit 5 (starting values of 0.25 and 0.1 , respectively) were being driven toward unrealistic values $(0.06$ and 0.2 , respectively) based on textural information for these units.

- parameter estimation converged on a solution after 12 iterations, with a final sum of squared residuals of $6.3 \mathrm{E}+7$.

\subsection{Combining Units 6, 7, and 8 Into a Single Aquitard Unit}

As discussed in Section 8.1, parameter estimation results obtained from the ACM-1a transient inverse calibration indicated that the hydraulic conductivity of Unit 7 should be reduced to a value similar to that of the Unit 6 and Unit 8 aquitards. The second basalt transient inverse calibration (ACM-1b) tested the grouping of these three low-permeability materials into a single aquitard unit. With the exception of this handling of the lower Ringold fine-grained units, the same simplified hydrogeologic conceptual model developed for ACM-1a was used. Starting parameter values were assigned based on results of ACM-1a 
(i.e., areally distributed leakage through uniform, unit thickness basalt). Following are the specifications of ACM- $1 \mathrm{~b}$ and a brief discussion of the transient inverse calibration results. Starting parameter multiplication factor values and corresponding results for each of the estimated parameters are presented in Table 8.2.

Table 8.2. Summary of Starting Parameter Scaling Factors and Estimation Results for ACM-1b (Units 6, 7, and 8 Combined Into a Single Aquitard Unit)

\begin{tabular}{|c|c|c|}
\hline Scaling Factor Description & $\begin{array}{c}\text { Scaling Factor } \\
\text { Starting Values }\end{array}$ & $\begin{array}{l}\text { Scaling Factor } \\
\text { Estimates }\end{array}$ \\
\hline \multicolumn{3}{|l|}{ Hydraulic Conductivity Distributions Within } \\
\hline Hanford Formation (Unit 1) & 0.90 & 0.87 \\
\hline Ringold Formation (Unit 5) & 2.10 & 2.02 \\
\hline Ringold Formation (Units 6, 7, and 8) & 1.0 & Not Determinable \\
\hline Ringold Formation (Unit 9) & 0.52 & $7.37 \mathrm{E}-4$ \\
\hline \multicolumn{3}{|l|}{ Specific Yield of the } \\
\hline Hanford Formation (Unit 1) & 0.25 & 0.26 \\
\hline Ringold Formation (Unit 5) & 2.06 & 2.07 \\
\hline \multicolumn{3}{|l|}{ Boundary Fluxes } \\
\hline Cold Creek Valley & 2.00 & 1.93 \\
\hline Dry Creek Valley & 1.0 & Not Determinable \\
\hline Rattlesnake Hills & 4.36 & 4.06 \\
\hline Surface Natural Recharge & 1.22 & 0.82 \\
\hline Areally Distributed Basalt leakage & 2.17 & 2.31 \\
\hline Erosional Window Leakage (Basalt) & & Not Estimated \\
\hline B-Pond Leakage (Basalt) & & Not Estimated \\
\hline Fault Zone Leakage (Basalt) & & Not Estimated \\
\hline
\end{tabular}

Conceptual model:

- uniform unit thickness defined for basalt confining layer

- erosional window not represented

- uniform hydraulic conductivity defined for the basalt confining layer

- a time varying constant head boundary condition was applied to the bottom of the confining layer estimated from observed heads in wells monitoring the upper basalt confined aquifer

- estimated potentiometric surface of the upper basalt confined aquifer was not corrected with head information from the unconfined aquifer within the erosional window, where the two aquifers are in direct communication

- Units 6, 7, and 8 were grouped into a single aquitard unit. 
Parameter estimation results of interest:

- results for the hydraulic conductivity of the grouped aquitard units had a low sensitivity coefficient indicating that it could not be determined. If none of the inverse simulations indicate this parameter is determinable, it will be set to the Ringold fine-grained unit permeability estimates utilized in the baseline model.

- results for the hydraulic conductivity of Unit 9 indicated a significant reduction, from a multiplier of 0.52 in ACM-1a to a multiplier of 7.4E-4. However, because of the simplistic basalt leakage conceptual model used in this simulation, this result was not used as the starting value for subsequent simulations.

- consistent with the previous inverse results, specific yield parameter estimates for Unit 1 and Unit 5 (starting values of 0.25 and 0.1 , respectively) resulted in unrealistic values $(0.06$ and 0.2 , respectively) based on textural information for these units.

- parameter estimation converged on a solution after six iterations, with a final sum of squared residuals of $5.9 \mathrm{E}+7$.

\subsection{Inclusion of Basalt Thickness and Erosional Window}

The third basalt transient inverse calibration (ACM-1c) incorporated a more complex hydrogeologic conceptual model that included representation of the actual basalt confining layer thickness (derived from isopach maps of the Elephant Mountain unit) and the erosional window in the vicinity of Gable Mountain and Gable Butte (Section 4.2.2). Starting parameter values were assigned based on results of ACM-1a (i.e., areally distributed leakage through uniform, unit thickness basalt). Following are the specifications of ACM-1c and a brief discussion of a parameter sensitivity analysis. Due to time and computational resource limitations, full inverse parameter estimation analysis was not conducted. Parameter sensitivity analysis results for this case were used to determine which parameters could be estimated and which would be specified as an estimated parameter in subsequent inverse parameter estimation analyses.

Conceptual model:

- variable thickness defined for basalt confining layer based on Elephant Mountain isopach map

- basalt confining layer thickness definition includes erosional window near Gable Mountain and Gable Pond

- uniform hydraulic conductivity defined for the basalt confining layer

- a time varying constant head boundary condition was applied to the bottom of the confining layer estimated from observed heads in wells monitoring the upper basalt confined aquifer

- estimated potentiometric surface of the upper basalt confined aquifer was corrected with head information from the unconfined aquifer within the erosional window, where the two aquifers are in direct communication 
- head-dependent flux applied at erosional window boundary nodes based on gradient determination using head in the upper confined aquifer one model node away from the erosional window

- Units 6,7, and 8 were grouped into a single aquitard unit.

Parameter sensitivity analysis results of interest:

- results for the hydraulic conductivity used in the erosional window flux calculation had a low sensitivity coefficient indicating that it could not be determined. If none of the transient inverse calibrations indicate this parameter is determinable, it will be set based on results of the preliminary design analysis.

\subsection{Inclusion of Yakima Ridge and Gable Mountain/Gable Butte Thrust Faults}

The fourth basalt transient inverse calibration (ACM-1d) incorporated a more complex hydrogeologic conceptual model that included representation of the actual basalt confining layer thickness (derived from isopach maps of the Elephant Mountain unit, Section 4.2.1), the erosional window in the vicinity of Gable Mountain and Gable Butte and a relatively small erosional feature near B-Pond (Section 4.2.2), and increased leakage associated with fault zones (Section 4.2.3). Starting parameter values were assigned based on results of ACM-1a (i.e., areally distributed leakage through uniform, unit thickness basalt) and the basalt feature design analysis discussed in Section 4.2. Following are the specifications of ACM-1d and a brief discussion of a parameter sensitivity analysis. Parameter sensitivity analysis results for this case were used to determine which parameters were determinable and which would be specified as estimated parameters in subsequent inverse parameter estimation analyses.

Conceptual model:

- variable thickness defined for basalt confining layer based on Elephant Mountain isopach map

- basalt confining layer thickness definition includes erosional window near Gable Mountain and Gable Pond

- hydraulic conductivity of the basalt confining layer was segregated into four zones to account for increased leakage associated with thrust faults and erosional features near B-Pond

- a time varying constant head boundary condition was applied to the bottom of the confining layer estimated from observed heads in wells monitoring the upper basalt confined aquifer

- estimated potentiometric surface of the upper basalt confined aquifer was corrected with head information from the unconfined aquifer within the erosional window, where the two aquifers are in direct communication

- head dependent flux applied at erosional window boundary nodes based on gradient determination using head in the upper confined aquifer one model node away from the erosional window

- Units 6,7, and 8 were grouped into a single aquitard unit. 
Parameter sensitivity analysis results of interest:

- as observed in the previous parameter sensitivity analysis, results for the hydraulic conductivity used in the erosional window flux calculation had a low sensitivity coefficient indicating that it could not be determined

- results for the hydraulic conductivity of fractures in the basalt confining layer associated with thrust fault zones indicated the parameter was determinable

- results indicated that inclusion of increased leakage at thrust fault zones reduced the sensitivity of the solution to areally distributed leakage through the basalt confining layer.

Following completion and interpretation of the parameter sensitivity analysis for this conceptual model, a full inverse parameter estimation analysis was conducted. This transient inverse calibration included estimation of all parameters tested in the sensitivity analysis, with the exception of leakage at the erosional window for which phase 22 results indicated that the parameter was not determinable. In all, a total of 14 parameters were estimated. Note: the hydrologic processes associated with parameters that are not estimated (in this case, hydraulic conductivity controlling leakage at the erosional window) are still included in the inverse calibration; for these cases, parameter values were set based on design analysis estimates (Section 4.2). Following is a brief discussion of inverse calibration results and a tabulation of starting parameter multiplication factor values and corresponding results for each of the estimated parameters (Table 8.3).

Parameter estimation results of interest:

- hydraulic conductivity controlling basalt leakage at the erosional feature near B-Pond had a low sensitivity coefficient indicating that it could not be determined. If none of the transient inverse calibrations indicate this parameter is determinable, it will be set based on design analysis estimates

- hydraulic conductivity of the grouped aquitard units was determinable and indicated that the permeability of the aquitard unit should be lowered approximately by an additional factor of 10

- consistent with previous simulations, specific yield parameter estimates for Unit 1 and Unit 5 (starting values of 0.25 and 0.1 , respectively) resulted in unrealistic values ( 0.06 and 0.2 , respectively) based on textural information for these units

- the addition of increased leakage at the Yakima Ridge thrust fault resulted in the inverse decreasing recharge associated with the Dry Creek Valley constant flux boundary. Dry Creek Valley is located at the southeastern extent of the Yakima Ridge thrust fault

- parameter estimation converged on a solution after eight iterations, with a final sum of squared residuals of $5.8 \mathrm{E}+7$. 
Table 8.3. Summary of Starting Parameter Scaling Factors and Estimation Results for ACM-1d (i.e., Areally Distributed, Erosional Window, and Thrust Fault Leakage)

\begin{tabular}{|c|c|c|}
\hline Scaling Factor Description & $\begin{array}{l}\text { Scaling Factor } \\
\text { Starting Values }\end{array}$ & $\begin{array}{l}\text { Scaling Factor } \\
\text { Estimates }\end{array}$ \\
\hline \multicolumn{3}{|l|}{ Hydraulic Conductivity Distributions Within } \\
\hline Hanford Formation (Unit 1) & 0.90 & 0.92 \\
\hline Ringold Formation (Unit 5) & 2.10 & 2.07 \\
\hline Ringold Formation (Units 6, 7, and 8) & 1.0 & $9.62 \mathrm{E}-2$ \\
\hline Ringold Formation (Unit 9) & 0.52 & 0.31 \\
\hline \multicolumn{3}{|l|}{ Specific Yield of the } \\
\hline Hanford Formation (Unit 1) & 0.25 & 0.25 \\
\hline Ringold Formation (Unit 5) & 2.06 & 1.96 \\
\hline \multicolumn{3}{|l|}{ Boundary Fluxes } \\
\hline Cold Creek Valley & 2.00 & 2.64 \\
\hline Dry Creek Valley & 1.0 & $2.37 \mathrm{E}-2$ \\
\hline Rattlesnake Hills & 4.36 & 4.56 \\
\hline Surface Natural Recharge & 1.22 & 1.10 \\
\hline \multicolumn{3}{|l|}{ Basalt Leakage } \\
\hline Erosional Window & & Not Estimated \\
\hline Areally Distributed & 1.00 & 8.19 \\
\hline Yakima Ridge Thrust Fault & 1760 & 163 \\
\hline Gable Mountain-Butte Thrust Fault & 1760 & 28100 \\
\hline Erosional Feature Near B-Pond & 5300 & Not Determinable \\
\hline
\end{tabular}

\subsection{Inclusion of Facies-Based Zonation of Unit 1 and Unit 5}

As discussed, specific yield parameter estimates for Units 1 and 5 (starting values of 0.25 and 0.1 , respectively) resulted in unrealistic values ( 0.06 and 0.2 , respectively) based on textural information for these units. In an attempt to improve estimates of specific yield for these units, five facies-based zones were identified within Unit 1, and two zones were identified within Unit 5 (ACM-2).

Geologic and hydrologic information was used to make a preliminary map of zones with relatively similar hydraulic properties within the saturated post-Ringold sediments (model Unit 1) and the upper Ringold Formation gravel and sand unit (model Unit 5). The zonation developed for Units 1 and 5 is shown in Figure 8.1. Data used to develop this facies-based zonation included borehole records, aquifer test data, water table gradient, and the current understanding of the geologic depositional environment that existed when these sediments were deposited. This task was somewhat easier for the post-Ringold sediments, which include the Plio-Pleistocene unit and Hanford formation, because the size of features with similar texture is much larger in this unit. Work to refine this preliminary zonation continues. 


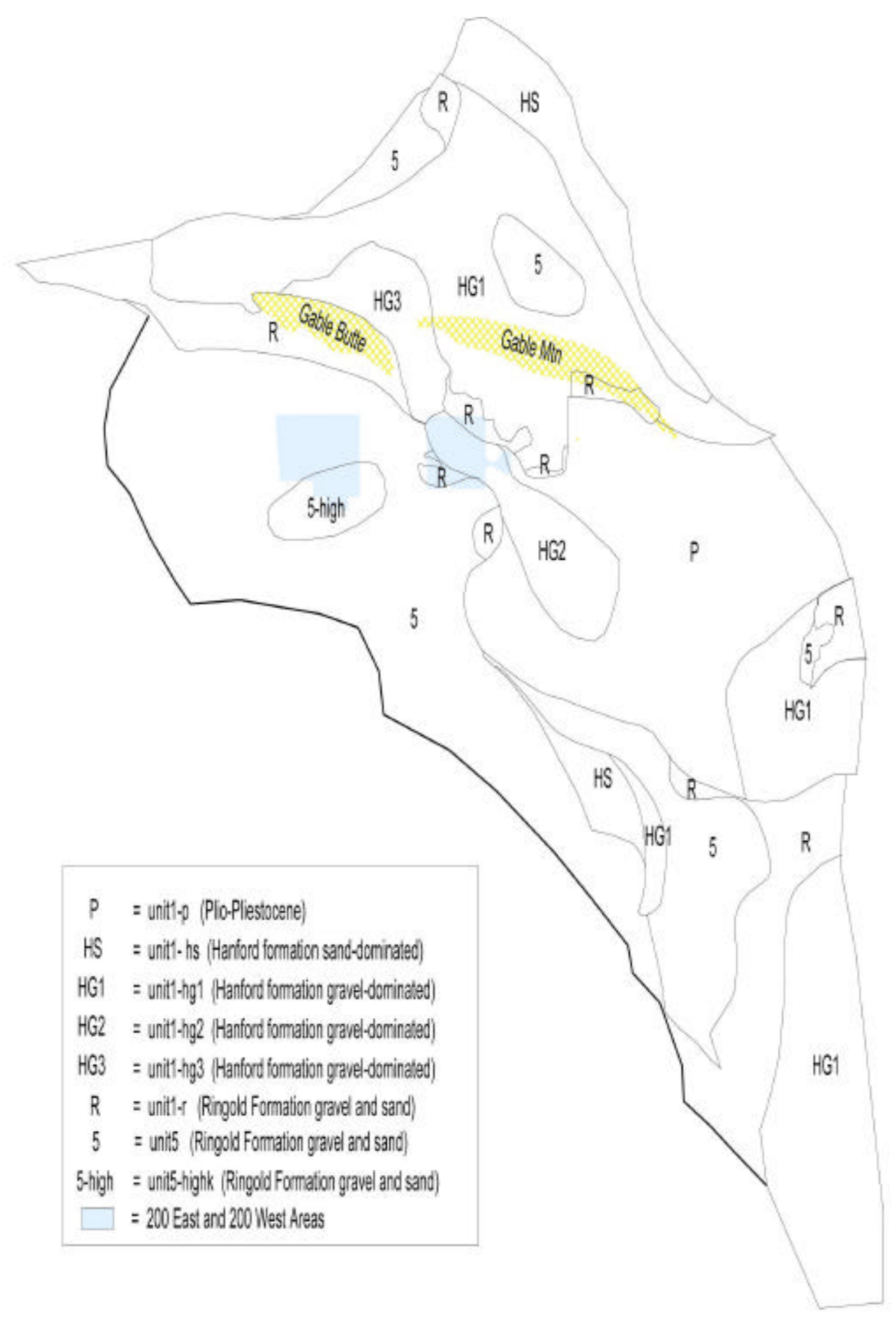

Figure 8.1. Facies-Based Zonation of Model Unit 1 and Unit 5 
For the preliminary evaluation of the post-Ringold sediments, wells where the Plio-Pleistocene unit and/or Hanford formation lie below the 1979 water table were identified on a series of geologic cross sections published by Lindsey (1995). Next, the 1979 water table was drawn onto these cross sections, and saturated thickness of the post-Ringold units was directly measured off the cross sections. The water table for 1979 was used because it was a time of relatively high groundwater levels in the eastern and northern portions of the Hanford Site, where the post-Ringold sediments exist below the water table. During this preliminary evaluation, some areas were identified where the uppermost saturated sediments had been previously classified as post-Ringold, but where the most recent interpretation indicated that only Ringold formation was present below the water table. Unit 1 elements within these zones were reclassified as Unit1-r and labeled with an $\mathrm{R}$ in Figure 8.1. The hydraulic conductivity and specific yield values for these reclassified zones were set based on model Unit 5 parameter values and tied to Unit 5 scaling factors during the inverse calibration. In future inverse modeling efforts, this reclassification will be incorporated into the model layer isopach maps used to build the three-dimensional model structure.

Although there are a number of different facies within the Plio-Pleistocene unit, only a single graveldominated facies (mainstream alluvial facies previously referred to as pre-Missoula Gravels) locally lies at or below the present-day water table in the east-central portion of the Hanford Site. Several other facies of the Plio-Pleistocene unit exist (Bjornstad et al. 2001), but these occur above the water table. Therefore, only a single hydraulic property zone is represented in the model for this gravel-dominated facies of the Plio-Pleistocene unit (designated P in Figure 8.1). It should be noted that in the prior model, baseline model, and ACM-1 (as discussed in Section 3.0), this gravel-dominated facies of the PlioPleistocene stratigraphic unit was included with the Hanford formation as part of hydrostratigraphic unit 1 (see Table 3.1 and Figure 3.3 b).

Cataclysmic flood deposits of the Hanford formation were divided into three facies (graveldominated, sand-dominated and silt-dominated). Textural information provided on Lindsey's (1995) cross sections was used to determine the predominant facies type. The Hanford formation lies below the water table only in the northern and southeastern parts of the Hanford Site. The gravel-dominated facies (see zones with labels starting with HG in Figure 8.1) prevails in these areas, with some sand- and siltdominated facies locally. In general, the texture of the Hanford formation becomes finer-grained away from the center of the basin (i.e., the Gable Butte-Gable Mountain axis). The silt-dominated facies was generally not found below the 1979 water table. Therefore, where they exist below the 1979 water table, the gravel-dominated facies and the sand-dominated facies of the Hanford formation (the zones labeled HS in Figure 8.1) were identified as separate hydraulic property zones along with the gravel-dominated facies of the Plio-Pleistocene unit (the zones labeled P in Figure 8.1).

Three hydraulic property zones within the gravel-dominated facies of the Hanford formation (HG1, HG2, and HG3, Figure 8.1) were delineated by examining hydraulic gradients and aquifer test data. An examination of existing data indicated that two areas within the gravel-dominated facies of the Hanford formation have significant differences in the hydraulic gradients, aquifer test results, and depositional history compared to the majority of the area, which is designated as HG1 in Figure 8.1. Zone HG3 (Figure 8.1), which covers the area in and around Gable Gap (between Gable Mountain and Gable Butte), was identified based on the existence of a very flat water-table gradient and aquifer test data that indicate very high hydraulic conductivities. This was also an area of very high energy during the cataclysmic floods because flood waters were channeled through the gap. The area of Hanford formation gravel southeast of this zone, labeled HG2 in Figure 8.1, was also identified as an area of somewhat elevated 
hydraulic conductivities compared to the gravel-dominated facies of zone HG1. This area is also important because it encompasses a large part of the 200 East Area, where many wells and discharge facilities are located.

Geologic information and aquifer test data indicate that the Ringold gravel and sand sediments that compose model Unit 5 display smaller textural features, and therefore smaller-scale heterogeneity in hydraulic properties, than the post-Ringold sediments. This is consistent with the fact that these sediments were deposited by the ancestral Columbia River system as it moved back and forth across the Pasco Basin. Over most of the Hanford Site, there is not enough data to delineate areas with consistently high or low hydraulic properties within this unit. However, in the vicinity of the 200 West Area, the distribution of wells completed in this unit is relatively dense, and aquifer tests have recently been completed in 16 of these wells. Based on these data, a zone of relatively high hydraulic conductivity was delineated around the southern part of the 200 West Area (see Figure 8.1).

To obtain starting conductivity values for each zone in Units 1 and 5 and all of Unit 9, the threedimensional conductivity field from the prior model was sampled, and statistics of the hydraulic conductivity distribution of elements within each zone were calculated including the arithmetic mean, median, and standard deviation (Table 8.4). Based on interpretation of these data, the median was selected as the most representative statistic, although the mean conductivity values showed the same general conductivity relationship between the various zones (e.g., both indicated that the gravel units should be set to higher permeability values than the units containing more fine-grained materials). The mean value was biased upward by relatively few elements that were assigned extremely high hydraulic conductivity values.

Table 8.4. Statistics of the Hydraulic Conductivity Distribution (m/d) of Elements Within Each Facies-Based Zone

\begin{tabular}{|c|c|c|c||}
\hline $\begin{array}{c}\text { Layer/Zone } \\
\text { Designation }\end{array}$ & $\begin{array}{c}\text { Arithmetic } \\
\text { Mean }\end{array}$ & Median & $\begin{array}{c}\text { Standard } \\
\text { Deviation }\end{array}$ \\
\hline \hline Unit 1-r & 1303.5 & 145.8 & 4234.4 \\
\hline Unit 1-p & 227.2 & 56.7 & 553.1 \\
\hline Unit 1-hs & 215.7 & 104.1 & 304.4 \\
\hline Unit 1-hg1 & 755.4 & 181.5 & 1939.7 \\
\hline Unit 1-hg2 & 4651.1 & 808.6 & 7852.3 \\
\hline Unit 1-hg3 & 4640.7 & 3451.9 & 4077.8 \\
\hline Unit 5 & 21.5 & 3.7 & 73.5 \\
\hline Unit 5-highk & 6.6 & 6.5 & 3.5 \\
\hline Unit 9 & 3.3 & 0.5 & 10.6 \\
\hline
\end{tabular}

As indicated in Table 8.4, the hydraulic conductivity for Unit 1 elements that were reclassified as middle Ringold (Unit1-r) was significantly higher than that of the previously classified middle Ringold elements (Unit 5). Because the range of hydraulic conductivity assigned to Unit 5 was based on available hydrologic characterization data, and the values sampled from the reclassified middle Ringold elements fell outside the expected range, the Unit1-r elements were assigned the same hydraulic conductivity and specific yield values as the Unit 5 elements. 
The above methodology for incorporating facies-based zonation of Unit 1 and Unit 5 was applied to develop a preliminary model for investigating the effects of parameter zonation on inverse calibration results. Although this work has been initiated, transient inverse calibration results and statistical performance measures for this case were not available in time to be included in this report. 


\subsection{Results and Evaluation of the ACM-1 Transient Inverse Simulation}

As discussed in Section 8.0, implementation of basalt leakage in the SGM was accomplished by adding basalt features in a stepwise fashion to investigate each feature's sensitivity and relationship with other estimated parameters. Section 8.0 contains a brief summary of parameter estimation results of interest for each of the intermediate simulations and the resulting basalt leakage inclusive model (ACM-1d). Detailed results from the ACM-1d transient inverse calibration for the historical period of Hanford Site operations (1943-1996) are discussed in Section 9.1. Discussions in Section 9.2 evaluate the regression results by following the "Guidelines for Effective Model Calibration" (Hill 1998; Cole et al. 2001a).

\subsection{Transient Inverse Simulation Results}

Modification of the baseline inverse model to incorporate intercommunication with the upper basaltconfined aquifer improved the capability of the resulting model to simulate historical trends in water-table changes over the entire site. However, as discussed in the following sections, some parameters continue to take on unrealistic values, indicating that additional conceptual model improvements are needed. Comparisons, measures, and discussions in this section parallel those summarized for the baseline transient inverse simulation results (Section 7.0) so results of the two models can be compared directly. The discussions in this section include spatial and temporal distribution of residual errors and residual error statistics.

\subsubsection{Spatial and Temporal Distributions of Residual Errons}

An overall comparison of simulated and measured water levels for the entire calibration period (1943-1996) for ACM-1d, with the first observations starting in 1948, is shown in Figure 9.1 as a scattergram plot of simulated head from the inverse model plotted versus the measured head. The scattergram also contrasts the scatter of residual error points with a 45-degree line that represents a perfect match between model and data, with the individual plotted points color-coded to indicate the magnitude of the residual error. Figure 9.2 shows a residual frequency histogram for ACM-1d over this same calibration time period that plots the number of residuals in each residual category from $-12 \mathrm{~m}$ to $+12 \mathrm{~m}$ in 1-m increments. The associated statistics for these comparisons are found in Table 9.1.

The graphical comparisons and summary statistics illustrate that, over the entire prediction period, a slight measurable improvement in overall model fit was realized for ACM-1d over that observed for the baseline inverse model. Residual error statistics indicate that 66.9 percent of the simulated values were within $\pm 1 \mathrm{~m}$ of measured values, and 99 percent were within $\pm 5 \mathrm{~m}$ compared to 65.8 and 98.6 percent, respectively, for the baseline inverse model. The overall mean residual was $0.09 \mathrm{~m}(-0.90 \mathrm{~m}$ for negative residuals and $1.26 \mathrm{~m}$ for positive residuals), which is slightly better than the residual results for the baseline inverse model of $-0.13 \mathrm{~m}$ for the overall mean residual ( $1.34 \mathrm{~m}$ for negative residuals, $0.87 \mathrm{~m}$ for positive residuals). The median and mean absolute error for ACM-1d was $-0.11 \mathrm{~m}$ and $1.07 \mathrm{~m}$, respectively, which was also slightly better than the comparable baseline model statistics, which were 0.12 and 1.09 , respectively. The residuals for ACM-1d ranged from $-11.9 \mathrm{~m}$ to $11.0 \mathrm{~m}$, which compares to $-11.1 \mathrm{~m}$ to $11.8 \mathrm{~m}$ for the baseline inverse model. The sum of squared residuals for ACM-1d was $1.79 \times 10^{5}$, while the sum of squared residuals for the baseline inverse model was slightly worse at $2.00 \times 10^{5}$. 


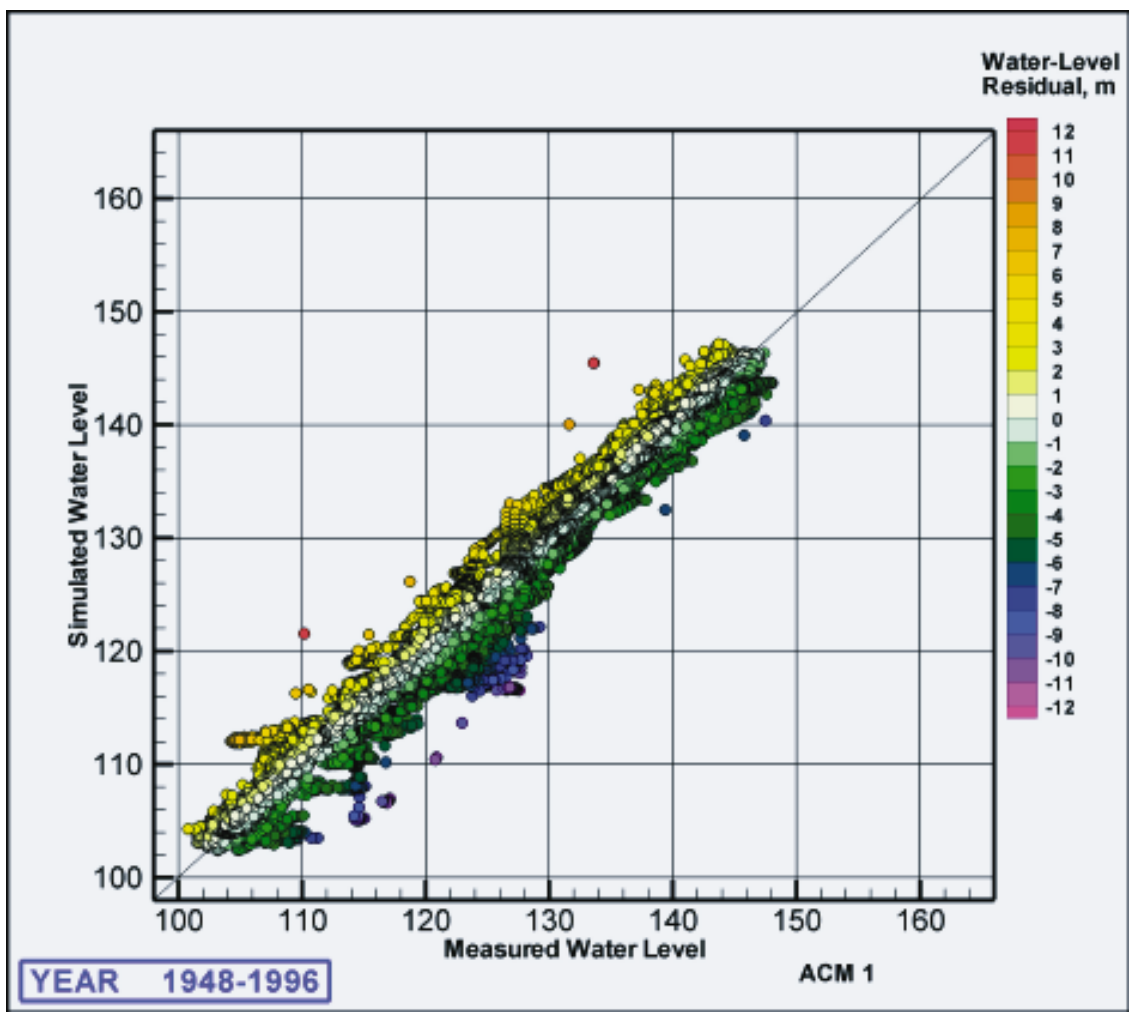

Figure 9.1. Measured Versus Predicted Heads (45-degree plot); All Observations for Best-Fit ACM-1d Inverse Model

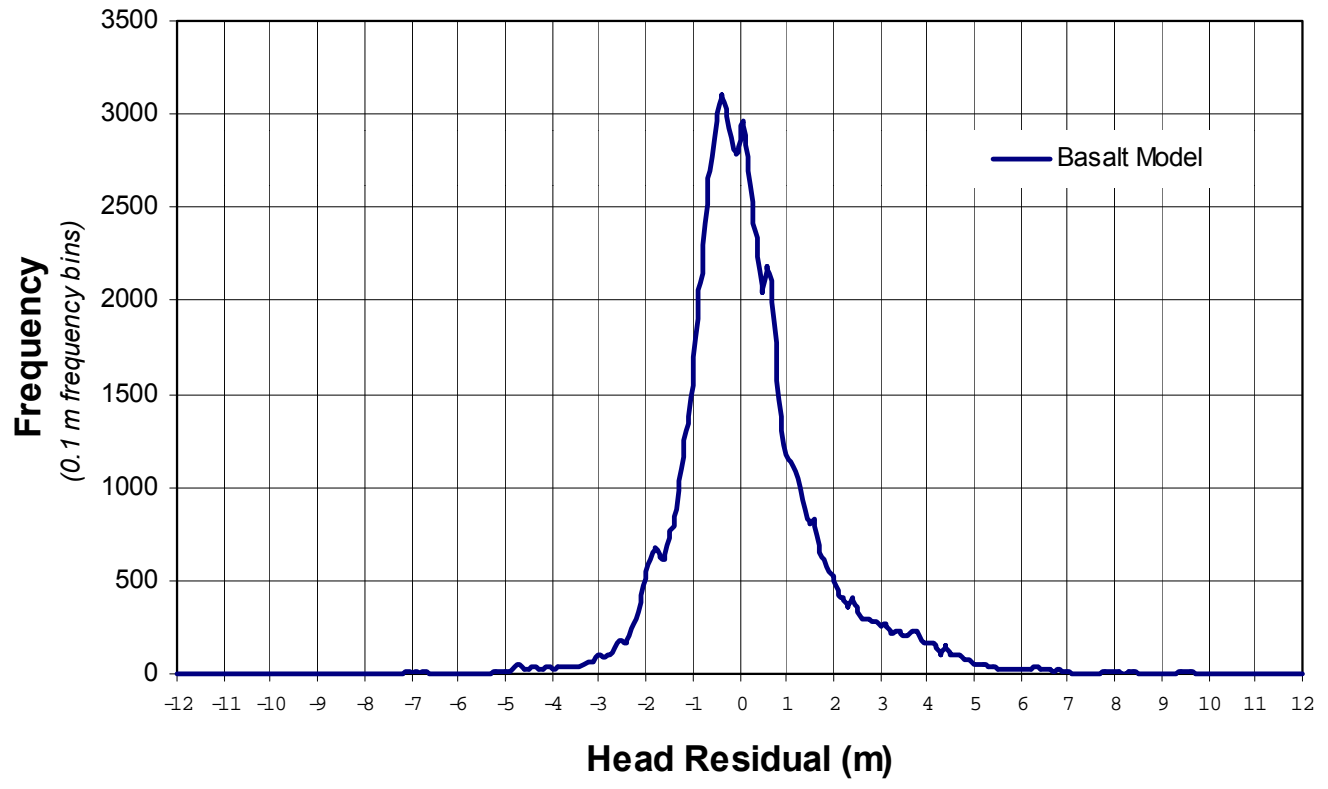

Figure 9.2. Histogram of Predicted Head Residuals; All Observations for Best-Fit ACM-1d Inverse Model 
Table 9.1. Summary of Residual Error Statistics of Best-Fit ACM-1d Inverse Model

\begin{tabular}{|c|c|c|}
\hline Residual Statistic & Value & $\begin{array}{c}\text { Number of } \\
\text { Observations }\end{array}$ \\
\hline \multicolumn{3}{|l|}{ Positive Residuals } \\
\hline Mean (m) & 1.26 & 34846 \\
\hline Standard Deviation (m) & 1.34 & \\
\hline $\operatorname{Min}(\mathrm{m})$ & 0.00 & \\
\hline $\operatorname{Max}(\mathrm{m})$ & 11.05 & \\
\hline \multicolumn{3}{|l|}{ Negative Residuals } \\
\hline Mean (m) & -0.90 & 41189 \\
\hline Standard Deviation $(\mathrm{m})$ & 0.82 & \\
\hline $\operatorname{Max}(\mathrm{m})$ & -11.87 & \\
\hline $\operatorname{Min}(\mathrm{m})$ & 0.00 & \\
\hline Overall Mean (m) & 0.09 & 76035 \\
\hline Standard Deviation (m) & 1.53 & \\
\hline Median (m) & -0.11 & \\
\hline Mean Absolute Error (m) & 1.07 & \\
\hline Sum of Squared Residuals $\left(\mathrm{m}^{2}\right)$ & $1.79 \mathrm{E}+05$ & \\
\hline Residual Range & Percent of Total & \\
\hline Between 1 and $-1 \mathrm{~m}$ & 66.9 & \\
\hline Between 2 and $-2 \mathrm{~m}$ & 87.4 & \\
\hline Between 3 and $-3 \mathrm{~m}$ & 94.0 & \\
\hline Between 4 and $-4 \mathrm{~m}$ & 97.3 & \\
\hline Between 5 and $-5 \mathrm{~m}$ & 99.0 & \\
\hline $\begin{array}{l}\text { Greater Than } 5 \text { or } \\
\text { Less Than }-5 \mathrm{~m}\end{array}$ & 1.0 & \\
\hline
\end{tabular}

The predicted change in water-table elevation contours for ACM-1d is presented for 1943 and in 10year increments between 1950 and 1996 in a series of plots found in the Appendix (Figures A.1a through A.1g). The Appendix also contains color-coded plots illustrating how the spatial distribution of measurements, their location, and the associated head residuals vary for the same times for which water-table elevation contours are shown (Figures A.2a through E.2g). In addition, the Appendix shows scattergrams of simulated versus measured heads for the same times for which water-table elevation contours and spatial distributions of residuals are shown (Figures A.3a through A.3g). The scattergrams contrast the scatter of residual error points with a 45-degree line that would represent a perfect match between model and data. The individual plotted points are also color-coded to indicate the magnitude of the residual error. All of the plots presented in the Appendix also have equivalent plots for the baseline model presented on the same page for comparison (see Section 7.0)

In general, goodness of fit measures for ACM-1d were somewhat improved over the same measures for the baseline inverse model for the full calibration period from 1943 to 1996, which represents the entire period of Hanford Site operations. However, the most noteworthy improvements in the ACM-1d transient inverse calibrated model is not associated with overall model fit but with incorporation of a more complex conceptual model (see Section 8.0) and parameter estimates that fall closer to the expected range 
based on previous analysis of available characterization data and the current conceptual understanding of the hydrogeologic system being simulated. Additionally, it should be noted that while this more realistic conceptual model might not be as important during the Hanford operational period when large fluxes were being disposed to ground, the additional flux from basalt interactions will likely be more important in determination of groundwater velocities and directions that would affect future predictions. The following sections discuss the hydrogeologic parameter estimates that were obtained from the best-fit calibration of ACM-1d.

\subsubsection{Hydraulic Conductivities}

The hydraulic conductivity distribution from ACM-1d is presented in Figure 9.3 in a similar manner as those from the prior model (see Figures 3.5) and the baseline inverse model (see Figure 7.3) to illustrate the changes in properties of the Hanford and the uppermost Ringold sediments resulting from the ACM-1 transient inverse calibration. The most notable changes between the prior model and baseline inverse model are seen in the distribution of hydraulic conductivities of the Ringold Formation (Unit 5), which outcrops at the water table over much of the western and southwestern part of the Hanford Site. Changes in the hydraulic conductivity distribution between the baseline inverse model and ACM-1d are much less pronounced, with only a 2 percent increase in the Unit 1 multiplier and an 8 percent decrease in the Unit 5 multiplier.



Figure 9.3. Hydraulic Conductivity Distribution for Best-Fit ACM-1d Inverse Model 
The best-fit estimates for the hydraulic conductivity of the Hanford formation (Unit 1) were found to be well within the reasonable range of previous estimates for this parameter. Previous work summarized in Thorne and Newcomer (1992) and Wurstner et al. (1995) indicate that the hydraulic conductivity of Unit 1 generally ranges from about 1 to $1,000,000 \mathrm{~m} / \mathrm{d}$ and is much higher than any of the other units that make up the unconfined aquifer system. Aquifer tests indicate that the minimum estimated hydraulic conductivity is about $1 \mathrm{~m} / \mathrm{d}$ (Thorne et al. 1993), and the maximum estimated value is about 10,000 $\mathrm{m} / \mathrm{d}$ (Thorne and Newcomer 1992; DOE 1988). However, the maximum hydraulic conductivity that can be estimated by an aquifer test is limited by the well efficiency and the flow rate that can be pumped with available equipment. Past calibration efforts by Wurstner et al. (1995) and Cole et al. (1997) have estimated that an upper limit of hydraulic conductivity for coarse-gravel flood deposits found in the central part of the Hanford Site is on the order of several tens of thousands of $\mathrm{m} / \mathrm{d}$. Estimates resulting from inverse calibration of the model were very similar to estimates in previous calibration efforts and are consistent with estimates developed largely from aquifer tests.

The best-fit estimates for the hydraulic conductivity of the Ringold Formation (primarily Unit 5) were found to be well within the reasonable range of previous estimates for this parameter. The Ringold Formation consists of sand to muddy sandy gravel with varying degrees of consolidation or cementation. Unit 5 is the most widespread unit within the unconfined aquifer and is found below the water table across most of the model region. According to Wurstner et al. (1995), hydraulic conductivities of Units 5, 7 , and 9 determined from aquifer tests vary within the range of about 0.1 to $200 \mathrm{~m} / \mathrm{d}$. However, as discussed in Section 8.2, parameter estimation results from ACM-1a indicated that the hydraulic conductivity of Unit 7 should be reduced to a value similar to that of the fine-grained materials of Unit 6 and Unit 8, resulting in a thicker aquitard unit comprised of Units 6, 7, and 8 at locations where all three layers are present. The inverse result for Units 6, 7, and 8 is consistent with other interpretations of this unit as is illustrated in the right hydrostratigraphic column shown in Figure 3.3b (from Lindsey 1995). This right hydrostratigraphic column illustrates that Units 6,7 , and 8 were interpreted as a single mud unit with discontinuous coarse unit inclusions, while the interpretation used in the prior model (i.e., left hydrostratigraphic column shown in Figure 3.3b) indicates that the same stratigraphic horizon is interpreted as a continuous mud layer (Unit 6) over a continuous conductive layer (Unit 7) underlain by another continuous mud (Unit 8). A few aquifer tests suggest that vertical anisotropy is in the range of 0.01 to 0.1 . Therefore, the range of $\mathrm{Kv}$ is estimated at about 0.001 to $20 \mathrm{~m} / \mathrm{d}$. Estimates resulting from inverse calibration of the model were very similar to estimates in previous calibration efforts and are consistent with estimates developed largely from aquifer tests.

\subsubsection{Storage Properties}

According to Wurstner et al. (1995) and Thorne and Newcomer (1992), specific yield for the Hanford formation (Unit 1) is estimated to range from about 0.1 to 0.3 and is expected to be higher for coarse, well-sorted gravel than for poorly sorted mixtures of sand and gravel. From previous work (Wurstner et al. 1995; Thorne and Newcomer 1992), specific yields of the poorly sorted sediments of the Ringold Formation are estimated to range from 0.05 to 0.2 . 
The best-fit estimate (0.0625) for the specific yield of the Hanford formation (Unit 1 ) and the associated confidence limits developed by the inverse calibration were not found to be consistent with

- reasonable ranges summarized in previous analyses of the hydraulic properties of these units since the best-fit estimate for specific yield of the Hanford Formation (i.e., 0.0625) was below the range of reasonable values $(0.1$ to 0.3$)$

- the descriptions of the facies for these units (e.g., some portions of the facies in zones HG1, HG2, and HG3 of Figure 8.1 are described as open work gravels)

- the depositional process (i.e., deposition related to the cataclysmic floods that inundated the Pasco Basin).

Similarly, the best-fit estimate (0.196) for the specific yield of the Ringold Formation Unit 5 and the associated confidence limits developed by the inverse calibration were found to be inconsistent with:

- the general interpretations for this unit since best-fit estimate (0.196) is at the upper end of the range of previous estimates ( 0.05 to 0.2$)$

- the facies description for Unit 5 (i.e., a clast to matrix-supported pebble-to-cobble gravel with a fine-to-medium sand matrix with some lenticular sand and silt interbeds, Lindsey [1995])

- wet sieve analyses of outcrop and intact core samples that indicate grain size distributions that are bimodal with $67 \%$ by weight pebbles and cobbles and the remainder consisting of medium- to fine-grained sand with mud content less than $5 \%$ by weight (Lindsey 1995).

The inconsistencies between the calibrated values and the prior information for both the Hanford formation and the Ringold Formation suggest that processes other than those considered in the numerical implementation of ACM-1 require evaluation. Other processes that may be evaluated in future inverse calibration efforts for their ability to provide more realistic specific yield estimates are the inclusion of facies-based zonation of hydraulic properties for the main transmissive model layers (i.e., Units 1 and 5) and uncertainty in the time required for wastewater discharges applied at ground surface to migrate through the vadose zone.

\subsubsection{Boundary Flux Estimates}

The estimated fluxes developed from a constant head boundary during previous calibration efforts provided the basis for the initial estimate used in ACM-1. While the various boundary fluxes at the Cold Creek and Dry Creek Valleys and at the base of Rattlesnake Hills cannot be independently verified, the estimated fluxes were found to be well within the reasonable range, given the uncertainty that could be expected in hydraulic properties of the principal hydrogeologic units found close to these units. The bestfit flux at Cold Creek Valley was a factor of 2.6 higher than the initial estimates. The best-fit flux estimated for Rattlesnake Hills was a factor of 4.6 higher than the initial estimate. Given the uncertainty in the overall hydraulic properties of the Ringold Formation found in the vicinity of Cold Creek Valley and the hydraulic properties of the Hanford and Ringold formations found along the base of Rattlesnake Hills, the increase in the overall estimate is not considered unreasonable.

Throughout the development of ACM-1, sensitivity coefficients for the flux from Dry Creek Valley indicated that the parameter was not determinable. However, in the final basalt inverse model (ACM-1d), 
inclusion of increased leakage at the Yakima Ridge thrust fault resulted in a sensitivity coefficient for this parameter, which indicated that it was determinable and that there was a significant reduction (by a factor of 0.02) in the estimated recharge associated with the Dry Creek Valley constant flux boundary. This decrease is not unexpected given the location of the Dry Creek Valley; it is located at the southeastern extent of the Yakima Ridge thrust fault (i.e., flux required at this location to meet the objective function that was previously being supplied by the Dry Creek flux boundary was replaced by flux from the Yakima Ridge thrust fault).

\subsubsection{Natural Recharge}

The best-fit estimates for natural recharge in ACM-1 were significantly improved over that for the baseline inverse. The best-fit estimates for natural recharge in the baseline inverse model were about 71 percent greater than the estimates previously made by Fayer and Walters (1995). This increase in the overall estimate of recharge was not considered unreasonable for most areas of the site, where recharge rates are on the order of 5 to $20 \mathrm{~mm} / \mathrm{yr}$. However, for some areas of the site where coarse soils exist and previous estimated recharge rates approach 50 to $60 \mathrm{~mm} / \mathrm{yr}$, this 71 percent increase in the overall recharge rate results in rates of 80 to $90 \mathrm{~mm} / \mathrm{yr}$, which are not considered reasonable. Results from ACM$1 \mathrm{~d}$ indicate only a 10 percent increase over the previous estimates (Figure 3.6), which is well within the range of natural recharge values considered reasonable. As postulated based on results of the baseline inverse effort, consideration of the interaction with the uppermost basalt confined aquifer improved the estimates of natural recharge by supplying a portion of the areally distributed flux entering the model domain that was needed to meet the objective function.

\subsubsection{Basalt Intercommunication}

As discussed in Section 4.0, there were several components of basalt leakage that were considered in the full implementation of ACM-1 including areally distributed leakage, increased leakage at the erosional window and a smaller erosional feature near B-Pond, and increased leakage along fault zones. Figures 9.4 and 9.5 show the simulated distribution of basalt leakage over the model domain in 1960 and 1996, respectively. The units for data presented in these figures are cubic meters of leakage per model time-step (i.e., per 6 months). The basalt leakage distributions shown provide an example of representative leakage fluxes for the range of groundwater mounding conditions observed over the simulated period. With the exception of leakage response in the vicinity of Gable Mountain, the general leakage response across the site was consistent over the simulated period, with downward leakage occurring throughout the area affected by the groundwater mound resulting from 200 Area wastewater disposal activities, and upward leakage occurring throughout the eastern portion of the site.

A comparison of Figures 9.4 and 9.5 in the vicinity of Gable Mountain and the erosional window shows the effects of groundwater mounding on leakage response at model nodes surrounding the erosional window. As anticipated based on design analysis to determine leakage at the erosional window, a leakage reversal was observed throughout this portion of the site during the 1960s, when the groundwater mound was at its maximum height. Figure 9.6 shows results of the simulated leakage at the erosional window, along with estimates of leakage based on analysis of the upper basalt confined aquifer head data (see Section 4.2.2 and Figure 4.12 for the estimation methods). Given that the estimated leakage response was based on head data for both the unconfined and upper confined aquifers at an interval of 10 years (where upper confined head data were available) with values interpolated in 


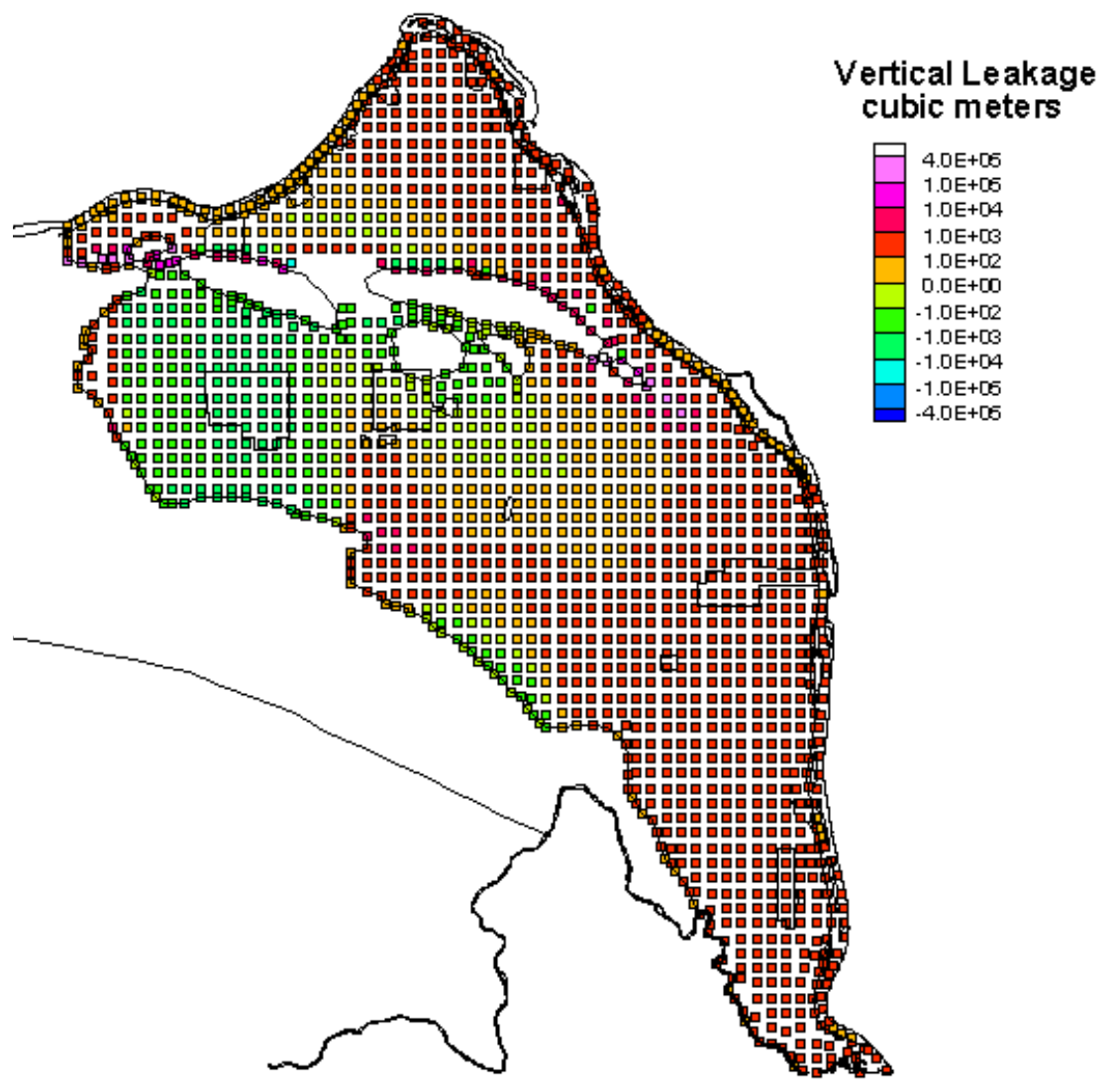

Positive Leakage - into unconfined aquifer

Negative Leakage - into confined aquifer

Figure 9.4. Simulated Basalt Leakage in 1960

between, it appears the simulated response provides a reasonable representation of basalt leakage at the erosional window. Although the simulated response does deviate from the estimated response at several times, the general shape of the simulated leakage response is relatively consistent with the original estimate based on average heads at several time planes (e.g., the flow reversal in the 1960s is approximated relatively well).

Although Figures 9.4 and 9.5 do show the effects of basalt leakage in the vicinity of the Gable Mountain/Gable Butte thrust fault, a closer inspection of flux results is needed to show the relative contribution of flux from each of the features affecting basalt leakage that were considered in ACM-1d. Figure 9.7 shows the areally distributed upward leakage, downward leakage, and net leakage flux over the period of simulation. Areally distributed leakage flux is calculated as the summation of flux across the basalt confining layer at all nodal locations outside the zones of increased leakage associated with faults and erosional features. As indicated, both the upward and downward leakage curves contain temporal variability that is primarily associated with wastewater disposal activities in the 200 Areas. The temporal variability of the net leakage flux (upward minus downward leakage) is increased since it contains the variability in both data sets. 


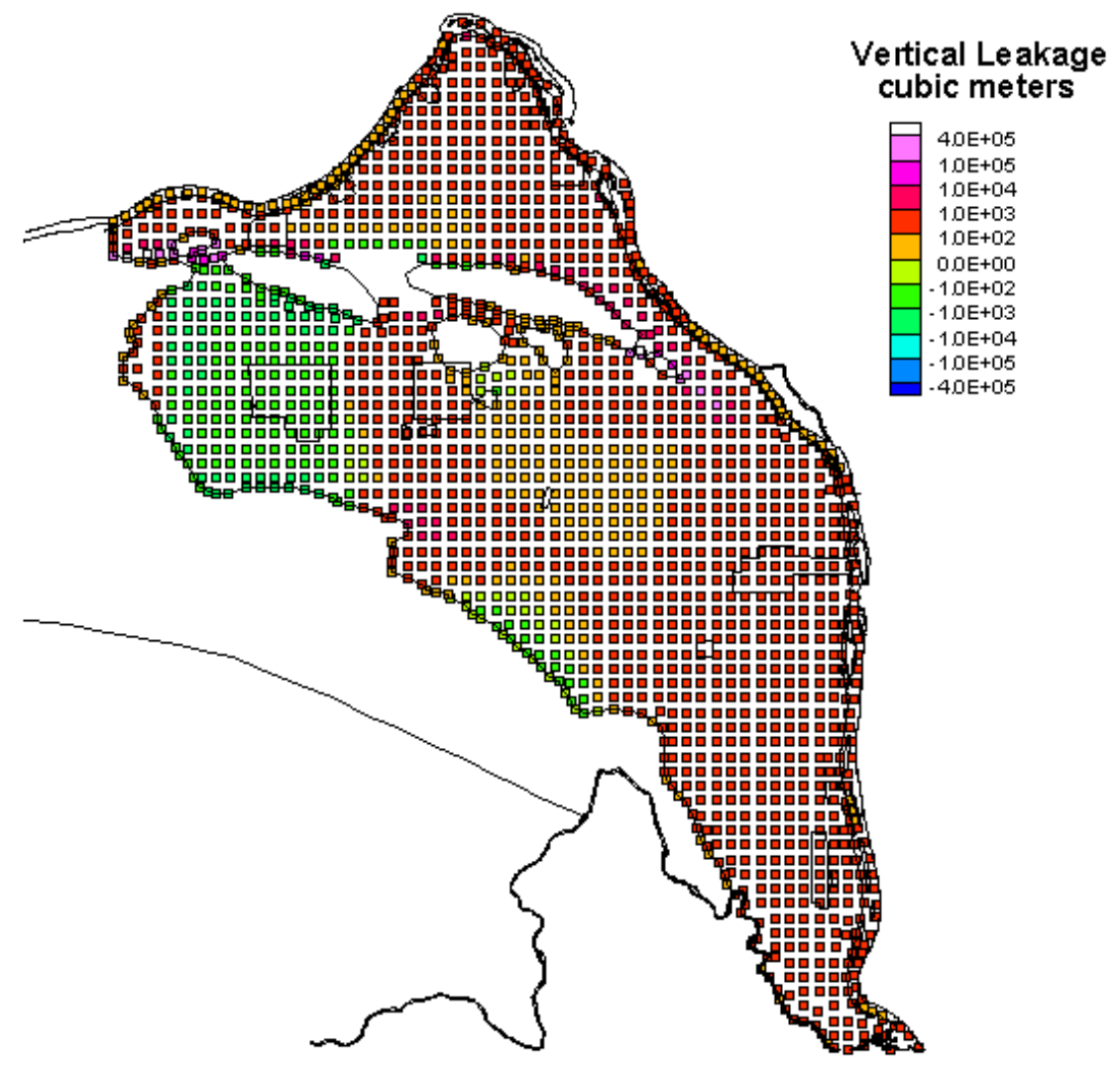

Positive Leakage - into unconfined aquifer Negative Leakage - into confined aquifer

Figure 9.5. Simulated Basalt Leakage in 1996

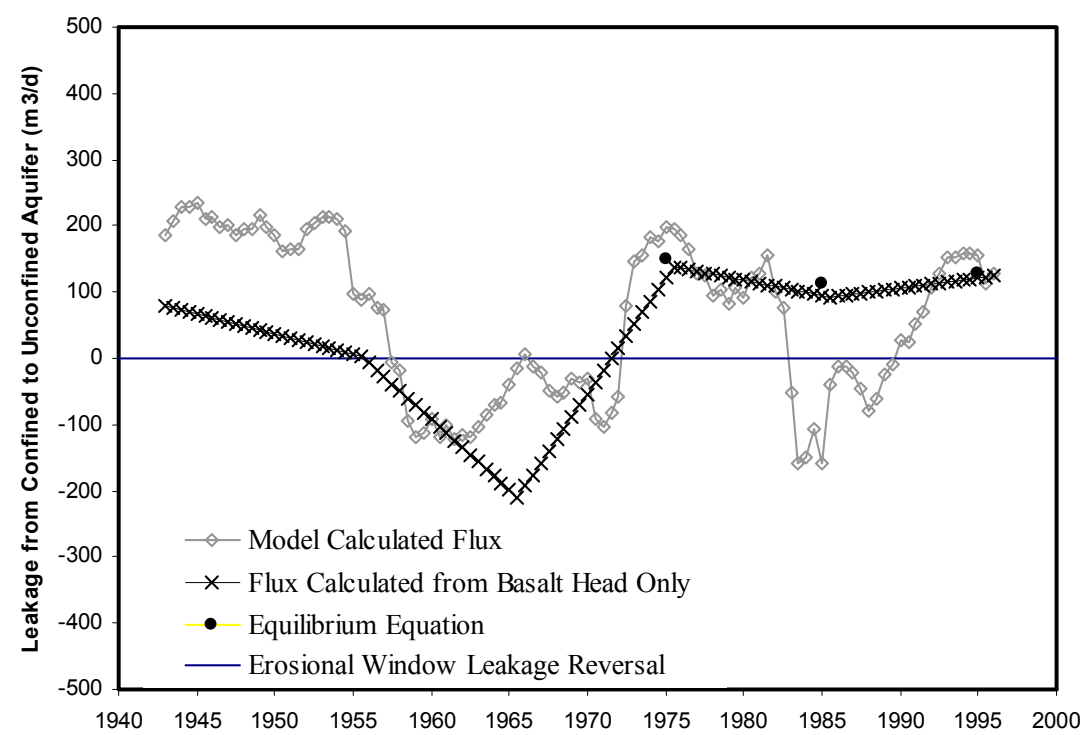

Figure 9.6. Estimated and Simulated Leakage from the Upper Basalt Confined Aquifer at the Erosional Window 


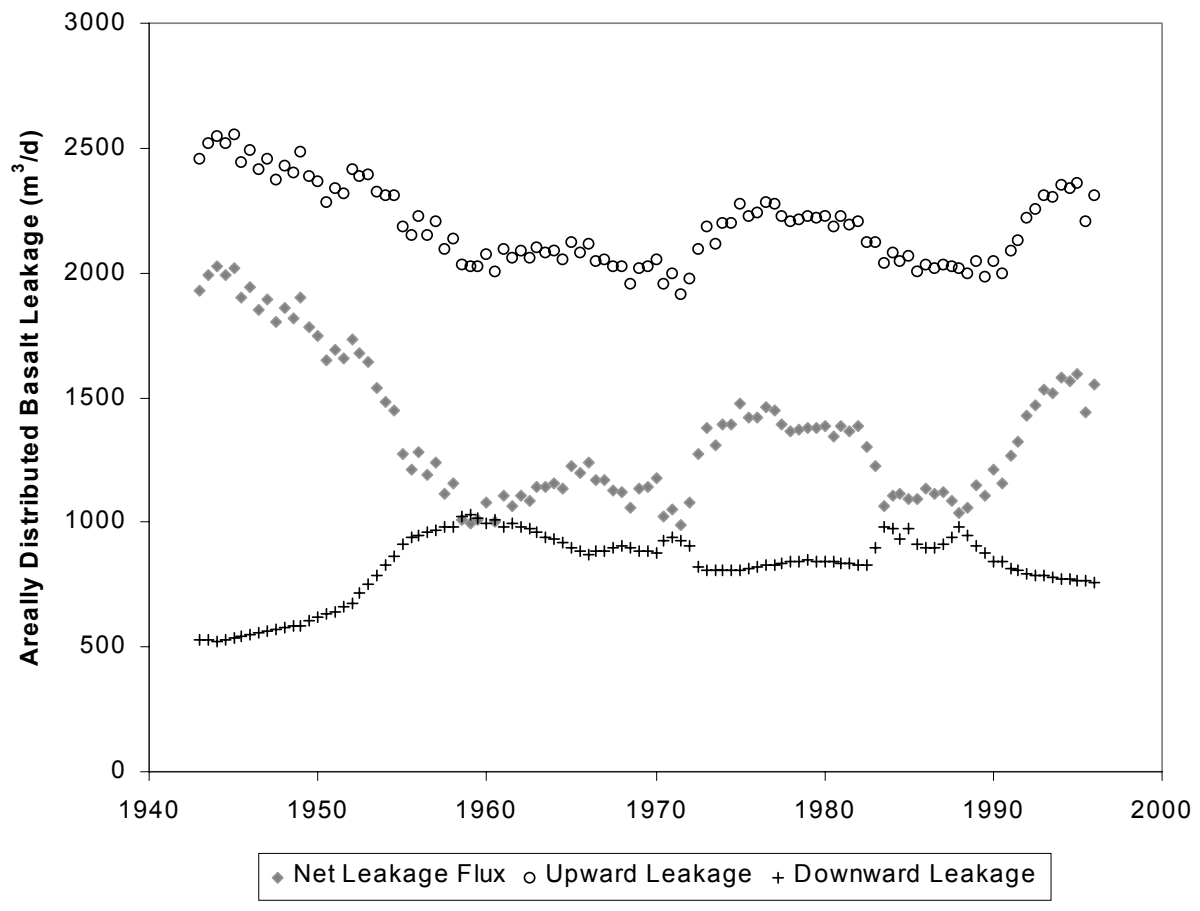

Figure 9.7. Areally Distributed Basalt Leakage Flux Over the Simulated Period

Figure 9.8 shows the relative contribution to net leakage flux for each of the features considered in ACM-1d (i.e., areally distributed leakage, increased leakage at the Yakima Ridge and Gable Mountain/ Gable Butte thrust faults, and increased leakage at erosional features in the vicinity of Gable Mountain). Data presented in this figure indicate that areally distributed leakage is the dominant mechanism, with leakage flux from faults and the erosional window contributing to a lesser extent. Based on these data, the time-weighted average basalt leakage flux contributing to recharge of the unconfined aquifer is $\sim 2000$ 3/d, or approximately 10 percent of the flux associated with natural recharge (see Section 3.1.3). However, the Gable Mountain Fault data presented in this plot were processed to omit simulated flux values at several nodal locations where flux was estimated to be an order of magnitude higher than at other segments of the fault.

Initial investigation of net flux values for the Gable Mountain fault indicated that two segments of the fault, one to the northeast of Gable Butte and the other to the southwest of Gable Mountain, were the source of the large, relatively variable flux rates (Figure 9.9). Closer inspection of geologic model structure in this region of the model domain indicated the reason that these segments of the fault were able to produce the relatively large leakage flux rates observed was that the basalt confining layer was directly overlain by the high-permeability Hanford formation (i.e., no Ringold mud units were present to limit upward leakage, as was the case along the remaining length of the fault). Even though our current conceptual understanding of increased leakage at fault zones is limited, we believe that increased leakage in these two limited areas is unlikely and is a result of an incomplete model of the underlying basalts. 


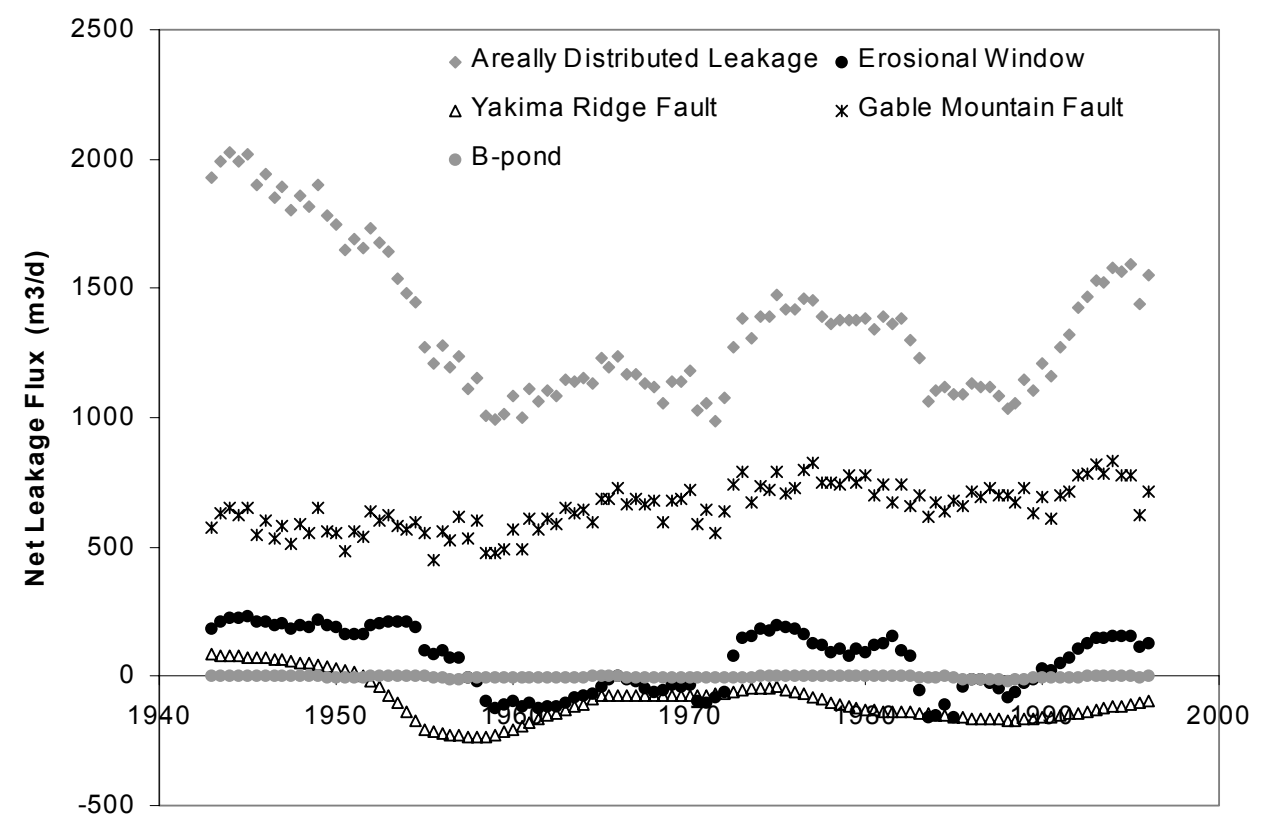

Figure 9.8. Relative Contribution of Each Basalt Leakage Feature to Net Leakage Flux

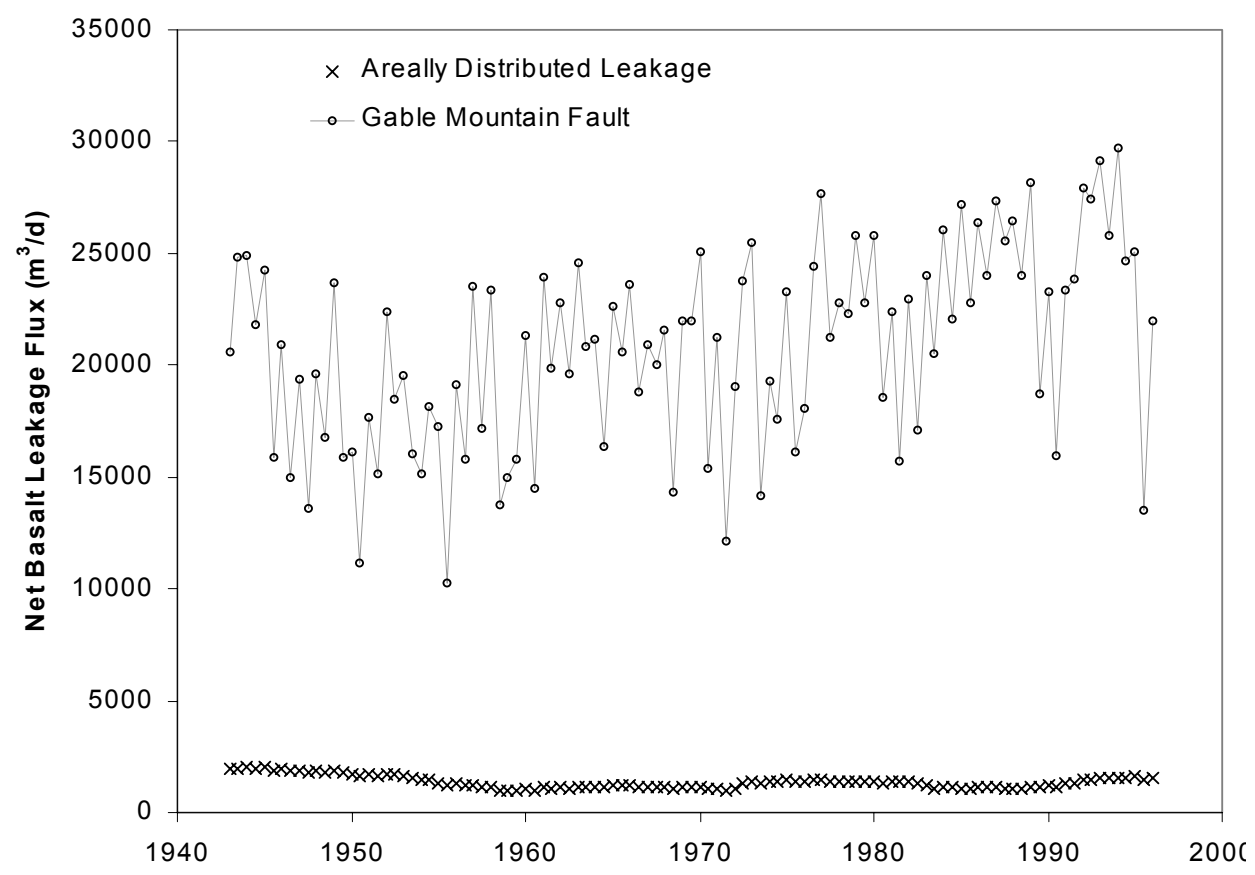

Figure 9.9. Uncorrected Leakage Flux at the Gable Mountain Fault 
It should be noted that inclusion of these high flux rates brings the total basalt leakage net flux to within the same order of magnitude as that associated with natural recharge. As stated, we believe that increased leakage in these two limited areas is unlikely and is a direct result of our incomplete model of the underlying basalts in the current implementation. The current model of the basalts, as has been discussed, represents only leakage from a time varying fixed interpretation of the potential distribution within the basalts and does not account for any of the basalt interactions that would allow the basalt potentials in these two small areas of high flux to drawdown in response to the large magnitude of the flux supplied by the basalts in these areas. Data on the basalts, where available (e.g., around the erosional window), indicate that the potential in the underlying basalts, because of the limited transmissivity of the basalt aquifer compared to that of the Hanford hydrostratigraphic unit is drawn down and follows that of the Hanford hydrostratigraphic unit, thus limiting the flux intercommunication between the systems. In the current implementation, the potential in the basalts is maintained near the two segments along the fault with out any flux related drawdown in the basalts to limit the predicted flux between the basalts and the unconfined system.

Additionally, these two areas are near the Columbia River, so the unconfined model response to these high, localized fluxes between the basalts and the unconfined system would be minimal and not likely to affect the model in a way that would be detected by the inverse procedure because the water would move directly to the Columbia River. To test this hypothesis, the calibrated basalt inclusive model (ACM-1d) was run with the fault leakage coefficient in these two high-flux areas along the Gable Mountain Fault set to zero to limit the Gable Mountain Fault-related leakage to more reasonable values (ACM-1e). Figure 9.10 shows a comparison histogram of predicted head residuals for all observations for ACM-1d and ACM-1e, and Table 9.2 compares the statistics for ACM-1e with the statistics for both the baseline

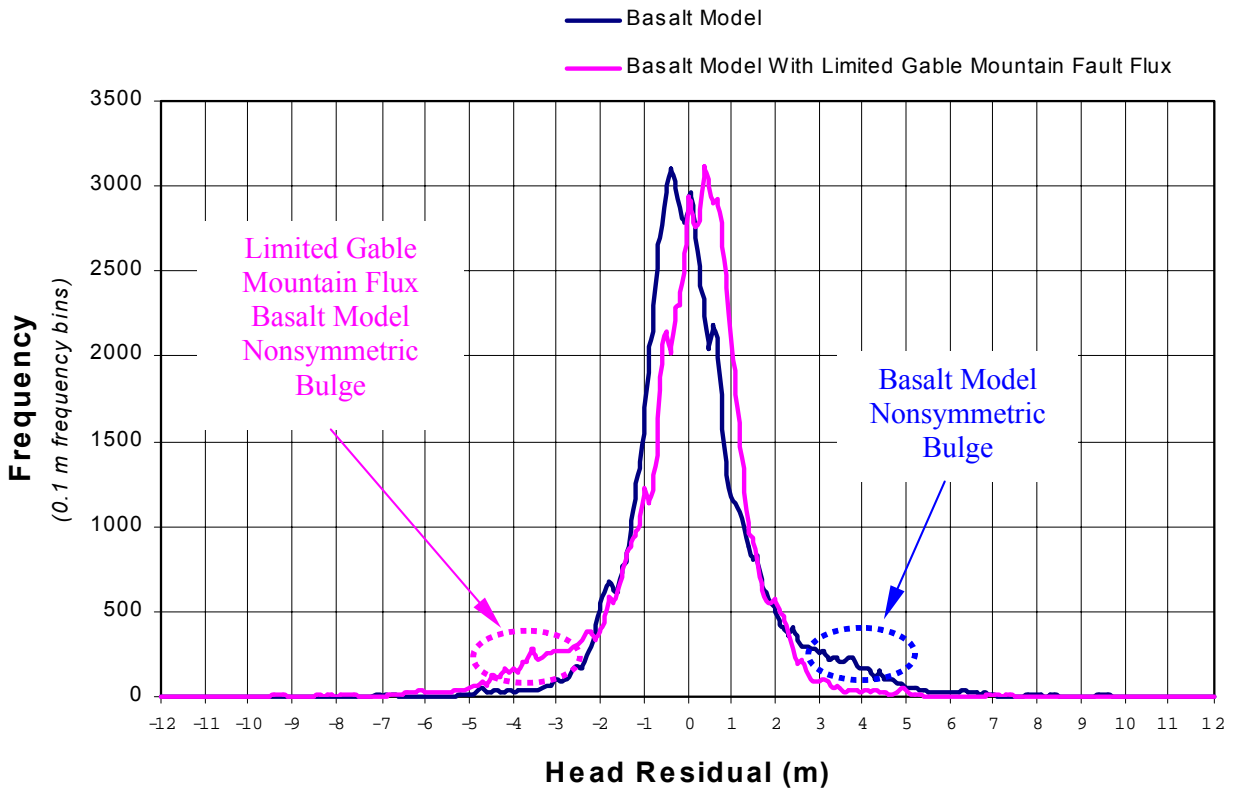

Figure 9.10. Comparison of Histogram of Predicted Head Residuals; all Observations for Best-Fit Basalt Leakage Inclusive Inverse Model (ACM-1d) and Best-Fit Basalt Leakage Inclusive Inverse Model With Limited Gable Mountain Fault Flux (ACM-1e) 
Table 9.2. Summary of Residual Error Statistics for ACM-1

\begin{tabular}{|c|c|c|c|}
\hline \multirow[b]{2}{*}{ Residual Statistic } & \multicolumn{3}{|c|}{ Inverse Case } \\
\hline & Baseline Model & $\begin{array}{l}\text { Basalt Model } \\
\text { (ACM-1d) }\end{array}$ & $\begin{array}{c}\text { Basalt With } \\
\text { Limited Gable } \\
\text { Mountain Flux } \\
\text { (ACM-1e) }\end{array}$ \\
\hline \multicolumn{4}{|l|}{ Positive Residuals } \\
\hline Number of Observations & 41719 & 34846 & 39232 \\
\hline Mean (m) & 0.87 & 1.26 & 0.87 \\
\hline Standard Deviation (m) & 0.74 & 1.34 & 0.81 \\
\hline $\operatorname{Min}(\mathrm{m})$ & 0.00 & 0.00 & 0.00 \\
\hline $\operatorname{Max}(\mathrm{m})$ & 11.76 & 11.05 & 11.77 \\
\hline \multicolumn{4}{|l|}{ Negative Residuals } \\
\hline Number of Observations & 34316 & 41189 & 36803 \\
\hline Mean (m) & -1.34 & -0.90 & -1.27 \\
\hline Standard Deviation (m) & 1.55 & 0.82 & 1.34 \\
\hline $\operatorname{Max}(\mathrm{m})$ & -11.07 & -11.87 & -11.05 \\
\hline $\operatorname{Min}(\mathrm{m})$ & 0.00 & 0.00 & 0.00 \\
\hline \multicolumn{4}{|l|}{ Overall Residuals } \\
\hline Number of Observations & 76035 & 76035 & 76035 \\
\hline Overall Mean (m) & -0.13 & 0.09 & -0.16 \\
\hline Standard Deviation $(\mathrm{m})$ & 1.62 & 1.53 & 1.53 \\
\hline Median (m) & 0.12 & -0.11 & 0.04 \\
\hline Mean Absolute Error (m) & 1.09 & 1.07 & 1.06 \\
\hline Sum of Squared Residuals $\left(\mathrm{m}^{2}\right)$ & $2.00 \mathrm{E}+05$ & $1.79 \mathrm{E} 05$ & $1.81 \mathrm{E} 05$ \\
\hline Residual Range & \multicolumn{3}{|c|}{ Percent of Total in Specified Range } \\
\hline Between 1 and $-1 \mathrm{~m}$ & 65.8 & 66.9 & 67.0 \\
\hline Between 2 and $-2 \mathrm{~m}$ & 87.1 & 87.4 & 87.1 \\
\hline Between 3 and $-3 \mathrm{~m}$ & 93.6 & 94.0 & 93.9 \\
\hline Between 4 and $-4 \mathrm{~m}$ & 97.1 & 97.3 & 97.4 \\
\hline Between 5 and $-5 \mathrm{~m}$ & 98.6 & 99.0 & 99.0 \\
\hline $\begin{array}{l}\text { Greater Than } 5 \text { or } \\
\text { Less Than }-5 \mathrm{~m}\end{array}$ & 1.4 & 1.0 & 1.0 \\
\hline
\end{tabular}

model and the ACM-1d. As indicated in the table, the statistics for ACM-1e and ACM-1d transient inverse calibrated models are virtually identical. The major difference is a slight shift in the median from slightly negative $(-0.11)$ for ACM-1d to slightly positive $(0.04 \mathrm{~m})$ for ACM-1e, as illustrated in Figure 9.10. The other noticeable difference is the shift in the non-symmetric bulge located on the right for ACM-1d and on the left for ACM-1e. None of the models (prior, baseline, ACM-1d, or ACM-1e) are able to properly handle this set of residuals and illustrate a remaining potential weakness in the conceptual models or their implementations. 
Although the Gable Mountain fault flux in the two localized areas represents a significant portion of the overall recharge entering the unconfined aquifer, it enters the system over a relatively small area near the Columbia River discharge boundary and, as our analysis shows, does not result in large head changes in the unconfined aquifer. However, this effect (if it is real) may be important for transport simulations because the additional recharge to Unit 1 could affect contaminant plume movement. The sensitivity of this parameter within the current conceptual model of basalt leakage will be investigated. Alternative conceptual models may also be proposed that will investigate the distribution of Ringold mud units along the Gable Mountain fault and their effect on leakage, and a more complete model of the uppermost basalt aquifer may be needed so the drawdown in the basalts can be modeled to account for the basalt-unconfined interactions. Another approach for determining the appropriateness of the simulated high flux rates along portions of the Gable Mountain fault will be to investigate groundwater chemistry in these areas to determine whether the chemical composition of groundwater is consistent with increased basalt leakage.

In summary, the initial basalt leakage conceptual model (ACM-1) provided reasonable estimates of intercommunication between the unconfined and upper basalt-confined aquifers and improved parameter estimates that were closer to the expected range based on previous analysis of available characterization data and the current conceptual understanding of the hydrogeologic system being simulated. However, several basalt leakage results will require additional investigation including 1) the high flux rates observed along two segments of the Gable Mountain fault (discussed above); 2) the predominant downward leakage in the vicinity of the Rattlesnake Hills constant flux boundary, which is inconsistent with the assumption inherent to this boundary condition; and 3) higher than expected leakage east of the Cold Creek fault, where high vertical gradients between the unconfined and upper basalt-confined aquifers exist but where thick, low-permeability basalt flows are expected to limit intercommunication.

\subsection{Evaluation of Transient Inverse Model}

This section provides an evaluation of the transient inverse calibration of ACM-1d using data for the historical period of Hanford operations (1943-1996). In this section, the regression results, model fit, and optimized parameter values are evaluated by examining various regression and statistical performance measures provided by UCODE (Poeter and Hill 1998). This evaluation will follow the guidelines for effective model calibration (Hill 1998) and the checklist provided as part of the UCODE distribution documentation. This section includes discussions of 1) regression measures, 2) evaluation of model fit, and 3) evaluation of optimized parameter values.

A shorthand is needed for the 14 parameters investigated during this inverse calibration effort:

$\begin{array}{lll}\text { - } & \text { K-U1 } & \text { Hanford (Unit 1) Hydraulic Conductivity Multiplier } \\ \text { - } & \text { K-U5 } & \text { Ringold (Unit 5) Hydraulic Conductivity Multiplier } \\ \text { - } & \text { K-U678 } & \text { Ringold (Unit 7) Hydraulic Conductivity Multiplier } \\ \text { - } & \text { K-U9 } & \text { Ringold (Unit 9) Hydraulic Conductivity Multiplier } \\ \text { - } & \text { SY-U1 } & \text { Hanford (Unit 1) Specific Yield Multiplier } \\ \text { - } & \text { SY-U5 } & \text { Ringold (Unit 5) Specific Yield Multiplier } \\ \text { - } & \text { F-CC } & \text { Cold Creek Valley Flux Multiplier } \\ \text { - } & \text { F-DC } & \text { Dry Creek Valley Flux Multiplier } \\ \text { - } & \text { F-NR } & \text { Natural Recharge Multiplier }\end{array}$


- F-EW Hydraulic Conductivity Multiplier Controlling Flux at the Erosional Window

- F-ADL Basalt (Unit 10) Hydraulic Conductivity Multiplier Controlling Areally Distributed Leakage

- F-YRF Basalt (Unit 10) Hydraulic Conductivity Multiplier Controlling Increased Leakage at the Yakima Ridge Thrust Fault

- F-GMF Basalt (Unit 10) Hydraulic Conductivity Multiplier Controlling Increased Leakage at the Gable Mountain Thrust Fault

- F-BP Basalt (Unit 10) Hydraulic Conductivity Multiplier Controlling Increased Leakage at B-Pond

- F-RH Rattlesnake Hills Flux Multiplier.

Additionally, a reference to a composite scaled sensitivity coefficient for a parameter will be written as $C s s$ (parameter), e.g., $C s s(F-N R)$.

\subsubsection{Evaluation of Regression Measures}

Besides the obvious failure-to-converge measure, UCODE provides additional information to evaluate whether the regression is well posed. This includes

- Marquardt Parameter, which is nonzero when the regression problem is ill-conditioned

- Parameter That Changed the Most, because the parameter for which the maximum fractional change occurs is likely to be at least a contributing problem when the regression does not converge

- The Amount of Change, the magnitude of change.

Another measure is when the number of "parameter estimate iterations" needed to converge exceeds the "on average" estimate given in Hill (1998) as approximately equal to twice the number of parameters (NP) being estimated (i.e., $2 \mathrm{NP}$ ).

Based on the phase 22 sensitivity analysis of all 15 parameters investigated for the full implementation of ACM-1, scaled sensitivity coefficient results indicated that 14 of the parameters were determinable. The hydraulic conductivity multiplier controlling flux at the erosional window had a scaled sensitivity coefficient ratio, Css(maximum)/Cs(F-EW) of 495 , which is greater than the value of $\sim 100$ discussed in the UCODE guidance document. As a result, this parameter was specified as "not to be estimated," and the subsequent phase-3 regression analysis was conducted with this parameter held at the value determined in the initial design analysis. Convergence was generally well behaved, and all the regression measures for the transient inverse calibration of ACM-1d indicated that it was generally a wellposed problem. The eight iterations for convergence were less than the "on average" estimate of 28 (i.e., $2 * \mathrm{NP}$ where $\mathrm{NP}=14$ ), and the Marquardt parameter was zero for every iteration in the regression.

Table 9.3 illustrates the numerical values for the parameter estimates and regression measures as a function of parameter estimate iteration (i). The composite scaled sensitivity coefficient ratio for the parameter with the smallest composite scaled sensitivity coefficient (Max/Min Composite Scaled Sensitivity Ratio) is also shown in Table 9.3 and it is calculated as Css(Maximum)/Css(Minimum). This ratio should always be less than $\sim 100$ for all the parameters to be estimated. 
Table 9.3. Parameter Scaling Factor Estimates and Regression Measures as a Function of Parameter Estimate Iteration (i)

\begin{tabular}{|c|c|c|c|c|c|c|c|c|c|c|c|c|c|c|c|c|}
\hline i & K-U1 & K-U5 & K-U678 & K-U9 & SY-U1 & SY-U5 & F-CC & F-DC & F-NR & F-ADL & F-YRF & F-GMF & F-BP & F-RH & $\begin{array}{c}\text { Max/Min } \\
\text { Composite } \\
\text { Scaled } \\
\text { Sensitivity } \\
\text { Ratio } \\
\end{array}$ & $\begin{array}{c}\text { Sum Sq. Wt. } \\
\text { Residuals }\end{array}$ \\
\hline 0 & 0.900 & 2.100 & 1.000 & 0.520 & 0.250 & 2.060 & 2.000 & 1.000 & 1.220 & 1.000 & 1760 & 1760 & 5300 & 4.360 & 1 & $6.80 \mathrm{E}+07$ \\
\hline 1 & 0.906 & 2.100 & 0.582 & 0.574 & 0.252 & 2.050 & 2.050 & 0.913 & 1.220 & 1.750 & 2410 & 3340 & 2990 & 4.370 & 89.2 & $6.62 \mathrm{E}+07$ \\
\hline 2 & 0.909 & 2.100 & 0.365 & 0.509 & 0.252 & 2.040 & 2.090 & 0.867 & 1.210 & 2.220 & 4250 & 6350 & 1740 & 4.410 & 91.6 & $6.47 \mathrm{E}+07$ \\
\hline 3 & 0.914 & 2.100 & 2.050 & 0.507 & 0.253 & 2.040 & 2.170 & 0.775 & 1.200 & 2.930 & 6420 & 12100 & 813 & 4.470 & 57.2 & $6.27 \mathrm{E}+07$ \\
\hline 4 & 0.925 & 2.110 & 0.152 & 0.875 & 0.245 & 2.000 & 2.330 & 0.337 & 1.170 & 4.910 & 642 & 20500 & 387 & 4.570 & 36.9 & $6.07 \mathrm{E}+07$ \\
\hline 5 & 0.921 & 2.120 & 0.084 & 0.284 & 0.248 & 1.980 & 2.570 & 0.139 & 1.130 & 7.410 & 251 & 29500 & 38.7 & 4.640 & 169.5 & $5.80 \mathrm{E}+07$ \\
\hline 6 & 0.924 & 2.070 & 0.094 & 0.539 & 0.249 & 1.960 & 2.630 & 0.062 & 1.120 & 7.750 & 139 & 28300 & 20.3 & 4.570 & 95.8 & $5.78 \mathrm{E}+07$ \\
\hline 7 & 0.920 & 2.070 & 0.096 & 0.300 & 0.248 & 1.960 & 2.640 & 0.025 & 1.100 & 8.200 & 164 & 28100 & 2.03 & 4.560 & 263.6 & $5.77 \mathrm{E}+07$ \\
\hline 8 & 0.920 & 2.070 & 0.096 & 0.310 & 0.248 & 1.960 & 2.640 & 0.024 & 1.100 & 8.190 & 163 & 28100 & 2.46 & 4.560 & 8115 & $5.80 \mathrm{E}+07$ \\
\hline
\end{tabular}

Non-determinable Parameters 


\subsubsection{Evaluation of Model Eit}

Section 9.2.1 indicated that, in general, the regression was well-posed and converged. This solution is thus the best fit for the problem posed. However, the quality of the model fit (e.g., how well it matches observations) must still be evaluated. In the rest of this section, the various statistical measures for evaluating model fit and residual statistics provided as part of the UCODE distribution will be presented and discussed to evaluate the results of the regression. Statistics on the residuals from the converged regression printed by UCODE follow:

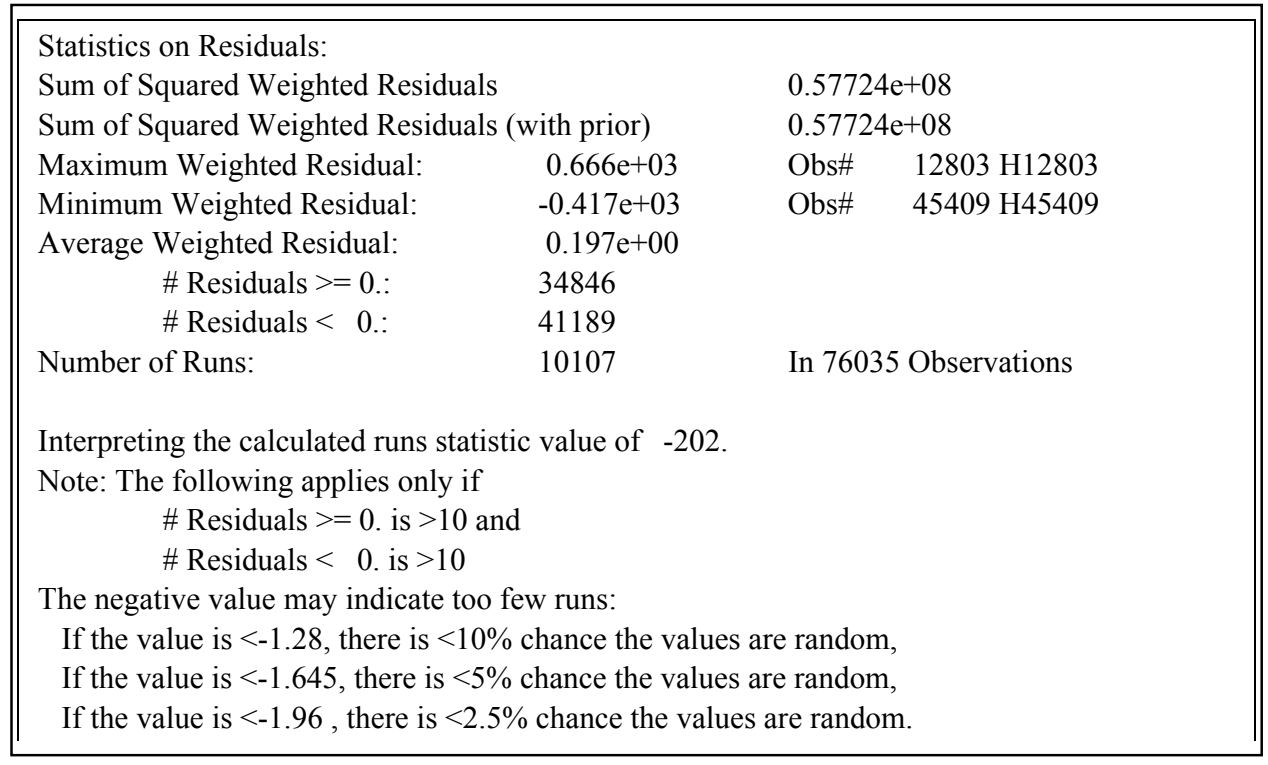

With more than 76,000 observations, it is impractical to present tables of observations, simulated values, residuals (calculated as the observations minus the simulated values), and weighted residuals. The maximum weighted residual indicates where the worst fit occurs relative to the expected fit and often reveals gross errors that can be identified and corrected. The minimum provides a context by which to judge the maximum value. An average-weighted residual near zero is needed for an unbiased model fit (usually satisfied if regression converges). The average weighted residual of 0.197 for ACM-1d was an improvement over results obtained from the baseline inverse model, which had an average weighted residual of 0.44 . This statistic will also serve as a basis for comparison against future inverse efforts examining alternative conceptual models. Hill (1998) indicates that, if weights reflect the measurement errors, weighted residuals that are on average larger than 1.0 indicate that the model is worse than would be expected given anticipated measurement error, and values smaller than 1.0 indicate that the model fits better than expected given anticipated measurement error.

The number of positive and negative residuals indicates whether the model fit is consistently low or high. Preferably, the two values are about equal. The numbers, 34846 negative and 41189 positive, are fairly evenly balanced around the average of 0.197 , as is better illustrated in the histogram in Figure 9.2. This figure provides more information about the distribution of residuals and indicates that the tails of the distribution are skewed on the positive side and thus not normally distributed. The number of test runs provides a statistic to help identify trends in spatially distributed weighted residuals since identifying trends (lack of non-randomness) by visual inspection is not always reliable. Too few or too many runs could indicate model bias. The number of runs, the runs' statistics value, and the means to interpret it are printed by UCODE (see above). For this regression the runs statistic indicates too few runs, and the 
calculated statistic indicates that there is less than a $2.5 \%$ chance the values are random. Personal communication with Eileen Poeter indicates there may be a problem with this statistic related to the way the observations are ordered in our input file because in UCODE the weighted residuals are analyzed using the sequence in which the observations are listed in the input file. Hill (1998) goes on to indicate that the runs test is included because it takes the order of the residuals into account, which is ignored in all the other summary statistics. If observations are grouped by location in transient simulations, too few runs commonly indicate positive serial correlation between residuals at individual locations. The effect of input observation ordering on the runs test will need to be investigated.

The following statistical information also provided by UCODE provides additional information about the model fit.

$\begin{array}{ll}\begin{array}{l}\text { Least-Squares Objective Function } \\ \text { (dependent variable only) }\end{array} & 0.57724 \mathrm{e}+08 \\ \quad \text { (w/parameters) } & 0.57724 \mathrm{e}+08 \\ \text { Calculated Error Variance } & 759.31 \\ \text { Standard Error of the Regression } & 27.556 \\ \text { Correlation Coefficient } & 0.99992 \\ \text { Correlation Coefficient (w/parameters) } & 0.99992 \\ \text { Maximum Likelihood Objective Function } & 0.57877 \mathrm{e}+08 \\ \text { AIC Statistic } & 0.57877 \mathrm{e}+08 \\ \text { BIC Statistic } & 0.57877 \mathrm{e}+08 \\ \text { Hannan Statistic } & 0.57877 \mathrm{e}+08\end{array}$

The weighted least-squares objective function value of $0.57724 \mathrm{e}+08$ is the same with and without parameters because no prior information was used. Given randomly distributed residuals and the same observations and weight matrix, a lower value of the least-squares objective function indicates a closer model fit to the data. This value is an improvement over the baseline inverse model's weighted least squares objective function value of $0.71381 \mathrm{e}+08$ and will provide a basis for future comparisons. Smaller values of the calculated error variance for randomly distributed residuals are desirable. Values less than 1.0 indicate that the model generally fits the data better than is consistent with the variances used to weight the observations and prior information; values greater than 1.0 indicate that the fit is worse. The standard error of the regression is the square root of the calculated error variance, and the same comments apply. The correlation coefficient with and without prior information is the correlation between weighted observed or prior information and simulated values. Correlation coefficient values below about 0.9 indicate poor model fit. The value of 0.99992 for the current regression would indicate a very good fit. The Maximum Likelihood objective function, the AIC, and BIC statistics for randomly distributed residuals can be used to compare one model with another where a lower absolute value indicate a better fitting model.

Another measure of model fit provided by UCODE uses ordered weighted residuals, which are the weighted residuals ordered smallest to largest. UCODE provides the correlation between ordered weighted residuals and normal order statistics. $\mathrm{R}_{\mathrm{N}}{ }^{2}$ values above the critical value printed by UCODE below indicate independent, normal weighted residuals. The value of 0.545 for this regression indicates the residuals are not independent normal weighted residuals. 




Generally, IF the reported CORRELATION is GREATER than the critical value, at the selected significance level (usually 5 or 10\%), the hypothesis that the weighted residuals are INDEPENDENT AND NORMALLY DISTRIBUTED would be ACCEPTED. HOWEVER, in this case, conditions are outside of the range of published critical values as discussed below.

The sum of the number of observations and prior information items is 76035 which is greater than 200, the maximum value for which critical values are published. Therefore, the critical values for the 5 and $10 \%$ significance levels are greater than 0.987 and 0.989 , respectively.

CORRELATIONS GREATER THAN these critical values suggest that, probably, the weighted residuals ARE INDEPENDENT AND NORMALLY DISTRIBUTED.

Correlations LESS THAN these critical values clearly indicate that we CAN REJECT the hypothesis.

The Kolmogorov-Smirnov test can be used to further evaluate the residuals.

In general, comparison of model fit statistics between the baseline model and ACM-1 indicate a slight improvement in model fit for the latter. The average weighted residual statistic of 0.197 and the correlation coefficient statistic of 0.99992 would indicate a good model fit. However, the other measures looking for patterns and trends in the residuals indicate the model fit is poor as indicated by the value of the calculated error variance, the 0.545 value for the correlation between ordered weighted residuals and normal order statistics which indicates the residuals are not independent, normal weighted residuals, and the runs test statistic which indicates trends are present in the spatially distributed weighted residuals. For a good model the residuals should be random. These measures, as indicated, continue to build on the baseline set of values for future reference as different conceptual models or conceptual model components are examined.

\subsubsection{Evaluation of Optimized Parameter Values}

Model error or fit may also be evaluated by examining the optimized parameter values to determine if they are unrealistic and if the confidence intervals on the optimized values do not include reasonable values. The section evaluates the optimized parameter values through the discussions of 1) estimated model parameters, 2) parameter-correlation coefficients, and 3) estimated confidence intervals in parameter estimates. 


\subsubsection{Estimated Model Parameter Values}

The optimal values of the parameters considered in the inverse calibration were calculated based on how well they reproduced the historical measurements of water levels during the period between 1943 and 1996. The objective function evaluated by the inverse calibration for the 1943 to 1996 period is the sum of the squared weighted residuals between simulated water levels and the approximately 76,000 water-level measurements made over the calibration period. The intent of the inverse-calibration procedure is to find the optimal combinations of parameters that minimize the objective function and to examine the various statistical measures that represent the quality of the regression.

Changes in the objective function during the calibration process (Table 9.3) resulted in the optimal combination of parameter scaling factors presented in Table 9.4. The baseline inverse calibration of the selected model to the 1943-1996 period resulted in an overall reduction of the objective function (i.e., the sum of the squared residuals) by about an order of magnitude over the prior model. The ACM-1 transient inverse calibration resulted in an additional 19 percent reduction in the objective function. The largest calculated changes to the base-parameter values associated with hydraulic properties (hydraulic conductivity and specific yield) were related to the hydraulic conductivity reduction of the aquitard comprising Ringold Units 6, 7, and 8. The largest changes to the parameters related to the boundary

Table 9.4. Summary of Parameter Scaling Factor Estimates Derived for the Basalt Leakage Inclusive Inverse Model (ACM-1d)

\begin{tabular}{||c|c||}
\hline \multicolumn{1}{||}{ Scaling Factor Description } & $\begin{array}{c}\text { Scaling Factor } \\
\text { Estimates }\end{array}$ \\
\hline \multicolumn{1}{||}{ Hydraulic Conductivity Distributions Within } \\
\hline Hanford Formation (Unit 1) & 0.92 \\
\hline Ringold Formation (Unit 5) & 2.07 \\
\hline Ringold Formation (Units 6, 7, and 8) & $9.62 \mathrm{E}-2$ \\
\hline Ringold Formation (Unit 9) & 0.31 \\
\hline Specific Yield of the & 0.25 \\
\hline Hanford Formation (Unit 1) & 1.96 \\
\hline Ringold Formation (Unit 5) & 2.64 \\
\hline Boundary Fluxes & $2.37 \mathrm{E}-2$ \\
\hline Cold Creek Valley & 4.56 \\
\hline Dry Creek Valley & 1.10 \\
\hline Rattlesnake Hills & Not Estimated \\
\hline Surface Natural Recharge & 8.19 \\
\hline Basalt Leakage & 163 \\
\hline Erosional Window & 28100 \\
\hline Areally Distributed & Not Determinable \\
\hline Yakima Ridge Thrust Fault
\end{tabular}


flux was associated with the Dry Creek model boundary, which, as discussed in Section 9.1.6, was affected by the inclusion of increased basalt leakage at the Yakima Ridge fault. The parameter value that changed the least was the multiplier for hydraulic conductivity of the Hanford formation (Unit 1). Although including basalt leakage in the current inverse model did little to improve the estimates of specific yield for Units 1 and 5 (Section 9.1.3), significant improvement was realized in the natural recharge estimate (Section 9.1.5).

\subsubsection{Parameter-Correlation Coefficients}

Part of the output of the inversing process as implemented in UCODE are the correlation coefficients of all parameters estimated in the process. In UCODE, correlation coefficients are defined as the covariance between two parameters divided by the product of their standard deviations (Hill 1998). According to Hill (1998), correlation coefficients range from -1.0 to 1.0 , with values very close to -1.0 and 1.0 indicative of parameter values that cannot be uniquely estimated with the observations used in the regression. As a diagnostic output for evaluating potential significant correlation coefficients, UCODE identifies parameter pairings with correlation coefficients between 0.85 and $0.9 ; 0.9$ and 0.95 ; and greater than 0.95. Guidance in training materials for UCODE (Hill et al. 1999) and in previous work described in Hill et al. (1998) has suggested that parameter correlations in these ranges, particularly those in excess of 0.95 , may be indicative of problematic strong correlation between parameter pairs. Strong correlation between two or more parameter values would bring into question the optimized estimates for the parameters in question. These parameter values would require some additional testing to assess the uniqueness of the optimized values estimated.

The correlation-coefficient matrix corresponding to the parameters estimated in the baseline transient inverse calibration is summarized in Table 9.5. This summary indicates that no strong correlation was found among the parameter values estimated in the inversing process.

\subsubsection{Confidence Intervals on Estimated Parameters}

Another important output of the inversing process using UCODE is the calculation of confidence intervals around final parameter estimates. Technically, the confidence interval around a parameter estimate is a range that has a stated probability of containing the true value of the parameter. Narrow confidence intervals around a parameter estimate are a general indication or measure of the level of precision in the parameter estimate, given the types of observations used in the regression analysis. Narrow intervals imply greater precision; large intervals indicate less confidence in the optimized parameter value.

A summary of 95 percent confidence intervals and the estimated value for each parameter considered in the inverse analysis is summarized in Table 9.6. Calculated confidence intervals around all of the parameters, with the exception of increased leakage at B-Pond, which was a non-determinable parameter, exhibited a relatively narrow range, suggesting a good level of precision in the final parameter estimates. 
Table 9.5. Parameter Cross-Correlation Matrix Plot (ACM-1d)

\begin{tabular}{|c|c|c|c|c|c|c|c|c|c|c|c|c|c|c|}
\hline & K-U1 & K-U5 & K-U678 & K-U9 & SY-U1 & SY-U5 & F-CC & F-DC & F-NR & F-ADL & F-YRF & F-GMF & F-BP & F-RH \\
\hline$\overline{\text { K-U1 }}$ & $\overline{1}$ & 0.131 & 0.056 & 0.181 & 0.106 & 0.177 & 0.225 & "-0.102 & 0.569 & "-0.007 & "-0.025 & 0.153 & -0.149 & $\overline{0.068}$ \\
\hline$\overline{\text { K-U5 }}$ & 0.131 & 1 & -0.154 & -0.347 & 0.179 & -0.104 & 0.058 & 0.160 & 0.341 & -0.030 & -0.363 & -0.035 & -0.083 & 0.192 \\
\hline 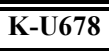 & 0.056 & -0.154 & 1 & 0.414 & -0.024 & -0.089 & 0.347 & 0.041 & 0.080 & 0.734 & -0.041 & -0.123 & 0.026 & -0.224 \\
\hline 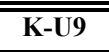 & 0.181 & -0.347 & 0.414 & 1 & 0.022 & -0.045 & 0.203 & -0.009 & 0.058 & 0.129 & -0.131 & -0.048 & 0.116 & -0.145 \\
\hline $\begin{array}{l}\text { SY-U1 } \\
\end{array}$ & 0.106 & 0.179 & -0.024 & 0.022 & 1 & -0.060 & -0.081 & -0.030 & 0.310 & -0.075 & -0.017 & 0.049 & -0.055 & 0.140 \\
\hline 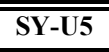 & 0.177 & -0.104 & -0.089 & -0.045 & -0.060 & 1 & 0.382 & 0.113 & 0.293 & -0.142 & 0.148 & -0.038 & -0.014 & -0.149 \\
\hline  & 0.225 & 0.058 & 0.347 & 0.203 & -0.081 & 0.382 & 1 & -0.345 & -0.021 & 0.396 & -0.020 & -0.004 & -0.025 & 0.144 \\
\hline$\overline{\text { F-DC }}$ & -0.102 & 0.161 & 0.041 & -0.009 & -0.030 & 0.113 & -0.345 & 1 & -0.085 & 0.021 & 0.253 & 0.002 & 0.014 & 0.042 \\
\hline $\begin{array}{l}\text { F-NR } \\
\end{array}$ & 0.569 & 0.341 & 0.080 & 0.058 & 0.310 & 0.293 & -0.021 & -0.085 & 1 & 0.012 & -0.069 & -0.166 & -0.085 & -0.497 \\
\hline 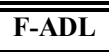 & -0.007 & -0.030 & 0.734 & 0.129 & -0.075 & -0.142 & 0.396 & 0.021 & 0.012 & 1 & -0.047 & -0.096 & -0.011 & -0.184 \\
\hline $\begin{array}{l}\text { F-YRF } \\
\end{array}$ & -0.025 & -0.363 & -0.041 & -0.131 & -0.017 & 0.148 & -0.020 & 0.253 & -0.069 & -0.047 & 1 & 0.024 & -0.011 & -0.185 \\
\hline $\begin{array}{l}\text { F-GMF } \\
\end{array}$ & 0.153 & -0.035 & -0.123 & -0.048 & 0.049 & -0.038 & -0.004 & 0.002 & -0.166 & -0.096 & 0.024 & 1 & -0.032 & 0.126 \\
\hline$\overline{\overline{F-B P}}$ & -0.149 & -0.083 & 0.026 & 0.116 & -0.055 & -0.014 & -0.025 & 0.014 & -0.085 & -0.011 & -0.011 & -0.032 & 1 & -0.036 \\
\hline$\overline{\text { F-RH }}$ & 0.068 & 0.192 & -0.224 & -0.145 & 0.140 & -0.149 & 0.144 & 0.042 & -0.497 & -0.184 & -0.185 & 0.126 & -0.036 & \\
\hline
\end{tabular}


Table 9.6. Parameter Scaling Factor Estimates and Associated Confidence Intervals (ACM-1d)

\begin{tabular}{|l|c|c|c||}
\hline $\begin{array}{c}\text { Scaling Factor } \\
\text { Description }\end{array}$ & $\begin{array}{c}\mathbf{9 5} \% \\
\text { Confidence Interval }\end{array}$ & $\begin{array}{c}\text { Best Fit } \\
\text { Estimate }\end{array}$ & $\begin{array}{c}\mathbf{- 9 5} \% \\
\text { Confidence Interval }\end{array}$ \\
\hline K-U1 & 0.912 & 0.92 & 0.28 \\
\hline K-U5 & 2.05 & 2.07 & 2.09 \\
\hline K-U678 & 0.0085 & 0.0096 & 0.011 \\
\hline K-U9 & 0.22 & 0.31 & 0.44 \\
\hline SY-U1 & 0.24 & 0.25 & 0.26 \\
\hline SY-U5 & 1.93 & 1.96 & 1.98 \\
\hline F-CC & 2.60 & 2.64 & 2.69 \\
\hline F-DC & 0.0026 & 0.024 & 0.22 \\
\hline F-NR & 1.05 & 1.10 & 1.16 \\
\hline F-ADL & 7.47 & 8.19 & 8.98 \\
\hline F-YRF & 70.4 & 163 & 378 \\
\hline F-GMF & 25900 & 28100 & 30500 \\
\hline F-BP & $9.98 \mathrm{E}-08$ & 2.46 & $6.06 \mathrm{E}+07$ \\
\hline F-RH & 4.46 & 4.56 & 4.66 \\
\hline
\end{tabular}




\subsection{Summary and Conclusions}

The primary objective of this inverse modeling effort was to investigate the effects of intercommunication between the Hanford Site unconfined aquifer and the underlying upper basalt confined aquifer and to determine whether the inclusion of basalt leakage could improve parameter estimation results and overall model fit. The inverse calibration methodology, which was developed during the baseline inverse calibration effort and is based on linking the Hanford SGM with UCODE, provides a good working tool for evaluating alternative interpretations of components of the site conceptual models. UCODE is a universal inverse modeling code developed jointly by the U.S. Geological Survey (USGS) and International Groundwater Modeling Center (IGWMC) of the Colorado School of Mines.

Basalt leakage in the SGM was incorporated by adding basalt features to the baseline model in a stepwise fashion to investigate each feature's sensitivity and relationship with other estimated parameters. Features that were selected for investigation included areally distributed leakage, increased leakage at an erosional window near Gable Mountain/Gable Butte and a smaller erosional feature near B-Pond, and increased leakage along fault zones. In general, goodness-of-fit measures for the basalt leakage inclusive model (ACM-1) were somewhat improved over the same measures for the baseline inverse model for the full calibration period from 1943 to 1996, which represents the entire period of Hanford Site operations. However, the most noteworthy improvement in the ACM-1 transient inverse calibrated model is not associated with overall model fit but with incorporation of a more complex conceptual model. The resulting parameter estimates were closer to the expected range based on previous analysis of available characterization data and the current conceptual understanding of the hydrogeologic system being simulated. Although parameter estimates were improved, some parameters continue to take on unrealistic values, indicating that additional conceptual model improvements are needed.

The baseline transient inverse calibration effort significantly improved the capability of the model to simulate historical trends in water table changes over the entire site. The improved inversing methodology provided in UCODE and the additional information provided in the longer period of calibration (i.e., 1943-1996) were contributing factors that improved the ability of the recalibrated prior model to simulate historical trends in water-table changes. All goodness-of-fit measures were significantly improved over measures of fit for the previously calibrated prior model for the same simulation period. The most noteworthy improvements realized by the baseline transient inverse calibration was its capability to fit historical trends of water-table changes and mound building observed near major discharge facilities in the 200 West Area. This improvement in the overall fit resulted in improved statistical performance in all categories (mean residual, range of residuals, and sum of squared residuals) for the 1943-1996 period of calibration.

Comparison of spatial and temporal distributions of residual errors between the baseline and ACM-1 models indicated that a measurable improvement in overall model fit was realized for ACM-1 over that observed for the baseline inverse model. The sum of squared residuals was reduced 10 percent from a baseline value of $2.00 \times 10^{5}$ to $1.79 \times 10^{5}$. Comparison of hydraulic conductivity distributions in the Hanford and uppermost Ringold formations (Unit 5) indicated a relatively small change between the baseline inverse model and ACM-1, with only a 2 percent increase in the Unit 1 multiplier and an 8 percent decrease in the Unit 5 multiplier. Results for these parameters were found to be well within the reasonable range of previous estimates. Parameter estimation results also indicated that the hydraulic 
conductivity of Unit 7 should be reduced to a value similar to that of the fine-grained materials of Unit 6 and Unit 8 , resulting in a thicker aquitard unit comprising Units 6,7, and 8 at locations where all three layers are present. This inverse result for Units 6,7 , and 8 is consistent with other interpretations of this unit (Lindsey 1995) in which Units 6, 7, and 8 were interpreted as a single mud unit with discontinuous coarse unit inclusions, while the interpretation used in the prior and baseline models interprets the same stratigraphic horizon as a continuous mud layer (Unit 6) over a continuous conductive layer (Unit 7) underlain by another continuous mud layer (Unit 8). The best-fit estimates of natural recharge for ACM-1 were significantly improved over those for the baseline inverse. The best-fit estimates for natural recharge in the baseline inverse model were about 71 percent higher than previous estimates, which resulted in unreasonable recharge estimates over a portion of the site (i.e., where coarse-grained sediments exist at the surface). Results from ACM-1 indicate only a 10 percent increase over the previous estimates, which is well within the range of natural recharge values considered reasonable. As postulated based on results of the baseline inverse effort, consideration of the interaction with the uppermost basalt confined aquifer improved the estimates of natural recharge by supplying a portion of the areally distributed flux entering the model domain that was needed to meet the objective function.

The best-fit estimate for the specific yield of the Hanford formation (Unit 1) and the Ringold Formation (Unit 5) (0.06 and 0.2, respectively), and associated confidence limits developed by the inverse calibration, were not found to be consistent with reasonable ranges summarized in previous analyses of the hydraulic properties of these units. In particular, the best-fit estimate (0.0625) for the specific yield of the Hanford formation (Unit 1) and the associated confidence limits developed by the inverse calibration were not found to be consistent with 1) reasonable ranges summarized in previous analyses $(0.1$ to 0.3$)$, 2) descriptions of the facies for these units (e.g., some facies are described as open work gravels), or 3) the depositional process (i.e., cataclysmic floods that inundated the Pasco Basin). Similarly, the bestfit estimate (0.196) for the specific yield of the Ringold Formation Unit 5 and the associated confidence limits developed by the inverse calibration were found to be inconsistent with 1) general interpretations for this unit and the range of previous estimates $(0.05$ to 0.2$), 2)$ the facies description for Unit 5 (i.e., a clast-to-matrix-supported pebble-to-cobble gravel with a fine-to-medium sand matrix with some lenticular sand and silt interbeds), or 3) wet sieve analyses of outcrop and intact core samples that indicate grain size distributions that are bimodal with $67 \%$ by weight pebbles and cobbles and the remainder consisting of medium- to fine-grained sand with mud content less than $5 \%$ by weight. The inconsistencies between the calibrated values and the prior information for both the Hanford and Ringold formations suggest that processes other than those considered in the numerical implementation of ACM-1 require evaluation. Other processes that may be evaluated in future inverse calibration efforts for their ability to provide more realistic specific yield estimates are the inclusion of facies-based zonation of hydraulic properties for the main transmissive model layers (i.e., Units 1 and 5) and uncertainty in the time required for wastewater discharges applied at ground surface to migrate through the vadose zone.

The simulated distribution of basalt leakage over the model domain was generally consistent with the conceptual model of basalt intercommunication, with downward leakage occurring throughout the area affected by the groundwater mound resulting from 200 Area wastewater disposal activities and upward leakage occurring throughout the eastern portion of the site. In addition, the simulated leakage response at the erosional window near Gable Mountain/Gable Butte, based on the general shape of the leakage response curve and results from previous design analysis, provides a reasonable representation of basalt leakage at this location. However, there were several basalt leakage results that were suspect and will require additional investigation during follow-on studies of alternative conceptual models. This includes 
the unrealistic flux values from the Gable Mountain fault along two segments of the fault close to the Columbia River, one to the northeast of Gable Butte and the other to the southwest of Gable Mountain. Preliminary investigations indicate these unrealistic values may be related to the current implementation of intercommunication between the unconfined and upper basalt confined aquifer systems.

In summary, the baseline three-dimensional transient inverse model for estimating site-wide scale flow parameters, including their uncertainties, using data on the transient behavior of the unconfined aquifer system over the entire historical period of Hanford Site operations, has been modified to account for the effects of basalt intercommunication between the Hanford unconfined aquifer and the underlying upper basalt confined aquifer. Both the baseline and ACM-1 applications of this newly developed methodology considered only the groundwater flow component and corresponding observational data set used in the three-dimensional transient inverse calibration efforts. Subsequent efforts will examine both flow and transport. Comparisons of the goodness-of-fit measures and parameter estimation results for the ACM-1 transient inverse calibrated model with those from previous SGM modeling efforts illustrate that the new three-dimensional transient inverse model approach will strengthen the technical defensibility of the final calibrated model(s) and provide the ability to incorporate uncertainty in model predictions related to both conceptual model and parameter uncertainty. These results, however, indicate that additional improvements are required to the current conceptual model framework. An investigation was initiated at the end of this basalt inverse modeling effort to determine whether facies-based zonation of Units 1 and 5 would improve specific yield parameter estimation results. A description of the justification and methodology used to develop this zonation is discussed; however, results were not obtained in time to be included in this report. Studies are under way to implement and test these and other improvements to the conceptual model. 


\section{Appendix}

Comparison of Selected Plots of Water Table Elevations and Head Residuals from Simulation of Hanford Wastewater Discharges (1943-1996) Using Baseline Model and Alternative Conceptual Model (ACM) 


\section{Appendix}

Comparison of Selected Plots of Water Table Elevations and Head Residuals from Simulation of Hanford Wastewater Discharges (1943-1996) Using Baseline and Alternative Conceptual Models (ACM) 


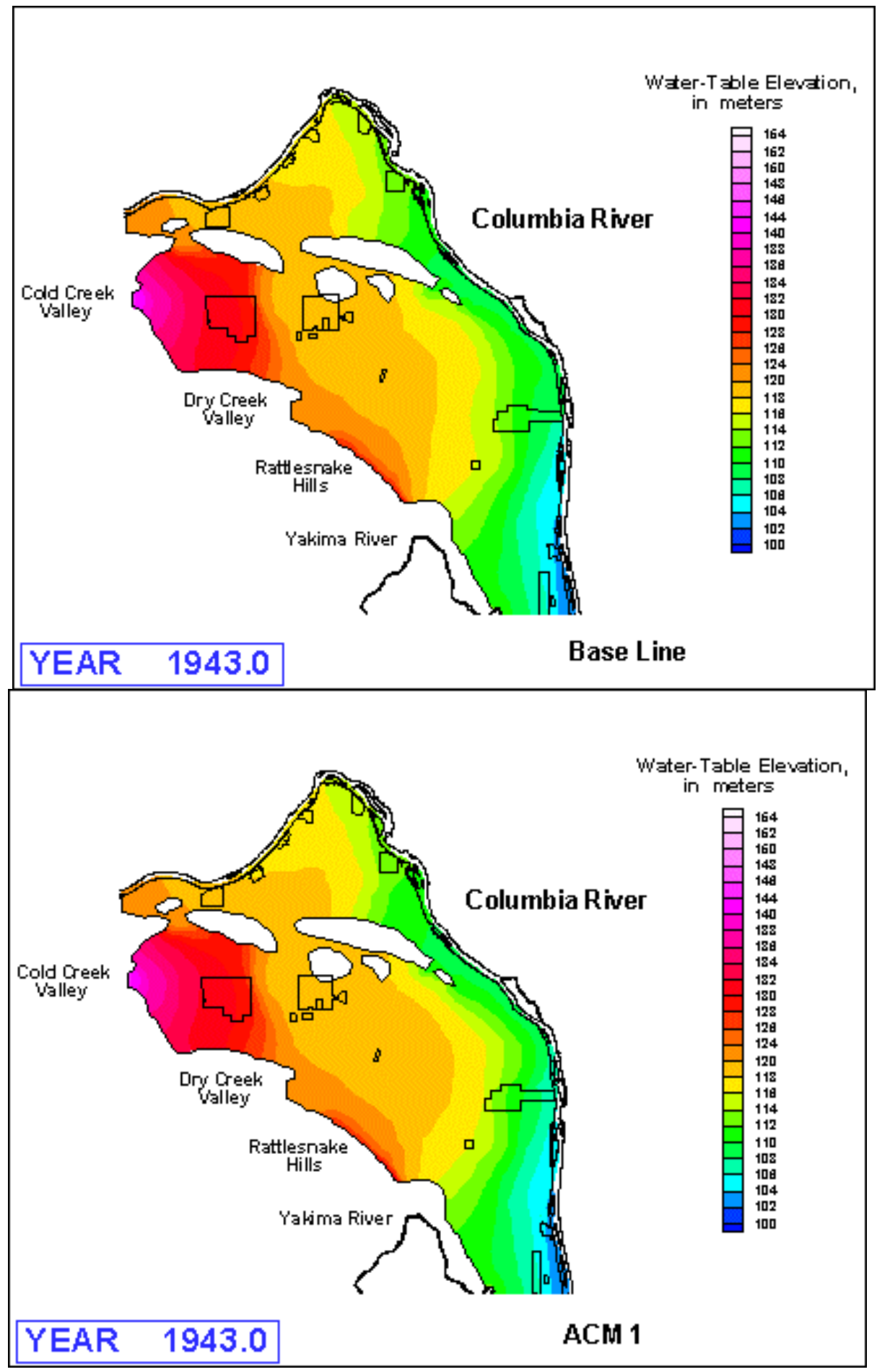

Figure A.1a. Simulated Water-Table Elevations for 1943 




Figure A.1b. Simulated Water-Table Elevations for 1950 


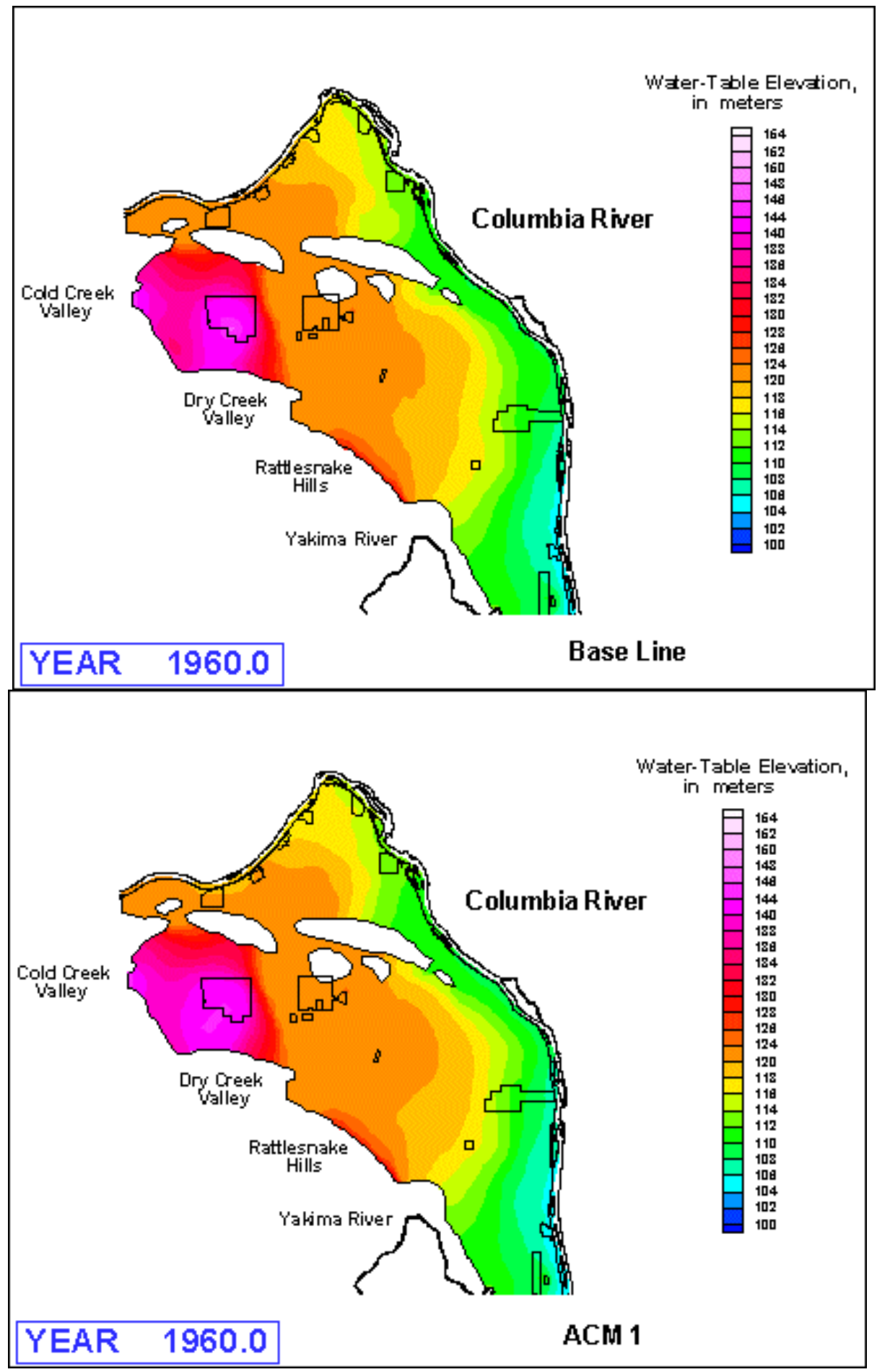

Figure A.1c. Simulated Water-Table Elevations for 1960 


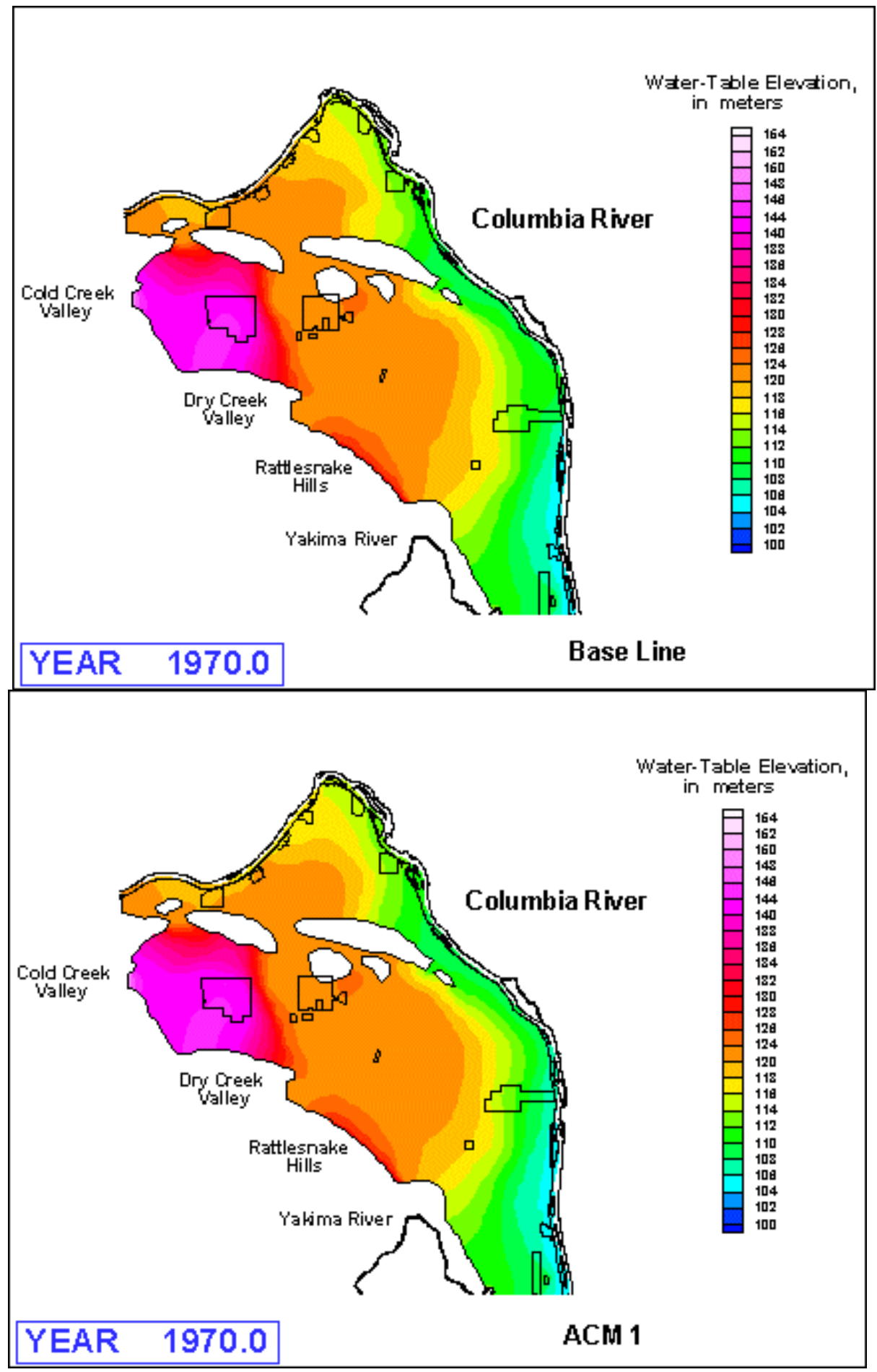

Figure A.1d. Simulated Water-Table Elevations for 1970 


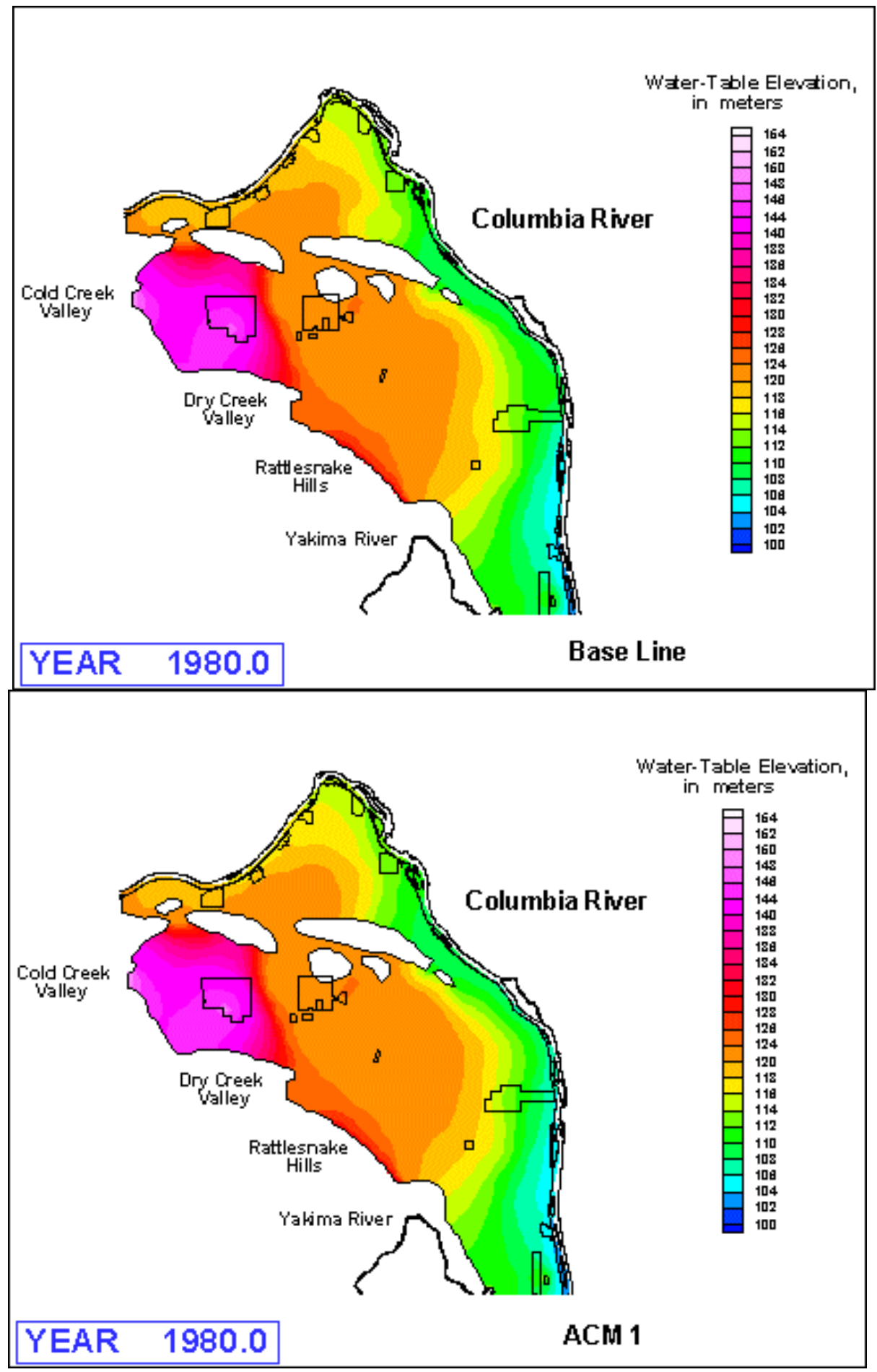

Figure A.1e. Simulated Water-Table Elevations for 1980 


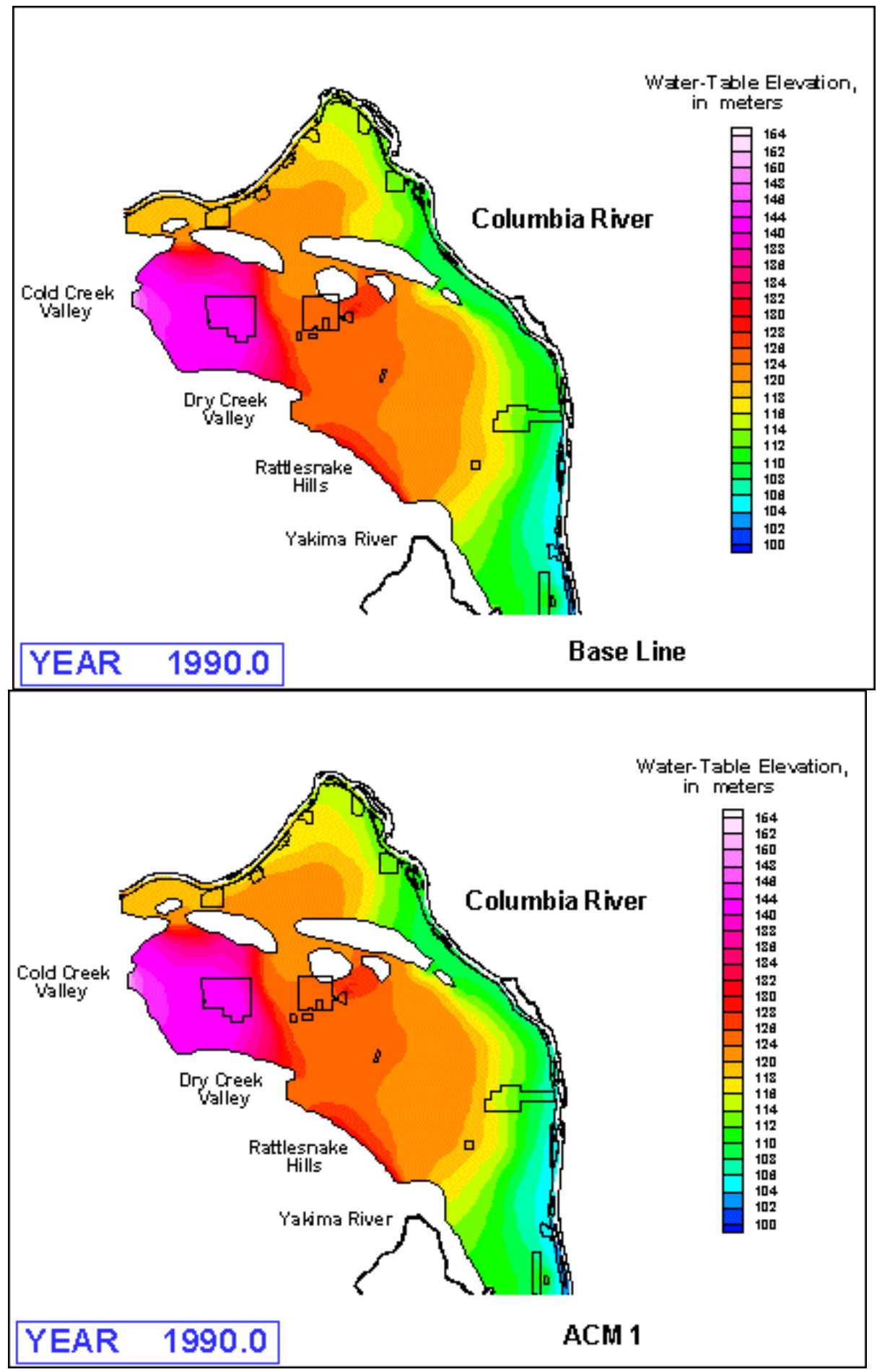

Figure A.1f. Simulated Water-Table Elevations for 1990 


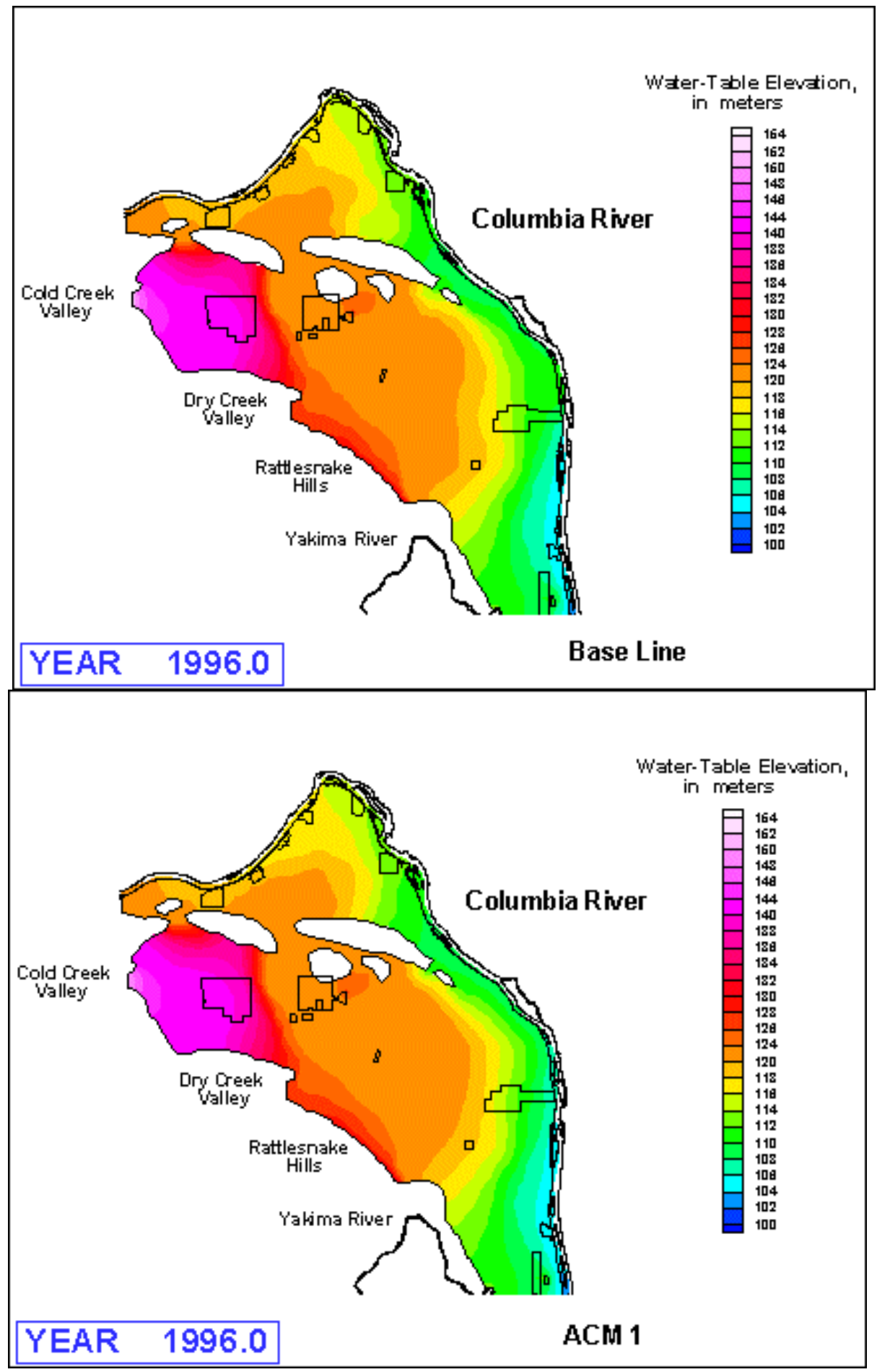

Figure A.1g. Simulated Water-Table Elevations for 1996 


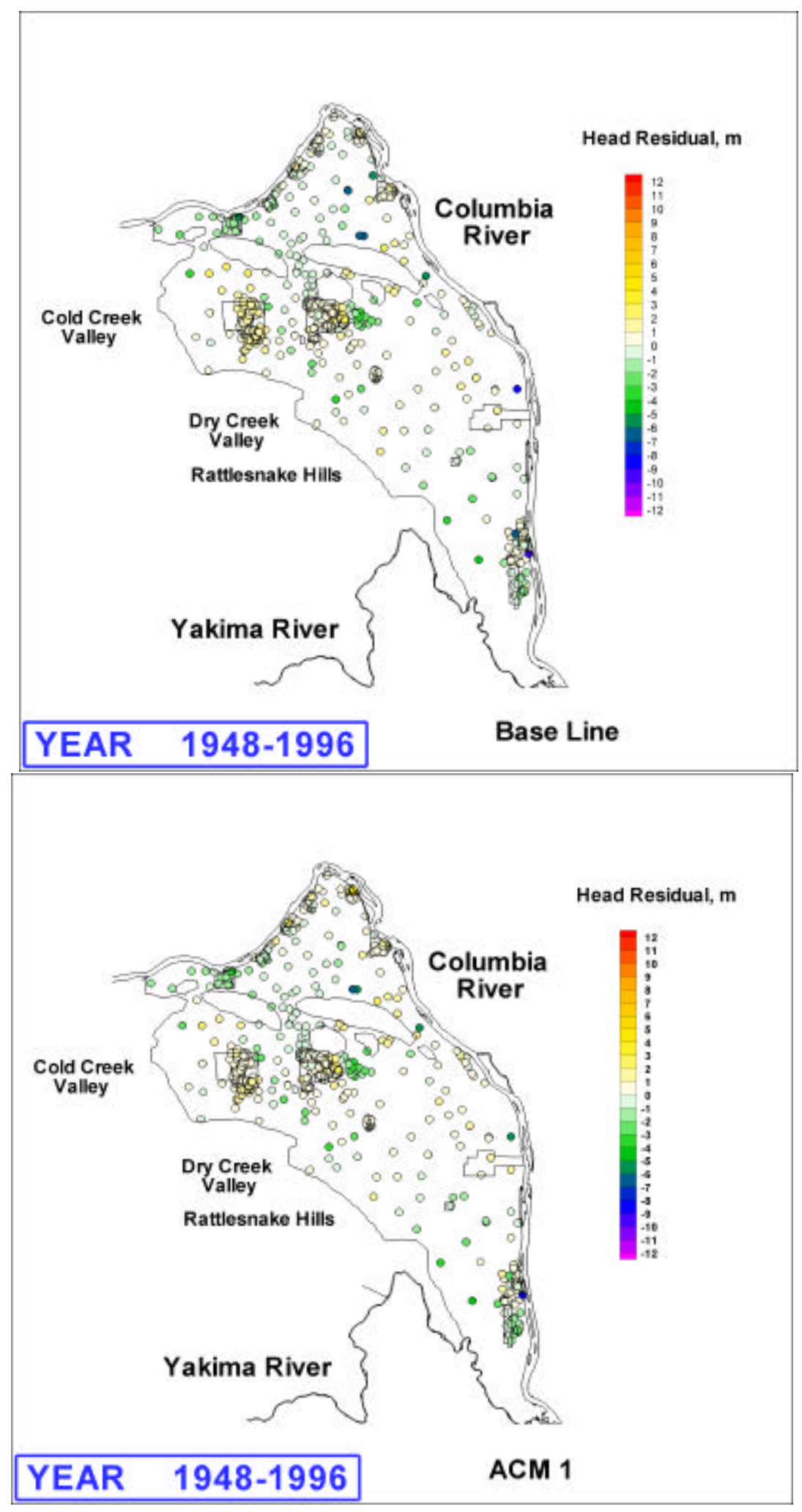

Figure A.2a. Hydraulic Head Residuals (Simulated - Measured Water Levels) for 1948-1996 


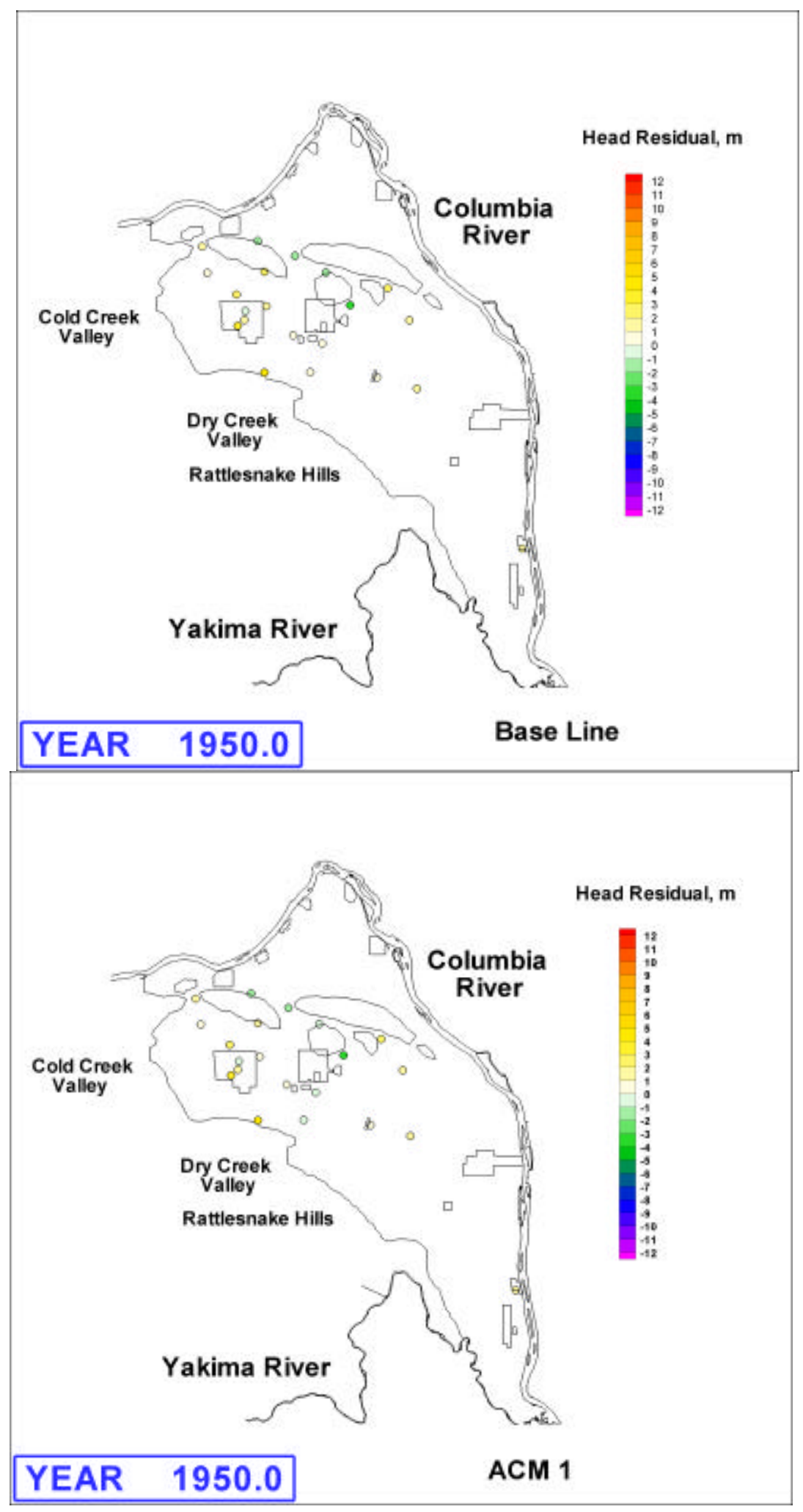

Figure A.2b. Hydraulic Head Residuals (Simulated - Measured Water Levels) for 1950 


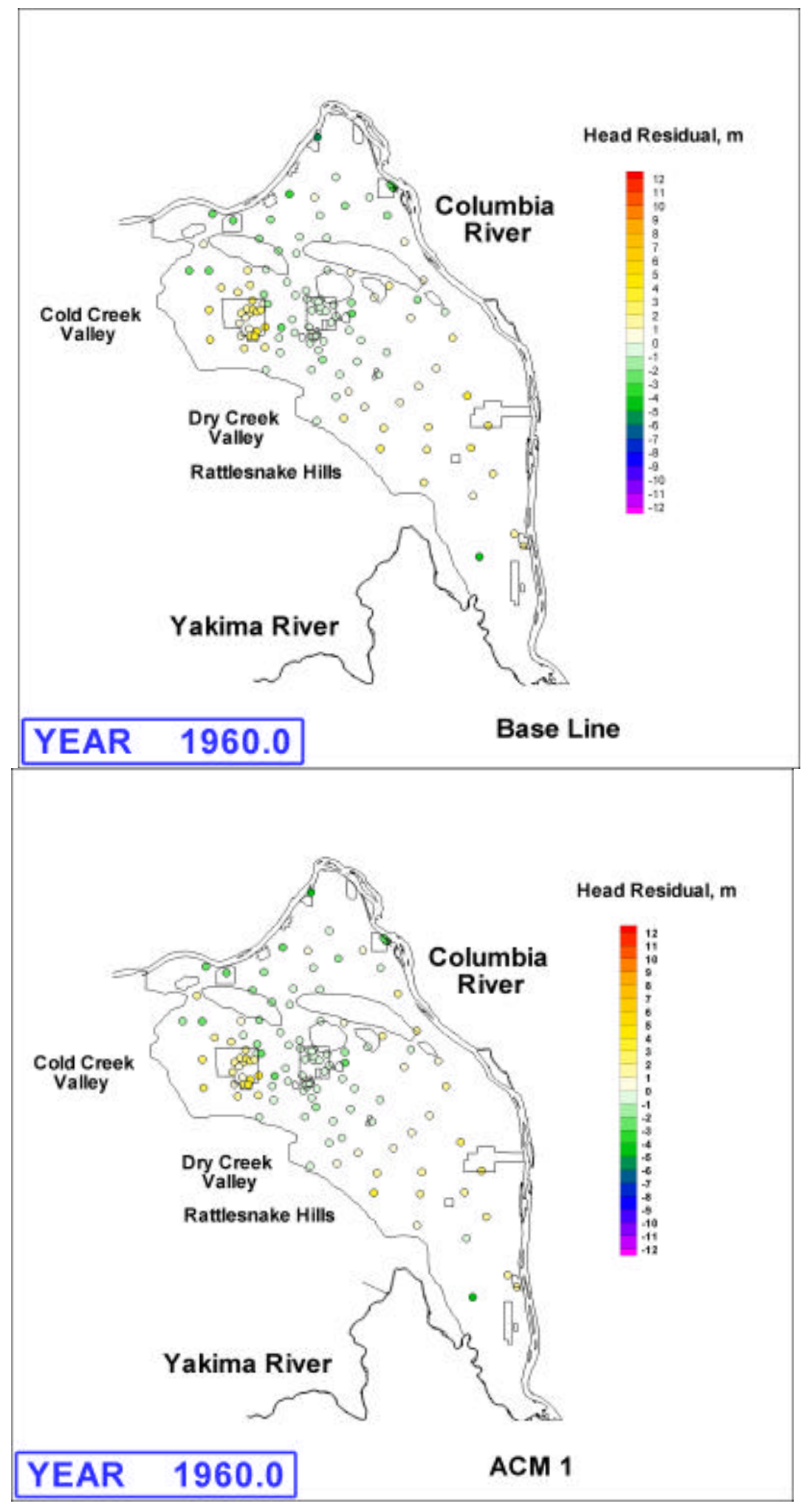

Figure A.2c. Hydraulic Head Residuals (Simulated - Measured Water Levels) for 1960 


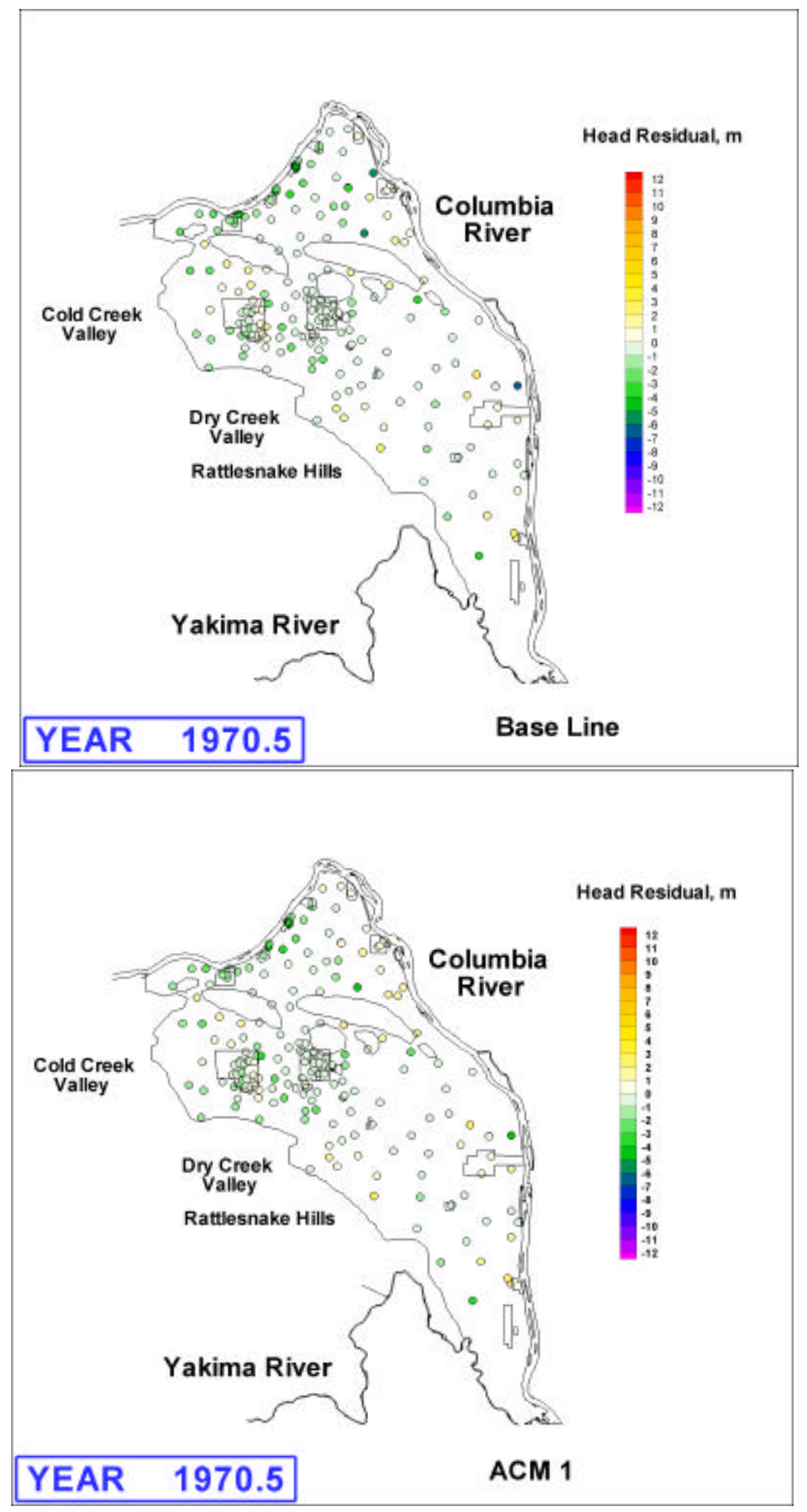

Figure A.2d. Hydraulic Head Residuals (Simulated - Measured Water Levels) for 1970 


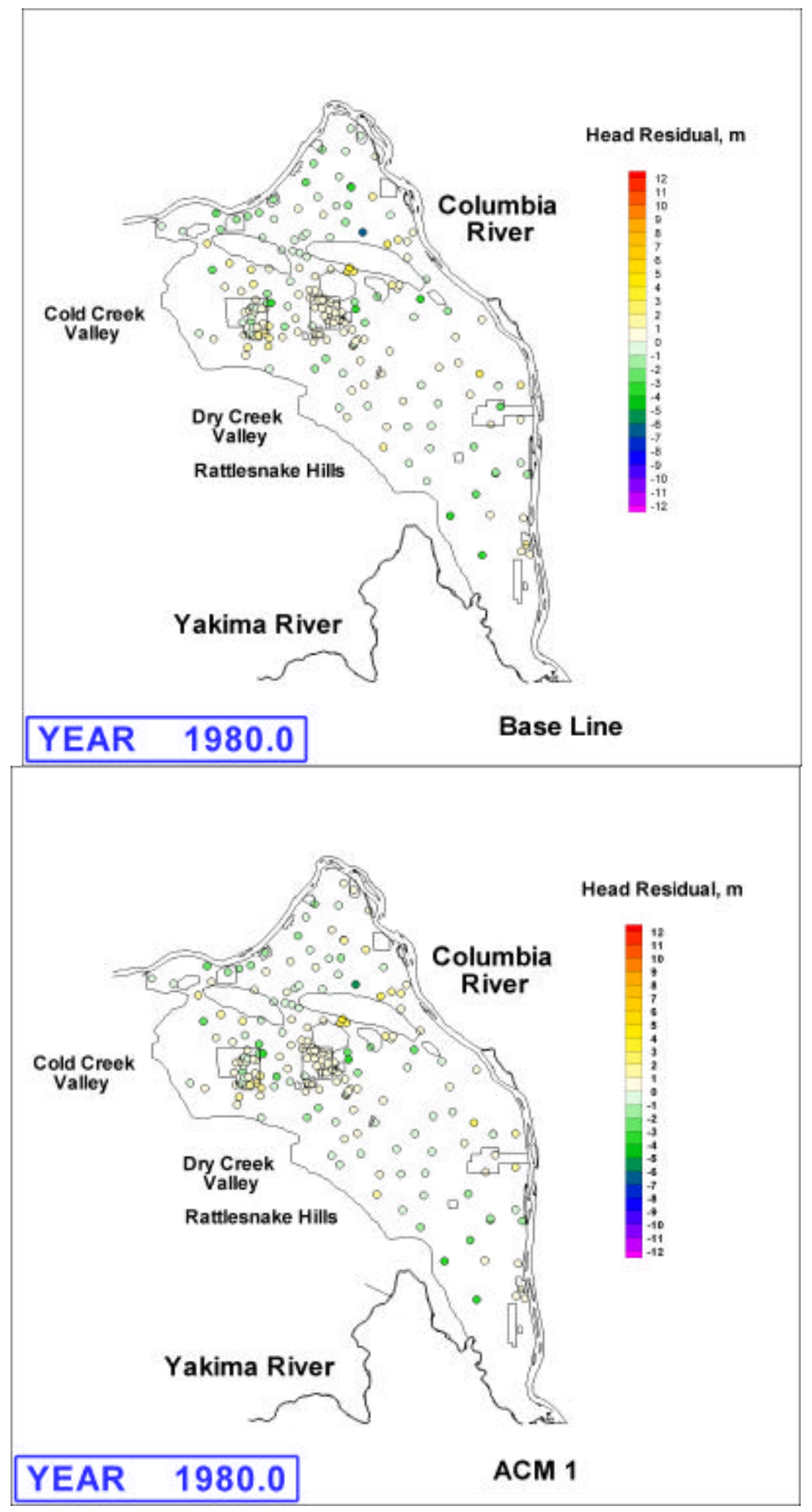

Figure A.2e. Hydraulic Head Residuals (Simulated - Measured Water Levels) for 1980 


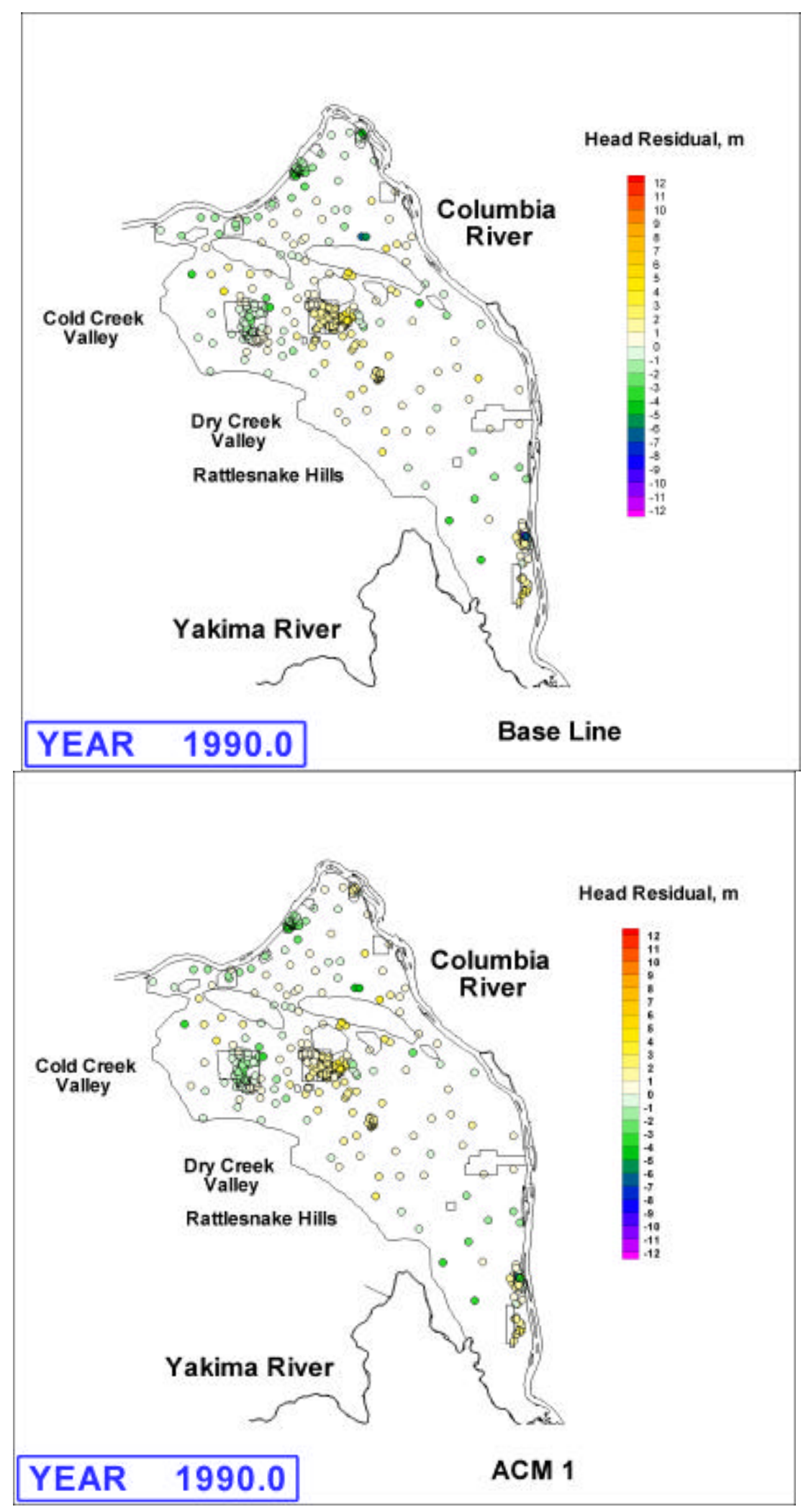

Figure A.2f. Hydraulic Head Residuals (Simulated - Measured Water Levels) for 1990 


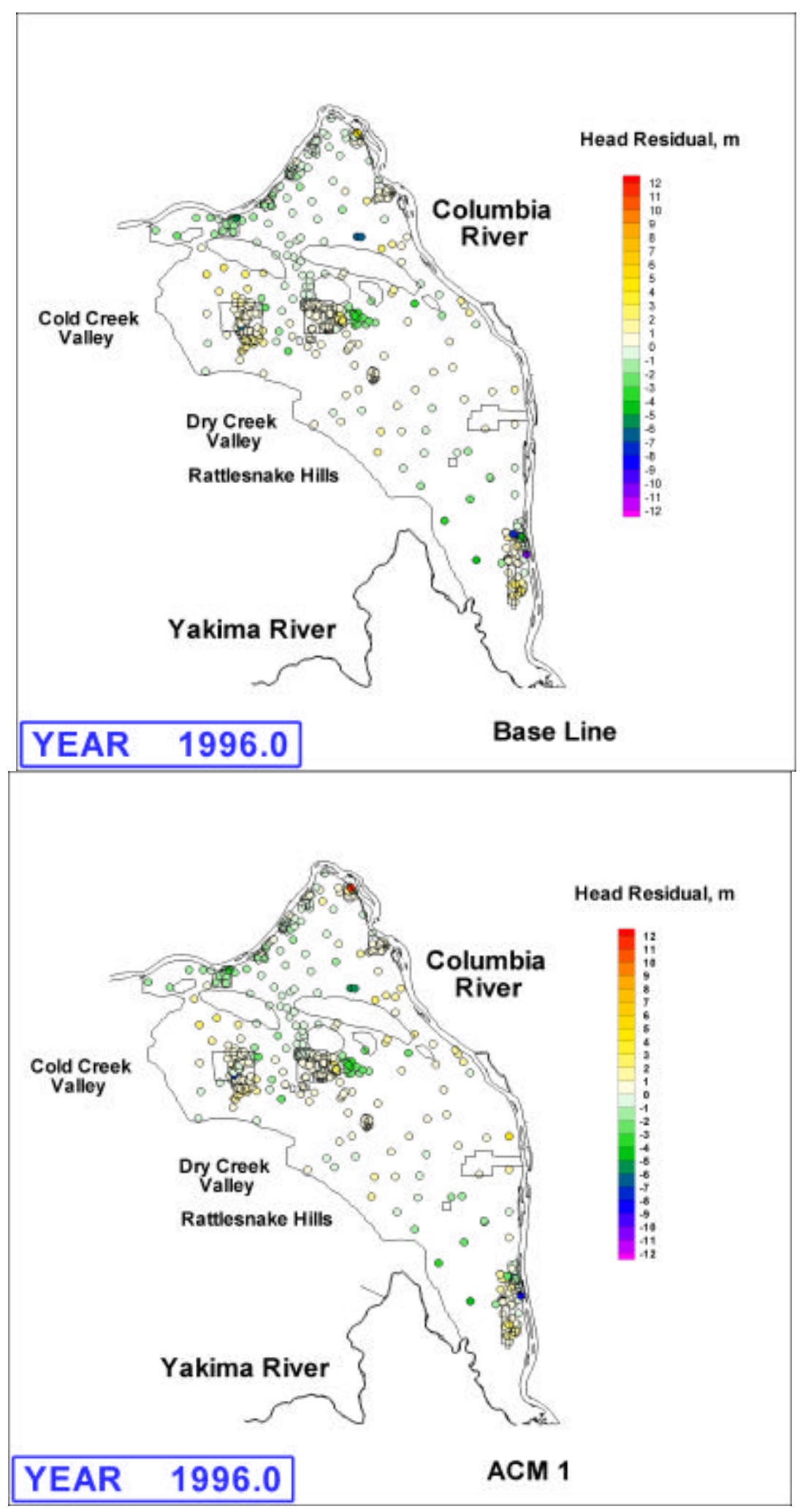

Figure A.2g. Hydraulic Head Residuals (Simulated - Measured Water Levels) for 1996 


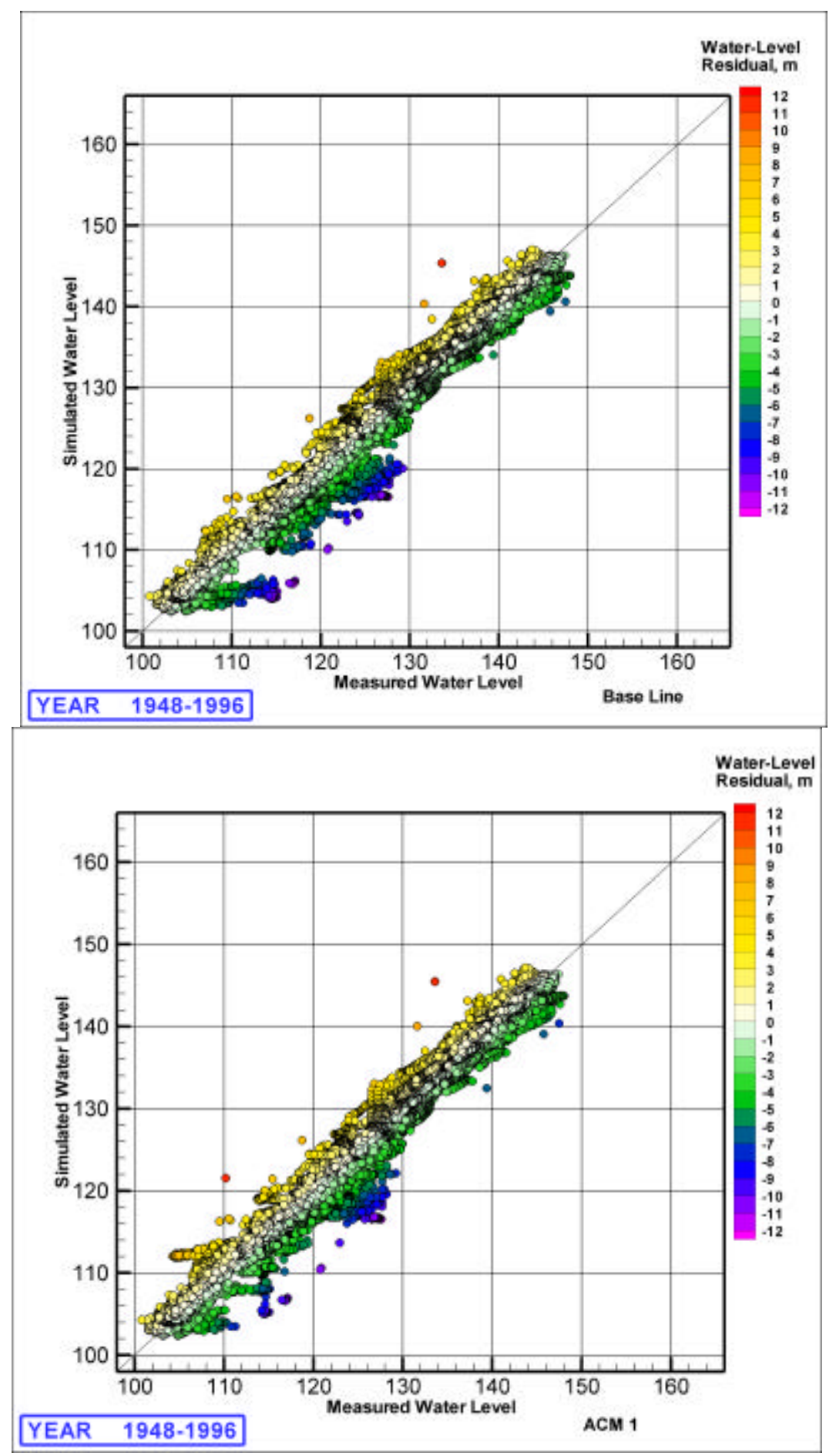

Figure A.3a. Comparison of Simulated Versus Measured Water Levels for 1948-96 


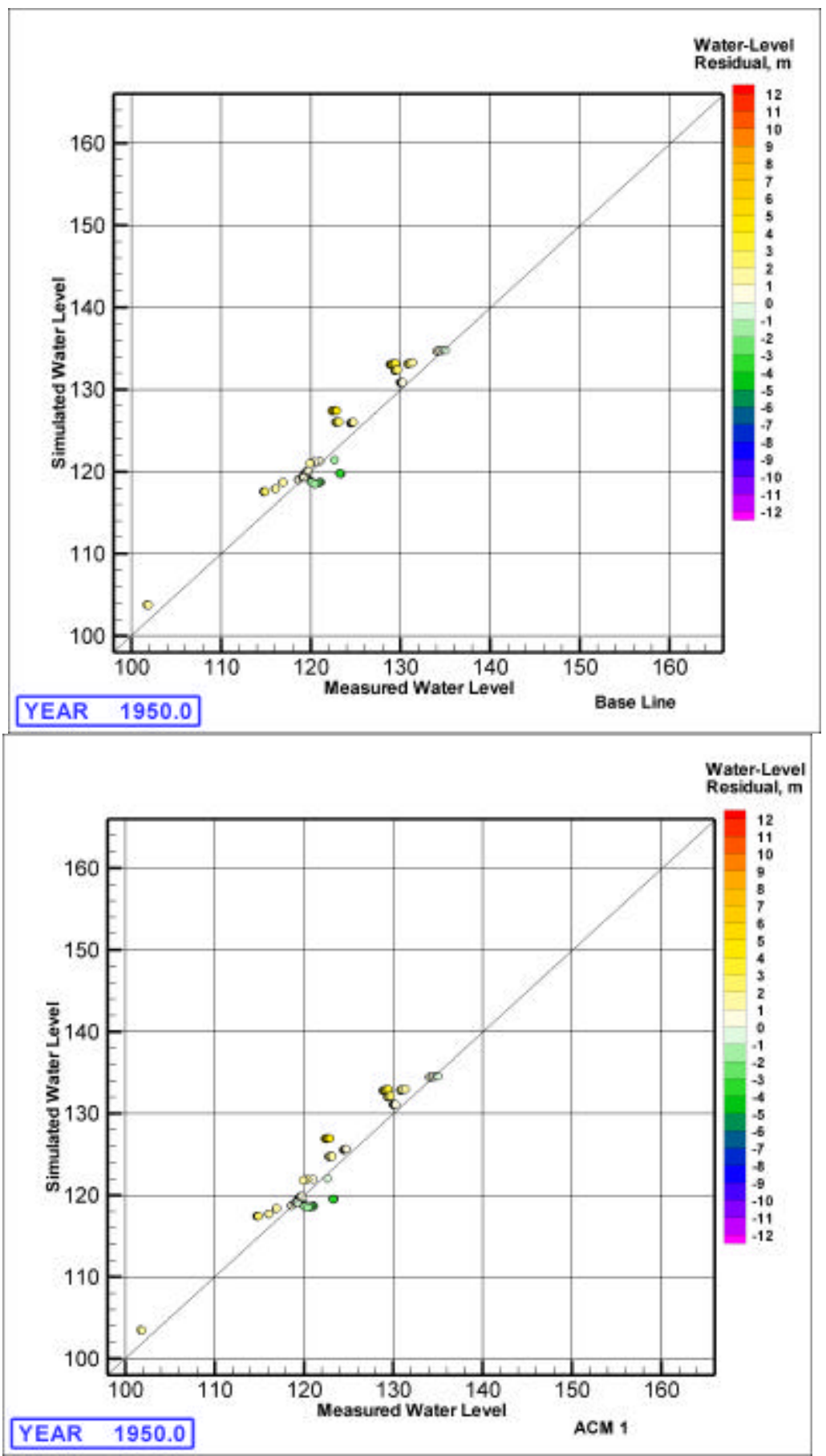

Figure A.3b. Comparison of Simulated Versus Measured Water Levels for 1950 


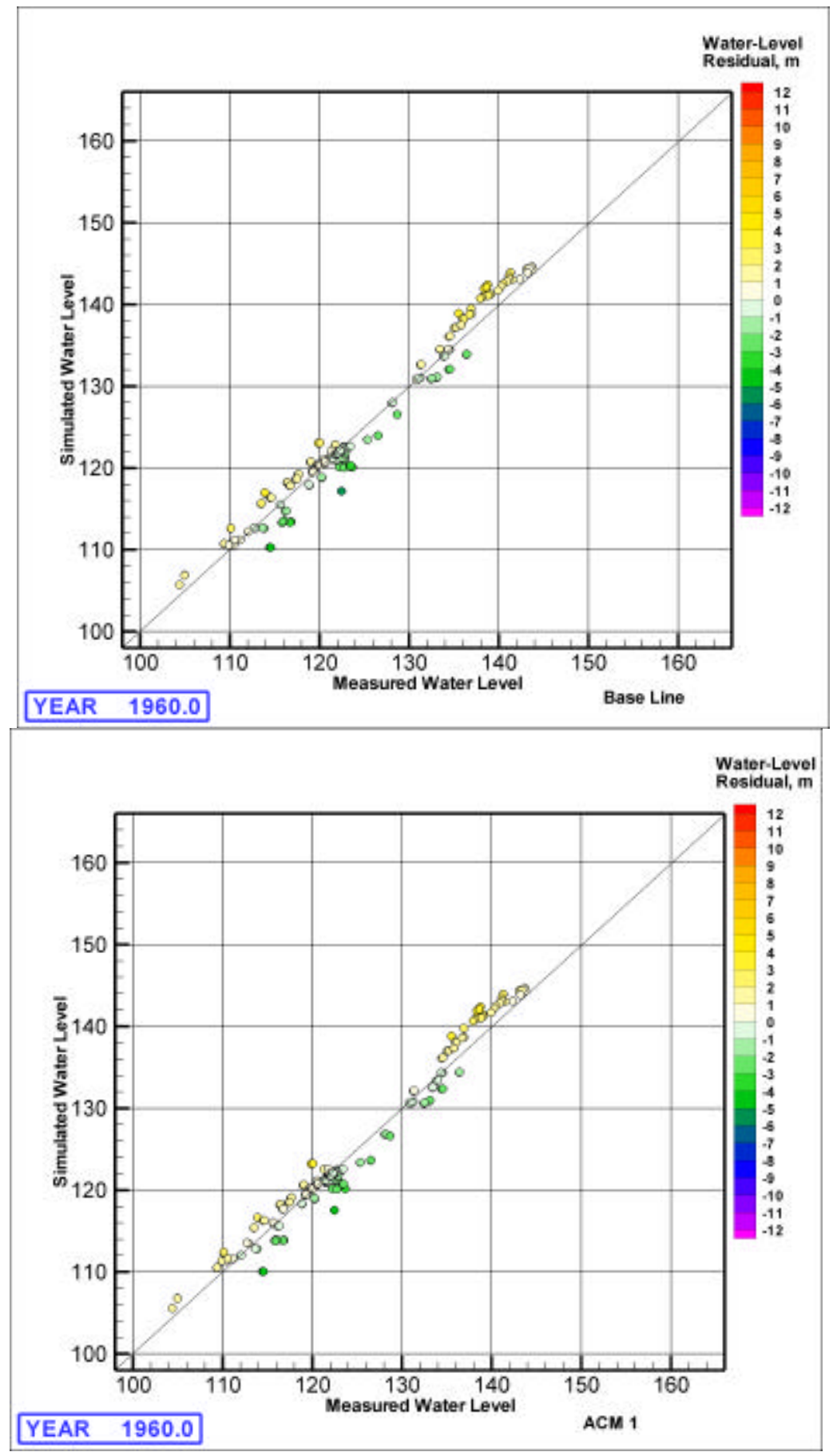

Figure A.3c. Comparison of Simulated Versus Measured Water Levels for 1960 


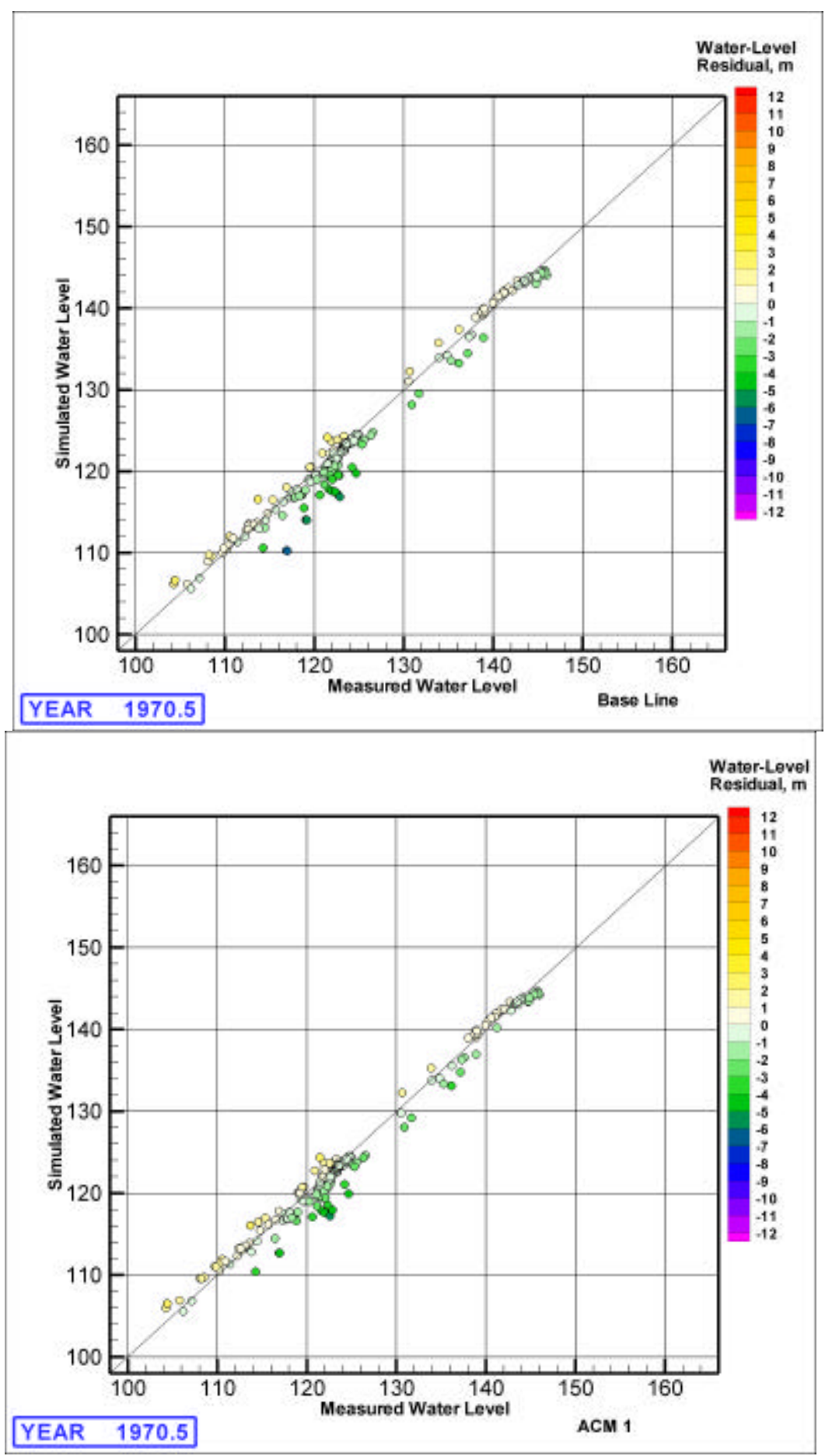

Figure A.3d. Comparison of Simulated Versus Measured Water Levels for 1970 


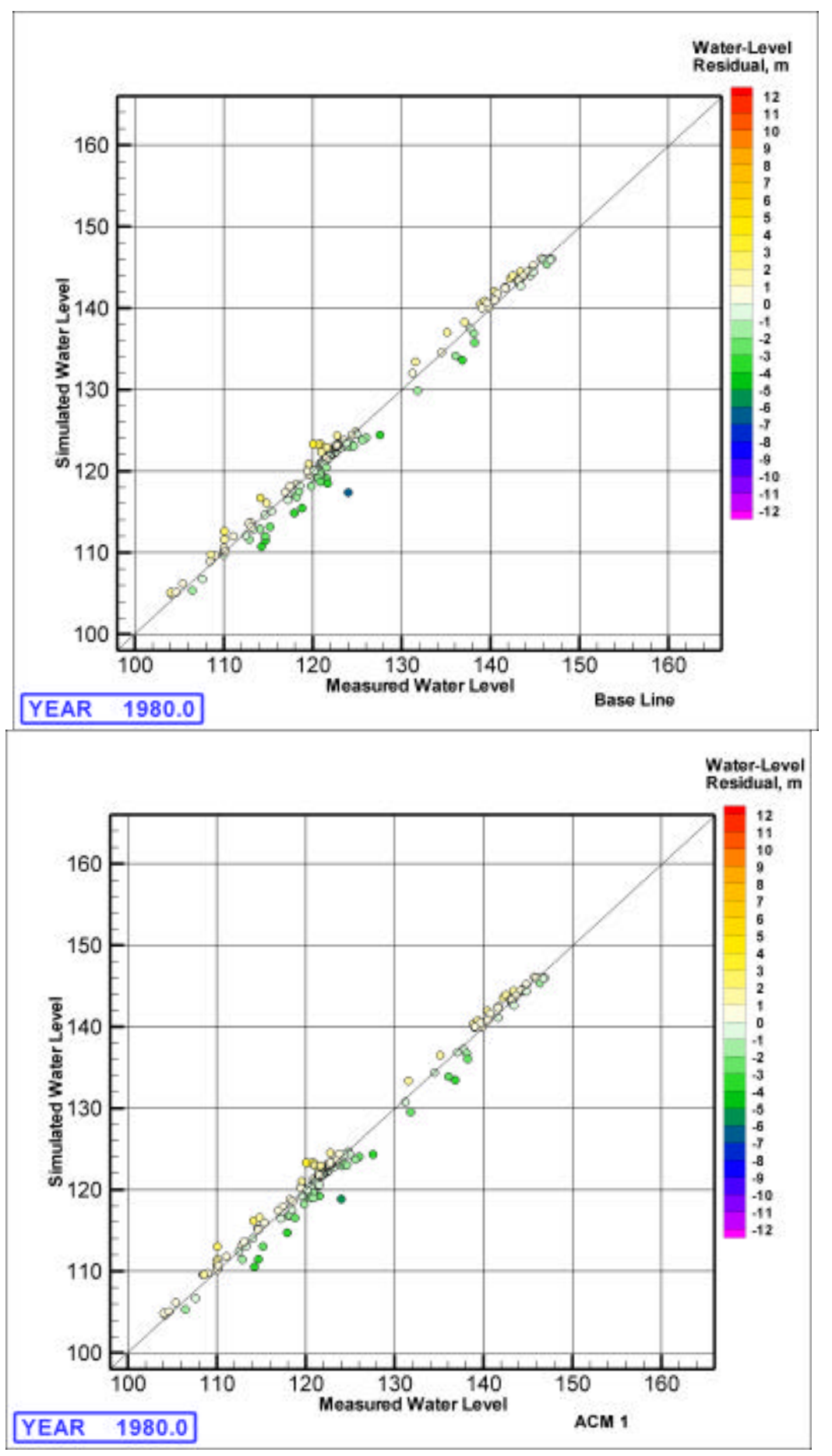

Figure A.3e. Comparison of Simulated Versus Measured Water Levels for 1980 


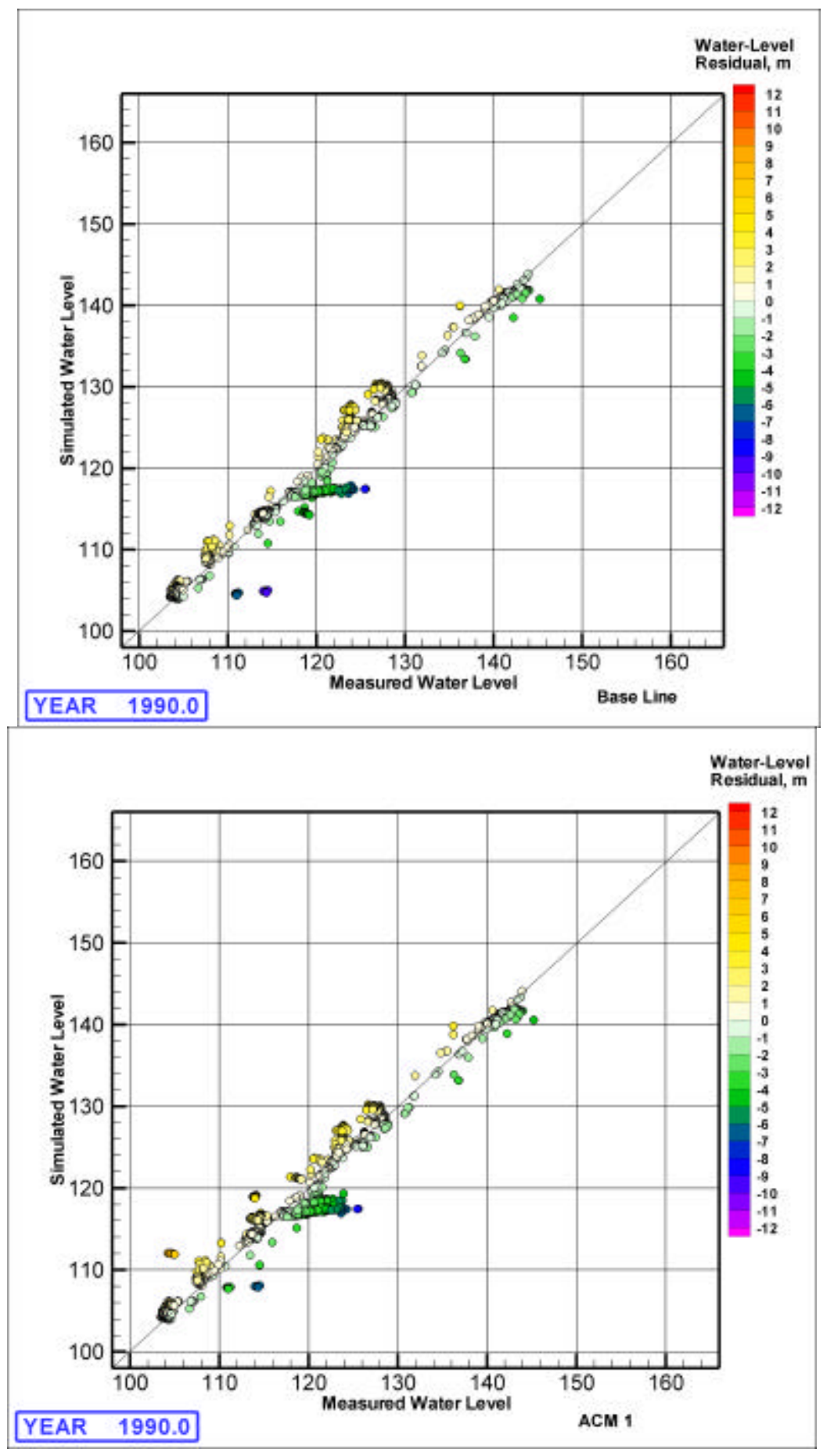

Figure A.3f. Comparison of Simulated Versus Measured Water Levels for 1990 


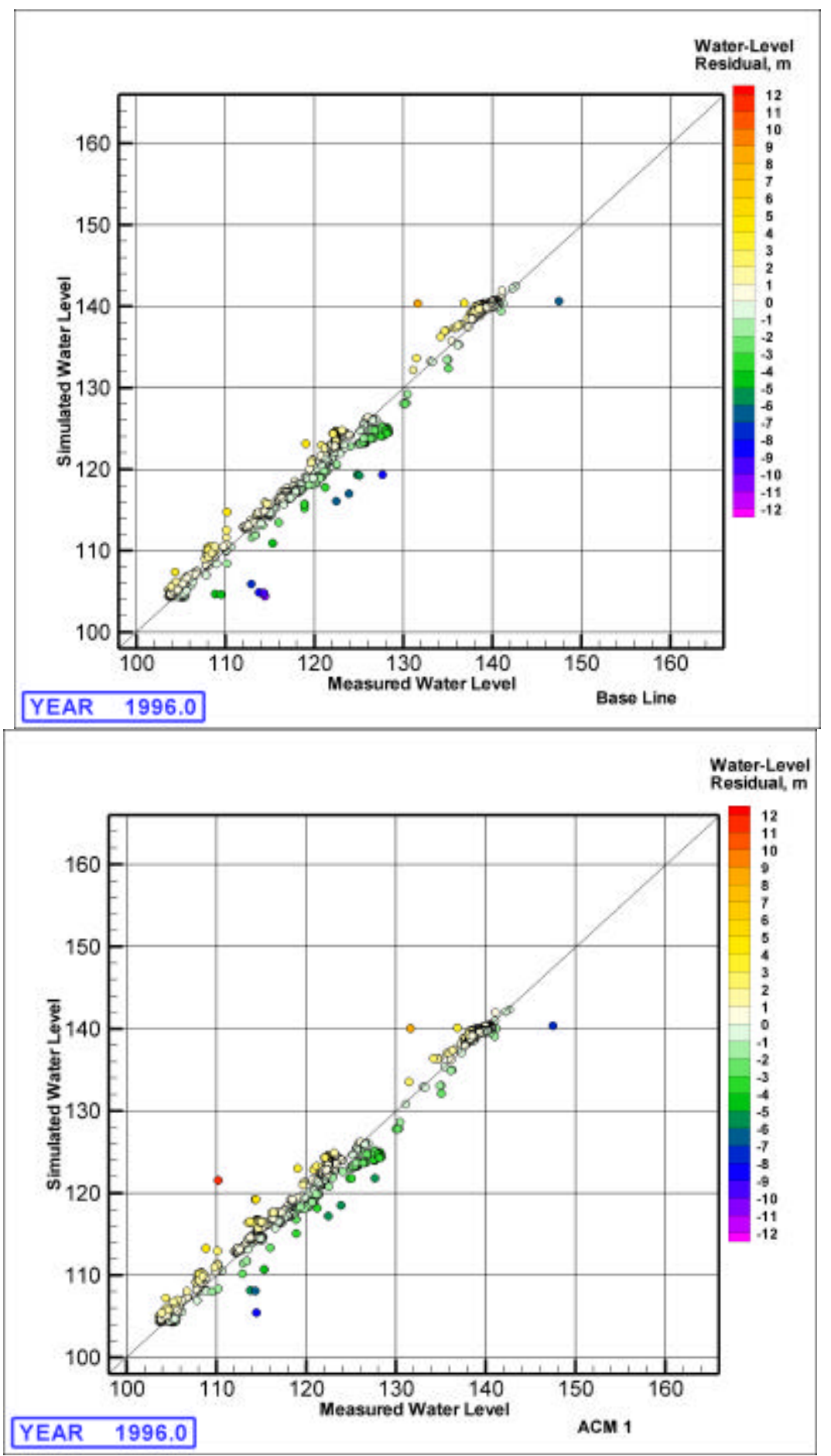

Figure A.3g. Comparison of Simulated Versus Measured Water Levels for 1996 


\section{Distribution}

No. of

Copies

\section{OFFSITE}

R. Buck, Jr.

Wanapum Indian Band

P.O. Box 878

Ephrata, WA 98823

2 D. N. Goswami

Washington State Department of Ecology

1315 West $4^{\text {th }}$

Kennewick, WA 99336-6018

2 Yakima Indian Nation

P.O. Box 151

Toppenish, WA 98948

ATTN: R. Jim

W. Riggsbee

2 S. Harris

Confederated Tribes of the Umatilla

P.O. Box 638

Pendleton, OR 97801

2 Nez Perce Indian Tribe

P.O. Box 365

Lapwai, ID 83540-0365

ATTN: D. L. Powaukee Judit German Heins

M. L. Blazek

Oregon Department of Energy

625 Marion St. N.E.

Salem, OR 97310

S. Bede

U.S. Ecology

P.O. Box 638

Richland, WA 99352

2 B. W. Drost

U.S. Geological Survey

1201 Pacific Avenue, Suite 600

Tacoma, WA
No. of

Copies

2 U.S. Department of Energy

Forrestal Building

1000 Independence Avenue, S.W.

Washington, D.C. 20585

ATTN: J. T. Bachmaier

A. Wallo

3 U.S. Department of Energy,Headquarters 19901 Germantown Road

Germantown, MD 20847-1290

ATTN: J. T. Bachmaier

M. K. Harmon

J. E. Rhoderick

3 M. Dunkleman

Department of Health

Division of Radiation Protection

Waste Management Section

P.O. Box 47827

Olympia, WA 98504-7827

\section{ONSITE}

5 DOE Office of River Protection

*C. A. Babel

H6-60

*P. E. Lamont

H6-60

*N. R. Brown

H6-60

*R. M. Yasek

H6-60

*R. W. Lober

H6-60

16 DOE-RL

*W. W. Ballard

A5-12

*B. E. Bilson

$\mathrm{HO}-12$

*P. F. Dunigan

A5-58

*R. F. Guercia

$\mathrm{HO}-12$

*B. L. Foley

P7-62

R. D. Hildebrand (2)

HO-12

*P. M. Knollmeyer

A5-11

*J. G. Morse

A5-13

*O. Robertson

HO-12

*Electronic distribution 
PNNL-13623

No. of

\section{Copies}

*G. H. Sanders

*J. P. Sands

*Todd A. Shrader

*A. C. Tortoso

DOE Public Reading Room (2)

2 Fluor Federal Services

*R. Khaleel

*R. Puigh

2 Fluor Daniel Hanford

*D. R. Hall

*M. I. Wood

S8-03

H8-44

3 CH2M-HILL Group, Inc.

*A. J. Knepp

HO-22

*F. M. Mann

$\mathrm{H} 0-22$

H0-22

3 CH2M-HILL Hanford, Inc

*C. C. Swanson

H9-02

*V. J. Rohay

H0-19

*W. J. McMahon

H9-03

1 Jacobs Engineering

*P. M. Rogers

H0-22

3 Bechtel Hanford

*L. R. Curry

H0-19

*B. H. Ford

HO-2 1

*M. J. Graham

HO-09

1 U. S. Environmental Protection Agency

*D. R. Sherwood

B5-01
No. of

\section{Copies}

59 Pacific Northwest National Laboratory

*B. Barnett

K6-81

M.P. Bergeron (5)

K9-36

*B. W. Bryce

K6-75

C. R. Cole (10)

K9-36

*P. E. Dresel

K6-96

*P. W. Eslinger

K3-54

*M. J. Fayer

K9-33

*M. D. Freshley

H0-21

*E. J. Freeman

K9-36

*J. Fruchter

K6-96

*G. W. Gee

K9-33

*G. Guench

K9-33

* M. J. Hartman

K6-96

*F. N. Hodges

K6-81

*V. G. Johnson

K6-96

${ }^{*}$ C. T. Kincaid

K9-33

*J. W. Lindberg

*S. P. Luttrell

*M. McKinley

*R. B. Mercer

*P. D. Meyer

${ }^{*}$ C. J. Murray

K6-81

K9-96

K8-41

K6-96

BPO

K6-81

K6-96

K6-96

K9-33

K9-33

K9-33

K9-18

K6-96

K6-81

K9-33

K9-33

K9-33

K6-96

K6-81

K9-33

K6-96

K9-33

K9-36

K6-96

K9-36

K6-81

K9-36

K9-36

K9-36

K1-06 